\title{
PHYSICAL EDUCATION AND SPORTING ACTIVITY FOR WOMEN DURING THE FASCIST ERA
}

\author{
Dissertation \\ Zur Erlangung des sozialwissenschaftlichen Doktorgrades des \\ Fachbereichs Sozialwissenschaften der Universität Göttingen
}

Vorgelegt von
Gigliola Gori
Pesaro, Italien

Göttingen, 2000 
Berichterstatter:

Prof. Dr. Arnd Krüger

Mitberichterstatter:

Prof. Dr. James Riordan

Tag der mündlichen Prüfung:

11 May 2000 


\section{Chapter 1}

Introduction

1.1 The general framework 10

1.2 State of research 15

1.3 Methodology 18

\section{Chapter 2}

Outlines of Fascism as a culture of virility 23

2.1 Historical and ideological premises

2.2 The myth of the new man

2.3 Fascist institutions and aesthetics

2.4 Virility in literature and art

2.5 The last period: Fascism and Nazism 49

Chapter 3

Model women and physical training before Fascism

3.1 Nineteenth Century women: modesty and gymnastics 
3.2 Emancipated women at the start of the Twentieth Century 73

\section{Chapter 4}

\section{Model women during the fascist era}

87

4.1 The revolutionary woman in early Fascism (1919-24) 89

4.2 The new woman of the regime: wife and mother (1925-35) 94

$\begin{array}{lll}\text { 4.3 The militarised woman throughout the war years (1936-45) } & 102\end{array}$

\section{Chapter 5}

5. Fascism and physical training of the female body 115

5.1 Sports medicine and eugenics 118

5.2 Physical education and sport in school and university 139

5.3 Training of physical education teachers 168

5.4 Spare-time motor activity 181

5.5 Health resorts 189

5.6 Visibility through sports: contests and displays 
5.7 Fashion, aesthetics and feminine form 219

\section{Chapter 6}

Sportswomen's profiles, biographies and interviews

6.1 The 'little Italian wonder': Ondina Valla

6.2 Biographies of eminent sportswomen

6.3 Oral interviews: living testimony to the past

\section{Chapter 7}

Conclusions

Footnotes 
Chapter 1 


\section{Introduction}

This book is the result of research that started long ago. It aims to examine how much Fascism opened the way to female physical education and sport in Italy. Of course, by using all manner of available media, fascist propaganda had spread throughout the country and world the image of a strong nation of healthy sportspeople, including women. It will also examine the possible effect of this female 'sportivisation' on women's emancipation in a country founded on traditional paternalistic values and hegemony.

The massive sporting phenomenon during the fascist era has already been studied by scholars of Fascism in general, and also analysed in specific books on sport, but the emphasis has been on the more prominent male sector of which Chapter 2 will give a general outline. In contrast, the female sector, that was underrepresented in fascist times, constitutes an interesting field for further investigation.

Chapter 3 will portray the previous situation in terms of female physical culture, starting from the pioneering nineteenth century; it will try to qualify and quantify the impact of Fascism on Italian women's sport.

The following Chapters 4, 5 and 6 will be broadly dedicated to this theme. They show that there existed different moral and even aesthetic model women, owing to an ambiguous policy which stressed maternity and, at the same time, demanded female engagement in society. 
Women had to move strictly within an old-fashioned framework designed by medicine and eugenics, religious and traditional education, while, on the other hand, the country aspired to modernity and had made a myth of sport. General female emancipation, which had been promised by the fascist revolution and was actually occurring in other industrialised nations, found it hard to advance under the regime because of male hegemonic trends in the country. However, the very engagement of women in some sporting activity promoted and supported a gender emancipation, as will be demonstrated in the present work.

\subsection{The general framework}

The Nineteenth Century, which is known as the period of the formation and strengthening of the newly-constituted Italian nation, was open to initiatives in favour of gymnastics on behalf of patriotism and hygiene, on the wave of the positivistic creed and scientific studies. Women were also involved in this new programme, although in a peculiar and restricted way.

The culture of the female body brought a new life-style and gave women a certain consciousness of their identity and rights, helping their acceptance within the Italian society. However, in the tumultuous first decades of the Twentieth Century, the increase of nationalism, and the advent of new and revolutionary ideologies, supported the Italian participation in the Great War, and led to the rise of the subsequent fascist movement. In those years, a few women, by means of feminist movements, became more aware of their identity and rights. These new women, opposing the previous, traditional model inherited by the patriarchal culture of the Nineteenth Century, were more involved in work, politics and society.

Nevertheless, under the subsequent fascist regime, the mass of women were forced to retire from public life and be submissive to men, but at the same time to strengthen their body and willpower within fascist organisations, adapting to the rather contradictory female models imposed by Mussolini and his hierarchy. In brief, this new woman had to stress and combine antithetical values in different ways, where respect for tradition meant 
spirituality and tenderness, while modernity meant physicality and ruthlessness.

However, the collective engagement in physical education and suitable sports contributed to renewing the traditional feminine image. Women became self-assertive, ready to leave house and family and to fight for ideological beliefs, in spite of masculine misogynous hegemony of the fascist era.

The following lines will give an introductory look at the initiatives undertaken during Mussolini's government in terms of general physical education and sport. These were considered the main way to increase social health, fighting spirit, devotion and dedication, up to martyrdom in the fascist cause. In brief, Mussolini's aim was to forge new men, a myth of Nietschean origin that at the beginning of this century had found supporters in Italy among intellectuals, preparing the way to the advent of Fascism.

Fascism intended to fully control Italian society as a whole by reorganising the life of the citizens of both sexes, including, of course, the education of the body and leisure activities. The democratic admittance and fruition of the different and numerous activities proposed by both the Ministry for Education, and the National Fascist Party, brought the great mass of Italians to practise all kinds of sport and other recreational activities, under the assistance and guardianship of the regime.

The latter, although taking autonomy from the people in terms of organising all their time, gave them a rationalised and assisted leisure, which was financed by the Social State, in order to obtain the widest consensus concerning any and every political choice delivered by Fascism.

In the gymnasium, stadium and sports ground, politics was banished in favour of a sort of 'activism' that attracted the masses because, at least, people could have a free choice, at no cost, of activities once only reserved for the highest classes.

The common people could start to practice many kinds of sports, visit the beautiful Italian cities and the most fashionable tourist places - travelling by 'popular' cheap trains made available by the State. They could also send their children to the numerous holiday resorts owned by the State. Indeed people enjoyed the very pleasant sensation to be at the centre of the regime's attention. 
Within the intentions of Fascism, the massive services offered for the development of physical education and sport had to accomplish the welldefined educational tasks of both regenerating the weak character of Italians by transforming them into a race of strong-willed, courageous new men, and removing citizens from a too private dimension of their life, in favour of a more social and collective one.

Mussolini himself was not a true racist, but strenuously believed in and protected the Italian race - simply meaning the Italian people - as the concrete and material expression of the Nation, and aimed at forging Italians. In the Speech of 26 May 1934, addressed to the Chamber of Deputies, the Duce affirmed: "Fascism will devote itself to the Italian people's character more deeply, instead of furnishing their brain too sumptuously."1

Those tasks were suitably carried out by the schools and extra-scholastic social organisations, by means of a complete overhaul of the pre-existing juvenile institutions and by an unceasing action of propaganda through the press, broadcasts and newsreels.

In fact, having very soon abolished those sporting societies which were independent and therefore outside the current fascist ideology - namely Boy Scout associations and those imbued with Catholicism or socialism - the National Fascist Party framed the sporting subject strictly into the Sports Charter of 1928.

In the Sports Charter, the values of physical education and sport practised inside the numerous fascist juvenile organisations were firmly instilled. Moreover, the youth were urged to develop a competitive spirit with periodic cultural and sporting competitions, such as the Ludi Juveniles, Agonali, and Littoriali, which were spectacular displays receiving great appreciation.

In so far as Italian women were also included in this wide programming, we will give a strong emphasis to this theme, which constitutes the main objective of the research. Actually, in the 1920s the involvement of women in sporting activities was encouraged by the fascist movement, according to the revolutionary spirit of the first period, which exalted the body and its actions. However, in the first part of the 1930s, when the regime was fully established, the campaign for demographic politics wanted women to be in 
the home and become submissive wives and strong mothers of numerous children. Physical activities for women were reduced to healthy basic gymnastics and a few suitable sports to be practised within fascist bodies, such as Opera Nazionale Balilla - ONB, under control of sport medicine physicians. Notwithstanding this, the Church was opposed to women's 'sportivisation'. This quarrel, as well as others against a number of fascist choices in sport, can be included in the wider debate on youth education that settled Church and State on antithetical positions.

The hegemonic fascist ideology had $\mathbf{b}$ compromise with the pre-eminent engagement of the Roman Church in the country not only over religion, but in political and juvenile affairs that concerned the Vatican. The power and prestige of the Catholic Church among Italians had to be seriously considered by Mussolini, who found a solution for a better internal and international consensus through a political Concordato [Concordat].

After secret long-lasting negotiations, the Italian and Vatican states signed this Concordat, also called Patti Lateranensi, on 11 February 1929. The historic document, dramatically called the 'restitution of God to Italy and Italy to God', stated that the Italian government agreed to the authority of the Roman Church over the country, thereby conciliating states which had been enemies since 1870 . Pope Pio XI enthusiastically affirmed that he had met a man [the Duce] sent by Providence. Through this Concordat, apart from tax-exempion and other financial help, the Church obtained a pledge that the Catholic doctrine would be taught in primary schools, religious marriages, which now also had civil recognition, were totally in religious hands, and Catholic associations could continue their activity.

However, the latter point, also concerning sporting and recreational activities, was controversial and not respected by Fascism for long. Although the Pope fought for their survival, all Catholic juvenile associations involved in sports were abolished in the early 1930s, so that they could not interfere with fascist juvenile institutions, whose paramount task was to forge a new fascist generation.

Other controversies between Fascism and the Church arose in regard to the racial laws of 1938 which separated Italy and the Vatican completely. Through these laws the regime meddled again in the Concordat by prohibiting marriages between Catholics and Jews, and other mixed races. 
What is more, the racial laws were the opposite of the charitable and universal spirit of the Church.

Obviously, the consensus between single priests and Fascism was denied even during the Concordat, or continued after the Vatican yielded, but these were personal choices which show that there existed problems between Church and Fascism all through the Mussolini era.

Owing to the political choices which brought the Kingdom to become an empire and formed an alliance with Nazi Germany, male and female models were redefined in the second half of the 1930s. In order to transform Italy into an armed nation, it was decided considerably to better the sector of physical and moral education of Italians through a new, militarised body, the Gioventù Italiana del Littorio - GIL.

By having soon absorbed all the pre-existing institutions, the GIL could fully control any and every citizen, women included. Therefore, female membership in GIL was strongly encouraged by the regime, which was aware of the fact that physically and morally stronger mothers and daughters were more and more needed to support the call-up of their husbands and brothers, as soldiers of the Fatherland.

Women's participation even in competitive mixed displays wearing fascist uniforms was quite usual in those years. Of course, massive involvement in social activities led more women to social emancipation, which was quite an unexpected, and probably undesired, result.

During the Second World War, these considerably trained and strengthened women were not enrolled in the Army, but supported men's enrolment and replaced men involved in the conflict at work. In 1943, after the destitution of Mussolini and the subsequent advent of the Repubblica Sociale Italiana - RSI (this was a new fascist republic founded by Mussolini in Northern Italy), volunteer female soldiers were accepted within the RSI army. At the same time, a number of women fought side by side with male partisans and participated actively in the 'civil war of liberation' against Nazi and fascist soldiers, up to the conclusion of the Second Conflict. 


\subsection{State of research}

As far as the history of physical education and sport is concerned, there is a lack of tradition in Italy. This discipline was not considered within History itself, although weak links could perhaps be seen within social history. Only recently has it found a certain acceptance within the university world, thanks to the research of a few scholars operating in the field of Contemporary History, Sociology and Education, and within Higher Institutes of Physical Education, recently transformed into university Faculties or Departments of Motor Sciences. A number of contributions have been made by sports journalists and amateur sport historians as well.

Within the history of Italian culture of the body, physical education and/or sports in general, several books and essays, and a number of articles from a few specialised magazines, have been printed in Italy during the last three decades.

Among these books, certain contributions should be mentioned, notably: Andreoli, P., author of general research on women and sport (La donna e lo sport nella società industriale [1974]); Bassetti, R., who published an essay on the Italian history of sport, drawing a number of biographical profiles (Storia e storie dello sport in Italia. Dall'Unità ad oggi [1999]); Bonetta, G., for his ample volume on bodily education (Il corpo e la nazione. L'educazione ginnastica igienica e sessuale nell'Italia liberale [1990]); Cambone, P., for a book on team-games (Giochi sportivi di squadra. Storia culturale dei moderni [1996]); Di Donato, M., author of a general history of physical education (Storia dell'educazione fisica $e$ 
sportiva. Indirizzi fondamentali [1984]); Ferrara, P., who published a welldocumented book on the history of gymnastics (L'Italia in palestra. Storia, documenti e immagini della ginnastica dal 1833 al 1973 [1992J); Fabrizio, F., who wrote on the history of sporting associations (Storia dello sport in Italia. Dalle società ginnastiche all'associazionismo di massa [1977]); Jacomuzzi, S., author of three volumes on the history of the most practised sports (Gli sport [1964-1965]); Giuntini, S., who published on physical education and sport during the last two centuries (Sport scuola e caserma dal Risorgimento al primo conflitto mondiale [1989]); Gori, G., for a book discussing the advent of sport and sports journalism (Educazione fisica, sport e giornalismo in Italia. Dall'Unità alla prima Olimpiade dell'era moderna [1989]) and for a collection of essays on physical education and sport during the Kingdom L'atleta e la nazione. Saggi di storia dello sport [1996]; Martini, M., author of a book on the origins of women's sporting activity (Correre per essere.Origini dello sport femminile [1996]); Papa, A. and Panico, G., who published a book on the social history of Italian football (Storia sociale del calcio in Italia. Dai club dei pionieri alla nazione sportiva [1993]); Pivato, S., who wrote about traditional sports in the nineteenth century (I terzini della borghesia. Il gioco del pallone nell'Italia dell'ottocento [1990]) and on sports and ideologies of the twentieth century (La bicicletta e il sol dell'avvenire. Sport e tempo libero nel socialismo della Belle époque [1992]; Sia lodato Bartali. Ideologia, cultura e miti dello sport cattolico [1985]; L'era dello sport [1994]); Porro, N., for his books on sport and policy (L'imperfetta epopea [1989] and Identità, nazione, cittadinanza. Sport, società e sistema politico nell'Italia contemporanea [1996]); Ravaglioli, F., who examined in detail the phenomenon 'sport' from a philosophical point of view (Filosofia dello sport [1990]); Teja, A., for a book about physical education of women (Educazione fisica al femminile. Dai primi corsi di Torino di Ginnastica educativa per le maestre (1867) alla ginnastica moderna di Andreina Gotta-Sacco (1904-1988) [1995]); Triani, G., who published research about the advent of summer seaside bathing (Pelle di luna pelle di sole. Nascita e storia della civiltà balneare [1988]); and Ulzega, M. P. and Teja, A., authors of a book about sport in the army 
(L'addestramento ginnico-militare nell'esercito italiano 1861-1945 [1993]).

A few collective books have been edited up to now, among them: AA.VV. (eds), Itinerari di storia dell'educazione fisica e dello sport [1987]; Grozio, R. (ed.), Catenaccio \& contropiede [1990]; Lanfranchi, P. (ed.), Il calcio e il suo pubblico [1992]; Noto, A. and Rossi, L. (eds.), Coroginnica. Saggi sulla ginnastica, lo sport e la cultura del corpo 19611991 [1992]; Roversi, A. (ed.), Calcio e violenza in Europa [1990].

As far as contemporary history reviews are concerned, Lanfranchi edited a single number in Ricerche storiche, (Sport, storia, ideologia [1989]), and Italian and foreign historians published essays in Storia contemporanea [1989 and 1990]. Among Italian specialist magazines, we should mention: Lancillotto e Nausica-Critica e storia dello sport; Ludica; Ludus-Sport and loisir - now simply Sport and loisir. There, articles and essays on physical education, traditional games and sports are to be found.

With regard to 'Sport and Fascism', however, little has been published. At least, Bianda, R., Leone, G., Rossi, G. and Urso, A., Atleti in camicia nera. Lo sport nell'Italia di Mussolini [1987], and Fabrizio, F., Sport e fascismo. La politica sportiva del regime 1924-1936, [1976] should be mentioned.

More specifically, on the theme 'Women's Sports and Fascism', there are articles in reviews, such as that by Addis-Saba, M. and Isidori-Frasca, R., "L'angelo della palestra. Esercizi muliebri per il regime", in Lancillotto e Nausica [I, 1986]. There are also contributions in books, by: De Giorgio, M., Le italiane dall'Unità ad oggi [1993]); De Grazia, V., Le donne nel regime fascista [1993]; Giuntini, S., in Torcellan, N., Gigli Marchetti, A. (eds.), Donna lombarda 1860-1945 [1992]; Gori, G., L'atleta e la nazione. saggi di storia dello sport [1996].

Finally, Rosella Isidori-Frasca published the very first book on Italian women and sport in the fascist era, entitled ... e il duce le volle sportive [1983] and, more recently, Lucia Miotti and Marilena Rossi-Caponeri edited Accademiste a Orvieto. Donne ed educazione fisica nell'Italia fascista 1937-1943 [1996]. 


\subsection{Methodology}

As theoretical background we will assume, by following Antonio Gramsci's theories on hegemony, ${ }^{2}$ that during the fascist era what took place in physical culture and gender relations had an impact on the struggle for hegemony, at the time and beyond, until our own time. In this respect, the research starts where Victoria De Grazia left off, ${ }^{3}$ looking in more detail at how the culture of consent worked in terms of women's physical activity. In a wider perspective, we will also look at this latter as a possible means to support the phenomenon of gender emancipation which was occurring in those years, namely the battle of Italian women against prejudices and discriminations for the achievement of equal rights and opportunities like men.

In the first part of this book, both the culture of the male body during Fascism and that of the traditional Nineteenth Century woman refer to written papers, archives and iconographies, as well as more recent publications.

However, there is a lack of important research concerning the physical culture of the new woman living at the beginning of the Twentieth Century. Nevertheless, the ideal model of this new woman can be displayed $a$ contrario through the defamatory readings of nationalists and futurists, regarding the persisting traditional and romantic woman of the past. 
The sources concerning a part of this book, that is an outline of the fascist culture of the body, are mostly based on recent publications which present a general picture of the situation of society at the time.

On the phenomenon 'Fascism', it should also be specified that in these latter years in Italy a process of historical review is ongoing. This process aims at verifying if the interpretation given of Fascism after the fall of this regime is true. In fact, Fascism could have possibly been investigated in a hasty and univocal manner. The monumental historical research of Renzo De Felice, who is reputed to be the greatest expert on Fascism, will obviously be given the highest consideration. ${ }^{4}$

As far as the main theme is concerned, i. e. the physical and sporting culture of women during the fascist era, the present research essentially refers to material produced during the fascist period. This material consists of legislative acts, books, daily newspapers, journals, specialist sporting press, photographs, films and works of art concerning sports. Obviously, due to the standardisation of the news, most of them having been previously selected by the fascist censor, the picture that appears is mostly factious and hagiographic, perfectly in line with the intentions of the regime.

In this book some room will also be given to biographies and oral testimonies taken from different levels of female athletes. There is the interview with the athlete Ondina Valla, winner of the first female Olympic gold medal in Italian history, as well as interviews given by mid-level athletes and by women simply practising a kind of sporting activity. The opinion of former physical education teachers trained in the famous Academy of Orvieto - they were young and active during the fascist era - will be reported as well.

These testimonies, although meaningful, feel the effects of a certain nostalgia for the good times spent in their youth. Really they do not offer reasonable objective contributions or critical elaboration - also due to the advanced age of those interviewed - but present the subjective way these individuals lived their sporting activity under the fascism regime and, more generally, how they felt at that time. 
Chapter 2 


\section{Outlines of Fascism as a culture of virility}

If one considers Fascism to be a political movement of the right aiming at totalitarism, undoubtedly it was first founded in Italy by Benito Mussolini. In Milan, on 23 March 1919, this movement took the name of Fasci Italiani di Combattimento [Italian Fasci of Combat]. In a few years the fascist movement conquered power as a consequence of the so-called 'March to Rome' of 28 October 1923, and very soon it took complete control of society under the government of the Duce.

In those years the rampant nationalism on which Italian fascist ideology was based found fertile ground everywhere in the world where the wounds of the First World War were still open, and especially in Germany through Hitler's national socialist ideology.

All the regimes and movements of the right, which arose between the two world wars, were somehow a tributary of fascist Italy. In fact, after the French Revolution, Italy had effected the first experiment of institutionalisation of a new 'secular' religion in Europe, ${ }^{1}$ and had already expressed all the leading ideas of subsequent Fascism, from the nationalisation of the masses to the 'religiosity' of the symbols. 
This plan included defence of the race, in which a massive culture of the body had an important part, as it contributed to forging the new Italian, following fascist aesthetics and style. This new man had to coincide with the model embodied by the leader Benito Mussolini to which Italians, with more or less success, were induced to identify.

As will be seen, at the beginning of the Twentieth Century, in Italy the predominant ideologies came together in the fascist revolution. Once power had been obtained, Fascism built a mighty pyramidal organisation, structured by the Partito Nazionale Fascista [National Fascist Party]-PNF, in order of hierarchy. The intention was to mobilise the masses according to the requirements of the regime, with ideology based on a kind of civic religiosity. It very soon became a political religion, where to the belief in myths, rites and symbols was joined faith in Mussolini, the 'man of destiny'. People were asked to "Believe, Obey, Fight" in the name of the Duce.

Care was taken to spread the ideology aimed at obtaining popular consensus in every political choice. In truth, consensus was discontinued in the course of time. It reached its apex in 1936, as a consequence of the victorious war in Ethiopia, when the myth of imperial Italy became a reality, but very soon it was reduced because of the excessive intrusiveness of the regime, being then crystallised into 'self-celebrations' more and more.

The final wound to consent came from choices made in foreign politics, such as the military failure of the war in Spain, the bonds with Germany and, accordingly, the racial laws imposed on Italy, and finally the participation in Hitler's war. ${ }^{2}$

The main aim of the fascist educational plan was fascistizzare, that is, to transform Italians - traditionally individualist and indolent - into an elected race of strong new men. They had to be mindful of the glorious past of the Roman empire and be ready to imitate its grandeur in order to found a new civilisation destined to last forever.

Such a plan, which accompanied Fascism from its advent, deeply involved school, employment, spare-time, culture and the arts. The task was to forge the character of citizens, so as to give birth to the new Italian, a virile, dynamic, bellicose individual. This plan was even a source of inspiration for Hitler who, in fact, with the re-organisation of German people's lives, was inspired by the Italian model with the Duce as its spiritual guide. 


\subsection{Historical and ideological premises}

As well as the phenomenon of the Fascism, the term 'fascism' also finds its roots in Italian culture. It derives from the Latin fascis, a symbol tied up with the cult of the 'sacred fire'. ${ }^{3}$

Before the constitution of the Fasci Italiani di Combattimento in 1919, the symbol of the fascio had already been used by the interventionist movement of the Fasci di Azione Rivoluzionaria [Fasci of Revolutionary Action], promoted by Mussolini in 1915, after he had left the socialist party. ${ }^{4}$ The symbol was also used by the futurist movement gathered in the Fasci Futuristi [Futurist Fasci]. However, the fate of that symbol remained tied to Mussolini and the fascist movement, which became the National Fascist Party in 1921, up to the fall of the regime in 1943.5

Within the Fasci Italiani di Combattimento there were dissatisfied veterans of the Great War - such as arditi soldiers, irredentists, futurists and D'annunzio's followers 6 - coming from a varied social extraction. They believed in comradeship born of the war, in an ardent nationalistic spirit and in the desire for a radical change in society. As exponents of the fascist 
truth, they were firmly directed by their charismatic leader Mussolini, and were ready for revolutionary adventure and to impose their creed by force. The conquest of power in 1922 was a real coup d'etat which neither the Government nor the King could oppose; it was then considered as a temporary and necessary turn to re-establish order in a nation deeply in crisis. In fact, it was the first step towards the foundation of a dictatorial regime which lasted two decades.

The success of the fascist men, who considered themselves defenders of the country and regenerators of its morals, could be attributed mainly to strong repetition of the theme of 'sacred Fatherland' on which the civil and moral unity of Italians was built. This was a successful ideological theme since the Nineteenth Century.

In 1861, after the Kingdom of Italy had been established, the problem of how to morally regenerate Italians became fundamental. In fact, Italians had suffered domination and division, losing their identity as a people for at least fourteen centuries, since the fall of the Roman empire. The Fatherland was seen as the 'supreme corporate body', and as the 'first educator' to which a 'religious' devotion, up to the sacrifice of life, had to be given. It found its ideologist ${ }^{7}$ in the authoritative Giuseppe Mazzini and its convincing advocate in the liberal executive class.

Up to about the end of the century, the liberal government, after having rejected the revolutionary and republican aspects of Mazzini's creed, had endeavoured to educate citizens in the cult of the Fatherland in respect of liberty, both acting on school and military education ${ }^{8}$ and emphasising the monarchic institution, Fatherland memories and heroism of the fallen.

Anyway, the nationalisation of the masses by means of exaltation of the cult of the Fatherland, by now diffused to a large extent through Europe, brought meagre fruits in Italy. In fact, the atavistic distrust of the aristocratic managing class by the people played against it. Rarely did common people become involved in patriotic choral demonstrations, as the leading liberals feared not being able to control their strength. Moreover, there was opposition from the Roman Catholic Church that, already deprived of temporal power after the 'seizure of Rome' in 1870, opposed the new civic religion by any means. Its main purpose was to maintain at least the spiritual supremacy in the consciences of Italians. ${ }^{9}$ 
At the beginning of the Twentieth Century the theme of civil religion and moral regeneration of citizens was no more a primary objective for the government, but it was mainly a matter of further study and debate among intellectuals.

As for the Church, it had to face the new danger of socialist ideology, being atheistic and materialist, as well as that constituted by the nationalistic 'heathenish' movement of Corradini, who had drawn inspiration from Japan. ${ }^{10}$ When the clearly anti-Bolshevik fascist ideology gained power, even the Church of Rome did not oppose it, considering the 'anticlericalism' of Mussolini less dangerous than Marxist ideology.

The end of the First World War, in which victorious Italy had sacrificed so many lives, had left the question of the town of Fiume and the region of Dalmazia unresolved. The claims on those territories, as well as a diffused 'state of effervescence' caused by participation in the Great War, gave a new impulse both to the theme of civil religiousness - which was celebrated by means of the cult of martyrdom and heroes - and that of revolutionary nationalism. These themes found authoritative voices in intellectuals of the time, such as Marinetti, founder of Futurism, and the celebrated poet D'Annunzio.

The futurist movement was founded by Filippo Tommaso Marinetti in 1909. It promoted such values as instinct, strength, courage, war, youth, sport, and dynamism and speed exemplified through the bicycle, motorbike, car and aeroplane. In his Fondazione e Manifesto del Futurismo [Foundation and Manifesto of Futurism] Marinetti affirmed: "Up until now literature has exalted thoughtful immobility, ecstasy and sleep. We want to exalt aggressive movement, feverish insomnia, running footsteps, mortal jumping, slapping and fisticuffs."11

Initially, Futurism imposed itself as a total ideology that incorporated art, custom, morals and politics in a revolutionary and nonconformist vision of life. It supported the fascist movement, but after 1920 the futurists detached themselves from it because they disagreed with the right-wing shift of Fascism. Since then, Futurism abandoned any totalitarian intention in the political ambit and survived as a literary and artistic school, finding followers and supporters in Europe. 
Futurism bequeathed a number of values to Fascism, such as the cult of anti-intellectualism, antagonism, virility, youth, speed, sport, and an innovative use of the language in political propaganda. Other values, such as dynamism and individualism were soon damped down in favour of the new fascist order. Despite the declared friendship between Mussolini and Marinetti, the only intellectual futurist who occupied and maintained a position in the government was Giuseppe Bottai (see Chapter 5.2).

D'Annunzio's movement was a way to understand and behave with regard to life according to the model offered by Gabriele D'Annunzio, man of letters, poet, aesthete of great charm, commander, and also sportsman. ${ }^{12}$ Having placed his very refined art at the service of the religious myth of the Fatherland, D'Annunzio became its high priest, i. e. the Vate. He restored the past greatness of ancient Rome, by that time forgotten, and brought new life into the political-religious ideologies of the preceding centuries.

Through the adventure of Fiume in 1919, D'Annunzio realised an admirable fusion between oratorical art, patriotic mysticism and political activis m. ${ }^{13}$ Together with his men - called legionnaires in remembrance of ancient Rome - the Vate established an Italian government in Fiume, the Regency of Carnaro. Among the political actions of that time was the foundation of the utopian League of Fiume, aiming at pushing all the oppressed populations to revolt. 14

The brief experience at Fiume ended with the painful abandonment of the city by order of the Italian government, but notably increased the myth of D'Annunzio as the winning new man in every enterprise, and therefore capable of founding the new Italy.

Mussolini, who had supported that occupation without directly participating in it, was considered a traitor as he had not taken part in the defence of the Regency of Carnaro. The enterprise of Fiume in effect constituted the first step in a wider revolutionary plan agreed by Mussolini, which was to end with the March to Rome - an idea of D'Annunzio - and the conquest of Italy.

After that march and the establishment of Mussolini as head of the government, in 1924 Fascism was tarnished by the assassination of the opposition deputy Giacomo Matteotti. Italy was deeply shaken and even the survival of Fascism itself was in grave danger. The scorn of many 
coagulated around the figure of D'Annunzio who, with his charisma, seemed the only one able to drive Italians to the realisation of the new Italy. However, the initiative failed to find practical realisation and the poet decided to retire to his residence at Vittoriale near Lake Garda. From there, he retired into himself, and became a disenchanted observer of subsequent events. 15

The Duce wanted to maintain a certain friendly relationship with D'Annunzio, but this was always polluted by ambiguity and jealousy: Mussolini felt both admiration for the genial man of letters, and a certain hostility towards the man himself, thus undermining the myth which fluttered about him. This passionate relationship, between love and hate, lasted until the death of the poet in 1938 .

In conclusion, the current ideologies of the first two decades of the century, having been interwoven with revolutionary appeals, nationalistic claims, juvenile dynamism and political mysticism, favoured the fascist movement which appropriated them. Despite the numerous 'punishment-expeditions' and the consequent violence committed by members of fascist squads, Mussolini conquered power with the March to Rome without shedding any blood.

In Italy the climate of uncertainty and disorder, almost on the brink of civil war, suggested a prudent acquiescence by most people in respect of the coup d'etat. This had been predisposed by Mussolini who had assured the connivance, or at least the neutrality, of powerful people. As a matter of fact, it was a 'telephone revolution', as the irascible fascist Italo Balbo said when he realised that the March to Rome had been little more than a parade. ${ }^{16}$ 


\subsection{The myth of the new man}

In the years of the fascist regime most Italians experienced the personal charm of Mussolini, fed by a conscious propaganda directed by himself. Man of the people and therefore able to understand people's demands, the Duce created a myth of himself by adapting the image of the Nietzschean superman to Italian mentality.

After having eliminated laws that separated good from evil, and with the death of the ethic-god, according to Nietzsche common men could become gods themselves, thus freeing their own omniscient and almighty superman by means of their own will and intelligence. This ideology was the basis of totalitarian European systems of the century, as forms of absolute hegemony over life and death, over good and evil. ${ }^{17}$

At the beginning of the Twentieth Century the superman cult was formed in Italy. This man, who had will power, power of thought and intensity of life, 
did not allow himself be suffocated by current ethics, but overcame them in order to give birth to a new man and a new Italy.

In 1915 the nationalistic writer Giovanni Papini, influenced by Nietzsche, had written the essay Maschilità [Manliness], where the new man had to be more brutal, bestial and barbarous, having abandoned his romantic spirit inherited from the past. ${ }^{18}$

Above all, the biography of the mythical master of life Gabriele D'Annunzio exemplified the aspiration to 'supermanism', which he pursued following a life completely away from the usual pattern, indeed beyond good and evil. Benito Mussolini, even as a young journalist and modest man of letters, aimed at becoming a superman. In fact in 1908, in one of his short essays entitled Philosophy of Strength, Mussolini underlined how Nietzsche - one of his favourite authors - had advocated the return of idealism by saying: "a new kind of free spirit will come, strengthened by the war, (...) a spirit equipped with a kind of sublime perversity, (...) a new, free spirit will triumph over God and over Nothing."19

Among intellectual currents, principally the futurist movement absorbed the mysticism of the superman accepting, like Marinetti did in his romance Mafarka le futuriste, the Nietzschean leitmotiv 'will-superman-flight'. The new man for the futurists was not an isolated individual, even if he could make his choices freely; he was "the expression of an elite of supermen, for their own decision gained by the same attitude toward life, by discipline and aspiration to guide the nation." 20

The new futurist man, in his disdain for death and bookish culture, but love for virile action and violence, for the dynamism of mechanics and for war considered by them to be a party ${ }^{21}$ - found followers among European young people who had grown up in the shadow of the Great War myth.

As for Italy, Marinetti, in an excited vision of the Italian spirit, maintained that there were people particularly endowed with "creative genius, elasticity in improvisation, strength, agility and physical resistance, impetus, violence, and fury in the fight."22 According to him, these qualities made the Italian people the noblest of all. This utopian and racist vision was a motive repeatedly used by Mussolini, inciting the glorious Italian race to become a protagonist of the great enterprises of the regime. 


\subsubsection{Mussolini as symbol of the new Italian man}

The futurist idea of the new man was aimed at internationality, ${ }^{23}$ and was also involved with individualistic choices. As a consequence, it was transformed by Fascism into the idea of the new Italian, a purely national model that best suited the plan of socialisation and standardisation of the masses. Such an idea was admirably personified by the new Italian, preeminently the Duce. With incessant propaganda using any possible means, Mussolini, as the greatest communicator and expert in psychology of the masses, ${ }^{24}$ built his myth and superimposed it onto the myth of Fascism, so much so that, in the following years, Fascism coincided with 'Mussolinism' more and more.

Once the declared anti-fascists had been eliminated by violence, or confined, the first objective of Mussolini was to achieve the 'sacralisation' of political ideology. It was a central theme around which the consent of the totality of individuals had to join, without distinction of any kind, as was expected for religious creeds.

From 1923 to 1932 the fascists placed side by side the public holidays of the previous civil religion and the new fascist ones. These public holidays celebrated consolidated myths - such as the Nation, the Monarchy, the Great War and the Fallen - but celebrations were also held to commemorate the March to Rome, the foundation of the fascist movement, and the birth of ancient Rome. 25

To the pre-existing national symbols the new fascist religion added new ones: the littorio fascio, the black shirt, the pennants, the skull and crossbones, the cudgel, the club, the dagger, the Roman salute, the hymn Giovinezza [Youth] and a new calendar for the fascist era.

In those years, manipulating history in its favour, Fascism attributed to itself the greatest merit for most of the events which were celebrated, and it eliminated those that could be in opposition to its politics. ${ }^{26}$

Finally, in the last decade of government, when the political 'sacralisation' of the regime was by then completed, Fascism dilated its myths, particularly emphasising the so-called Stirpe Italica [Italic Descent] - meaning the Italian speaking people proudly conscious of their roots deepened into glorious ancient Rome - as heir to the Roman spirit and empire. Meanwhile, the juvenile push that had supported the advent and the affirmation of Fascism 
suffered a process of sclerosis and repeated self-representation. ${ }^{27}$ Ceremonies, parades, sporting shows, Duce's speeches to 'oceanic crowds' in delirium, imitated more and more those coeval with Hitler's Germany. (Chapter 5.6)

Like any other religion, the fascist religion needed its own idol, incarnated in Benito Mussolini, whose fame, moreover, was already consolidated before the advent of the regime. Of modest origins, with irregular studies and a difficult youth for his rebellious and nonconformist character, Mussolini was endowed with great intuition and ambition.

The determination that he put into each choice gave him popularity and followers from the beginning of his political career. As a child of the people, initially he joined the socialist party but later detached from it because he refused to agree to or share its neutralism. From 1914, as founder and director of the daily newspaper Il Popolo d'Italia, he promoted Italian participation in the Great War, where he fought with honour and was also wounded.

After the war he used his newspaper as the voice of the fascist movement. His personal charisma and the strength of his ideas were amplified by the press, and he set himself at the head of the movement. With the support of economic power and the middle classes, he conquered the piazze [squares] and with them power.

The myth of Mussolini as statesman, whose power he was fully aware of, saved Fascism from the crisis of 1924, after Matteotti's murder. Mussolini's myth also allowed him to charge himself with the moral responsibility for that tragic event. From 1926, after having abolished all liberties and centralising all powers, the Duce devoted equal care to consolidation of the regime. The latter had to cohabit with the realities of monarchy and papacy, and making allowances for individualism in the Italian people.

Mussolini presented himself as the perfect prototype of the new Italian, "the living and working model of the ethical and political individuality" to which Italians had to aspire. ${ }^{28}$ His young age, unscrupulousness in politics, dynamism in action, and publicised passion for speed, movement and sport, were values already exploited by the futurists. These values differentiated Mussolini totally from the rulers who had preceded him, and 
presented him as a modern and efficient head of state, able to achieve peace, order and progress in Italy.

He lived at a time which had discovered the effectiveness of radio, photography and cinematography over writing, thanks to the simplicity with which such media were able to approach the masses, even if illiterate. Films, photo and radio were mobilised to exalt the omnipresent Duce, the 'envoy of destiny' who could save Italy.

The 'extraordinary' qualities of the Duce were visually displayed in perfect 'fascist style'. These qualities were shown by means of theatrical gestures, which were rough but effective. Hands on hips, legs wide apart, set jaw, rolling eyes, the orator Mussolini spoke to the crowd in a virile, stentorian voice. The spectators, when appropriately solicited, had to answer the Duce coram populo, shouting their assent in unison. ${ }^{29}$

This frequent display was usually recorded by photographers and cinemaoperators. They portrayed Mussolini from the lower level towards the top, in order to elevate his rather stumpy figure. His speech was immediately diffused by radio and then publicised all over Italy by means of newsreels and photographic services.

In 1930, a notable contribution to the growth of Mussolini's myth was offered both by the school of Mistica Fascista [Fascist Mystics], focusing on the cult of the Duce, ${ }^{30}$ and by innumerable hagiographic biographies published in those years. ${ }^{31}$ These emphasised the self-made man Mussolini, the difficult years of his infancy, his heroism in war, his care for the humble, his sobriety, his tireless ability in work and sport. By somehow describing his parents as 'saints', those biographies even celebrated his 'holy' birth!

The rest was done by censorship, thereby preventing news which might darken the image of the Duce. Daily the press received sheets delivered by the central Press Office of Rome. These sheets of dispositions, the socalled veline, detailed what could be published and with which emphasis. It was forbidden to alter the perfect image of the new Italian prototype Mussolini - refusing for instance to approach him with the negativity of illness or death. Emblematic in this sense was the velina that ordered: "Do not say that the accident to Agnelli's child occurred along the Mussolini Jetty of Genoa, but just say that it occurred in the Sea of Genoa."32 
In the Thirties the myth of the Duce led to the 'Mussolinism', which was almost the total identification of Fascism with Mussolini. He was isolated like a god on Olympus. Distrusting everyone and everything he actually became the one and only person in command, and doggedly managed to adhere completely to the granite self-image he had built.

This phenomenon was fatal both to him, because the ideology he embodied in his person was petrified, and to the development of Italian civic conscience. Italians, already accustomed to obsequiousness and political delegation to power-people, because of their unfortunate historical past, put their destinies in the hands of this new powerful deus ex-machina - the Duce - once again.

The hazardous political choices that Mussolini effected in the second half of the Thirties - the empire, the alliance with Hitler, the wars - might also be interpreted as attempts to revitalise Fascism and Mussolini's image, by then aged, in the eyes of Italians and the world.

In spite of this, the propaganda induced Italians, spellbound by the myth of the Duce, to believe that, by means of the strength of his ideas, the will of his actions, the sturdiness of his 'always young' body, finally Mussolini would ransome them from the past and drive the country to a glorious future. The price to be paid seemed quite reasonable: to allow the transformation urgently required, i. e. to become new Italians.

\subsection{Fascist institutions and aesthetics}

The new Italian was the fruit of conversion to the new religion of the State. By not detracting from orthodoxy, the regime devoted maximum effort to the Italian's 'fascistisation', i. e. to mould character and habits of life to the fascist-style, which represented a new aesthetic model incarnated by Mussolini.

Unlike the liberal rulers that had preceded him, the Duce did not fear the masses, and was not against them, but claimed that the masses could not be governed by themselves. A popular leader and a strong government were necessary. In order to transform the masses into the Italic Descent, it was necessary to convince them to follow the new fascist aesthetics and lifestyle. This task had to be realised through the suggestion of abstract 
symbols and the living symbol of the Duce that could efficaciously act on the irrationality of popular feeling.

In fascist aesthetics, close to the cult of choral beauty expressed by the masses celebrating the liturgies of the regime, the cult of physical beauty had a remarkable place. The higher and middle classes had already been aware of this myth for a long time, as they were fascinated by D'Annunzio's sophisticated aesthetic model and, more generally, by the paradigm of classical beauty.

In Europe, since the beginning of the Eighteenth Century, the idea had circuleted that a well-structured mind should correspond to an adequate bodily structure. A beautiful body would represent conciliation between the aspiration for order and the aspiration for progress, through the clear harmony of its forms modelled on the aesthetic canons of classical statuary. ${ }^{33}$

Fascism exalted the cult of classical masculine beauty, as it suited the plan to make the Italian man virile by means of special attention to his physical sturdiness and to eugenics. The virility of the masculine body was essential to re-propose, in a modern key, the ancient and bellicose Italic Descent as the new national model, then as the European, and finally the international.

The beauty of a virile and sturdy fascist man, eternally young and powerful, was opposed to the ugliness of the non-fascist man, identified in the aged liberal bourgeois with his flabby body, the Negro from Ethiopia with his too marked features, the Jewish profiteer with his prominent nose, naturally, according to the enemy, to destroy from time to time. ${ }^{34}$

The new Italian was induced to assume the 'fascist style' which consisted in supporting the canons of beauty advocated by the regime, that is to put, like the ancient Romans, mens sana in corpore sano at the service of the cause. Having installed a colossal hierarchical organisation, the regime inserted in it all citizens from birth, as the youngest bodies and minds would have accepted the new creed with the freshness of their years, assuring in that way the faithful perpetuation of the time.

Among the institutions for early childhood we should recall the foundation of the Opera Nazionale Maternità ed Infanzia [National Maternity and Infancy Body]-ONMI, in 1925. The sanitary, hygienic and preventive assistance to mothers and children up to three years old was here of 
primary importance. The aim of ONMI was the defence and physical and moral improvement of the race. ${ }^{35}$ In fact, in its statute it said: "to educate 'fascistically', that is manfully, Italian youth: here it is one of the fundamental aims of the Regime, whose urgency and beauty are felt by everyone." 36 In that way the regime intimately insinuated itself in the Italian social tissue, endeavouring to 'fascistise' the worlds of the school, workplace and sparetime. The regime especially promoted the education of the youth at school. In 1921, 35.8 of the population was illiterate, but in 1931, during the fascist era, this decreased to $21 \%$, a concrete sign of the current modernisation of society. Obviously the school was also an essential means for bringing children to the fascist creed and to an efficient pre-military formation. ${ }^{37}$ (Chapter 5.2)

The pupils were enlisted in the Opera Nazionale Balilla [National Balilla Body]-ONB, which had been founded in 1926 to support the school in the physical and moral improvement of the youth. Male and female children from 8 to 14 years, compulsory in uniform, were framed in groups whose names evoked values linked to the Roman spirit, the Fatherland and the War. According to their age and sex, male children were called Balilla, Avanguardisti, and female children Piccole Italiane, Giovani italiane. In addition, younger children of both sexes were enrolled as Figli della Lupa [Children of the She-Wolf]. One of the most famous slogans of the ONB was "Book and musket, Balilla perfect" as if to underline the soldierly character of the organisation.

Whoever did not continue studies was enlisted from 1923 in the Milizia Volontaria per la Sicurezza Nazionale [Voluntary Militia for National Safety]-MVSN, and from 1930 onwards in the Fasci Giovanili di Combattimento [Juvenile Fasci of Combat]-FGC, institutions with a pure military character in preparation for the levy.

In the universities the Gruppi Universitari Fascisti [University Fascist Groups]-GUF were operational, and since 1927 they came under direct power of the PNF, where sporting activity was combined with pre-military training.

Adults were warmly invited to enrol in the PNF and to wear the camicia nera [black shirt] at least for the assemblies of the Sabato Fascista [Fascist Saturday]. At the end of 1942, the maximum expansion of the PNF was 
recorded, and the fascist organisations as a whole had 27,376,571 members, out of a population of about 46 million citizens. ${ }^{38}$

As far as spare-time was concerned, since 1925 the Opera Nazionale Dopolavoro [Spare-Time National Body]-OND was founded, for manual and intellectual workers, without apparent political pressure. Indeed, this OND was a colossal and unique organisation of its kind. In 1935, the OND boasted cinemas, theatres, companies of amateur actors, orchestras, bands, professional and cultural associations, libraries, and choral-music schools. ${ }^{39}$ Among the activities proposed by the OND, both modern sporting activities and the most traditional games had wide assent (Chapter 5.4).40

By the middle of the Thirties, the expansionist aims of the Duce accelerated and therefore the main purposes of the nation had to be defined again. The model of a generically militarised nation was replaced by that of an armed and aggressive nation. In each of the Fascist bodies the military character of indoctrination and that of physical training were emphasised, in view of possible future wars.

After the victorious war against Ethiopia, which led to the foundation of the Empire in 1936, those bodies were encompassed in the Gioventù Italiana del Littorio [Italian Littorio Youth]-GIL, which lasted from 1937 up to the fall of the regime.

The already-mentioned bodies improved their self-representation in the country, and therefore that of the fascist creed, by means of spectacular mass assemblies where, to the usual ceremonies with their rites and symbols, were added numerous gymnastic and sporting contests, on behalf of activism and physical fitness. Among these displays the Littoriali, the Agonali, the Ludi Juveniles, the Campi Dux, and the OND contests should be mentioned (Chapters 5.2 and 5.6).

In the presence of the Duce and his hierarchy, crowds of spectators enthusiastically followed the athletic performances in uniform. These embodied the uniformity and order of fascist aesthetics in the geometric perfection of their choreographic execution.

As far as the sporting education of soldiers of the levy was concerned, it should be underlined that since 1921 the Central Military School of Physical Education of Rome was widely equipped with ultramodern laboratories and facilities. This school trained officers in teaching discipline in the barracks. 
The physical activities for soldiers, with a rich and varied programme, had to be executed by naked-torso pupils in the open, granting the use of a sweater in winter. These pupils were trained daily for about 90 minutes. Furthermore, regimental collective contests were organised regularly, so as to test the standard of the soldier's physical preparation.

As years went by, the training programme for officers increased considerably. From 1934, officers, and non-commissioned officers in reserve, were forced into post-military training which had to be repeated for about ten years. Finally, a sort of general military training was decreed for people aged from 18 to 55 years.

Fascism, as we have seen, had absorbed and firmly proposed themes of pre-existing cultural currents. It had fully accepted the central position of physical education and sporting activities in the military training of the masses. In particular, it was inspired by the futurist movement that, aiming at a virile education of the people, supported the pre-eminence of gymnastics over books. ${ }^{41}$

Marinetti wrote: "Male children, according to us, should be trained far from female children, because their early games are clearly masculine ones, that is without affective morbidity, womanish sensibility, but lively, bellicose, muscular and violently dynamic ones."42

The ideal futurist state, of course, had to take care of physical, moral, intellectual and patriotic education, including daily gymnastics at school, and had to found many physical education institutes for the training of future teachers. 43

The publicity that the futurists wanted to give to the diffusion of sporting habits can be exemplified by the script for a film, entitled Vita Futurista, where scenes of "morning gymnastics, fencing, boxing, sword fighting (between Marinetti and the futurist Remo Chiti) and boxing matches (between Marinetti and a Mr. Ungaro)" were shown. ${ }^{44}$

Since the beginning, the practice of physical education and sport was considered by the fascist regime to be an efficacious way of matching aggressiveness, violence, and that 'status collective effervescence' inherited by the Great War, with the moulding of well-disciplined and efficient new people. In those years, the country was equipped with numerous stadia, ${ }^{45}$ gymnasia, sports fields, ${ }^{46}$ and male and female academies to train future 
teachers of physical education. ${ }^{47}$ The intention was to transform Italy into a sporting nation whose model would gain the admiration of other people.

The result of these policies was quite remarkable: in 1928 there were about 502 sporting facilities in the country, but in 1935 these had increased to 5,198 - gyms, athletics and other sports fields. In the same year, 1935, the number of students involved in physical education at school was 470,000 in total, a big number if we compare it to that of 180,000 pupils in 1928.48

The sporting sector was well controlled by either eliminating left-wing sporting associations, or strongly delimiting the field of action of the Catholic ones. ${ }^{49}$ In addition, from 1926 onwards the heads of the Comitato Olimpico Nazionale Italiano [Italian National Olympic Committee]-CONI were men of sure political faith. 50

In December 1928, the Carta dello Sport [Sports Charter] was issued. It officially fixed the importance of physical and sporting education, which had to be practised by organisations of the regime, such as ONB, MVSN, OND, and GUF. The Carta dello Sport, by putting CONI at the head of all sporting federations, added to its institutional task of connecting Italy to the International Olympic Committee-IOC the task of being the only body responsible for Italian sport as a whole. ${ }^{51}$

The result of this political choice was good, as far as sporting image was concerned. At international level CONI worked quite well, as the results of the Olympic Games and other world competitions demonstrated abundantly. In fact, Italy gained second place among participant nations at the Los Angeles Olympics of 1932, third at the Berlin Olympics of 1936,52 and won the football World Cup in 1934 and 1938. Furthermore, in those years a number of Italian boxers, cyclists, aviators and motor racing drivers gained records and victories in international contests. 53

In the Thirties, the regime not only drew in new people through popular physical activities, but also successfully forged champions by selecting the most talented individuals, who were trained as sports professionals. Stimulated by economic support, honours and prizes, ${ }^{54}$ and excited by the fascist propaganda that defined them as super-heroes, these athletes, well known in the USA as 'Mussolini's boys', had the task of increasing national pride and the new image of Italy, by fighting successfully with a virile and dynamic spirit against the Great Powers. 
In a famous speech to athletes, Mussolini ordered: "You must be tenacious, chivalrous, daring, [you must] remember that when you fight outside the country, at that very moment the honour and the sporting prestige of the nation are entrusted in your muscles and above all in your spirit." 55

As sporting displays created consensus by admitting huge masses of spectators, they bloomed in a prodigious way in the Thirties. The press reported that in 1936 there were about 30,000 sporting displays, followed by about 40,000,000 spectators. 56 Probably there was some exaggeration with incessant propaganda, and data were probably mystificated, however these numbers are indicative of a very popular phenomenon, on which the regime counted as a way to encourage spectators to be more active, by fully adhering to the new fascist style.

\subsubsection{The sportsman Duce}

The exaltation of the virile body as a metaphor for the fascist creed was common to all fascist movements, but its materialisation in the body of the Duce was a peculiar Italian phenomenon. In fact, Mussolini was raised to symbolise the virility itself, not only by the power of his ideas and the loving enterprises which were attributed, with some reason, to him, ${ }^{57}$ but by the strength of his muscles and the versatile talent that - it was told - allowed him to practise every type of sport with success.

Above all, the Duce loved motor cars and therefore motor-racing as well as aeronautics, having surely been influenced by the futurists whose art according to the harsh judgement of the anti-fascist Gobetti - was merely "the art of a salesclerk traveller of sporting objects"! 58

During the years of his government, Mussolini used to exhibit himself also as experienced in horse riding, fencing, swimming, gymnastics, tennis, skiing and boxing. $59 \mathrm{He}$ had himself photographed running among soldiers, skiing down the Terminillo Mountains, swimming in the Adriatic Sea, and harvesting the grapes or reaping the corn together with farmers. In general, he also showed his naked chest without any embarrassment.

These sporting-agricultural displays aroused the admiration of people because in Italy, a poor country with a prevalent rural economy, they represented the Duce both as a kind of Nietzschean super-sportsman, and as a man of the people. 
Flattering words were often devoted to the sporting abilities of Mussolini, 60 but there was some mystification, since the Duce was not pre-eminently a man of sport. As a young man, he had done some fencing, which was a popular activity in Italy, especially over questions of love and politics, and his passion as spectator at boxing bouts was well known. But with regard to other sports, he was still an intellectual of the Nineteenth Century, far from Marinetti's modern model. ${ }^{61}$

As a matter of fact, Mussolini, a sickly person for most of his life, considered basic physical education important for health, and considered sport as "an effective means to inculcate discipline and team-spirit in a society he judged too anarchic and individualist."62

Having assumed the importance of sport in modern societies - and being an exhibitionist pre-eminently - he wanted his image to coincide with that of the sportsman par excellence, and therefore he perpetuated this further myth in the country and abroad. Actually the Duce was not a 'real' athlete, and his myth did not need to change much over the years, nor compromise with age.

It was related that, in his Villa Torlonia residence, he invited the foreign press expressly to be present for his horse riding, and fencing and tennis matches against very complaisant sports teachers. ${ }^{63}$ He also had his presence pointed out on beaches as a swimmer, on the snows as a skier, and in the skies as a pilot, in order to enchant people, be portrayed in photos and filmed on newsreels.

The Duce was not handsome; he was short with a big bald head, a face with prominent features characterised by a lantern jaw. However, he embodied the aesthetic model of virile beauty in the eyes of most male Italians who, spellbound by his magnetic charm, wanted to imitate his physical appearance and life style.

This phenomenon was particularly evident among the leading class of the regime, the so called gerarchi [members of the hierarchy] among whom Achille Starace should be remembered. He, the disliked caricature of Mussolini, was a loyal defender of the fascist style by practising all kinds of sporting exercises.

In 1938, Starace forced his already aged colleagues to perform physical exercises that were difficult even for a young man. In a notorious Sheet of 
Disposition of 1938, he actually insisted that, on the occasion of a meeting in Rome, the aged employees of the National Directory and the Federal Secretaries show off by diving from a springboard, horse-jumping and swimming 50 metres. ${ }^{64}$ This ridiculous show was not repeated.

In conclusion, in those years the Duce's self-styled athletic body - the living symbol of fascist virility - became the main source of inspiration for Italian men and was celebrated in literature, in the figurative arts and films, as will be shown in the next section. 65

\subsection{Virility in literature and the arts}

During its early years, Mussolini's ideology had been the object of a cultural debate, so much so that in 1925 intellectuals openly took sides and signed two opposite documents, the Manifesto of fascist intellectuals, compiled by the philosopher Giovanni Gentile,66 and the Manifesto of anti-fascist intellectuals, compiled by the philosopher Benedetto Croce. ${ }^{67}$ But, having eliminated the more dangerous anti-fascists, Fascism now wished to control the rest of its enemies, although it did not intervene too much in the field of elite culture. In fact, those intellectuals were to be acquiescent or disengaged in regard to the fascist regime.

In synthesis, one might say that at its highest level the cultural world especially literature - was not at the service of the current ideology, although it was not too vital and bright. ${ }^{68}$ Mussolini himself considered the past not a barrier to the new, but as a point of departure for a glorious future. $\mathrm{He}$ 
was therefore eclectic and open to novelties, also because he did not have a precise taste. 69

In the field of popular culture the fascist regime was omnipresent. Daily newspapers, periodic reviews and scholarly texts, as well as the whole of the literary production - from romances to biographies - were rigorously controlled by the regime because of their broad dissemination in society.

\subsubsection{Mussolini's literary portraits}

Among the intellectuals supporting Fascism with more or less conviction, many were seduced by the charm of the Duce. The playwright Luigi Pirandello, Nobel prize-winner in 1934, used to say about Mussolini: "He, you see, makes Italy, and makes the world, he makes all of us as he wants: he creates us from time to time according to his whim."70

The anti-conformist writer Curzio Malaparte composed a poem for the Duce, which sketched an effectively synthetic portrait of him. ${ }^{71}$

The aggressive physical image of the Duce, a metaphor for his political aggressiveness, not surprisingly in 1929 suggested an essay to Marinetti, Ritratto di Mussolini [Mussolini's Portrait], which said: "Physically he is built in the Italian way, outlined by inspired and brutal hands, forged and engraved according to the model of the masterly rock of our peninsula. Imposing, square jaw and prominent disdainful lips, which spit boldness and aggression on everything which is slow, pedantic and meticulous."72 The famous journalist Indro Montanelli, although critical toward fascist ideology, in his youth wrote an article entitled Mussolini e noi [Mussolini and we], that well interpreted the feeling of the average Italian in respect to the Duce: "When Mussolini looks at you, you cannot but be naked before him. But he is naked before us as well. There are people who, to be considered somebody, need to wear a uniform or badge, but not Mussolini. His face and 'torso of bronze' rebel against draperies and harness. Anxious and impatient, we snatch them from his back, contemplating only the inimitable essentiality of this man, whose shaking, vibrating and thumping are formidably human. The rest is not important."73

\subsubsection{Mussolini's art portraits}


All the arts were appropriated to the physical image of Mussolini, his muscular 'torso of bronze', and to the model of their production.

The theme of the athletic body of the Duce was already present in the Twenties, but at the beginning of the Thirties it received an additional impulse, as it was set at the centre of the propagandist campaign to spread the fascist style among Italians. ${ }^{74}$

At a low artistic level, we find the Mussolini-subject in the illustration of books, posters, medals and postage stamps, in the show-rooms of amateur artists and in manufactured handicrafts. The common people, having received the message, exalted in their turn the effigy of the Duce, making his portrait even out of unsuitable materials, such as flowers or grains of corn. ${ }^{75}$ Those Mussolini portraits were found hanging on cardboard in people's homes. It has been calculated that between eight to thirty million postcards - drawn from the photos of Mussolini - were circulated in fascist times. The successful cult of the virile male, in fact, answered the well solidified feelings of Italian society, still deeply sexist and patriarchal. ${ }^{76}$

At an intermediary artistic level - and in order to promote 'popular universal art' as a culture without an class distinction - great pictorial and mosaic decoration was launched for public buildings. Of course, this was an easier way to show Italian art, in comparison with museums, since usually common people felt uncomfortable in going to places of elite culture, such as traditional museums. This fact had already been denounced by the futurists, who accused museums of being mere symbols of 'obsession of culture'. 77

As for 'militant art', which was art openly set at the service of the political ideology of the regime, it was viewed as a "perfect means of spiritual government".78 'Militant art' was broadly encouraged by means of shows, contests and prizes, such as the annual Littoriali of Art, the Cremona Prize, and the periodic Trade Union Exhibitions.

There, the idealised images of virile bodies, belonging to the Duce and other athletic fascist men, were often shown in pseudo-photographic portraits. The aesthetic value of those pictures was mainly based on the choice of beautiful models, in a tedious representation of the healthiness of the 'Italic Descent'.79 
Even figurative art of the highest level, which in the years of the regime was mostly expressed by the currents of the Futurism, Novecentismo and Modernismo, stuck - with some exceptions - to the themes proposed by Fascism, by creating sculptures and paintings inspired by them.

Once more, the principal theme was the athletic body of the Duce, which was portrayed standing or sitting on horseback, dressed like a Roman commander, ${ }^{80}$ a Renaissance prince, ${ }^{81}$ a revolutionary hero, ${ }^{82}$ a sacred icon, ${ }^{83}$ or portrayed as the hero of fanciful allegories. ${ }^{84}$

In 1932, on the occasion of the tenth anniversary of Fascism, the Exhibition of the Fascist Revolution was held in Rome. It recalled some of the best figurative artists of the country who gave special attention to the human figure as an inspiring model for their art. Above all, the figure of Mussolini was the omnipresent subject in every showroom, as the synthesis of the Italian people and Fascism itself. ${ }^{85}$

The architecture of the regime was monumental, following the Roman architectural style, but at the same time simplified in the squared lines of the Modernismo rational fashion. Even those architects broadly used the theme of the virile Duce's body, and that of the ideal fascist athlete, for decorating their buildings.

In the Mussolini Forum - an architectural complex designed by Enrico del Debbio in 1927 - the Stadio dei Marmi [Stadium of the Marbles] was one of the best examples of architecture in the 'fascist style'. The superior perimeter of that stadium was decorated with 60 colossal statues of white marble, representing naked athletes as symbols of the eternal youth and virility of the new Italian.

The intent of these 4 metre-high colossuses was to evoke ancient Roman greatness, but actually they echoed both the Renaissance David statue by Michelangelo and the nineteenth century naked figures by Ingres. However, those statues not only stimulated malicious comments of Italian women and homosexual voyeurs, ${ }^{86}$ but also the irritation of the Church of Rome and of 'respectable people' unaccustomed to nudity exhibited too openly. 87

Besides, in the architectural complex of the Mussolini Forum, a gigantic obelisk of marble was erected - weighing 300 tons - dedicated to the Duce, as the craftsman of every rebirth and animator of every enterprise. The obelisk, in recalling the granite image of the Duce, somehow represented the 
phallic metaphor of him, and therefore perfectly suited the virile context of the Forum. 88

The Mussolini Forum was also planned to take a colossal bronze statue of 80 metres in height, symbolising the strength and virility of the new Italy. Obviously, this half-naked Hercules should have had Mussolini's features but, after having moulded the ggantic head of the Duce, and his foot, in bronze, they realised that the complete work was technically impossible. The plan was quietly set aside in great haste, and Mussolini was saddened. 89

\subsubsection{Cinema and fascist propaganda}

As for cinematography art, although it had been institutionalised by the regime, it did not produce real state cinema, so much so that only a few films were openly propagandist. Among them were: Vecchia guardia by Blasetti, Camicie nere by Forzano, Ragazzo by Perilli, L'assedio di Alcazar by Genina, and Luciano Serra pilota by Alessandrini. 90

A few films, such as Sole e terra madre by Blasetti, focused on agriculture and others, such as Rotaie by Camerini, on the industrialisation of the country, which were themes particularly linked to fascist policies. Of approximately 700 films produced in those years, most had no close reference to political reality.

Together with the historical series of films in costume, among which at least the colossal Scipione l' africano by Gallone has to be mentioned, the series of telefoni bianchi [white telephones] gained great acclaim. The latter series showed the amusing life of a low and middle bourgeois, indeed a kind of absent-minded person thinking in an optimist way. However, if one takes a closer look, one can see that the disengaged objective of the protagonists love affairs, family, money - and their pride in their own social condition even if modest - perfectly complied with the aims of Fascism. In fact, it considered the citizens' indifference to politics as functional to the stability of the regime.

In the 'white telephones' series of films, the Italian way was embodied in the male protagonist - generally a young and winning man - who resolved the most tangled situations by giving the enemy 'four slaps'. 
The most required actor for embodying the prototype of the Italian male virile and slow of speech - was Amedeo Nazzari but, in truth - due to his tall and elegant figure - Nazzari reflected the American ideal of the handsome Latin man, and not the Italian masculine beauty then incarnated by the Duce! 91

Rather than to feature films, the duty to indoctrinate society was entrusted to documentaries, and to the new reels of the LUCE [The Cinema Educational Union], a body founded in 1924. The documentaries were delivered to the population didactically by means of lessons on agriculture, history and geography, and by propaganda about industrial realisations, reclamation of territory and archaeological discoveries.

Particular attention was devoted to documentaries on the demographic rise in Italy, presenting images of happy and multiple maternity. Furthermore, these documentaries involved themes linked to eugenics and defence of the race, showing struggle against illness and the strong and methodical new Italians involved in gymnastics and other sporting performances.

It was mainly left to the compulsory projection of the newsreels in schools, communes and cinemas to ensure the maximum diffusion of the news, obviously filtered in advance by Mussolini's Press Office. The declared aim of the newsreels was the civic and moral education of citizens, but really they were pompous and resonant boxes of fascist parades and celebrations.

A particular emphasis was then given to choreographic and paramilitary exhibitions of fascist youth and to the image of Mussolini, shown in his public, and sometimes private, life. All Italians, including those who lived in distant regions, could see the Duce in person, admire the magnetism of his looks and his unrestrained gestures. 92

Mussolini was fully aware of the extraordinary effect of those images, which he wanted to reverberate all over the world. For instance, in 1933, he agreed to be the protagonist of an American film directed by Thomas, titled Mussolini Speaks, where he behaved with the boldness of a movie-star. In the final scene of the movie, the Duce was filmed in the Roman Forum, as if to underline his ideal connection with the great figure of Julius Caesar. Also in that film, his characteristic body language was made up of agitated gestures combined with hard, statuary postures of great effect. Really, 
most scenes displaying the Duce among the crowd were just a selection of images filmed previously by Italian newsreels. ${ }^{93}$

Mussolini Speaks was circulated mainly abroad, where it successfully presented a positive image of the self-made man - Mussolini - the new politician, the athletic leader of Italy.

In conclusion, Italian culture as a whole tried to make Italians a virile people - by making the Duce a myth - especially by means of the figurative and cinematic arts. Notwithstanding, Italian culture really acted more as spectator than as actor of the tragi-comedy played time after time by fascist politicians on the colossal stage of the nation.

In fact, there was a number of elite individuals endowed with a free spirit who were blamed for being too cool to fascist ideology. In those years they were scornfully called 'defeatists'.

\subsection{The last period: Fascism and Nazism}

With the coming to power of Hitler in 1933, Italian Fascism had to compete with another right-wing totalitarian regime.

Immediately, Mussolini enthusiastically underlined, through the press, that the birth of that new fascist regime in Europe had been inspired by the Italian, ${ }^{94}$ but in the following years the Duce had to deal with a dictator he considered dangerous, and with a nation historically considered an enemy of Italy, at least since the previous century. 
Hitler had always declared himself a fervent admirer of Mussolini and the Italian fascist government, from which he had taken inspiration in many fields, ${ }^{95}$ but nobody could be indifferent to the sinister spell he exerted on the German people, nor the exasperated anti-Semitism of his creed. What is more, in exalting the superiority of the German race above others, Hitler's ideology even impugned the Latin race.

In the early years of Nazism, the Duce conducted a policy certainly not favouring the Germans, but because of the war against Ethiopia, which had been condemned by the League of Nations, Mussolini came closer to Hitler's policies.

In 1938 this alliance brought the promulgation of racial and anti-Semitic laws in Italy. ${ }^{96}$ Both the Great Council and Mussolini tried to justify such policies, by explaining to the people that Fascism was not subject to the Nazi dictatorship at all, but it was pursuing a coherent strategy of defence of the Italian race, already planned for a long time. ${ }^{97}$ In fact, a kind of racism toward the black people of Africa - especially after the conquest of Ethiopia - had promoted severe dispositions imbued with an apartheid spirit, in order prevent both the Italian colonisers and the natives from fraternising. ${ }^{98}$ This racist choice of 1938 cost the regime much in terms of consensus, either in opposition by the Church of Rome, or in that delivered by most Italians. Owing to the extensive domination and rules suffered over the ages, the Italian people were a melting-pot of cultures and races and actually they were much less anti-Semitic than anti-German. In fact, whereas the Jewish community had lived on Italian territory peacefully for ages, the Italian population had suffered from and harshly fought against the Austrians in recent years. As a consequence, common opinion did not make a refined distinction between Germans and Austrians, both speaking the detested stentorian German language. In addition, the chilly and at the same time imperious Hitler image, displayed by newsreels, frightened Italians considerably.

The racist campaign against Italian Jews was indeed a political choice by Mussolini. Even though ideologically not anti-Semitic, ${ }^{99}$ the Duce probably wanted to teach the international Jewish community, who had been opposed to the victorious war of Ethiopia, a lesson. At the same time, Italian fascists deserved a new exciting objective. That racist campaign offered young 
militant men, who were disappointed in the results of the 'fascist revolution', a real cause in which to dissipate their frustrations, and also an ideal reason for fighting. 100

The racist question was debated at different levels in Italy, and the racist choice was also supported by some intellectuals who, through their publications and declarations, tried to explain its scientific truth and its philosophical and ethical reasons. 101

According to this racist policy, the values of the Italic Descent were further emphasised, so much so that on the occasion of the anti-Hebrew Congress of 1938, Rome was even baptised as the Capital of the Aryan Empire. Also inside a written project for the Roman Exhibition E 42 - which then did not take place due to the war - the threatening expression 'Italic Race' replaced the previous and more reassuring 'Italic Descent'. 102

The supremacy of the Aryan race in the world was a central aim of Hitler's policies, whereas Mussolini's aim substantially focused on the transformation of the Italian people's character and life-style. Whereas the ideological theme of the supremacy of Aryans only referred to the past, which made the actions of fallen heroes - and the ancient Germanic heroes a myth, the new Italians, although heir to the ancient Italic Descent, had to throw themselves into an indefinite glorious future which would induce populations of even different races to admire and imitate them, in a utopian plan for a world-wide 'fascistisation'.

After all, subsequent events demonstrated that Italian racism inspired by Hitler had not too devastating effects, because only a few people really believed in the correctness of the racist laws, and as a consequence the laws found it difficult to be applied. ${ }^{103}$ In this field Germany gained power over Italy late in the war, but they hardly gained hegemony anywhere in Italy.

By the end of the Thirties, in view of a war which Mussolini saw far in the future, the suggestion offered by the mobilisation of the German people deepened also the military mark of Italian life, by acting on the supposed heritage of the ancient Roman spirit.

Under the pro-German PNF Secretariat of Achille Starace, and on behalf of the glorious Italian race, all Italians had to address each other as voi [you]. They also had to greet each other in a more virile way, by stretching their right arm in the so-called saluto romano [Roman salute], and the soldiers 
had to march on parade with the passo romano [Roman step], which was the Italian version of the Teutonic goose step.

Moreover, anything which could be considered alien to the Roman spirit from regional dialects to foreign words - was officially banished, so as to keep people 'purely European', and to preserve the physical and psychological characteristics of the race. But these bans hardly worked.

In order to imitate Hitlerite-Germany, from 1937 onwards the mobilisation of the masses received the highest impetus under GIL, and naturally physical education and collective pre-military drill were encouraged considerably.

The main aim of Italian physical training still focused on popular health, strength, discipline and will, without any aesthetic satisfaction, whereas the extreme cult of the male body as a symbol of Aryan beauty - which in Germany had been expressed as the search for fine bodily shape according to Hellenic canons - did not find correspondence. ${ }^{104}$

Hitler's blonde athletes, whose bodies appeared to be sculpted like Greek ephebs, were rather different from Mussolini's boys, incarnating a more modest bodily model. In Italy, the virile ideal was not principally expressed by the athletes' perfect bodies, but by the strength of their moral will, which had to be trained not only for physical activities but for daily life.

With their naked but undefined torsos, with their brown and short Mediterranean legs engaged in the hard task of marching in Roman step, the young Italian men could be seen as a dull and uninteresting imitation of the Hitler Jugend (Hitler Youth) chilling in their uniform beauty and spectacular, perfect execution of the goose-step during the Nazi parades.

But, since the middle of the Twenties, when Nazism was still very far from attaining power, Italian Fascism had worked hard to obtain perfectly synchronised exhibitions by semi-nude young men, as a vital sign of their discipline and cohesion. On this there is early evidence in the words of Lando Ferretti - man of sport and party - who in 1928 had commented on the athletic exhibition of soldiers by saying: "To watch thousands and thousands of statuesque soldiers, naked under their martial helmets, immediately obey orders as a single soldier, means watching a powerful and disciplined sight, which is irresistible."105 
In conclusion, the Italian people did not attain a perfect homogeneity, and did not totally become transformed into new Italians, even after twenty years of attempts and indoctrination. Probably, the hardest obstacle to homogeneous transformation of society was individualism - and a certain critical attitude towards politics - of Italians, as the fruit of secular geographical, historical and cultural divisions within the country.

In a more general way, in spite of insistent propaganda urging the common people to adopt a new 'fascist style', their taste was never levelled and, outside the political ambit, the cultural debate could continue undisturbed. On the other hand, the Nazi Germans harshly fought against 'degenerate art', and even burned books and works of art in order to affirm a unique kind of art that was the 'pure art'. 106

Even the two leaders, Hitler and Mussolini, although joined together by a strong personal charisma and a self-awareness as 'men of destiny', were incomparably different. Whereas Hitler played his part with terrifying conviction, Mussolini was less determined, but took advantage of events, also using a kind of cynical opportunism that, as time went by, even damaged himself. 107

Hitler's image - being taken from Northern mythology and the Nietzschean superman - was quite chilly and detached, whereas that of Mussolini deepening its roots in the rural and patriarchal tradition of the Romagna region, was openly displayed to the crowd. In fact, Italians were informed about his meals, obviously frugal, about his extraordinary ability to work by affirming: "The Duce never sleeps!"-, about the lapidary brevity of his thoughts, even written everywhere on walls in large letters, and finally about his ever young and athletic virility.

Moreover, the extrovert Mussolini, who was used to all possible means of communication, did not fail to show the world the modern image of himself as an eminent political athlete in history. 108 This image received world-wide consensus, as can be demonstrated by the fact that, in 1938, the USA gave him first place among dictators of the time, whereas Hitler, a gloomy and introverted person, received very poor acclaim. ${ }^{109}$

Nazi socialism, which had made the beauty of the male body one of its symbols, could not avail itself of Hitler's image to promote this symbol to the world. In fact, and perhaps due to the irony of fate, Germany had a 
leader who, by having a poor physical and mental interest in and ability at sport, had no way to embody the ideal type of the Aryan race.

Mussolini's so-called athletic body, in spite of being unhealthy, was widely displayed as the prototype of the 'Italic Descent'. The repeated public exhibitions of his bronze torso were judged somehow to be undignified, if not ridiculous, especially - not surprisingly - by his ally Adolf Hitler. ${ }^{110}$ 
Chapter 3 


\section{Model women and physical training before Fascism}

The hundred years which preceded the advent of Fascism were characterised by the patriotic and nationalistic ideals of romantic culture. The dream of unifying Italy under the Savoy dynasty, after years of wars 
and political and diplomatic negotiations, was reached in 1861, and it was completed after the siege of Rome in 1870. The new Kingdom of Italy gave itself the objective of forming the Italian nation by unifying very different cultures, mentalities and traditions inherited under secular rule of foreigners and the Roman Church. This objective actively engaged the young State which desired to affirm its own identity and power in line with other nations. On the wave of enthusiasm for German military gymnastics, practised in Piedmont by the Savoy Army since $1833,{ }^{1}$ civilian gymnastics societies arose in Italy. Initially, they were attended by the aristocracy and the high bourgeoisie, whose long-standing attention to the body - and its physical training - as protagonist of the destiny of individuals together with spirit and mind, was a strong idea re-proposed by Illumines recently. 2

From mid - Nineteenth Century, this idea was transformed more and more into a social aspiration, engaging the government in a project of general physical regeneration of the population, aiming at principally involving the workers, who were least defended in respect of the industrialisation and modernisation taking place in the country.

In those years the various gymnastic societies on the territory joined together and founded a national federation. Although having various fortunes and changing its leaders, this federation directed Italian physical culture as a whole. ${ }^{3}$ In the last part of the century sports associations for sailing, rowing and cycling arose in the country, while the new English games of cricket, lawn tennis and football began to appear on the Italian sport scene. Some of these new sports initially relied upon the national federation, but later freed themselves from its tutelage by organising their own competitions and founding new national federations. ${ }^{4}$

All these contributed much to popularising the new English games, and especially football for which even its history was troubled. As a matter of fact, in an attempt to absorb and nationalise the football game, its Italian origin was reclaimed, by making it descend from the old Florentine calciogame. At the beginning of the 20th century football replaced the giochi ginnici, i. e. gymnastic games mainly deriving from the Renaissance period, as the traditional pallone al bracciale and tamburello games, which had predominated in the Nineteenth Century. ${ }^{5}$ Football became the national game pre-eminently. 
The gymnastics federation could excellently represent the gymnasticpatriotic ethics of Italians of the time by organising colossal exhibitions true gymnastic rallies - where great exploits were a metaphor for the greatness of the Fatherland.

Being faithful allies of the liberal government, the national gymnastics federation displayed flags, distributed medals and encouraged national anthems, on behalf of the most radiant patriotism, during its periodic national and international competitions which were held in the principal Italian cities. ${ }^{6}$ Clearly this kind of display was reminiscent of the German gymnastics festivals, but this is nothing to be surprised at, since Italian gymnastics of the time followed the Turnen ideals which had been transferred and adapted to Italians by the Swiss Rudolf Obermann.

As in other European countries, in Italy the process of mass nationalisation used the great gymnastic-patriotic parades as one of the most effective symbols to transmit to the people the sense of their belonging to the nation through a kind of 'nationalisation' of the body. The theme of the pedagogical value of gymnastics at school was then faced by the new state from the beginning as the main way of affirming the ethical-social role of physical culture in Italy. ${ }^{7}$

Gymnastics was added to the disciplines of the scholastic curriculum by laws and decrees that made it compulsory and updated the programmes. ${ }^{8}$ In the Nineteenth Century scholastic physical activity as a whole aimed to strengthen youth, looking towards military service, as well as to manfully forge the character and regenerate the physical side by improving the health of the people.

The practice of gymnastics within schools and society was not only undertaken by boys, because the scholastic institution worked hard to promote also educational gymnastics for girls, especially for inculcating hygienic and healthy habits.

As time passed and by following the associative model of male gymnastics, a new interest towards a social and competitive activity developed among women who practised physical education at school. In fact a few women succeeded in overcoming obstacles, interposed by a mentality mainly patriarchal and manlike, to being accepted as members by some important gymnastic societies. Obviously, this new social area, which had hardly 
been conquered from the men's, as well as the first exhibitions of female gymnasts in public, not only caused indignation among the 'respectable people' but also admiration among the most open-minded men.

At the turn of the century, strong nationalistic and colonial stimuli cancelled out the positivist optimism which had characterised the previous years - and with it the political 'myth of peace' - more and more. ${ }^{9}$ Attention to the virile and manly body was emphasised. The body was considered the living and ideal gymnasium to be trained for future war enterprises.

In the same period, however, the female body remained firmly tied to the medical sciences which made the female body an instrument only to improve health and provide a growing population. The few and daring female athletes who, by challenging conventions, competed in sports even together with men, were at least considered a kind of phenomenon, but certainly not an acceptable model of femininity.

The most cultured women and female workers were in those years looking for finding space in the civil and social life of the nation. A small but determined number of intellectuals, in fact, started fighting for their own rights, and opened up a process of gender emancipation on the wave of the feminist movements active in the rest of Europe.

The Nineteenth Century traditional model of physically and morally fragile women, modest and only dedicated to domestic care, was flanked by a new model of women, more open to new opportunities in terms of jobs, who wanted to participate in decision-making and in the civil events which were ongoing. They were obstructed by strong nationalistic and anti-feminist new movements which were imbued with women's inferiority.

Specifically in the culture of the body, while the government urged the male population to become stronger, it still asked the 'weaker sex' only to adhere to mild physical-hygienic practices which could help procreation and the growth of healthy children in the Fatherland.

Darwin's theory of the evolution of the species - and as a consequence the emphasis given to the strengthening of the body without any gender discrimination - did not find accord in Italy. Both the more traditional Italian culture and the Roman Church considered Darwin's theory a revolutionary attempt to unhinge the Sacred Writings. 
Foreign essays supporting female mental and biological inferiority were circulating freely in Italy since the beginning of the new century. Many Italian intellectuals were convinced that women were really limited, and the only natural destiny for them was not society, but the family, whereas others blamed traditional women for blackmailing men sexually.

During the Great War, in which Italy participated from 1915, physical education and sport, as well as any other activity which was not strictly linked to war, were naturally put aside. All able bodied men were sent to the Front, while women massively entered the field of work. This new engagement, which was successfully faced by women, signalled the first concrete step toward their civil, economic and social emancipation.

As to the revolutionary post-war period, which was characterised by grave social disorder, it also involved an elite of conscious and participating women who adhered to avant-garde movements or supported the preexisting liberal, Catholic or socialist organisations. At that time women thought to contribute to the Italian cause and at the same time obtain those rights that were traditionally denied to them, but the advent of Fascism restructured the dimensions of their aspirations a great deal.

\subsection{Nineteenth Century women: decency and gymnastics}

In the last century the common model of women adhered to Catholic Church dictation, which wanted women to be modest, reserved, religious, charitable and to remain housewives. Being anchored to tradition, the 
Catholic Church through the Pope's authority opposed any form of women's emancipation by underlining their family duties as being fundamental. 10

As far as the romantic culture of the time was concerned, it emphasised through poetry and literature woman's fragility and sensitivity in general, her silent heroism or, on the contrary, the languid and sinful sexuality of the 'vamp', a new model that appeared at the turn of the century.

In addition, the then acting legislation considered women to be eternal minors, almost juridically incapable and therefore deprived of principal economic and civil rights. Following the Family Law, which had been regulated in 1865 by the Pisanelli Code, women were subjected to the authority of the male head of the family, and, once women were married, they were excluded from the children's tutelage and they could not act in commercial or legal ambits without their husband's consent. ${ }^{11}$

Notwithstanding this conservative trend, Italian women found a measure of emancipation, although tardy compared with the feminist movements of other countries, by entering the school and work world. In fact the working women of the factories, the office workers and the teachers fought hard for their rights in society. ${ }^{12}$

A further incentive in terms of emancipation came from the growing affirmation of bodily culture, following the new positivistic science creed. This culture, which propagated the sanity of the body as an absolute social value, with no gender exclusions, moved the stagnant water of the secular masculine and paternalistic tradition by offering the female body a certain attention.

\subsubsection{Physical activity before Italian unification}

In Lombardy, since the first decades of the century, innovative ideas were circulating on the culture of the body for women also, under the influence of Illumines. The Clias's text Callistenia o ginnastica per le giovani, which had been translated into Italian by Young in 1829,13 as well as the experience of Cremona by the priests Ferrante Aporti and Alessandro Gallina - who favoured the practice of gymnastic games for children of both sexes for at least one hour a day - are valid examples. ${ }^{14}$ 
The main impulse came from Rudolf Obermann, who on several occasions intervened in favour of female gymnastics. In his lessons, issued in the periodical review Letture di famiglia, he proposed, besides dancing classes, a wide series of physical exercises and games to help female children become more generous, strong and proud, so as to renew their role of women and mothers. Naturally girls had to be trained apart from boys, and follow a suitable programme of exercises avoiding too strenuous activities, but the target for both sexes was quite similar, i. e. to forge people capable of facing any and every kind of battle all through their life with a strong and virile spirit.

By practising and believing in gymnastics - Obermann underlined - the future parents, and especially the future mothers who are particularly important in the formation of the progeny, would improve their ability to mark children's physical and moral education, whereas "that simpering, those affections, those affected demonstrations of fine feelings, those excesses of irritability would be banished, those faints forgotten (...)."15

Obermann's virile programme of gymnastics was not original, but based on previous and current experiences held successfully in the German and Swiss area, according to Guts-Muths, Pestalozzi, Jahn and Spiess. Obermann's proposal also of strengthening the Italian male population found it easy to be accepted in general, whereas his feminine gymnastics were considered with a certain mistrust both by the middle class, because of its 'virility', and by the lower class, because it was thought to be a danger to physical safety. 16 Nevertheless, if this programme had been strongly supported by the leading liberal class, which was aggregating around the Savoy Dynasty, male and female gymnastics would have developed together.

By Casati's Law of 1859, educational gymnastics became a compulsory discipline in the curriculum, without expressing any gender reserve but, in fact, the current national trend was that only boys were able to practice it. However, in Naples, in 1861, it was stated that all Reali educandati femminili [Royal educational institutes for girls] had to start compulsory courses of dance and gymnastics, by statutory norm. ${ }^{17}$

This initiative, an exception in the Italian panorama, is not easily understandable if we do not take into consideration the previous cultural 
and political history of Naples, which had been particularly vital. There, in the last decades of the Eighteenth Century, Illumines had found important followers believing in gymnastics as a pedagogical value for all citizens, and in 1786 Gaetano Filangieri had even published a book - Scienza della legislazione - supporting physical exercises for both sexes.

Then, Naples had lived an exciting but brief revolutionary experience as Parthenopean Republic in 1799, and later, during the Kingdom of Joseph Bonaparte and Joachim Murat (1806-1815), Naples had somehow breathed again the wind of freedom, fraternity and equality, inherited from the French Revolution.

\subsubsection{Educational gymnastics after unification}

By Casati's Law, primary school male teachers were able to attend special training courses, from 1861 onwards. These courses were held by the new teacher training School of Gymnastics - directed by Obermann - and taken in the gymnasiums of the first Italian Gymnastics Society of Turin.

Statistics show that, in the school year 1863-1864, there were 17,923 male pupils, but only 57 female students, involved in gymnastic classes in 255 Italian schools. ${ }^{18}$ It should be added that among those schools only 41 had gymnasia and equipment, and most teachers were self-styled, having been soldiers, professional acrobats, dancers and horsemen. In particular, the wide lack of female pupils can be explained by the common creed that gymnastics was somehow a dangerous discipline for women's health and modesty, especially when teachers were men.

Finally, from 1867 onwards, the Ministry of Education decided that specific female teachers courses were to be organised in the School of Gymnastics at Turin, to prepare teachers devoted to female students. In the meantime, provincial, administrative and school authorities of the newly-established Kingdom of Italy were urged by the government to encourage the diffusion of educational gymnastics for both sexes in primary schools across the country.

The region of Venetia, which was annexed to Italy in 1866, was particularly favourable to female gymnastics. In fact, before its reunion to the Fatherland, the Venetian population had been under the Austrians for long, learning from them the habit of practising gymnastics in Fröbel's 
kindergartens. In the region of Venetia, Pietro Gallo started a course for 48 primary school female teachers in 1868, and in the following year 466 girls could practice educational gymnastics at school. 19 Statistics of 1872 report that in the city of Venice, out of 6,939 pupils attending gymnastics, 2,561 were girls. 20

In the 1870s, also in the cities of Bologna, Genoa, Padua and Verona, female gymnastics classes were successfully experimented in primary schools.

In 1872, 51,012 male and 16,285 female pupils practised gymnastics in Italy, that is, in only 8 years girls had increased three hundred times, but their distribution in the country was unequal. In 70 provinces, only 48 had female gymnastics classes in their schools, and the majority of them were concentrated at Turin, Milan, Venice, Verona and Naples.

In the school year 1874-75, the so-called Normal Gymnastics School for teachers of secondary school was opened within the already mentioned Gymnastics Society of Turin. Later, in 1877, Dr. Emilio Baumann founded a new teacher training school within the Virtus Society of Gymnastics, to help that of Turin in order to train gymnastics teachers of both sexes.

Baumann strongly supported his project by affirming that only 249 female teachers had gained the gymnastics degree in the last three years, in Turin, and among them 183 were already teaching in that area, whereas in Bologna there was nobody. He obtained support from the municipality for his school by adding that "female teachers especially could find a new job and start a brilliant career." 21

Baumann's rational gymnastics was inspired both by the military Obermann's and the scientific Ling's methodologies, but it was adapted to Italian basic needs and scarce resources. Baumann was against 'artificial exercises' - such as those executed by means of the gymnastics equipment prescribed both by Obermann and Ling - whereas he was in favour of 'natural exercises', like walking, marching, climbing, jumping, and so on. They had to prepare people to undergo any difficulty in social life and at work, by strengthening body and will.

Baumann's method found it difficult to be applied in Italy. In fact, looking at the data collected in 1884, which reported that on the whole only 24 Italian cities and towns had gymnasia, and only 11 outdoor gymnasia, ${ }^{22}$ one 
deduces that those pupils attending the School of Bologna, once having become teachers could not apply much of Baumann's 'natural exercises', as there was a great lack of gymnasia and open spaces in the schools of the time. Most of them could only train children within classrooms by means of the poor 'gymnastics in the midst of school benches', proposed by Baumann as well.

Other physical education innovators, such as Pietro Gallo and Costantino Reyer Castagna, strongly co-operated in organising Baumann's School of Bologna, which was considered modern in comparison with that of Turin. By the end of the 1870s, the Minister of Education, Francesco De Sanctis, won his battle against the still lasting prejudices against gymnastics at school - and especially female gymnastics - within Parliament, using both his moral power and his cultural weight. De Sanctis's action was inspired by the most advanced nations, such as England, Germany and Switzerland, where gymnastics was considered a fundamental way of education and physical and moral regeneration of the youth.

After the previous Casati's Law of 1859 which had not been applied widely in the territory, educational gymnastics again entered into the school as a compulsory discipline by De Sanctis's Law of 1878. In Article 3 it stated: "In female schools of every order, gymnastics will have an exclusively educational character and will be regulated by special rules"23

To provide for the lack of qualified gymnastics teachers, from 1879 to 1882 the government launched a wide campaign to bring primary and secondary school teachers up to date throughout the country. In 1879, the biannual Schools organised in 9 Italian cities opened to a certain number of teachers. There is evidence that in the first year of the course 364 teachers attended those 9 Schools. In addition, about 933 intensive courses took place in different Italian provinces, and among them, 416 courses were attended by women.

Naturally common people, and even school authorities, did not totally agree and did not always operate according to De Sanctis's Law, as in those years the female programmes of educational gymnastics were inspired by the School of Turin, and therefore appeared as a bad copy of the male ones, $i$. e. stiff movements executed also by means of German gymnastic 
equipment, and soldierly exercises, really far from the current image of womanly softness and grace.

As an example, in 1879 the provincial Director of Education of Florence, a certain Cammarota, shared "the disgust that 25, 30 and 35 year old women participated in jumping, turning around, and so on",24 and a number of female teachers successfully asked for exemption from teaching gymnastics at school, because of public opinion and the press.

Reluctance to train young girls in gymnastics, mainly due to the prevailing romantic model of weak women of that time, did not help the optimistic plan of giving all Italian women energy and health through physical education. Almost all girls hid dirty hair and face under a thick layer of powder, and their gymnastics teachers had also the task of teaching elementary norms of hygiene. As an example, it was reported that in 1871, of 600 young girls practising gymnastics at school, 550 used powder. ${ }^{25}$

The recruitment of teachers was fragmentary and inadequate, so much so that in 1886, there were only 756 female gymnastics teachers owning a qualified degree in Italy. ${ }^{26}$ On the other hand, judging from the complaints which were gathered by the sports press, these teachers achieved deeds of real heroism and self-denial, because they gained only 'starvation wages' by teaching in government schools. In a letter published in the specialist magazine Il Ginnasiarca, a young teacher compared the poor salary she received - 46.70 Lire a month - to that given by the municipality to other teachers for the same engagement, that is "net 600 Lire, besides accommodation and firewood". 27

\subsubsection{Italian culture and educational gymnastics}

In the last decade of the century educational gymnastics in general, by that time frozen into intellectual formulas, was more similar to other disciplines, and taught in just the same heavy and boring way. Scholars of both sexes had to learn by heart long series of physical exercises to be repeated up to a perfect and simultaneous execution. This trend was widely debated within the cultural world, which was divided between supporting the current traditional physical education in gymnasia, or the new sports and games in the open, imported from England. 
Among the writers, Edmondo De Amicis, who in general held strong traditional gymnastic beliefs, stigmatised the pretentious over-statement by which physical education was discussed in those years. With regard to female bodily culture, De Amicis was against all excesses, criticising the obtuseness of the Government which demanded gymnastics courses even for "old mothers with grey hair, young pregnant women or women breastfeeding their babies, nun-teachers: a real heaven-sent scourge!"28

De Amicis's romance of 1892, Amore e ginnastica, is emblematic of the current outlook concerning modern women fond of gymnastics. The author wrote a story about a sturdy teacher of gymnastics, Miss Pedani, who was beautifully shaped but very simply and modestly dressed, free from any coquetry. De Amicis presented this Miss Pedani as a new model of woman, a kind of apostle of gymnastics on behalf of Italian health. She accurately described how good were female pupils in practising difficult gymnastic exercises at school, by saying: "I have a dozen pupils ... who could perform in theatres, true acrobats who can turn around a fixed bar, jump on a board of about 1.50 metres, vault, ... their arms and legs being of steel."29

According to the time, Miss Pedani was depicted in a masculine image (probably inspired by two well known gymnastics teachers of Turin, Rosa Giordana and Teresa Bertotti), to be at the same time admired for her strength but feared as possible wife and mother. In actual fact, the strongest faith in her mission opposed Miss Pedani to any possible marriage, so much so that in the romance she answered the hopeless suitor asking for her hand that she was not tender, her heart was manlike, she could not become a good mother.

Naturally the argument concerning educational gymnastics and/or games involved not only intellectuals in general, but also scholars from the scientific and technical fields. Among medical scholars, the famous physiologist and university teacher Angelo Mosso supported athletics and sports in contact with nature after the English fashion, by affirming that educational gymnastics practised in the Italian school was too difficult to be learnt and at the same time too modest in motor achievements.

Mosso was aware of the economic and social problems linked to the modern industrialisation of the country, and recognised that public or 
private schools were mostly attended by wealthy Italian children, whereas poor children lived miserably apart. In fact, statistical data of 1881 reported a percentage of 61.03 male and 73.51 female illiterates in the country. ${ }^{30}$

Mosso called for sports and games for all, and especially for the delicate children of the working class, as the best means to fight illness and dangerous pollution in the cities. He was also aware of the feminine condition, and proposed suitable activities, even Swedish ladders, for improving common women's strength and health, as well as men's. ${ }^{31}$ Mosso's target was to lead male and female pupils toward the practice of modern sports, as these were healthy, social and recreative activities in the open. ${ }^{32}$

Most scholars of the technical field did not agree with Mosso. At that time the physician Dr. Emilio Baumann tried bettering health and will through his rational gymnastics even by teaching it into classrooms. He was not against sport and games in general, but, more realistically, he was perfectly aware of the poor conditions of pupils and schools, and criticised English sports as an affair only for wealthy people.

Also the physician Dr. Angelo Gamba, from the teachers' training School of Turin, doubted that games and sports were suitable for young and adolescent girls, although admitting they were somehow valid. In his opinion, sports were right for strong boys, while Italian girls had too weak a constitution and delicate health to successfully face sports without dangers. Consequently, he claimed that first of all female pupils had to train the upper limbs and practice active suspensions by the arms. ${ }^{33}$

These discussions brought new school programmes of physical education, signed by the Minister of Education Martini, and published in 1893. There, military-nationalist traditions, new English sports and scientific-rational bodily culture were compromised..$^{34}$

Gymnastics, now called physical education, was reviewed considerably, by reducing choreographs, marching and military drills, and adding modern, scientific and healthy exercises like those indicated by Baumann. Some athletics and English games - such as lawn tennis and football - were also included, according to Mosso and the scholastic programmes of most advanced nations such as Germany. Finally, on behalf of national pride and identity, the so-called giochi ginnici [gymnic games] of the Italian 
Renaissance, together with a long list of children's popular games from different areas of the country, were added. 35

As far as the 1893 female programmes were concerned, they still advocated a kind of physical education inspiring soundness, energy, courage, so as to prepare good mothers and educators. Generally being considered unsuitable for women's delicate characters, competitive games were not recommended with the exception of lawn tennis and swimming, the latter taking into consideration female morality and decency. ${ }^{36}$ However, a 'virtual' window to female sport was officially opened.

The fall of the government and the nomination of a new Minister of Education - Baccelli, marked the setting aside of the 1893 innovative programmes that were never implemented.

The new politics of Francesco Crispi showed his determination to create a strong military nation, capable to repress internal disorder and to carry out colonial designs. Crispi directed Baccelli towards projects of a kind of scholastic-military conscription for boys aged 16 to 19, and encouraged popular gymnastic societies, which were still the forges of future soldiers. The problem of female bodily culture was left aside; as before, girls continued practising just educational gymnastics at school, in application of 1878 De Sanctis's Law.

Once Crispi fell from government, democratic initiatives were undertaken, such as the foundation of the Istituto nazionale per l'educazione fisica e $i$ giuochi ginnici nelle scuole e nel popolo [National Institute for Physical Education and Gymnic Games in Schools and for the People], in 1897. It aimed at diffusing a variety of physical activities to benefit young and elderly Italians, men and women, rich and poor. In the optimistic programmes of the Institute, all women were encouraged to practice sports, through national and local ladies' committees consisting - it was stated - of bright and realistic women, strongly determined to organise physical activity among young and elderly women.

The intentions were noble, but many problems made the life of the Institute precarious. Having strongly supported the diffusion of sports and games in Italy, and of course that innovative Institute, Mosso later bitterly affirmed that all projects were deflated little by little by inaction. ${ }^{37}$ 


\subsubsection{Sports pioneers of the 19th century}

By the end of the Nineteenth Century the way of women's achievements in sports did not pass through scholastic institutions or central government, but through the existing male gymnastics societies, as will be seen later.

The prevailing patriarchal culture of the country which exalted women's role within the family - also confirmed by Pope Leone XIII's Encyclical Arcanum in 1880 - the moralist vision of female body that emphasised womanly decency, together with the biological outlook on female population mainly as race producers, did not help in urging women to take up competitive physical activities. In brief, by the turn of the century modern sports were still a masculine 'preserve'.

Exceptions to this trend can de found by turning the pages of newspapers of the time. There, the few Italian women's sporting enterprises were depicted as an amazing and unusual phenomenon to be looked at with special attention. Not surprisingly, a number of sportswomen were aristocratic ladies following the current European habits of their class, but there were also students and workers of middle and even lower class who enjoyed taking part in sporting events, bravely challenging common opinion. A magazine reports that the first $100 \mathrm{~m}$ female foot-race was held on 8 September 1889 in Arona, a little town of Lombardy, within Ludi Aronesi [Games of Arona]. The winner of the race, organised by the local Pro Patria Society, was a certain Miss Colombo, who competed against Miss Radice and Zaccheo. ${ }^{38}$ In the next year, 1890, a foot-race was performed in Verona by girls in decent bathing-costume, and about 10,000 spectators were present. There is also evidence of two working women from Lombardy - Anna Pozzi and Maria Tamburini - who challenged each other to a long distance foot-race of about $3 \mathrm{~km}$, in 1898. This race, disputed in Milan from Garibaldi Gate to Venice Gate, was followed by most citizens with astonishment. ${ }^{39}$

From local newspapers we also know that a female fencer, a certain Miss Giulia De Luca, had marvellously performed against a man during a fencing meeting held in Rome at the Exhibition Palace, on 21 November 1889. Two years later, in 1891, Giulia had newly performed against men in Rome and Catania, and finally, in the Politeama theatre of Naples, she competed against men together with her pupil Siena Rocchetti. 40 
In 1881, at a national gymnastics and fencing contest held in Naples, male and female gymnastics teams displayed together; for the occasion, a special female regatta contest had been scheduled, but insistent rain did not allow this amazing women's show. ${ }^{41}$

Italian target-firing societies enrolled women from 1895. The first was Margherita Magagnini, who competed in a Roman contest on September of the very same year, the rest became members of northern societies..$^{42}$

Mountaineering was a passion for Margherita of Savoy, the Queen of Italy. She started climbing Piedmontese Alps in 1885, and her example helped common women to try this difficult activity as well. As far as we know, in 1894 a group of men, and for the first time 8 Italian women, climbed the Monte Rosa [Pink Mountain] jointly. 43

On 6 April 1893, the Lawn-Tennis Club of Rome organised its first female contest, where the participants were exclusively aristocrats, and in Milan the first female tennis contest was held in 1896. It was reported that in the same year Miss Franca Florio competed in a tennis match together with three men. 44

As far as cycling is concerned, a number of aristocratic ladies, such as Princess Agnese Hercolani and Countess Clementina Bastogi, tried to popularise female cycling in Italy, by following the enthusiasm of Queen Margherita of Savoy who enjoyed cycling as well as pedestrian sport and mountaineering, as has been already said. ${ }^{45}$

As a matter of fact, we know about a famous cycling challenge held in 1893 around Doria Square of Milan, between the florist Adelina Vigo and the beautiful actress and singer Lina Cavalieri. ${ }^{46}$ In addition, there is evidence that in 1983 and 1894 a number of mixed cycle races were organised in Milan, Genoa and Lugo of Romagna, and the female cyclist Alessandrina Maffi competed many times against men, successfully. ${ }^{47}$

These women cyclists provoked scandal or at least malicious comments, and in 1894 the Unione Velocipedista Italiana [Italian Cycling Union] decided to officially ban any female competitive cycling race. But, the prestigious Audax prize, instituted in 1897 for cyclists who covered $18 \mathrm{~km}$ in no more than 18 hours, was given to Alessandrina Maffi in 1898.48

In the same 1897, in the famous La Scala Theatre of Milan, female dancers had to learn how to get on a bicycle and perform, for an original ballet titled 
Sport, choreographed by Luigi Manzotti. This ballet, which presented sports such as horse-riding, fencing, tennis, target-firing, rowing, football and gymnastics, involved not only dancers and acrobats, but members of Pro Patria and Forza e Coraggio gymnastics societies. ${ }^{49}$

Actually, Italian female pioneers were early examples not only in Italy but in the whole world. Their extraordinary enterprises should be placed beside the most celebrated British ones, through a number of eccentric ladies competing in athletics, archery and boxing, at about the same time. But in many sports, such as the future national game of football, women were later entrants in Italy than in many other nations.

3.2 Emancipated women at the start of the Twentieth Century 
At the beginning of the Twentieth Century, Italian politics were characterised by a progressive democratisation of the Liberal-State. Among the leading liberal class some politicians had a positivist faith and championed the rights of the lower classes, but social change had to take place without any social disorder, according to a strategy which did not 'dramatise' ideological conflict but allowed its course to be followed, all the while, evolving with it.

This was now the era of Giovanni Giolitti, an eminent statesman of positivist thought, who encouraged and carefully controlled the industrial transformation of Italian society for a number of years. Women were also involved in this process, constituting half of the workers engaged by industry, because of the lower salary they were given. 50

In the first years of the century the process of democratisation of the country brought a new law concerning work and production, which reduced working time. From 1902, workers were encouraged by the government to practice physical education in their spare time. This trend helped their early emancipation from the most traditional womanly roles, and also helped their emancipation in the field of sporting activities. In fact, working side by side with men, female workers became aware not only of their duties but their right to have a social life, and enjoy their choices.

However, in the years preceding the First World War a strong nationalistic and anti-feminist stream was opposed to women's emancipation and cast them back to the home again.

\subsubsection{Popularisation of competitive gymnastics}

As has been already mentioned, the diffusion of female sporting activities in the country had started by the end of the Nineteenth Century. In those years ladies of the upper and middle classes could join sports associations where gymnastics, athletics and games were widely practised by men. Not surprisingly, these women were helped to affirm their rights in terms of competitive gymnastics and modern sports by progressive men, in general relatives already involved in gymnastics societies.

The first, emblematic example came from the gymnastics teacher Leopoldo Nomi-Pesciolini. He opened a female section also attended by his daughter Ida, within the Sienese Society of Gymnastics in 1881.51 The pioneering 
experience of Siena did not last for long, but the idea bore fruit in the following years.

In 1890, the Roman Gymnastics Society put on physical education classes for wealthy female children of 5-14 years. This Society, which had been founded with legal aid of the National Gymnastics Federation, also supported the creation of a committee of aristocratic ladies, supervised by Fortunato Ballerini, on behalf of that powerful Federation.

In 1891, that women's committee organised ballroom dancing courses, and elegant carnival parties, which testified to the world-wide aristocratic tone of the first initiatives. In 1897, by Art. 1 of the Roman Gymnastics Society Statute, it was stated that the women's committee had to spread female physical education among citizens through gymnastics, dance, and 'gymnic' and sport games. In that year, a special display reserved for the English ladies living in Rome was organised by the women's committee. In it, an amazing women's cycle-race, with different 'feminine' abilities, took place. ${ }^{52}$ At about the same time, in Florence the Women's Central Committee was formed inside the National Gymnastics Federation, during the Beventh National Council. This Committee, led by ladies of the aristocracy, had the task of spreading physical education among common Italian women by means of conferences, exercises, gymnastics and sports games. It also stated that sub-commissions of at least three ladies had to be organised by the new Committee in every Italian province.

Judging from appearances, that project was good, but actually the Committee did not urge women to take up modern sporting activities, rather to do a peculiar kind of 'feminine' physical activity. Strength and energy of the body were banished, but plasticity, smartness and flexibility of movements were recommended, so as to emphasise women's grace without effort. ${ }^{53}$ Apart from the programme - which was clearly old-fashioned - the work of the Committee was little. Those aristocratic ladies were mainly absorbed by their world-wide engagements, and their relationship to the National Federation was characterised by submission to authority, i.e. to the influential men who had promised much 'on paper', but actually did not support women's activity sufficiently.

In the industrialised cities of the north, the rising female movement in favour of modern sports was more aggressive and determined. Women's sections 
were founded within the biggest sporting societies, but at the beginning they had problems to be accepted and to be allowed to work in full autonomy. Those sporting societies, masculine chauvinist 'strongholds', were still anchored to the martial and virile ideology of the past that claimed sport as a male preserve, forbidden to the 'fair sex'.

The way women of the north found the key to open the doors of gymnastics societies passed through enlightened men, as for example Eng. Angelo Radaelli, or emancipated ladies such as Dr. Amelia Cavallero Mazzucchetti from Milan. In fact, the Female Mediolanum was founded in 1897 at Milan inside the Mediolanum Society, supported by a group of middle class ladies - mostly schoolteachers - determined to ask for a board of women only, and to act autonomously. They started their own programme by organising Alpine excursions, as well as dance and swimming courses.

Again in Milan, in 1898, the Female Insubria Society was founded, aimed especially at organising inter-scholastic gymnastics contests among girls, such as Clementina Arcari Coup for little girls, and Vis et Elegantia Coup for female students and sport society members. ${ }^{54}$

In Turin, the Gymnastics Society first opened a lawn tennis female section in 1898 , then admitted girls to its gymnastics courses.

At the beginning of the Twentieth Century, of a population of 34 million inhabitants only about 100,000 practised physical activities within gymnastics associations. The increase of women's sections in those associations was relatively notable in northern cities such as Alba, Asti, Brescia, Genoa, Modena, and in Rome; there, not only high or middle classes ladies were involved, but women of more modest background.

In Turin, for instance, the 'classy' Gymnastics Society of Turin counted 22 female gymnasts in 1900, 68 in 1901, and about 400 in 1907, while in 1901 the popular Gymnastics Society and Free School for Workers counted 39 and 47 female pupils respectively; in Milan, Insubria counted 50 female members in 1898, and 130 in 1903, and Mediolanum reached 200 inscriptions in the very same year. ${ }^{55}$

This relative popularisation of female gymnastics within societies led to the first Italian women's contest, hosted by Milan in 1902 as a spectacular sideshow within the most important male gymnastics contest. This exhibition in 
public was judged unsuitable for women by most spectators, as common people were not against women's gymnastics within gymnasia, but against the display of their well-trained bodies in public, as they could excite men's sexual desire.

Even eminent individuals, such as Gregorio Valle, Member of Parliament, boycotted the initiative by uttering harsh words against the performance of young girls, who unbecomingly showed emotion and strain in competing for victory, as well as the short pants worn under their very long skirts, lifted just a little by high-jumping. Valle wrote: "it was such an indecent performance that, on behalf of decency and respect for feminine dignity, I am sure this female gymnastics competition of Milan will not be repeated in the future." 56

Anyway, in spite of traditional morality that still defended the modesty of women's body as a sacred temple, in the following years this kind of mixed show was considerably developed in the country. In 1904, the famous 6th Gymnastics National Contest held in Florence hosted 94 female athletes of Milanese, Messinese, Modenese, Pistoiese and Roman gymnastics societies. ${ }^{57}$ In 1905, the municipality of Vercelli organised a special national gymnastics contest in which 59 male and 6 female teams took part, and in 1907, about 4,500 women participated in the national gymnastics meeting of Venice. ${ }^{58}$

Naturally, separate trains, hotels and timetables were accurately organised in Venice, to save the decency and morality of the female teams, under a committee of Venetian ladies' s severe control.

The female gymnasts who went to Venice were members of societies of northern and central Italy, as in the southern part of the country women of any social class were generally denied physic al activities..$^{59}$

The First National Contest, totally performed by women only, was held in Milan in 1908. There, the 18 competing female teams mostly came from the industrialised towns of Italy, where work was helping women to become emancipated from the most traditional patterns. These women, who had found it hard to be integrated inside sporting associations, finally succeeded. 
The Second National Female Contest was held at Turin in 1911 and, according to statistics, in 1913 about one third of 200 Italian societies had female sections.

Of course, in those years women still had to fight to obtain more power, technical autonomy and specific programmes within those associations led by men. On the other hand, female competitive gymnastics displays were then accepted in Italy, as public exhibitions of an educational discipline previously performed in school, on behalf of moral and physical strength, and improvement of racial health.

\subsection{2 'Manlike' sports for modern women}

From the first decade of the century onwards, female athleticism appeared within gymnastics societies. In 1911, popular 'special individual contests for female adults' were organised on the occasion of the National Gymnastics Contest at Turin, where athletes had to throw an iron ball of about $5 \mathrm{~kg}$., make a long jump, and run $80 \mathrm{~m}$ in at least 15 seconds; in 1912 female athletes competed also in high jumping at Vicenza. ${ }^{60}$

At the start of the Twentieth Century, tennis, considered a suitable sport for women, was practised by high society children in important cities such as Florence, Genoa, Milan and Turin. The female tennis star of that time was Rosetta Gagliardi. 61

In those years, a number of daring women of different social classes challenged the common opinion that sporting activities were manlike. People gossiped, and the press wrote of their enterprises with admiration and astonishment at the same time, by considering those aggressive, strong and muscular modern women as models totally opposite to the bashful, weak and delicate model of femininity still lasting from the past century.

In 1914, Miss Luigina Serponi ran 100m in just over 16 seconds, but one should add that she was wearing a very long and heavy skirt, for the sake of feminine decency. ${ }^{62}$ In 1910, we meet again the cyclist Miss Maffi, and also Maria Forzani; both competed energetically in Milan, and their cycle race was filmed by Luca Comerio in the documentary Corsa ciclistica femminile [Female cycle race]. ${ }^{63}$

It was reported that Rosina Ferrario was the first woman to obtain the prestigious licence at Caproni's aviation school, in 1913; in 1914, the 
famous motor-cyclist Vittorina Sambri, a 'tomboyish' girl, achieved the fastest average speed among competitors, during the Italian Championship in Turin. ${ }^{64}$

The tennis player Rosetta Gagliardi practised also fencing and swimming, and became a well known skater in 1911, when she won the first national roller-skating championship in her gender category; another all-round athlete, Dina Mancio, did well in ice-skating in 1915.65

In !902, the Rari Nantes Society of La Spezia organised the first championship for female swimmers, who covered $200 \mathrm{~m}$. In the following years, female swimming contests were held in cities on the sea, such as Genoa, Bari and Naples. Generally, a very few women were involved in this kind of competitions and had to cover 100 or 150 meters at least. 66

Down-hill skiing and mountaineering took their first steps in the first decades of the century. There is evidence that women participated in skiing contests in 1909 and 1914, competing also in bob and sledge, and founded the Unione Sportiva Studentesse Italiane [Italian female Students Sporting Union] in 1918 at Turin, where courageous women learned to climb without any masculine help. ${ }^{67}$

In those years, although cycling was really popular among women, it was still considered morally and physically dangerous for women, and not only by common people or the Catholic Church, but eminent physicians. One of them, Paolo Mantegazza, in his book L'igiene della bellezza published in Milan in 1912, supported ball games and foot-races for girls, but was against cycling: "Eve's daughters should not get on a bicycle if they wish to combine hygiene and morality."

\subsubsection{Physical education and sport at school}

Leaving aside the sporadic phenomenon of 'manly' sports played by women, as well as the popularisation of female gymnastics within sporting societies, by the beginning of the century the most important problem was still to increase physical education, and include some sports in the basic scholastic curriculum. After many years of debate this problem had not been resolved.

In 1901 statistics reported a decrease of female illiterates (from 73.51 of 1881 to 60.82 in 1901) according to a democratic policy which had 
encouraged families to send their children to school. Indeed, primary schools were actually the only way these children, especially the poorest, could learn to properly train their bodies and learn hygienic habits for life. But, in fact, it was reported that in 1904 about $50 \%$ pupils of both sexes had obtained exemption from physical education classes in a number of Italian schools. This could be explained by the fact that actually most schools lacked running water and the so-called gymnasia were one-time churches or basements where dust, humidity and coldness reigned everywhere. 68

These problems were partially faced by the new Daneo's Law of 1909, which, being inspired by the work of a previous commission led by Angelo Mosso himself in 1904, was more open-minded.

In brief, this Law promoted official recognition of physical education teachers (but not higher salaries!), regulated pupil's exemptions, increased the number of hours devoted to the discipline, and added games and sporting activities to the curricular programme. It also stated compulsory university courses of physical education, so as to train future teachers of any discipline as a way for at least solving the problem of physical education teachers' recruitment.

Daneo's Law was poorly applied in Italy for a number of reasons principally lack of gymnasia and facilities, financial support, unpreparedness of teachers - including those linked to the international scene, that advised the government rather to use the money for improving the army.

\subsubsection{The anti-feminist years before the First World War}

Throughout the years, an increasing number of initiatives were undertaken in terms of general female emancipation. Different groups of women, linked to socialist, Catholic and bourgeois movements were fighting for civil rights, but after the first decade of the century the advent of new paternalist politics slowed down female emancipation and therefore their social life, including sporting activities.

Women's emancipation suffered the progressive giving up of the positivistic faith in linear human progress without too many gender discriminations, as well as an increase of nationalistic ideologies which wanted strong women for bettering the Italian race, but contradictorily wanted them at home - far 
away from physical activities - for producing numerous children up to exhaustion.

This new trend was also supported by studies from abroad on female biological inferiority, such as that of Otto Weininger focusing on the female sex and character, and that on the mental female inferiority by Paul Julius Moebius. The latter claimed that, according to their nature, women realised themselves only by means of maternity and childhood, while any 'unnatural' attempt at emancipation brought 'masculinisation' of women and a decline of the human species. 69

Times had changed and the irrational 'myth of war' replaced the positivistic 'myth of peace'. Imperialistic pressures induced the Italian government to undertake a general militarization which brought about the outbreak of war in Libya in 1911.

This policy aimed at giving a strong preparation to youth by means of military gymnastics at school and within civil society, so as to increase the number of soldiers and instil sentiments of duty and obedience of the law. Especially the Italian Federation of Gymnastics was then charged to organise special courses for military preparation from 1907, by order of the government.

In contrast, and only for the sake of hygiene of the race, a basic physical training was given to girls at school, but nothing else was done for promoting female adult sporting activities in society. Women were required to stay at home and have many children, for the same nationalistic motivations: maternity was the only way they could prove to be true patriots. $^{70}$ As a consequence, only in the Twenties did the National Gymnastics Federation found a new and more powerful Gymnastics Female National Committee with its statute, norms, programmes and contests; more on this in Chapter 5.6.

In those years, the stronger nationalistic and anti-feminist current running in Italy was supported by many intellectuals. Among them was the journalist Giovanni Papini, who believed in biological female inferiority, ${ }^{71}$ and the already cited poet and writer Gabriele D'Annunzio (Chapter 2). He promoted a negative female model by portraying women mainly as sensual, 'vamp' creatures to be loved up to perdition. ${ }^{72}$ 
Even the most modern movement of Futurism, founded by Filippo Tommaso Marinetti in 1909, demonstrated a low opinion of traditional Italian women, by looking down on them.

Futurism exalted virility and war on behalf of Italian men's pride, and speed, machine and flight on behalf of technology. These values, as has been already mentioned, rotated around bodily culture, which was greatly encouraged as the discipline capable of bringing down traditional intellectual culture imbued with classicism. By having established the "supremacy of gymnastics over books",73 Futurism demanded the foundation of special institutes for physical education teacher training, but women were left out of their programmes. At school, boys had to be trained apart from girls, because their early games were "clearly masculine, lively, bellicose, muscular and violently dynamic, without affective morbidity and womanly sensitivity". ${ }^{74}$ In general, the futurists considered the traditional women as dangerous, because of their romantic and weak spirit, as well as the modern 'vamps', who - it was said - blackmailed men sexually.

The impulse given by Futurism to the practice of physical activities, even through the invention of new, 'simultaneous' sports, ${ }^{75}$ did not really influence the conservative masculine trend of the time. In fact, only female dancers were involved in futurist performances, symbolising items such as the machine and flight by means of dynamic air-dance, on behalf of futurist fisicofollia. ${ }^{76}$

However, Futurism cannot be considered a movement totally against women, because it did not believe in a presumed female inferiority, which was actually caused by different spiritual and bodily cultures, but in a possible gender equality. ${ }^{77}$ As a consequence, futurists supported the Suffragette movements and gender liberation, so as to give women the same opportunities and rights as men. ${ }^{78}$ Several women joined the futurist movement and contributed to its cause, but this phenomenon was restricted to intellectual ladies mainly coming from the arts.

\subsubsection{Women's emancipation through the Great War}

The advent of the First World War was really favourable to female emancipation in general. Since the war was costing many lives, the home front needed women's moral support and strength, as well as working 
women in industry, agriculture and public service. In addition, the war front also needed women as volunteer nurses in military hospitals. Consequently, in those years the government encouraged and exalted women's heroism and spirit of sacrifice by all means, and public opinion started looking at women with new respect. It was optimistically commented on that in terms of feminism Italian women had obtained much more in those years of war than in the previous decades.

By the end of the war the Italian feminist movement was not sufficiently strong. In fact, since 1910 the movement had been ideologically and politically divided among nationalist, interventionist, Catholic, proletarian and pacifist women. By the second decade of the century, futurist women and D'Annunzio's women also started contributing to the feminist cause, but their extremely avant-garde ideals increased the general confusion.79 Furthermore, the Great War had emphasised the already existing differences between higher and middle class women - mainly engaged as volunteers and the lower class of working women, whose rights in terms of work had to be defended also after the conflict.

Women could find common ground only by promoting a kind of 'female social action', mainly focusing on their right to vote, which was generally agreed to. However, the idea of leaving women at work was not popular in the country, because people thought working places had to be left to the surviving men of the war. ${ }^{80}$ Consequently, the law concerning woman's legal capacity, which was finally approved by Parliament in 1919, was ironically considered as a kind of 'demobilisation-prize' given to working women, before sending them home again. ${ }^{81}$

In the same year, anyway, working women's rights were defended by Sacchi's Law which stated that women could equally compete to become employees in public offices. The fall of the government did not allow the most important bill concerning a woman's right to vote - which had already been passed in 1919 by the Chamber of Deputies - to be approved by the Senate. That bill was set aside in 1920.

As far as the sporting front was concerned, during the above-mentioned years Italian feminist movements stressed women's physical culture, also being encouraged by their idol, Gabriele D'Annunzio. In fact, under the revolutionary Regency of Carnaro (where men and women had equal rights 
and duties, including military service), D'Annunzio had stated that "bodily education should be practised by both sexes in well-equipped outdoor gymnasia". 82

However, the problem of supporting female sport was not really faced in Italy, apart from some exceptions, such as that offered by the new and modern review Almanacco della Donna Italiana. It hosted a section specially dedicated to sportswomen since its first issue in 1920.83 This section, then written by Giuseppe Monti, was considered quite innovative up to transgression, as the Italian general outlook of the time still obstructed female sporting activities by reserving them as men's affair, as usual.

In conclusion, at the start of the Twenties, Italian women found it hard to affirm the rights they had achieved during the Great War. The new fascist movement, which seemed to offer a strong answer to most Italian problems, attracted people of different creeds and classes. Among them, some combative women joined the aggressive Mussolini ideology, believing that its revolutionary power could help their cause. 
Chapter 4 


\section{Model women during the fascist era}

During the two decades of Fascism, the ideal image of man was embodied by the virile Mussolini, as has already been seen. (Chapter 2.3) On the other hand, Italian women had to embody different models of femininity, deriving from a policy which had to combine - time after time - aspirations for modernity, secularisation and imperialism, with expectations of saving traditionalism, religiousness and stability in the country.

Although all Italians suffered these contradictions, there is evidence that especially women of all classes, the weakest part of the population, had to put aside most of their expectations. Fascinated by the Duce, most Italian women adapted themselves to Mussolini's will by modelling themselves on his plans on behalf of the fascist cause. The wind of female emancipation blowing from the beginning of the Twentieth Century was moderated more and more by an emphasised 'masculinism', which was affirming that women were different from, and inferior to men.

In the beginning, this old-fashioned trend was not really supported by Fascism, which in its pioneering years appeared as one of the most modern, innovative and revolutionary movements, far from any gender discrimination. At that time, women were convinced that Fascism could also fight for their rights, but in the following years, after the regime was firmly established, the question of female emancipation was set aside more and more, in favour of a manly hegemony based on the traditional paternalism lasting down the ages.

Pressed by the Catholic Church, traditionally supporting female modesty and maternity, as well as by a strong demographic policy and several economic problems, Fascism did not support any more the modern model of working woman of the previous years. Discouraging outside work by all means, the regime aimed at relegating women to the home for most of their time.

In the spirit of sacrifice for the Fatherland, inherited by people from the Great War, women just had to do the housework and bear numerous children, so as to take part in the building of the new fascist state by means of their political maternal role. Apart from this, women did not count for much, and their political and social involvement was restricted to those 
organisations strictly controlled by the Fascist Party, and feminine Catholic associations.

Within this framework, basic physical education and some sports were considered a state affair, a means to strengthen the body and spirit of young female Italians, according to the expansionist plans of the regime and current eugenic theories. (This will be discussed in the next Chapter 5.1) From the mid-1930s, when Italy was involved in conflicts against Ethiopia and Spain and then in the Second World War, some changes in terms of feminine models had progressively developed. Then, women were encouraged to participate in social and political life considerably more, so as morally to involve them in supporting their husbands and male children for the call of the Fatherland.

Strengthened by years of silent sacrifice and insistent patriotic propaganda, as well as by basic physical education, several combative women even participated in the world conflict, supporting both fronts. In fact, after the fall of Fascism in 1943, and in the subsequent civil war, a number of women went to northern Italy, which was still held by Mussolini, and enrolled in the fascist army as volunteers. There, they fought with honour, flanking the soldiers of the new Italian Social Republic -RSI of Salò.

On the other hand, numerous women joined and supported partisan groups of different faiths, who were fighting against Nazi and fascist soldiers for the liberation of the country. Both showed that during the fascist era the role of women had changed and that women had become more self confident, ready to leave homes and families for a superior cause. 


\subsection{The revolutionary woman of early Fascism (1919-1924)}

In Italy, the end of the First World War was a dangerous period which could easily have led to civil war by having left not only social and economic problems, but violence, individualism and fragmentation among people. In that period, the European feminist movement was still admired by Italian women, but in general it was not considered a movement which could suit the Latin temperament.

Latin women had to pursue their own way by adhering to femminismo latino [Latin feminism] based on a strong sense of maternity, tradition and sacrifice, an ideology which - it was said -1 could unify all women within a universal category. On the other hand, the battle for suffrage and other civil rights was occurring. For example, in 1919, Italian women were allowed to work as private professionals and employers of the state, by Sacchi's Law. Feminine emancipation was supported by many movements of different political currents. Among them were D'annunzio's movement involving people of both sexes in the heroic enterprise of Fiume, and the rising fascist ideology. After all, Fascism was considered as one of the most concrete ideologies, capable of rapidly assuring a new and modern order in the tumultuous life of Italians.

Around the beginning of the second decade of the century, a number of men and very few women joined the fascist movement. In 1919, in San Sepolcro Square of Milan, Mussolini and others, such as nationalists, socialists, futurists, republicans, and 'Arditi' groups, ${ }^{2}$ founded the movement Fasci di Combattimento, as has been already mentioned.

Nine women were present, among them Giselda Brebbia, an active member of the socialist party, and the teacher Regina Teruzzi, who was a capable organiser of lower class women. ${ }^{3}$ In the following years, up to the famous 'march to Rome' which brought Mussolini to power, a few hundred Italian women were enrolled in the fascist movement. For instance, in the years between 1920 and 1922 there were 200 female fascists in Brescia, 28 in Verona, 100 in Florence. ${ }^{4}$

Mostly, these were eccentric and bellicose women interested in nationalist and/or socialist ideologies and politics, who believed in the values of modernity and emancipation that Mussolini and his followers were 
spreading all over the country. In fact, the first and progressive fascist programme of June 1919 had stated not only full freedom for citizens in general, but also the right of 'integral' suffrage for women.

By believing in a new order, these women embodied the virile and aggressive model woman previously proposed by Futurism, and participated in violent actions against their opponents, together with the male fascist squads. For example, during the Gymnastics Contest of Venice in 1919, a number of female athletes participated in a scuffle together with their fascist friends, against a group of so-called 'cowards';5 in 1920, a certain Cesarina Bresciani participated in the bloody assault on the Town Hall of Verona, with her brother and other young fascists; and, in 1922, 30 armed fascist women lead by Mrs Scarpa harshly repelled a group of socialists from the fascist centre near Udine. ${ }^{6}$

In its early years Fascism was helped both by aristocratic ladies - such as the Marquise Cristina Malenchini and Corinna Ginori Lisci, the Countess Luisa Capponi, Laura Scotti and Maria Grazia Vannicelli - and a number of middle class women.

Some of them had lost their sons and husbands in the Great War, others were important people, such as the futurist women whose pseudonyms were Magamal and Futurluce (Eva Kuhn Amendola and Elda Norchi, respectively), the famous socialist Margherita Sarfatti, and the journalist Elisa Majer Rizzioli. ${ }^{7}$ This latter founded a new body in Milan in 1921, the so-called Fasci Femminili [Feminine Fasci], fighting to affirm fascist ideals and increase fascist power in the territory, alongside the masculine Fasci di Combattimento.

The Roman Feminine Fasci were founded in 1921 as well, where about 20 women were very soon involved in dangerous scuffles against anti-fascists. ${ }^{8}$ They supported the famous 'march to Rome' by organising a number of first aid places in the Capital, in case of a counter-attack by the Italian army. Naturally these Roman women had to temporarily leave their families and spend their time working hard, with the arrival of the fatal 'march'.

One of the youngest, Piera Fondelli, wrote in her diary of the spirit that breathed through those days: "I was away from home for four days and nights. We used to sleep in armchairs for a few hours inside hotels where we were in charge of organising the first aid places, and naturally the owners 
of the hotels were enrolled in the fascist party. I was keeping in touch with my mother by telephone. We could not believe that the country, the king, the army, the authorities, in brief, Italy as a whole, would have delivered to us a handful of men - and a very small percentage of women - ready for action, aiming to restore order in every street, school and factory."9

On 1 June 1923, Mussolini participated in the Venetian Feminine Fasci Congress where, for the first time, one of the most famous fascist symbols "the black shirt' was worn by a number of women. They promised the Duce fervour, faith and sacrifice for the fascist cause.

Women who joined Fascism thought themselves to be modern and emancipated, but in truth they still embodied the bourgeois model stated by men long ago, and their rights and needs were underestimated by men as well. The traditional 'feminine spirit of sacrifice' was exalted by all means on behalf of the 'cause'.

As has been mentioned before (Chapter $\mathbf{3}$ ), in the previous liberal decades the 'cause' mainly consisted of women being healthy mothers of numerous children for the glory of the Fatherland, but women had to leave work and politics to the men. After the feminist wind blowing in the years of the Great War weakened, the 'cause' stated that women had to fight and sacrifice - now alongside men - but the 'cause' consisted in the glory of Mussolini and his virile ideology. Fascism, clearly a violent and misogynous ideology, did not believe in, and therefore did not support at all, women's political involvement.

On 27 December 1921, the fascist daily journal Il Popolo d'Italia wrote: "The women's Fascist Groups will devote themselves to propaganda, charity, welfare and other duties, while every political action led by the Fascis of Combat is excluded."

On the other hand, Mussolini's policy concerning women's rights was ambiguous. At the start of his political life he was a socialist with a moderate sympathy for feminism, but later on he 'forgot' his first interests so as to please the Catholic Church, restore the paternalistic tradition of Italian people, and emphasise the new myth of virility at the same time.

In an interview published by the Petit Parisien of 11 November 1922, Mussolini declared he was in favour of universal suffrage for men, but not 
for women, especially because women would always vote in favour of men. 10

During the fascist women's congress held in Padua in 1920, however, Mussolini had said: "Fascists do not belong to the crowd of the vain and sceptics who undervalue woman's social and political importance. Who cares about voting? You will vote!" 11

Moreover, at the congress held in Rome on 14 May 1923 by the prosuffrage International Alliance, Mussolini affirmed: "Given the public Italian spirit and the trend of our political development, the concession of women's vote finds no opposition in any party. As far as the government is concerned, I feel I am entitled to declare that, apart from unforeseen happenings, the fascist Government stands firm for the right to vote concerning different women's categories, starting from the administrative voting field." 12

At least this right was then given by Parliamentary Law, but by the end of 1925 the administrative elections were totally abolished, according to Mussolini's new extraordinary laws which lasted up to the fall of Fascism in 1943.

In conclusion, one could say that during the early Fascist period a number of aristocratic and middle class women set their hopes on Mussolini, and even conservative Catholics deceived themselves that Fascism would have helped women's emancipation by promoting female work.

In the pages of the Catholic magazine La donna italiana, issued in 1924, it was said: "The right to work is a holy human prerogative which has been sanctioned by religion, won through titanic battles, and fully granted by common conscience nowadays. We should continue to claim that not only men, but also women should have to earn their bread by the sweat of their brow, and protection and respect should be paid to those women who leave their quiet homes and enter the wild forest of the world."13

But Mussolini's policy concerning women's rights, in the beginning uncertain and ambiguous, became anti-feminist once power had been obtained, as will be demonstrated later on. Nobody could really plead that cause.

At the beginning of 1920s, when the fascists were fighting to assert themselves, Italian women who were against Fascism were too weak and 
divided to be capable of developing a strong opposition. On the other hand, the self-confident and aggressive women who had fought alongside fascist groups were suspiciously seen as possible lesbians, and were sidelined.

The case of a firm patriot, Ines Donati, is an example. She supported the fascist cause with daring actions, and early Fascism celebrated her as a heroine, but soon her myth was buried as she was suspected of being a lesbian, unsuitable for representing the model of the new woman of that time. By the second half of the 1930s it was celebrated again, as will be seen later on.

In the early fascist years only very few courageous women tried to support the anti-fascist cause, ${ }^{14}$ whereas several women joined the fascist groups with enthusiasm and faith. The rest of the female population looked at Fascism with little hope or quiet resignation. 


\subsection{The new woman of the regime: wife and mother (1925-1935)}

In the years 1925-1926 the process of 'fascistization' of Italians started, aiming at the authoritarian integration, organisation and education of citizens within the new fascist state. This state would not longer be considered distant and extraneous, but a body where Italians would realise their existence.

In those years, alongside the virile model of the new man, the model of the new woman was propagated, but it was a rather abstract image, as no woman had enough personal charisma or power to embody it. Anyway, the 'official' image of the fascist woman was far from the modern model of the beginning of the Twentieth Century and the years of the Great War, when emancipated working women were really appreciated by Italian society. However, this female fascist model re-echoed age-old custom.

In spite of a modernity of façade, new Italian women had to be just daughters, wives, and mothers for life. After the regime was firmly established, women were even considered incapable of controlling the organisations they had founded, such as the Feminine Fasci, which passed to the powerful hierarchy member Augusto Turati's leadership in 1926.

At the beginning of the 1930s, gender discrimination among female intellectuals reached its apex through the case of the famous writer Grazia Deledda. Although winner of the 1926 Nobel Prize, she could not become a member of the prestigious Academy of Italy, the most exclusive association of the cultural elite of the country. By the way, this Academy had been an idea of Mussolini's inspirational muse and lover Margherita Sarfatti. 15

In those years also the famous poetess Ada Negri was not admitted to the Academy of Italy, then really a fortress of male culture; however, in 1930 she received a 'consolation', the Mussolini Prize.

Women still claiming their rights were accused of being demodée, ridiculed and depicted as 'emaciated and spectacled old maids', according to the current negative image of English Suffragettes. ${ }^{16}$ Besides, the traditional themes of Italian woman's modesty and spirit of sacrifice were exalted once 
again, through both the fatherly advice of the Catholic Church and insistent fascist propaganda.

The new woman had to combine different and even antithetical values, where respect for tradition meant religiousness and tenderness, while modernity meant dynamism and strength. For this kind of woman probably Mussolini was inspired by his mother, Rosa Maltoni, whose culture (she was a primary school teacher), religious spirit, firmness, exemplary life and early death had left an indelible mark on the Duce. In his autobiography, Mussolini wrote: "My greatest love was for my mother. She was so quiet, so tender and yet so strong."17

Really, Rosa Maltoni incarnated the stereotypical 'Italian Mother' of the Nineteenth Century, that deepened her roots both in the firm Roman Matron and Holy Madonna, representing Latin and Catholic cultural models respectively.

Rosa Maltoni somehow lived on both in Mussolini's wife, Rachele, a silent, tolerant partner and domestic woman, and in his preferred daughter, Edda, who had a vivacious and passionate nature like her grandmother.

In particular, while aristocratic women carried on the modern usage of their class, the new bourgeois generation inspired by Edda were sufficiently modern and emancipated but, on the other hand, still respectful of traditional values. In fact, during her lifetime, she enjoyed sports, journeys, cars, and even trousers like aristocrats, but was reputed to be an obedient daughter, a good wife and a busy mother as well.

At the same time, common women were induced to forget the American model incarnated by blonde movie stars, with their slender bodies and freeand-easy manners, in favour of the Mediterranean model of flourishing and modest woman, whose broad hips and round breasts - it was said -favoured maternity (see Chapter 5.7). ${ }^{18}$ In addition, the latter had to be fit and strong by practising physical education and sports at school and in the state organisations, so as to be sufficiently healthy for procreating strong children for the Fatherland.

As already stated, Mussolini's position regarding women's rights, which had been uncertain and ambiguous during the early years of government, became clearly anti-feminist from the second half of the 1920s, when the fascist regime was fully established. Socialist and communist movements - 
which also involved a number of women - were abolished in Italy between 1925 and 1926, and only female organisations tied to Fascism or Catholicism were supported or tolerated.

On the occasion of his famous Speech of Ascensione of 26 May 1927, which was addressed to the Chamber of Deputies, the Duce openly revealed a 'macho' perspective by saying: "We have created a special Tribunal that is functioning perfectly without problems, and it will even improve its actions, especially if the female element, that brings into serious things the signs of frivolity, will be left outside its walls."

In the same speech, which was entitled and issued as The fascist regime for the greatness of the fatherland, Mussolini emphasised demographic power as a prejudicial question to increase the economic and moral power of a nation, and affirmed that the destiny of the Italian race had to be saved.

In Rome, on 28 October 1927, the Duce officially received the Feminine Fasci delegates from all provinces for the first time. On that occasion, he said to those important women, who obviously were convinced supporters of Fascism: "I need births, many births. I wish every year the country adds to its wealth of new and healthy lives." 19 This clear message was supposed to be spread among all female Italians.

Mussolini was convinced that 'size is power', 20 and intended to emulate the most powerful nations by conquering new colonies. There, the nationalist dream of civilising new peoples under the Italian flag, and giving a job to all citizens would have been fully realised. As a consequence, the new Italian man had to marry young and become the father of numerous children for the Fatherland, and the new woman had a duty to bring up children and be a good housewife. Work was considered a man's affair.

A new body protecting maternity and children health, Opera Nazionale per la Maternità ed Infanzia [National Maternity and Infancy Body]-ONMI, was founded in 1925, and special additional taxes discouraging celibacy were issued by law in 1926 .

In addition, a number of laws discouraging or limiting female work were published in the following years. The Royal Decree of 9 December 1926 did not allow female teachers to participate any more in contests for teaching Letters, Greek, Latin, History and Philosophy; by Royal Decree of 20 January 1927, working women's salary was reduced to half of that given 
to men; the Law Dispositions of 1928 discouraged female students from continuing their studies at secondary school and university levels, by doubling their taxes; by the Decree of 28 November 1933 women's employment in the state administration was limited considerably, as - it was said - these workers could not easily reconcile work and maternal duties. ${ }^{21}$ By the Law of 14 June 1928 all families with six children or more were financially helped by the state, and did not have to pay annual taxes any more. This notwithstanding, the low salary of most fathers of a family compelled them to control maternity and send mothers out to work. In 1931, it was reckoned that about half Italian families lived on two incomes. ${ }^{22}$ The new Penal Code, elaborated by Alfredo Rocco from 1926 to 1931, emphasised the still lasting gender discrimination and even legislated on morality of families. Consequently, the so called 'honour crime' ( Art. 587) somehow permitted fathers, brothers and husbands to kill their daughters, sisters and wives, just to protect men's honour. In this case the term of punishment was reduced to a three to seven year sentence, instead of about thirty for common murders. The Rocco Code considered men's rights superior in the family and society. Besides, abortion was punished as a very serious crime - it was defined a crime against the race [!] - so as to protect the demographic policy of that time.

In those years the family, on the whole a private institution, became more and more a public affair. The demographic policy brought about a special day dedicated to maternity and infancy, so as to celebrate the most prolific Italian mothers. In 1933 it was decided that the right day was 24 December, just before Christmas, so as to emphasise that to be a mother was both a secular duty for the greatness of the Fatherland and a religious mission, comparable to that of Holy Madonna. ${ }^{23}$

The myth of maternity was spread all over the country by the media, especially the press and newsreels, which displayed effective images of common mothers who breast fed their babies surrounded by other children of tender age.

As examples of this kind of propaganda, the fascist review Critica fascista wrote in those days: "If one looks at Italy as a whole, from its poems to pictures and churches, one finds that everything is a hymn to virginity and maternity, which are firm hinges for the family",24 and a wet-nurse, 
Antonietta Girolamo, became popular among Italians through the press because she could produce about 2.5 litres of maternal milk daily!25

Many women of good social standard and fascist faith were involved in supporting this campaign for the protection of maternity, and voluntarily spent their time visiting poor children and mothers. They not only brought them food and clothing, but good advice on domestic economy.

Poor families were also supported by ONMI and other associations controlled by the Party and Catholic charitable bodies. Once a year Mussolini in person, and his hierarchy, used to give poor children gifts, such as toys and other goods, during the famous ceremony called Befana fascista [Fascist Epiphany], which constituted an effective tool of propaganda.

Although in perfect step with the encyclical Casti Connubii of 1930 by Pope Pio XI - which not only opposed female work, "a perversion for the family as a whole", but any kind of birth-control - the demographic plan to increase Italian population was not at all successful. Statistics show that the birth rate, calculated per 1,000 inhabitants, was $29.9 \%$ in the years 1921 $1925,27.1 \%$ in 1926-1930, and $24 \%$ in 1931-1935, thus showing a decrease. ${ }^{26}$

Within these data there were differences from region to region, and the most prolific were the southern. There, the traditional rural economy still needed many children as future hands for agriculture, but infantile mortality was high, due to poor nourishment and hygiene. For instance, in 1922, for every 1,000 children, about 128 died during the first year of life, and in 1940 about 103. On the other hand, in the northern and central regions of Italy, the process of industrialisation had brought many people from the country and more and more unemployed in the cities.

In those years, apart from the aristocracy and the political class, only the middle class had an acceptable living standard. However, both wishing to give their children the best goods and education, and keep their life style, these families were not too prolific. ${ }^{27}$

In brief, the work done by ONMI in terms of hygiene and prevention of illnesses was effective, especially through the work of sports physicians and health resorts (see Chapter 5.1 and 5.5), but the demographic campaign was on the whole unsuccessful. Mussolini's idea that more than four children 
were the best means to defeat infantile mortality and other 'negative factors'28 was not convincing, as well as his slogans: "Who is not a father is not a man", "Through maternity the woman attains her best beauty", and "War is for a man what maternity is for a woman". In conclusion, the Duce's dream to have about 8 million bayonets - i. e. soldiers - ready for the call, was never realised.

Apart from economic problems because of the world crisis of 1929, the fascist demographic campaign was obstructed by a very modest and nonhomogeneous economy at home, where low salaries and unenployment were widely spread. This trend not only discouraged couples from increasing the family, but convinced women to accept any kind of job for a very low salary, and to knock on different doors - no matter if they were fascist, Catholic or private - asking for help.

Mussolini tried to oppose the silent obstructionism of Italians by even denying publicly that women were discriminated against and submissive to men. In his speeches the Duce often eloquently encouraged women to be fertile and openly demonstrated his personal admiration for 'Latin femininity', by saying for instance in 1934: " ... The Italian woman is a mother pre-eminently: instinctively she is resistant to sterile masculinisations from overseas [meaning the USA], which estrange the woman from her biological mission, that is the higher spiritual mission as well: to continue the race and therefore history through giving birth."29

In the same speech the Duce added: "The Italian woman has the great privilege of not having sacrificed her perfect femininity to any idol of the time. To speak about 'submission' to man is an absurdity, as well as to speak about old-fashioned mentality."30

By emphasising the theme of the feminine biological mission, Fascism really aimed at obstructing both work and cultural development of women burdened by family duties. Through the years, this policy was supported both by the Church of Rome and most authoritative scholars, such as the endocrinologist Nicola Pende.

After the quoted Casti Connubi of 1930, in 1931 Pope Pio XI wrote a new encyclical, Quadragesimo Anno, which recommended that: "Mothers of a family should work at home or nearby the home pre-eminently, and do the housework. Mothers who are compelled to work far from domestic walls 
owing to the low salaries of fathers ..., this is a disorder that one should eliminate by all means."31 Since then, at the end of wedding ceremonies the priest delivered to husband and wife a copy of Casti Connubi, and a wedding insurance with information on the natality prize as well, so as to underline that religious spirit and civic duties could co-operate for the success of the current demographic campaign.

As for Nicola Pende, the eminent director of the Institute of Medical Pathology at the University of Rome, he was against gender equality and woman's engagement in most kind of jobs. He recommended maternity as the pre-eminent objective for women, and expressed these theories in a popular book, in which he said, for example: "Woman's body, and her moral and intellectual qualities, are suited to maternal functions, whereas man's body and spirit are suited both to muscular work and achievements in arts and sciences". ${ }^{32}$ One should add that, showing much originality, fascist political ideology was put together in Pende's book with biology, psychology, anthropology, sociology, pedagogy, and racism.

In only 15 years the number of female workers was reduced in Italy. In 1921 they were $32.5 \%$ of the total work force, but in 1936 only $24 \%$ and, what is more, fascist propaganda ridiculed their image, which was mostly embodied by ugly and manlike intellectual women or stupid secretaries, who - as was said - worked just to buy silk stockings. ${ }^{33}$

However, in spite of the male hegemonic will from high quarters, the official policy against women's work and cultural development was generally not very effective, and many Italians did not adhere to the imposed model of woman of that time.

Especially middle class and intellectual women continued to work and fight for feminine emancipation, and not only in their drawing-rooms but by means of national associations. In fact, in 1920 the Federazione Nazionale Laureate e Diplomate [National Federation for University and Secondary School Graduates]-FILDIS was founded, but in 1935 it had to give up since its political profile had become lower and lower. It was agreed that FILDIS was too involved in international feminist movements.

In 1930, Luigia Pirovano founded the Alleanza Muliebre Culturale Italiana [Italian Cultural Feminine Alliance] which, according to the current ideology, 
declared itself anti-feminist, but often fought against gender discrimination, especially in defence of lower middle-class working women. ${ }^{34}$

In about the same period, a female association supported by Fascism was active in Italy. Inspired by the International Professional Women's Organisation from the USA, this powerful Associazione Nazionale Fascista Artiste e Laureate [National Fascist Association for Female Artists and Graduates]-ANFAL was directed by Maria Castellani Autentico. In a few years, ANFAL created a network of about 80 provincial sections where intellectual women of good social standing organised work and art exhibitions at a local, regional and even national level. They tried to adhere to the fascist model of woman by spreading the idea that, when necessary, personal ambition should be sacrificed for family values, and a subordinated rank in social activities was a natural way for Latin women.

On the other hand, as the state censure controlled daily journals much more than periodicals, non-conformist opinions and tastes were sometimes expressed in specialist female magazines of that time. For instance, looking at the women's review Almanacco della donna italiana, which was issued from 1920 to 1943, one can find different and contradictory points of view in comparison with those expressed by official Fascism.

In the first half of the 1920s the Almanacco della donna italiana was clearly feminist and fought in favour of women's suffrage, education and work, in opposition to the current mentality. In the following years, when the regime was established, one can find here a number of articles which did not stress at all the official policy of woman's role as housewives.

While in general Fascism considered female intellectuals and professionals as a negative aspect of bourgeois ambition and vanity, ${ }^{35}$ Almanacco della donna italiana emphasised women's intellectual role by printing hundreds of biographical articles on self-confident and successful professional women, and it used to review in detail books by Italian and foreign female writers. ${ }^{36}$ In addition, rarely did this magazine support the outstanding role of housewife or the myth of the Duce, which were the main topics for the rest of the women's press in Italy at that time. ${ }^{37}$ 


\subsection{The militarised woman throughout the war years (1936-1945)}

Mussolini's low opinion of women did not change much throughout the war years, but it had to adapt itself a little to circumstances. Then foreign policy became more aggressive, and the dream to found the Roman Empire again a reality. As more and more men were away in the military or administration of the colonies, women were encouraged to take over jobs that had previously been reserved for men.

The 'charming' Mussolini started to address his speeches to 'oceanic crowds' of women gathered in squares, and his words were broadcast so as to reach about 800,000 families by radio. ${ }^{38}$ It is reckoned that in only three years, from 1935 to 1937 , about 10 official speeches were specifically addressed to Italian women, from whom further deprivations were asked.

By the end of 1935, while men were fighting in Ethiopia, women were mobilised in a campaign for economic self-sufficiency, so as to counteract harsh sanctions imposed by the League of Nations. In his speech of 1 December 1935 to 850 women, the Duce expressed his indignation at those unjust sanctions, and asked the deeply-affected audience to help the Fatherland.

From the most wealthy to the poorest mother of a family, they answered the call generously, and very soon exchanged their gold wedding rings for iron or steel, really a precious gift for the country engaged in conflict. About 430,000 gold rings were collected in the cities of Rome and Milan. ${ }^{39}$

A theatrical ceremony re-echoing Roman times - the Faith Day - was held in Rome on 18 December 1935, so as to give that gift a special significance. Through those poor metal rings a religious spirit and civic duty met and collaborated again, and a kind of wedding between Fascism and Italian women was symbolically celebrated.

At that time every housewife revealed a special talent in recovering secondhand tools in metal for the Fatherland, such as pots and old gates, and substituted foreign with native goods and food. What is more, she displayed an unexpected determination in morally adapting to these restrictions. 
Apart from the sacrifice to have their husbands and sons far away in Africa, women thought they actively were participating in the desirable foundation of the glorious fascist Empire from home, through further sacrifices. While men had to risk their lives, women had to front daily battles against a life of hardship for the same cause.

On 7 May 1936 victorious Mussolini, who had conquered Ethiopia, spoke to the crowd from the famous balcony of the Venetian Palace in Rome. Then, the consensus with Fascism reached its apex, and Italians were completely fascinated by the Duce. During that speech he found appropriate words to congratulate about 100,000 women, standing opposite the famous balcony:

"The victory of our troops in East Africa is also due to you, women of Rome and Italy. Fascist Italy (...) had given you a delicate and decisive task: to make a fortress of the Italian family so as to resist the sanctions. You women accomplished this task. The Fatherland pays tribute to you in its gratitude."40

Private involvement of volunteer women in social assistance became more and more a state service and a political duty. From the second half of the 1930s, these women, called Visitatrici [District Nurses] had to attend special training courses organised in collaboration with the Red Cross, and used to wear a uniform. They not only visited poor families to provide charity, but organised children's health resorts, domestic economy courses, handicraft laboratories, and employment agencies for women.

By Decree Number 696 of January 1937, the National Fascist Party stated the greatest care should be given to mobilised women by increasing their number and activity in fascist bodies. Two new organisations, Giovani Fasciste [Young Fascists] for young women of 18-21 years, and Sezioni Operaie e Lavoranti a Domicilio-SOLD (sections of women working in factories and at home), were founded in 1935 and 1938, respectively.

In those years, the figure of one of the most 'virile' and combative women of early Fascism, Ines Donati, became again a myth in Italy. In the past this myth had been stressed but then softened, for it was considered unsuitable to embody the quiet and feminine new Italian woman. Now, Ines Donati was considered as an exemplary heroine once more, and her remains were 
transferred to the Chapel of Fascist Martyrs in the Roman cemetery of Verano.

In conclusion, the result of the campaign for general mobilisation was really good. In the African colonies, daring women equipped with rifle and uniform were on guard in the camps alongside their husbands and brothers, while in Italy the number of women enrolled in Donne Fasciste [Fascist Women] and Massaie Rurali [Rural Female Workers] doubled from 1934 to $1937,{ }^{41}$ and at the outbreak of the Second World War about one quarter of young and adult valid women were members of fascist organisations.

Statistics show that in 1940 about 750,000 women were enrolled in Donne Fasciste, 1,480,000 in Massaie Rurali, 500,000 in SOLD, and 450,000 in Giovani Fasciste. ${ }^{42}$ In the same year, about 3,600,000 female children and adolescents were enrolled in Opera Nazionale Balilla [National Balilla Body]-ONB, then controlled by Gioventù Italiana del Littorio [Italian Littorio Youth]-GIL. (On these bodies, see Chapter 5.2.)

On 20 June 1937, the already-mentioned ANFAL organised in Rome a colossal exhibition concerning health resorts and children's assistance in Italy. About 60,000 women were present at the inaugural address of Mussolini, who could not but express his admiration for such a work and event which - he affirmed - had no precedent in the history of the world. ${ }^{43}$

Step by step, time was changing in favour of women. Although 'masculine' for ages, the cultural world had to open up to a number of female intellectuals.

Then came the so called 'revolutionary', but really retrograde, proposal by Ferdinando Loffredo to found schools reserved for women where any professional instruction was avoided. ${ }^{4}$ That was judged an exaggeration by high quarters. Even the Minister for National Education Giuseppe Bottai, who was one of the most lucid and cultured men of that time, but also an anti-feminist (see Chapter 5.2), firmly criticised Loffredo's proposal.

Loffredo, a brilliant Catholic scholar in social sciences, was an enemy of women's emancipation and therefore favourable to traditionally patriarcal families. In 1938 he was still affirming, for instance that: "Feminine emancipation had not produced advantages in the fields of sciences and arts, but on the contrary constituted the most serious danger, capable of destroying what the white people's civilisation has already produced", and: 
"Women have to return to the absolute subjection of men, whether fathers or husbands; subjection, because of their spiritual, economic and cultural inferiority." 45

In spite of Loffredo's and other influential or common men's opinion, not all women suffered from an inferiority complex. On the contrary, in the very same years a number of intellectual women had become more self-confident and had bettered the quality of their work considerably. Consequently, they could not be left out of cultural events any more, and participated in some high-level national contests with brilliant results.

The composer Barbara Giuranna gained first place in the National Fascist Trade Contest of Musicians in 1937, the poetess and journalist Fanny Dini won the annual competition 'Poets of the Mussolini Era' in 1938. Finally, in 1940, the poetess Ada Negri became a member of the Academy of Italy, and in the same year, that Academy published the first volumes of a collective biographical work on important Italian women of all times.

At a lower level, from 1938 onwards, the Littoriali of Culture and Sport, the University contest organised by Gruppi Universitari Fascisti [University Fascist Groups]-GUF was opened to female students, but it was separated from male Littoriali. From 1941 onward, female and male students could jointly participate in the same Littoriali contests. (On Littoriali of Sport and other female sporting competitions, see the next Chapter 5.6)

Even in the political ambit, some initiatives were undertaken in favour of women's involvement, as a clear sign that they were improving their lot. For instance, in 1938 the new statute of PNF admitted women to the 'fascist conscription', which was held on 23 March (the foundation of the Fasci of Combat); members of Feminine Fasci were allowed to wear proper black uniforms - the colour-symbol of Fascism - like men; some were employed as functionaries in fascist centres, and received a salary from the PNF; from 1937 these women availed themselves of female inspectors in the Central Committee of Feminine Fasci. ${ }^{46}$

In 1938, Mussolini thought that one of these very capable inspectors, Clara Franceschini, could become a member of the National Council of the PNF. In truth this idea was not realised because of opposition from the most traditional members of the Council, as well as another innovative project. The latter dealt with the admission of women to the prestigious Chamber of 
Fasci and Corporations, which was a new institution replacing the Chamber of Deputies. ${ }^{47}$

In the cultural field, professional and artistic women enrolled in ANFAL were really supporting the aggressive war-propaganda of that time. They thought they would have more chance in the working world if men were engaged on the battlefield. 48

On 28 May 1939, a political and at the same time folkloric event was organised in Rome by female auxiliaries of PNF, so as to clearly display to the country the great mass-mobilisation of Italian women. About 70,000 women gathered for this soldier like parade, in which about 15,000 women marched past the Duce and the authorities in their fascist uniform, coloured regional costume, working dress, and sportswear. Ordered groups of female cyclists, drivers and horse riders were parading as well. 49

It was a contradiction in itself, but women had to be truly fascist in those years, and therefore 'virile' and active in society, and at the same time had to leave work and honours to men and be mothers of numerous children. This happened according to a policy which tolerated the presence of young female workers, but obstructed the work of adult women by protecting maternity and workmen.

The percentage of births, which was about 24 per 1,000 inhabitants in the previous years 1931-1935, fell to 23.4 in the years 1936-1940.50 In his speech of 25 October 1938, Mussolini accused the lazy Italian bourgeoisie of obstructing fecundity, by saying: "The bourgeois in an enemy of sport. $\mathrm{He}$ is the greatest enemy of anything that could disturb his perennial state of rest. He is a pacifist, easy to be moved, always humanitarian and sterile. $\mathrm{He}$ is sterile because he thinks of it. In fact, fecundity is a state of instinct. Too much rationality is hostile to those primordial, irrepressible and deep forms of humanity." 51

In addition, the Decree of 5 September 1938 stated that the number of women serving in state or private offices had to be reduced to $10 \%$ of the total work-force. This severe disposition opposed both the presence of women especially in the educational field, and the negative trend of the current demographic campaign.

However, at that time the modern model of woman engaged in working and leisure activities had spontaneously developed alongside the imposed model 
of the modest housewife, in spite of - or probably also thanks to - the ambiguous fascist policy regarding women. Contradictorily, it wanted them as active subjects in fascist society, and at the same time as passive objects relegated to domestic duties.

On the other hand, a difficult war-time economy needed working women who received low salaries and the most humble and precarious jobs, but officially the regime spoke against women's work. It encouraged social involvement of young women in sporting and spare-time activities organised all over the country but, once they had become healthy adults, common women had to forget those diverting and interesting experiences and be just busy and modest housewives.

In truth, women's social and political activities mostly mobilised an elite of aristocratic and middle class adults, and among them especially teachers and employers, who could easily leave housework and children to servants and nurses. Statistics show that in 1921 there had been about 380,000 maids serving in families, while in 1936 the number had increased to about $585,000.52$

Lucky women freed from heavy family duties and engaged in social and political life became a fascinating model to which the new female generation aspired willingly. In the magazine Almanacco della donna italiana, Luigi Gozzini published an article about the result of an investigation held in Rome in the late 1930s. ${ }^{53}$ A questionnaire, distributed among female students by the Governatorato dell'Urbe [Roman Administration], showed that the inspirational model of those girls was completely different from that propagated by fascist ideology. Amazingly, only about $10 \%$ of the scholars were interested in housework, and about $27 \%$ confessed they really hated it; their aspiration to form a new family was really vague, and they enjoyed talking about romance and dancing parties much more than about child-welfare; what is more, very few girls wished to become mothers, and planned to have no more than one or two children. ${ }^{54}$

Official dispositions obstructing women's work and their emancipation had to come to grips with reality by the end of the 1930s and the beginning of the 1940s.

In 1939, after the occupation of Albania and the 'Steel-Pact' with Hitler, Mussolini exhorted women to further engagement. As they now had to 
support his imperialist choice and poor people's new needs, the Duce said: "Fascist women have a very important task in the field of assistance among families of the people, and especially those where the men are in the army. Many families live in misery and others suffer hunger." 55

In the fatal year of 1940, when the Italian army was involved together with Nazi Germany in the Second World War, suddenly any previous limitation to women's work was cancelled. By the Decree of 5 June 1940, women from 18 to 45 years old were allowed to work. They were employed in state and private working activities in place of men, ${ }^{56}$ but had also to combat the sacrifices at home for the growing lack of food and goods.

This notwithstanding, the new civil Code issued from 1939 to 1942, did not better women's inferior roles in the family at all; the 'new' cultural spirit stressed the unity of the family under men's patriarchal authority, and families were under state control. ${ }^{57}$ What is more, in 1940 a young man could win a national prize by writing: " ... due to racial objectives, the regime has eliminated from work all categories of women whose activity has only the task of satisfying hedonistic requirements. Everyone knows that women's work ... does not favour an increase in marriage and therefore in the population. As a consequence, the engagement of female workers has been limited in various ways, especially for those jobs which are peculiarly masculine." 58

However, Italian women started to free themselves from the patronage of their men engaged on the war-front, and learned to make up their own minds.

A number of women left their families and participated in the conflict as volunteers of the Red Cross alongside men, others assisted the wounded in domestic hospitals and supported soldiers by means of letters, hand-made food and clothes.

In 1941 Mussolini did not fail to declare his admiration for Italian women, especially those quiet and self-confident nuns previously engaged as volunteers in Albania and now acting near the front. In his speech of 18 December, addressed to all Italian women, the Duce ended by asking them for 'total hatred' against the enemy. ${ }^{59}$

At that time an increasing number of women were critical of the aggressive politics of the government that had brought their men to dangerous wars 
and their families to misery. Like most Italians, they did not believe in, nor support, the current racial laws, and protected both persecuted Jewish and absentee Italian men by even hiding them at home. At last, the death and bombardments in the country not only destroyed families and houses, but seriously undermined women's consensus.

On the other hand, men's consensus to Fascism was weakening as well, step by step with unsuccessful results on the external fronts. Mussolini had promised Italians a quick war and few dead, but really the conflict was asking from civil and armed people increasing sacrifices and much too much blood. Although propaganda emphasised victories and hid defeats, Italians were murmuring about battles lost by German and Italian soldiers and victories of the Allies on different fronts.

The first strong sign of popular discontent came with a strike organised by workers of both sexes in March 1943. In spite of fascist dispositions forbidding strikes, this succeeded and the FIAT car-industry of Turin could not but give in.

Finally, on 25 July of the same year the Duce was dismissed by the Great Council, and was imprisoned by order of the King. Then, most Italians were hopeful the war would end soon, even if not victoriously. However, subsequent dramatic events, including Mussolini's flight and Nazi German harsh reaction against 'treacherous' Italy, brought about a civil war lasting up to 1945 .

While the Allies were conquering the South of Italy, many daring women decided to participate in this awful fraternal conflict alongside men. A part of them, about 30,000 women, were provided with arms and strenuously fought together with Communist, Catholic and secular groups of partisans against fascists and Germans.

In addition, about 70,000 women were involved in the 'Groups of Female Defence' organisation, which had been founded in Milan in 1943, so as to actively support the Resistance movement. 60 Among women partisans, 623 died, 4,563 were imprisoned, and 2,750 deported to Germany. 61

On the other side, the Repubblica Sociale Italiana [Italian Social Republic]- RSI, a new state founded on 18 September 1943 by Mussolini in northern Italy, was regrouping the people so as to combat the Allies and the Italian partisans. On 14 April 1944, by Decree No. 447, the Duce asked for 
women's enrolment in the army and a number of them, about 6,000, answered the call. 62

Once they reached the territory of RSI, these women were selected for special training courses and wore the uniform of Feminine Auxiliary Service - SAF - which was part of the regular RSI army, or served in the Decima Mas, Brigate Nere and other autonomous fascist groups. Some were adults brought up in the true faith, involved in fascist organisations, but there were many idealist young women far from politics as well.

On the whole, women of the RSI were imbued with patriotic values, and a bellicose and fraternal spirit at the same time, and they aimed at the defence of Italian honour from 'traitors', up to the death. They were not armed but had the delicate task to support RSI soldiers by all means.

Strengthened by two decades of physical exercises, speeches and sacrifices, and educated by the myth of the Fatherland, they thought to replace 'cowardly' men who had delivered the country into the hands of foreigners. About $60 \mathrm{SAF}$ auxiliaries died before 25 April 1945 - Liberation Day - and about 90 women were murdered after the civil war had ended;63 if one considers also those involved in other fascist groups, the number of the dead was about 300 in total.

A recent book presents an interesting memorial by the most influential exponent of the SAF, Brigade General Piera Gatteschi, that displays and documents the spirit in which the animated auxiliaries engaged in that military body. ${ }^{64}$

Both female partisans fighting for the Resistance, and auxiliaries engaged in the hopeless adventure of the RSI, were looked upon distrustfully by men, who still considered women as weak and emotional persons, unfit for the war.

In fact, these women revealed unexpected physical and moral strength, and became heroic combatants on both fronts. They were exemplary nuns and dispatch riders in the zone behind the front, and at the same time supported unfortunate families of the fallen soldiers. This is clearly testified to in recent literature on the Italian Civil War of 1943-1945, including women's letters and diaries. ${ }^{65}$ 
Summarising, the paternalistic ideology of the regime had built a cultural model of 'true woman', the Latin mother, which was propagated through the years, but this did not always coincide with the reality of the country.

In truth, during the fascist era women's condition was changing, and time after time had to suit the social dynamics which combined economy, politics, creeds and needs of the population with a diffused gender yearning for emancipation. However, this process was widely conditioned by the common idea that men were more intelligent, stronger and more capable than women, and the latter could somehow be redeemed from their inferiority by means of the supreme biological mission of maternity.

History tells us that under the regime, although women had worked actively not only at home but in agriculture, in factories, offices, social assistance and fascist seats, this did not count much in Italian society.

They had learned to love their country at school, in fascist bodies, and through nationalistic propaganda, but any and every political decision regarding the destiny of the Fatherland was firmly in men's hands.

Within juvenile organisations, they had trained their body and even learned to march in perfect order and discipline like soldiers, but this was just a means for bettering their health in view of a copious progeny, as far as they were told for ages - sport and war were men's affairs.

However, during the long years of war Italian women learned at their own expense that conflicts were women's affairs as well. From 1935 to 1943 they suffered severe deprivations at home as a consequence of the imperialist plans designed by the pre-eminent Italian man, Mussolini. What is more, women had to undergo further suffering for a tormenting fraticidal war lasting up to 1945, due to the weakness, bewilderment, lack of preparation and foresight of men.

During this civil war a number of women rebelled against the 'spirit of resignation' typically attributed to them down the ages, and decided to transform themselves from victims to protagonists of history by actively participating in the defence of the country at men's side. In fact, after years of sacrifice and restrictions, but also engagement, promises, hopes and nationalistic exaltations, their personality had notably strengthened.

In spite of popular opinion, and according to modern mentality, these women had emancipated themselves from most traditional roles and were 
sufficiently self confident to leave their homes and support combatants involved in the Resistance or the RSI.

At that time, women's cause did not only consist in the defence of different ideological choices and their own life, but in a generous protection of civil society harshly tried by war, through a diffused spirit of feminine solidarity. 

113

Chapter 5 


\section{Fascism and physical training of the female body}

This chapter takes a look at the initiatives undertaken during Mussolini's government in terms of women's physical education and sport. In the first half of the Twenties the training of a woman's body was supported by the fascist movement, according to the revolutionary spirit of the first period. In the second half of that decade, when the regime was firmly established, sportswomen were considered to be both the ideal ambassadors of the fascist new style throughout the country, and ideal mothers of the strongest children. Young women were trained in the Feminine Fasci, under control of the Fascist Party.

This new sporting trend was bitterly censured by the Roman Catholic Church and old-fashioned popular opinion which were both afraid of a 'masculinisation' of Italian girls, and of a possible loss of feminine modesty and interest in family and maternity. As a consequence, women's sport was considerably reduced. The prevailing opinion was that the innate competitiveness of sporting activities could be reproduced in everyday life, with the unacceptable result - from a narrow-minded point of view - of distracting women from their household duties and launching them into work and politics.

As women had already gained a certain degree of emancipation, working away from home in the industrialised areas of the country, the societal danger that they could invade fields traditionally reserved to men was a real problem.

In addition, it was murmured that sport could cause female sterility, a real danger to Fascism given the demographic campaign for increasing the population. As a counter-measure, various dispositions limiting women's rights in terms of work had already been issued since 1926.

After all, the conciliation of the different roles that women had to play was almost impossible: as reproducers of the race they had to embody traditional roles, such as being stoic, silent, always at men's disposal; as 
citizens and patriots they had to be modern, that is combative, present on the public scene and ready for the call-up.

Naturally, with physical education and sport, the 'apple of Fascism's eye', there existed different roles to be played by women. On the one hand, there were highly considered physical activities where charm and gracefulness were privileged, but on the other, there were competitive sports where the required strength and aggressiveness left the athlete's sex out of consideration. The latter, furthermore, had the task to spread across the world the idea of a changing nation with sporting citizens of both sexes.

Since its advent Fascism had encouraged the practice of women's sport as a sign of revolutionary modernity, so it was officially unable to take sides against it. Anyway, being aware of the popular growing discontent about female athletes - too 'tomboyish' and easy going - Fascism entrusted science with the task of establishing activities which were more suitable for women.

This decision, which was taken at the beginning of the Thirties, gave CONI and the Italian Federation of Sport Physicians a free hand in terms of female sport. Thus, female sport was put in a sort of gender 'ghetto'. Physicians agreed upon the eugenic utility of basic physical education, which was highly recommended, whereas common women were advised against competitive sports.

As far as non-competitive sports were concerned, they were also considered to be good but were restricted to a few activities, such as swimming, skiing, skating, tennis, basketball and athletics, the latter being limited to a few disciplines. Moreover, most of these sports, by requiring suitable facilities and equipment, remained just dreams for the majority of Italian women who nourished themselves simply on the newspaper pages of sports deeds of the fortunate female elite.

However, at school some of these activities and a basic physical education were practised within the ONB and GIL organisations, and in summer holidays in the numerous health resorts spread all over the country. Both had the task of bettering women's health, discipline and team-spirit.

As far as competitive sport was concerned, in those same years the regime started an accurate selection of talented girls, so as to export the winning model of Italy as the pre-eminent sports nation in the world. 
Although women's sporting activities were officially discouraged and therefore unpopular, there could be some new talents to be discovered among the little girls attending physical activities in schools, and/or within fascist youth organisations.

In so far as there was a lack of qualified female staff, an elite of modern physical education teachers was trained in a new university school, the Academy of Orvieto, from 1932 onwards. In those years other teachers were recruited among female primary school teachers and other experts in physical education, naturally imbued with true fascist faith.

They started a 'capillary' selection of future female athletes. At least being a small minority, these girls could train undisturbed, as they would not have compromised the official image of a submissive and modest woman, according to the prevailing model strongly supported by the fascist hierarchy and Mussolini himself.

Those athletes, well prepared by male coaches (seldom female ones), constituted a kind of elite who, for that period, were allowed a lot of freedom. They took part in mixed national and international contests and therefore they were looked at with perplexity and admiration, due to a certain lack of constraint in their manners and in the comradeship they showed towards their companions.

Even if their strong muscles were not a current model of femininity, on fields of contest female athletes properly symbolised the moral strength, besides the physical, of Italian fascist women.

Through the years, Italians had to come to a compromise with different aesthetic feminine shapes. At the beginning, the inspirational model was the tomboyish slim woman of the roaring Twenties, then the American slender and athletic women's body, which was opposite to that of the 'Latin model', i. e. the Italian 'true woman' whose broad hips and round breasts favoured maternity.

Finally, the tonic and muscled body of national sportswomen was affirmed in the Forties. Press and fashion collaborated in stressing these different aesthetic canons, and works of 'militant-art' did not fail to depict especially the charm of strong Italian sportswomen's shape, as will be described later. 


\subsection{Sports medicine and eugenics}

By the mid-1930s, sports medicine was a new field which deeply interested scholars and politicians in Italy. Among the pioneers of sports medicine Dr. Ugo Cassinis has to be cited. Since 1925, he was the director of the laboratory of physiology applied to sport at the Farnesina Military School of Rome. That laboratory had the task of testing talented boys, by evaluating their physical condition, and addressing them to different sporting activities. Moreover, within the laboratory these athletes were periodically controlled to evaluate their bodily reactions to training.

Cassinis was Italian observer at the First International Congress of Sports Medicine which took place in Amsterdam during the Summer Olympics of 1928. There, he was acquainted with the development of sports medicine in Europe, and especially in Germany, as far as scientific research and organisation were concerned. When, in October 1929, the physician Dr. Giacinto Viola founded the Medical Association of Physical Culture, Cassinis was elected a member of its national committee.

In the following month, under Augusto Turati's leadership, CONI established the Federazione Italiana Medici dello Sport [Italian Federation of Sport Physicians]-FIMS, on the successful initiative which had brought the foundation of the International Federation of Sports Medicine, ${ }^{1}$ on the occasion of the 1928 Winter Olympics of St. Moritz. Very soon FIMS became the main reference point for scientific research on sport in Italy, and Cassinis was appointed a member of the Technical Committee of Physicians, to which the task of concretely starting the Federation was given.

This Committee consisted of the most influential doctors interested in sports medicine, representing different geographical areas of the country, such as Arrigoni and Poggi-Longostrevi (Milan), Viziano (Turin), Barbacci, Cartasegna and Pini (Bologna), Cassinis and Zauli (Rome), Polacco (Trieste), Podestà (Bari), and Sorrentino (Ancona). 
Between 1929 and 1930, these specialised doctors organised scientific and practical courses of sports medicine for common physicians, and courses for coaches and sporting masseurs, so as to spread all over the country the idea that sports medicine was not limited to first aid, but aimed at following youth from the beginning, by actively collaborating with physical education teachers, coaches, sports societies and athletes. In particular, a special course lasting two months took place in Milan in 1929. This course, which was attended by female physicians, was led by Poggi-Longostrevi, a doctor particularly favourable to women's sport, as we will see later on. ${ }^{2}$

Among the many initiatives undertaken in those years, it is important to mention the first Institute of Sports Medicine, founded by the Fascist politician Leandro Arpinati in 1929, aimed at evaluating students and professional athletes. In only two years (1929-1931), in this very modern and efficient Institute - positioned close by the Littoriale Stadium of Bologna - 1,383 boys and 1,022 girls were visited and controlled by sports doctors two or three times at least, and 342 competitive athletes were evaluated to address them to the most suitable sporting activity. In addition, a special hospital for traumatology, called the First Sanitary Sport Shelter, was founded in Rome in 1930 by CONI, to take care of all injured sportsmen free.

In 1930, the FIMS Technical Committee of Physicians discussed and approved the Statute and Regulations, whose main task was co-ordinating and controlling the whole sporting activities of the nation, from the medical point of view. In application of that Statute, 14 physicians of FIMS were nominated as regional inspectors and 20 as provincial heads. Cassinis was elected Secretary of the Federation, later moving to Extraordinary Officer in 1931, and then he became President of FIMS from 1933 to 1941. Then FIMS was abolished in favour of a new body, the CONI Sanitary Service led by the CONI Secretary, up to the end of the Second World War.

\subsubsection{FIMS on the national and international stage}

At the beginning, FIMS found it difficult to introduce qualified, specialised physicians within the Italian sporting societies. Most of these societies already had links with doctors who devoted themselves to athlete injuries, and therefore did not like asking for external FIMS physicians, possibly 
controlling not only the athletes but the sporting activity as a whole. In addition, both coaches and athletes believed FIMS specialists could obstruct their work, and somehow restrain their enthusiasm over sporting events.

In the 1930s, FIMS was active not only in the organisation and diffusion of sports medicine within the country, but in improving scientific knowledge by holding periodical national meetings - such as the congresses of 1932, 1935 and 1938 - where a number of physicians presented papers concerning their own experience, and disseminated foreign theories. In those years FIMS also published an interesting review, Rivista di Medicina dello Sport, edited by Dr. Viziano.

The Italian school of sports medicine was inspired by international scientific production, adapting it to Italian needs, and lack of means as well. Anyway, this school was also active, and sometime original, as far as biometrics and constitutional doctrines applied to sport were concerned. In this field the Italian school just followed the way previously laid out by a number of Italian physicians of the past century.

Pioneers of sports medicine should be mentioned, such as Dr. Emilio Baumann for his scientific studies of physical education, Dr. Achille De Giovanni for his constitutional methodology, Dr. Luigi Pagliani for his anthroponometric evaluation, the hygienist Dr. Paolo Mantegazza, and especially the famous physician Prof. Angelo Mosso for his extended research in physiology to sport. They published their studies, and invented new instruments for anthropometrical and physiological evaluations. Consequently, in the first decades of this century Italian sports medicine especially developed the previous stream of research.

Naturally, the Italian constitutional school was aware of German, French and American studies - by Arnold, Anthony, Bach, Baker, Gordon, Latarjet, Magnus, Marchal, Rautmann, Süpfle, Thooris, and others - which influenced its work. ${ }^{3}$ However, the scientific production of the Italian school of the time was abundant but not innovative as a whole, with some exceptions. In fact, it had well-known constitutionalist scholars, such as the physicians Giacinto Viola and Nicola Pende.

Viola invented a new constitutional method for physically evaluating sports people, and also new medical instruments for measuring each 
morphological individuality, like the balance-anthropometre and the compasses of thickness. Pende, an expert in endocrinology, mainly focused on the mutual relationship between somatic structures and psychical activity, from which he developed a complex methodology for classifying different constitutional types.

In addition, by putting their methodologies together, Viola and Pende presented an original work by means of the Viola-Pende evaluating schedule, which was well known abroad, as will be seen in the next lines.

Italian sports medicine also researched physiology and psychology, quoting in their papers the studies of influential foreign scholars, such as Abramson, Asher, Atzler, Boigey, Bouardel, Casper, Christensen, Embden, Herxheimer, Jänsch, Knoll, Kohlrausch, Lagrange, Lorentz, Mülly [sic!], Orskov, Reich, Rosenbaum, Schmith [sic!], Simonson, Zuntz. ${ }^{4}$

In this field, an original contribution came from research on hygiene and nourishment of sportsmen, by Calligaris Cassinis, Baglioni, Chiurco, Davì, Del Guerra, and Tavernari. They especially looked at the effect of coffee and wine (which were the most popular drinks in Italy) on sporting activities, concluding that those were just kinds of 'honest' drugs, that could not damage athletic performance at all. 5

In 1933, FIMS started actively participating internationally, by hosting the Second International Congress of Sports Medicine in Turin and Rome. After that interesting meeting, in which scholars especially debated the problem of evaluating sports people, ${ }^{6}$ FIMS decided to pursue a number of important objectives on the internal front.

In brief, these objectives aimed at: a) obtaining full support by the university world in terms of teachers, classes and especially laboratories, which the country lacked; b) preparing FIMS doctors accurately, in the scientific and practical fields; c) promoting a general acceptance of FIMS physicians within all sporting societies; d) checking all sports people through special tests, evaluating them from anthropological, morphological and functional points of view.

In 1934, at the International Congress of Chamonix, FIMS was represented by Viola, who presented his methodology for evaluating the physical constitution of individuals, so as to address them to the most suitable sports. Viola's method not only found international agreement in 
Chamonix, but was widely applied in Italy through the so called Biometrical schedule for physical evaluation.

By the middle of the Thirties, the number of qualified sports physicians increased, since the presence of FIMS doctors in the territory was reputed to be politically important. The fascist government was really interested in improving the efficiency of its champions, as well as in the medical support for physically evaluating Italian youth, as the starting-point for strengthening the race. In 1935, about 2,000 FIMS members came under CONI, in charge of leading the medical branch within the existing fascist bodies, the Army and sports societies, and 17 regional and 74 provincial FIMS inspectors were nominated to control and co-ordinate the whole activity in the country. However, FIMS did not do much in scientific research, nor in number and quality of laboratories and facilities, mainly due to a lack of financial support.

Finally, as far as fascist politics was concerned, Italian physicians did not oppose it, officially. On the contrary, in their speeches and writings most of them did not fail to demonstrate gratitude to the regime for the special emphasis given to medicine, sport and health. Poggi-Longostrevi and Chiurco published popular books warmly praising Mussolini himself and the numerous sports medical activities carried out by fascist bodies, and Pende openly declared even in favour of the racial laws of 1938, supporting one of the most questionable fascist policies.

\subsubsection{FIMS and female athleticism}

At the beginning of the Thirties, the Fascist regime considered the newlyconstituted FIMS, which by statute was entrusted with sport politics in general, and with sport culture as well, as the most qualified body to resolve a very delicate problem arising in those years, i. e. female athleticism in Italy. In the beginning Fascism had encouraged women's sport and was hardly in a position to take sides against it, but on the other hand this trend was more and more censured by both the common people and the Roman Catholic Church.

In particular, the prevailing opinion among people was that competitiveness within sport could be reproduced in everyday life, and launch women into the morally dangerous world of work and politics, at that time completely 
dominated by men. Moreover, among the numerous prejudices against women's physical activities, the idea that sport could be dangerous to female reproductive organs, possibly causing female sterility, was deeply held in Italy.

As far as the Church was concerned, it was afraid of a possible 'masculinisation' of Italian sportswomen, and also of a disregard for family values, maternity and modesty, especially if sports would be practised in 'promiscuity', namely in mixed groups. The regime was aware of the growing discontent with regard to women athletes, so much so that it entrusted to the medical profession the task of deciding which activities were more suitable for women. In fact, this transfer of authority, decided by the Fascist Great Council during the meeting of 16 October 1930, gave FIMS a free hand.

In 1932, on the occasion of the First National Congress of Sports Medicine (which was held before the Los Angeles Olympics), many papers were dedicated to female athleticism. By reading the proceedings of that Congress, held under Arpinati's patronage, one can obtain an interesting view of the prevailing opinions concerning female sport. It derives not only from the thoughts of physicians, but also from those of qualified teachers and coaches.

Among the physicians Dr. Cassinis has to be cited first. In his paper ${ }^{7}-$ May a woman practice sport? - Cassinis discredited the fear that physical activity could make women sterile by recalling the sporting habits of the healthy and prolific women of Northern Europe. He then censured a certain mentality that women should be close to the home, to protect their morality. Nowadays, women - he said - live, fight and work with the same rights and duties as men. Nevertheless, Cassinis considered that the purpose of a woman's life was maternity, and he disapproved of home segregation as well as of hard work outside, especially if carried out in unhealthy places.

He warmly supported physical activity in the open air, on mountains, rivers or at sea, in order to properly prepare female bodies to achieve their mission better. Such activity, besides strengthening the body and bettering health, improved the will and balanced the female character by eliminating those states of irascibility and nervousness which negatively affect children and husbands. 
Cassinis then looked closely at possible physical activities for young women. He advised against athletic, acrobatic and agonistic gymnastics, but recommended methodical, analytical and applied gymnastics as well as callisthenics. In particular, he supported Ling's analytical gymnastics, and above all respiratory exercises.

As to sporting activity, Cassinis thought that certain kinds of physical activities could improve a woman's health and character, while preserving aesthetics and femininity. The most recommended athletic specialities were high and long jumping, javelin throwing, and running, but just for fun. Especially 100, 200, 400 and 800 meter races should be absolutely forbidden, if practised for agonistic purposes. Also hurdling, discus throwing, putting the shot and pole-vaulting were not considered suitable for women.

Cassinis thought that some sports, such as mountaineering, skiing, rowing, swimming and diving were really beneficial because they were complete, encompassing physiological, anatomical and hygienic aspects. $\mathrm{He}$ recommended team games, such as basketball and volleyball, because they produced harmonious bodies and stimulated discipline and emulation. Fencing, or indoor sport, were not advised. Fencing was not as aesthetically suitable for women as 'callisthenics' gymnastics, rhythmic dance, or ballet.

Cassinis also discussed upper-class sports, such as golf, tennis and motorracing. He believed these were nothing special compared with less expensive sports.

Cassinis, concluding his paper, underlined the fact that the strongest nations put physical education ahead of everything. Italian woman, without a strong body and will, could never become the perfect mother of the new Italian moulded by the regime.

Another physician, Dr.Viziano, presented the first results of an investigation - which was still ongoing - into the influence of exercise on menstruation. ${ }^{8}$ The results referred to a questionnaire focusing on sporting activities in relation to the menstrual cycle, in which 19 athletes of the Gymnastic Society of Turin had responded. The concluding results were positive. In fact, according to these results it was found that most athletes did not report any particular indisposition and did not stop their exercises during 
menstruation. Some had found in sport a remedy for painful menstruation. Two of them even had declared that, while menstruating, they had participated in true competition without any loss of form. Definitely, Viziano concluded, sports practised by athletes seemed not to be unfavourably influenced by their menstrual cycle.

Not all participants of that Congress agreed with practical activities during menstruation. In fact, in a brief paper Dr. Giaccone affirmed (based merely on scientific readings he did not specify!) that menstruating women should avoid all sports, even the less strenuous ones, because: "... in the period, the female body, due to its increased requirements, is really in equilibrium with regard to body exercises, thus it cannot be diverted by weariness [by practising sport]."9

In the second part of his paper, Viziano referred to important findings of female sport studies carried out in those years by Duentner and Helleland, Schlesinger, Runge, Casper, and McCloy. Viziano concluded by saying that sport, in general, need not be forbidden to women. The question of which sports were more suitable to women, enabling them to obtain an improvement in physical condition for future maternity, was an open one for Viziano: "Concerning female sport, at least we mean quality but also dosage, as well as the opportunity of starting at a convenient age, after a good preparation through various levels of physical education." 10

As already stated, at the First National Congress of Sports Medicine a number of speakers who were not doctors, but teachers and sports coaches participated by contributing their experiences. In particular, a lawyer was found to defend female sport from the accusation that it was dangerous to health: the lawyer's name was Marina Zanetti, a famous athlete, sports manager and coach (see Chapter 5.6).

Her paper said that from "healthy, harmonious and non-excessive sports come the best benefits" for women. ${ }^{11}$ In addition, due to a peculiar quality of the Latin female - including the Italian - there was no danger of sport overload: the Latin female, due to her nature and habits, was endowed with harmony and gracefulness, so much so that she "instinctively escapes from foreign, exotic overloads". 12

As far as athletics were concerned, Zanetti affirmed that even the common people understood that athletics helped to strengthen the female 
reproductive organs. The lack of danger could be demonstrated by cases of more than ten years of athletic activity without injury.

Also the physical education teacher Mrs. Lugnani was in favour of female physical activity. In her paper, however, she did not support sporting activities, only gymnastics. She asked for special care to be taken when choosing the kind and intensity of exercise. She proposed the American doctor Bess Mensendieck's method, ${ }^{13}$ based on static gymnastics without the use of apparatus. Lugnani wished to integrate it with the rhythmicdynamic gymnastics of Delsartes, Stebbing, and Kallmeyer, and with the rigorous musical gymnastics of Dalcroze.

Lugnani concluded her paper by suggesting that swimsuits be worn during gymnastics lessons in order to give the body more freedom and oxygen and by urging that a shower follow exercise. Naturally this idea of nudity came from Mensendieck's method, but it was adapted somewhat to the Italian mentality, by suggesting at least a swimsuit, for the sake of female modesty. Prof. Baglioni, Chairman of the First Congress, summed up the works presented there, concluding that in general the speakers agreed that appropriate and moderate sport activity did not damage but helped the normal functions of the female sexual organs, such as menstruation. Moreover, this activity built a healthy and harmonious body, and directed youth's energy away from sexual excesses stimulated through modern cinema, dance halls, and reading. ${ }^{14}$

At the International Congress of Sports Medicine of 1933, held in Turin and Rome, Prof. Rabino of Turin presented the results of a test concerning the relationship between menstruation and fatigue in sport.

A set of questions, filled in by 100 female athletes showed that: 48 athletes did not stop training during menstruation; 20 stopped training very seldom; 15 practised a mild training by abolishing running and jumping; 17 did not train at all during menstruation. Among the latter 17 athletes, 12 admitted they were influenced by the advice of families and doctors, and only 5 suffered real pain. In addition, 76 athletes said that their menstrual function had been improved by physical activity.

Prof. Rabino concluded by saying that well-trained female athletes could practice sport during menstruation, but on condition that they did not strain themselves too much. ${ }^{15}$ 
At the Second National Congress of Sports Medicine in 1935, Dr. Sirio Lentini's paper was openly in favour of the political views of the regime in terms of female sport.

Initially Lentini underlined that, following the regime's ideology, sports medicine should become a kind of social medicine. It should take care of all citizens, as far as orthogenetic-physical education and proper sporting preparation were concerned, up to the end of puberty. These two forms of physical activity - Lentini said - contributed to the same end, that was "the integral human reclamation." 16

Then, on the specific question of female sport, Lentini considered competition as an exceptional event. It should always occur with good taste and composure. He also suggested that within Gruppi Universitari Fascisti [University Fascist Groups]-GUF, physical education lessons should be given to female students. During these lessons - Lentini thought many activities should be practised, such as gymnastics, track and field, rhythmic dance, swimming, basketball, tennis, volleyball, skating, mountaineering, and excursions.

National sporting displays for women should also be organised. In these, as called for by the most illustrious Italian physicians, some disciplines, such as cycling and horse-riding, should be excluded. In fact, these latter sports altered the statics of spinal columns and internal reproductive organs. They overdeveloped the muscular and skeletal apparatuses so much that the somatic femininity of Italian women, and their attitude to procreating and rearing children, could be seriously compromised.

Lentini, concluding his contribution to female sport, drew quite a terrifying portrait of the 'virilized' female athlete: "a body abundant in muscles and lacking in breast, a face turgid with blood vessels, a big neck and a hard expression; vehement language that is sometimes even violent."17

To that Second National Congress Dr.Tranquilli-Leali contributed a series of data collected from young people who had suffered traumatic injuries by practising sports. These data referred to cases that had occurred in the Arnaldo Mussolini Hospital of Bologna, from 1930 to 1935.18 Among 704 injured athletes, who were grouped according to sporting disciplines, there were only 23 girls. 
It should be noticed that 7 female athletes - that is a third - practised 'discouraged' sports, such as 'cheap' cycling and 'expensive' horseback riding and motorcycling; 9 practised popular sports, more 'welcomed' by the regime, such as skiing, track and field and skating; the remaining 7 practised motor-racing, a very elitist sport. The data could be interpreted to show that whereas in the Thirties male sport was really popular, female participation in sport was limited, even in a rich and modern city such as Bologna.

Looking at the Proceedings of the subsequent Third National Congress of Sports Medicine, in 1938, one might argue that the topic 'female athleticism' was not debated any more. In fact, only one paper was partially dedicated to female sport, by Dr. Montanari-Reggiani. 19

In it, he summarised the opinion of official medicine by affirming that undoubtedly women could practice a certain amount of sports with good results in terms of physical efficiency, and also underlined the positive influence of sport on procreation, childbirth, and suckling. During menstruation, naturally women had to avoid any competitive activity or stressful training, in as much as this was a very delicate period.

At university, he said, female students should practice only those sports previously prescribed by medical sciences, following their physical and psychological constitution. Within GUF, generally female students were recommended the most suitable activities by doctors of GUF, who had also the task of controlling and limiting their training, according to the different capacities and attitudes.

Montanari-Reggiani related a brief experience from the University of Modena, where voluntary nurses of the Croce Rossa Italiana [Italian Red Cross]- CRI had collaborated with him, then a physician of GUF, from the first medical examination of female students.

The nurses had $\mathrm{b}$ observe the students, and evaluate every physical and psychological change occurring during their training. In addition, they tested the students in three different periods of time, the first being at the beginning of the activity, the second in the days prior to the University sport contest the Littoriali, and the third and last one in the subsequent days.

Concluding, Montanari-Reggiani affirmed that those data had been a useful instrument for GUF doctors of the University of Modena, and could also 
be an important source for further statistical studies on female athleticism, through the Central Sanitary Service of GUF.

\subsubsection{Illustrious physicians and women's athleticism}

In the Twenties, the practice of female sport, due to its hygienic and moral implications, was a topic of scientific study and debate before or outside FIMS. Important physicians clearly expressed their ideas and left interesting written sources in articles and books. Among them, Dr. Goffredo Sorrentino from Ancona, teaching at the University of Bologna, should be cited, because he was one of the earliest supporters of female athleticism in Italy.

In 1921, that is before the advent of Fascism, Sorrentino wrote an article on the popular newspaper La Gazzetta dello sport, exalting the Italian sportswoman as most exemplary. In the female sports contests of the time - he said - the female athlete had clearly demonstrated her muscles could do better than just dancing the foxtrot or quick step. In Sorrentino's opinion, sporting habits did not damage female modesty at all, but, on the contrary, contributed to keeping women healthy and far from the current provocative fashion - i. e. short skirts and transparent stockings - and the dangerous trend of flirting, or making-up, much too much.

According to scientific studies of the French scholars Marey, Demeny and Hebert, Sorrentino proposed to check sportswomen throughout their activity. Italian physicians, he underlined, should test every improvement, or worsening, of the athlete's physical condition, especially by controlling heart, lungs and body weight. In addition, women should be trained gradually, and their muscles accurately prepared, by means of those basic and scientific exercises indicated by Hebert and Heckel [sic!]. In Sorrentino's opinion, women should reject the most dangerous sports, such as boxing, wrestling, football and rugby, whilst tennis, volleyball, basketball, medicine-ball, a few traditional Italian ball games (sfratto and tamburello), and track and field, were highly recommended.

Sorrentino affirmed that athletics had to be considerably adapted to the weaker female body. For example, the weight of discus, shot, javelin, and Scottish hammer [which amazingly he considered a suitable sport for women] should be reduced by half, the sprint to 70 metres, the long 
distance run to 1,000 metres, and the triple jump should be excluded altogether.

In conclusion, Sorrentino supported female athleticism in Italy, affirming that a rational training and sporting activity would not change beautiful Italian women into the ugly 'gun-women' of the circus. On the contrary, following the habits of the female population of the most advanced nations, and the proposals of eminent scientists from abroad, Italian women would become more harmonious and robust by sporting activities in the open. At the same time, those women would keep out of the unhealthy drawing-room conversation, or the morally dangerous dance-halls. Indeed Sorrentino should be considered a pioneer of female sport, as in the Twenties not only in Italy but also abroad most scientists did not support women's competitive sport very much.

As has already been mentioned, at the beginning of the Thirties the problem of female athleticism became a main topic, so much so that it was widely debated also outside FIMS by influential physicians of the time. Nicola Pende - the pathologist, clinician and endocrinologist already mentioned presented a paper to the First National Congress of ONB Physicians in 1930. In it, he emphasised the danger that some sports and physical exercises could cause women, deforming their spirits and bodies.

Being aware of a serious diminution of fecundity occurring in those years, he thought that it would be better to give women a basic, healthy physical education in order to prepare them for their fundamental function of maternity, according to the current ideology. However, by practising sports, Italian girls could embody the sterile and masculine model of the modern woman by becoming maschiette, i. e. tomboyish. ${ }^{21}$

The opinion of Giuseppe Poggi-Longostrevi, one of the founders of FIMS, initially differed considerably with regard to the problem of women and sport. In two articles published in La Gazzetta dello Sport, in which the Great Council Meeting of 16 October 1930 was respectively announced and commented on, he was in favour of female athleticism.

In the first article, written before the Great Council, Poggi-Longostrevi faced the problem by asserting that physical exercises outdoors were needed if women were to become healthy, strong, robust mothers. $\mathrm{He}$ spoke of the recent wonderful display of the Female Athletic Championship 
in Florence and of the Female World Games held in Prague, where strength and joie de vivre were displayed before the admiring eyes of 30,000 spectators. "Whoever criticises the wish to achieve records does not reflect that no progress would be possible in the world without competition."22 Women, as well as men, had the right to obtain benefits from sports and to protect themselves from the ill-effects of sedentary work. They had the right to become more dynamic, as required by tumultuous modern life. Physical exercises strengthened body and spirit, but sports and athletics formed character. Nor did young women sacrifice their grace and harmony, not even when striving for sport records.

Poggi-Longostrevi's second article, ${ }^{23}$ written after the Great Council Meeting, reflected the prudent position expressed there. He mitigated his enthusiasm for female athleticism. In fact, the Great Council had stated that everything that distracted women from their fundamental mission of maternity had to be avoided.

Therefore, Poggi-Longostrevi informed his readers that FIMS had the task of deciding upon the best age to start training for competitive female athletes. Of course, true sports people would never impede the development of female athleticism, but, by moderating dangerous enthusiasm, they would channel them along the desired path. Female athleticism would then be allowed only to the few perfectly and thoroughly trained bodies, after years and years of basic, pre-athletic exercises.

In his book Cultura fisica della donna ed estetica femminile, of 1933, Poggi-Longostrevi analysed the problem more deeply, concluding that women's sport had to be encouraged, but strictly under medical control. Athletes from 12 to 15 years old should be tested and directed to the most suitable sport activities. Girls 18 and older should be allowed to compete in true sports.

Every kind of sport was safe for a well-trained adult body, but some were more suitable for young girls. Track and field was good, because women's races had reduced distances, and high and long jumping were no longer dangerous because modern landing pits softened the fall. Even putting the shot, javelin and discus throwing, by using lighter female implements, were now safe. Swimming and ball games were highly recommended, as well as skiing, tennis and skating. 
Poggi-Longostrevi spoke forcefully in favour of talented sportswomen. Strong female athletes, true champions, were examples of their disciplines and lived only for sport. They were the exception, the pride and glory of the nation, the improved model of the Italian race, to be admired everywhere.

In contrast, ordinary women would harmoniously develop their bodies by practising motor activities as amateurs and by following precise hygienic norms in order to protect their sexual organs. In fact, Poggi-Longostrevi was quite convinced that physical culture and exercises were the only possible therapy for the most critical periods of female life - menopause and senility. ${ }^{24}$

In 1935, Professor Gian Carlo Chiurco of the Sienese University published an extensive essay, drawing a picture of Italian physical education and sports physio-pathology, completed by an up-dated bibliography on national and international scientific research on sports medicine. In it, after having expressed his firm opposition to professional sports people in general, he supported the idea that motor activities had to be practised joyously outdoors.

As far as women's sport was concerned, Chiurco spent several pages describing meticulously those activities he felt were more suitable and the reasons why. His position was similar to that of Poggi-Longostrevi. Both believed that, even if the female anatomy and physiology were different from men's, sporting exercises could not be forbidden. On the contrary, they should be encouraged and adapted for women.

Following the studies by Edith von Lölhöffel, he stated that lanky, short or normal stature women excelled at different sports. Long distance races were needed because of their good influence. Hurdling races, putting the shot, discus throwing and pole-vaulting were all forbidden unless prescribed by physicians. In any event, the most suitable activities for women were rhythmic gymnastics, skiing, swimming, rowing, racing, and fencing. ${ }^{25}$ Chiurco also shared the opinion previously expressed by Cassinis that in the Fascist State women could not simply live at home and be distanced from healthy activities. In fact, these activities contributed to shaping future good mothers, with a good, well-balanced character, capable of producing strong and healthy children. 
Sport activities were particularly important for women who lived at home or worked in offices and laboratories, especially if their lives were sedentary. At least, he agreed with Viziano, and with many other scholars from abroad, on the fact that sports did not adversely affect female sexual organs and that they could be practised in moderation during pregnancy and after childbirth. Among the initiatives undertaken by medicine to trace the borders of female motor activity, one should mention the remarkable competition launched in 1934 by the magazine Rivista di Terapia Moderna e di Medicina Pratica, on the theme 'Principles and limits to be adopted in regard to physical education for women'.26 [Unfortunately, further news about this competition have not been found in the press of the time.]

In 1936, a discordant opinion came from the medical field by Dr. Ferdinando Loffredo, who published a political essay on Italian families. He vehemently opposed every kind of sport for women, affirming that sportswomen had a number of sexual disturbances - such as painful menstruation, reduced uterus and ovary function - and, what is more, their bodies presented evident signs of masculinity.

Loffredo also claimed that abroad female sports had been the main cause of women's removal from their families and therefore of demographic decrease and loss of womanly modesty. In addition, Loffredo was convinced that female sports could also encourage the 'ideal of nudity' present in some foreign countries, with negative consequences for general morality. ${ }^{27}$ At that time, the modesty and morality of all sportswomen were strictly controlled by fascist bodies, to please parents and the Church of Rome.

Finally, in 1940 Poggi-Longostrevi published a book on sport medicine, where a chapter was dedicated to female sport.28 In the introduction, he again faced the problem of female athleticism, by emphasising the most advanced foreign studies (by Brandt, Droust, Duenter, Guggisberg, Merken Schesinger and Roung) as well as national ones (by Baglioni, Bolaffi, Nizza, Viziano, and especially by Cova), supporting women' sport.

In addition, Poggi-Longostrevi quoted a recent speech by Mussolini who praised the few Italian female athletes who, once married, had very soon become healthy mothers of healthy children. In his book Poggi-Longostrevi was clearly against any limitation on female sport, as "past experience 
demonstrated that most physical activities had been excluded through an excess of fear." 29

Italian women's education, he said, was traditional and far from the American promiscuous model, so much so that women could not be given a free hand in sport. Anyway, both from the moral and aesthetic points of view, there should be no further delay, as most sporting activities maintained femininity and modesty, and preserve grace and figure.

In addition, by following the example of harmonious and prolific women of primitive societies, who used a sort of natural athletics, Italian girls too would perfectly develop their abdominal muscles, favouring beauty and future maternity at the same time.

Poggi-Longostrevi also reported the positive opinion of the physician Professor Cova, warmly supporting outdoor physical activities for women, as they improved muscular energy, blood circulation, and the genital apparatus, with great benefit for a demographic increase of the population.

In the last part of his chapter, Poggi-Longostrevi pointed out that a selected team of Italian sportswomen had successfully participated in the Women's World Games of Prague in 1930, and more recently in the Berlin Olympics of 1936, but remarked that female athleticism was not sufficiently popular in the country.

He thought that both sporting activity and training would improve the intrinsic qualities of women, i. e. agility, ability, grace, keeping them in good health, and developing endurance in general, but naturally women should avoid unsuitable sports and should not emulate men's stress. In addition, women's physical activities, such as athletics, tennis, skiing, skating, golf, swimming, and basketball, should not be abandoned during the menstrual period, as in most cases the results were excellent, in terms of sporting achievement and genital health.

Poggi-Longostrevi terminated his chapter by displaying data on 10 Italian athletes involved in the Prague Games. Those data demonstrated that all athletes regularly practised their favourite sports during menstruation, and 9 out of 10 with good results. 


\section{1.4 Conclusion}

According to the fascist political programme of moulding the new Italian, and by means of a number of researches specifically applied to male sport, FIMS clearly supported the male practice of sporting activities at every level, so as to increase the health, strength and will of the race, and to produce budding champions. Naturally, FIMS physicians were aware of possible damage caused by an excess of sporting activities in the delicate periods of pre-puberty and adolescence but, once boys were grown up, they showed that they needed no protection at all.

Sport doctors advised young boys (9-12 years old) to confine themselves to swimming, wrestling, fast running (25-50 metres), and ball games. They also advised boys (13-16 years old) to focus on a gradual amount of games and athletics, where running had to be limited to 100-200 metres. Young men (17 years old onwards) could practice all sports freely, but at the beginning they were advised to avoid long distance running, so as to protect their heart and lungs. Once completely developed, the most robust and talented of these young sportsmen could become true champions. ${ }^{30}$

However, the specialist controversy over female athleticism that was going on in the first half of the Thirties demonstrates that FIMS was protective of women. FIMS physicians considered women a peculiar and delicate subject to be looked at with special attention and in a protective spirit, so as to preserve maternity, modesty and femininity.

Anyway, this problem was debated within the medical field, but did not involve the common people very much. On the other hand, people were aware of the intransigent hostility of the Church with regard to female sport. Among many hostile occurrences, one can cite the letter, sent by the Pope to the Vicar Cardinal, against the female gymnastics competition of Rome; 31 the severe censure of eugenic and sexual education supported by the regime, by Sant'Uffizio; 32 numerous moralistic articles such as the one published in L'Osservatore Romano. It was insinuated here that spectators watched women's sports in order "to admire the competitors' physique rather than their good form in the pure sporting sense". 33

To sum up, even if most physicians came out openly in favour of a moderate female athleticism, in the mid-Thirties they did not influence much the conservative trend of the country. On the contrary, Fascism completely 
supported the eugenic theory of race - and protected maternity exaggeratedly - emphasising its most backward side. According to this theory, the regime considered women "products and prisoners of their reproductive organs, from brain to legs." 34

In fact, once the revolutionary push that had characterised Fascism in its first years wore out, female athleticism was no longer encouraged. In those years, Fascism replaced the model of the dynamic and socially-emancipated woman of the Twenties by the model of the flourishing and prolific mother, in spite of prevailing medical opinion.

Mussolini and his hierarchy were persuaded of the intellectual and physical inferiority of females and suspected elsewhere that sport did not favour maternity, even if most physicians had demonstrated that this was only prejudice. The Regime reduced female athleticism until it became more and more a marginal event for talented sportswomen, who performed apart from ordinary sports amateurs.

Sports technicians of the regime had the task of selecting only the very talented young girls, who were then trained for competition. Mostly, their coaches were chosen among the most experienced, and generally were men from abroad. For example, at the beginning of her career the athlete Ondina Valla was trained by a certain Mr. Gaspar from Hungary, and then by Mr. Combstock from the USA, who was also in charge of training the Italian athletics team of both sexes for the Berlin Olympics of 1936.35 These coaches used training elite sportswomen and sportsmen in roughly the same way, but even at a lower level coaches did not care about gender too much. However, prevailing medical opinion supporting a certain number of sports did not find practical application with regard to those girls who were not chosen for competitive athletics. These girls had to practice a moderate, unexciting general gymnastics, led by ordinary physical education female teachers, where a perfect, simultaneous execution of the exercises counted more than technical content.

As a matter of fact, in the Thirties the main objective of the regime was to forge new and strong men by means of sporting activities, and healthy women by means of just basic physical education. This latter focused on eugenic, aesthetic, and moral achievements, such as providing strong and 
healthy children to please Fascism; grace and beauty to please men; modesty and composure to please the Catholic Church.

This appears clearly in Article 4 of the ONB Norms for Small Italians and Young Italians (see Chapter 5.2), in which it is said: "Female physical education has to focus on increasing the endurance of the body, and on increasing the aesthetic conformation of small and young girls, whilst every competitive, or even athletic, form is excluded, as well as any professional tendency which is not suitable to female disposition of the female body."36 Only at the end of the Thirties did the debate on female athleticism become a popular topic, as the competitive fascist State started considering it as an important way of displaying to the world that Italian women as a whole were not old-fashioned or weaker than foreign athletes and, what is more, their 'sportivisation' could really better the quality and number of their children, and increase womanly consensus to the fascist ideology.

Apart from the relatively good results of Italian female athletes at the 1930 World Games of Prague, and at the 1936 Olympics of Berlin, in the Thirties women's athleticism had not developed much, owing to the already cited prejudices and obstacles. Consequently, it became a subject of further scientific investigation and popularisation. As an example, in the abovequoted book of 1940, Poggi-Longostrevi presented scientific data collected on the occasion of the far-off Games at Prague (1930), trying to convince people that female athleticism was healthy and safe, even during menstruation.

In fact, after years of research, speeches, papers and books, Italian sport physicians had demonstrated abundantly that sport/eugenics/demography were not antithetical at all, but jointly could contribute to the political cause of developing the new Italian race. ${ }^{37}$ This notwithstanding, by the beginning of the Forties female athleticism still roused some suspicion of possible dangers to health, maternity and 'virilisation' of women, among many Italian families.

The question remains whether this was really a problem of Fascism or would the Italian physicians have written the same without living in a fascist nation? The same arguments against women, for instance, can be found in democratic England and the United States, and in Nazi Germany. It is 
therefore difficult to pinpoint to what extent Fascism influenced this argument. 


\subsection{Physical education and sport in school and university}

The physical and sporting education of Italian women had to adapt to the pedagogic goal pursued by the fascist school, and therefore to the feminine model that was suggested in those years. As institutions for sports medicine, (Chapter 5.1) hygiene and therapeutics, (Chapter 5.5) schools also favoured eugenics for the sake of 'Italic Descent' soundness, slowing down the development of women's sports in a nation that defined itself preeminently as 'athletic'.

Generally, the scholastic, extra-scholastic and academic educational institutions, influenced by old and new prejudices on the mental and physical abilities of women, hindered their emancipation, more or less openly. This can be inferred even from a somewhat cursory examination of the scholastic provisions, of the didactic programmes in force at the time, and from the type of gymnastic and sporting activities chosen for young women during those years.

\subsubsection{From Gentile's Law to Bottai's School Charter}

With the advent of Fascism, the project of rendering school a political institution serving the new ideology could not be entrusted to the men in power at the time, more prone to action than to theoretical considerations. Therefore it was decided that the project be passed to the philosopher Giovanni Gentile who, on 15 March 1923, in his capacity as Minister of Education, drafted the Scholastic Reform Law No. 684.

This law aimed for a difficult compromise between the previous cultures the liberal and the Catholic - and the new fascist culture that needed to create its own ruling elite, and at the same time 'fascistize' the Italian masses through the school system.

Actually Gentile's Law, then defined by Mussolini as "the greatest revolutionary act ventured by the fascist Government", 38 poorly came up to fascist expectations. Gentile also wanted the school system to form the future ruling class, through strict historical and philosophical studies in secondary school, which were attended only by members of the upper classes because of the tough selection and heavy burden they presented. 
Moreover, Gentile's Law did not suitably support the professional and technical formation of the lower classes in view of future employment, but exploited 'merit' as a primary value, stressing the selective and classoriented quality of studies.

Granting autonomy and recognition to private schools, which in Italy were traditionally mostly religious, Gentile's Law disappointed both the fascists, who could not easily control its programmes and activities, and the seculars, ideologically hostile to confessional schools. ${ }^{39}$

In short, Gentile's Law remained conservative because it continued the directives of the remote Casati Law of 1859 - though with concessions to religion - and did not adequately activate the process of 'fascistizing' the masses. It therefore underwent numerous alterations during the following fifteen years.

With the Concordat of 1929 , that substantially mollified relations between Fascism and the Catholic forces, fascist ideology with its myths and rituals was able to penetrate the Italian school to a greater extent.

The Ministry of Public Instruction became the Ministry of National Education, a more appropriate denomination for an institution that took on the duty-right of educating the population in the new ideology. Authoritarianism and hierarchy were strongly accentuated. In schools, 'State books' were imposed, answering to the new historical, political, economic and juridical requirements claimed from the time of the March to Rome.

Members of the teaching class, which as a whole seemed too conservative and unenthusiastic towards the new fascist mysticism, were subject to deportation for anti-fascist ideas, even if expressed in private.

Particularly, in 1929 teachers of primary and secondary schools were compelled to give up their cultural liberty by taking an oath of allegiance to Fascism. The following year university professors as well were forced to take such an oath: of 1,225 teachers, only a dozen refused to do so. Moreover, the presence of women teachers in the school system was regulated and reduced at the end of the Twenties. (Chapter 4.2)

Gentile himself was a fervent anti-feminist. Since 1919, he had opposed women's teaching, fearing they would invade the field of education. According to Gentile, women did not possess, and would never possess, 
the "originality of thought, nor that iron spiritual vigour, that constitute superior, intellectual and moral forces of humanity and that must be the pillars of the school aimed at forming the superior spirit of the country." 40 Despite these ideas being widely shared, the percentage of women going to school grew during Fascism. Illiteracy, affecting about half of the female population in 1911, was reduced to $24 \%$ in 1931 . Yet, during the fascist period the number of boys in primary school was steadily double the number of girls. For example, in 1926 about 3,634,556 boys and 1,736,420 girls were counted; in 1931 respectively 4,761,690 and 2,266,333; in 1940 the ratio was 5,213,004 and 2,504,232.41

In 1901, junior secondary school was attended by about $28 \%$ of males and $23 \%$ of females between the ages of 10 and 14, but in 1931, this percentage grew to $65 \%$ for males and $53 \%$ for females.

As for senior secondary schools, in 1931 females were definitely at a disadvantage because they made up 25-30\% of the 379,000 enrolled. These last data, if compared with the limited number of registered pupils in secondary schools in 1901 (91,991 total students), show a growth percentage of $400 \%$ in only twenty years. 42 (The number of females enrolled in school in 1901 is not inferable from the statistic data in our possession.)

Nevertheless, during Fascism the number of dropouts before the conclusion of primary and secondary school was higher among females. Among the possible reasons for this withdrawal was lack of confidence in the intellectual potential of females by the school, the family, and society, as well as the knowledge that at the end of schooling employment possibilities would be strongly affected by maternity and family. 43

In 1924 Gentile's philosophy inspired the creation of a 'special' school for girls, the female Lyceum, where they studied a little of everything, from humanistic subjects to arts, to traditionally 'feminine' household activities. This school, counting very few students and mostly girls from the upper classes, invoked the indignation of most emancipated women and closed down after only four years. 44

Gentile's Law raised criticisms from various sides and from Mussolini himself, who had wanted and praised it; on 18 March of 1931, he declared 
to the Council of Ministries that it had been: "a mistake due to the times and to the forma mentis of the former minister". 45

After about fifteen years of mending and refining, on 19 January 1939 the Minister of National Education, Giuseppe Bottai, proposed a scholastic 'renovation' to the Grand Council - The School Charter - that was presented as a sort of continuation of Gentile's Law. Actually, it represented the soundest attempt to 'fascistize' the school system according to the ideological choices of the time.

In the 29 Statements of the School Charter, a general emphasis on militaristic culture and on indoctrination of the young transpires quite clearly. In fact, it was specified that the goal of education should be moral and cultural formation, as well as political and military training; furthermore, the scholastic obligation - meant as a social service - was to be continued until the age of 21 even by those who did not complete their studies, at the Juvenile Fasci of Combat and at the Italian Littorio Youth- GIL.

Regarding the problem of the Jews, who had been hit with racial laws, in his School Charter Bottai commented: "The Jews will have their school, within the State; the Italians will have theirs. That is all."46

In conclusion, in the School Charter the secondary role of women was again emphasized, as opposed to the superiority of male intellect.

Bottai proposed a clear-cut distinction between female and male education, the former aimed at preparing for the notable role of family matron. In fact, Statement 21 claimed: "The destiny and social mission of women, distinct in fascist life, are based on different and special Institutes of Education. The transformation of mixed schools is to be carried out according to the definition of the new 'work of women' in the co-operative order. The feminine order consists of a Feminine Institute, of three years, which receives girls from Middle School, and a Magistery for all the girls who graduate from the Feminine Institute. These Institutes spiritually prepare females for managing the household, and teaching in pre-schools." 47

A significant example of how young women were educated at the time is represented by the model composition Quando indosso la mia divisa di Piccola Italiana penso ai miei doveri di donna Italiana [When I wear my uniform of a Small Italian I think of my duties as an Italian woman]: on 9 December 1939 a girl in elementary school wrote: 
"I am a Small Italian. ... I wear my Small Italian uniform when I have to go to the parades. When I wear it, I feel in my heart a great love for Italy, deep honour for my country. ... Even when I am a woman I will wear my uniform. Italian women must imitate ancient Roman women. They stayed home to raise their children and educate them. They wove cloth and they cleaned the house. We should follow their example, stay at home and clean, wash and cook. These are the duties of a real Italian woman."48

In conclusion, the 1939 School Charter offered a strong theoretical backup to the anti-feminism, militarism and racism of those years, but wartime events did not permit their practical realization.

In the Italian Social Republic of 1943-1945, the Minister of National Education Carlo Alberto Biggini's circulars were still reminiscent of the spirit of the old Gentile reform, recanting the Statements of the 'traitor' Bottai.

Note that the 'Bottai treason' was carried out, with the co-operation of other hierarchy Commanders, on the occasion of the famous meeting of the Grand Council held on 24 April 1943, in which the majority voted (19 in favour, 7 opposed, 1 abstained) against the regime, thus causing the defeat of the Duce.

\subsubsection{Physical activities in extra-scholastic institutions (1923-1937)}

As for the specific problem of physical education in Italian schools, a first solution was suggested in the second half of the Nineteenth Century. In fact, educational gymnastics had become a mandatory course in Italian male and female schools, and in 1909, with Daneo's Law, a serious attempt at modernizing its programmes and opening it up to sports and games was carried out. (Chapter 3.2)

Yet, the approach of the First World War and the hostility of the more conservative physical education teachers did not favour the implementation of that law. On the contrary, the war accentuated the pre-existent, endemic deficiency of teachers and gymnasia, because many of the former were lost on the warfront and some scholastic buildings were damaged. Moreover, in the immediate postwar period, an economic, political and social crisis of vast proportions entirely mobilized the powers in force at the time. 
The problems that scholastic physical education had had for years were once again set aside. The debate among the experts in this field progressed, as they divided into many currents of thought offering different solutions to revitalize Italian physical education.

Giuseppe Monti, follower of Baumann and notable director of Turin's Institute of Magistery for the training of female physical education teachers, stated that discipline had to remain at the heart of the school system, as an integral part of the educative progress.

Others, such as General Luigi Gasparotto, wanted it to be committed to the victorious army, while a third line of thought, headed by Romano Guerra, at the time director of Rome's Institute of Magistery, claimed that physical education should be separated from the conservatism of the Italian school system. For Guerra this new physical education, inspired by the Swedish scientific method and by the English sport policy had to be modern in organization and self-governed; in other words, it had to remain outside the scope of schools.

In those years, male physical education teachers were trained in Rome's Institute of Magistery, while female teachers trained in Turin and Naples, overcoming the prejudices of those who still believed that motor activities and sports were exclusively male. In fact, in 1921, among the students of the Institute of Magistery, about $42 \%$ were women, against a paltry $6 \%$ in 1911.49

In obvious contrast to Gentile's pedagogic doctrine, which believed in the educational process and in physical education as part of spiritual education, his 1923 law fully backed Guerra's proposal. Consequently, physical education left scholastic institutions, teachers were disbanded and the Institutes of Magistery in Rome, Turin, and Naples were closed down.

As for the students, Gentile's Law literally stated that: "Pupils of all public and officially recognized middle schools affiliated with the Ministry of Education, should perform their physical education courses, in case of need, at the gymnastics and sport clubs designated by the National Body." 50 Gentile's Reform freed municipalities and districts of the burden of providing gymnasiums and sports grounds, a task that was passed on to the Ente Nazionale per l'Educazione Fisica [National Physical Education Body]- ENEF. Actually this body, which should have improved physical 
and sports education, was a failure mostly due to lack of economic and organizational support, and of methodological and operative clarity.

Teachers were now paid from taxes imposed on the students and, after the suppression of the Institutes of Magistery, no new physical educators could be trained.

Nor could ENEF resolve, within itself, the unbiased difficulty of controlling the activities of sport clubs scattered throughout the national territory that should have assisted ENEF in organizing sport activities for youngsters in secondary schools.

After four years of vain attempts entrusted to three different managements, the Council of Ministers decreed, on 12 October 1927, that the competencies of ENEF be passed to the extra-scholastic institution of the National Balilla Body- ONB.

ENEF was suppressed by Royal Decree No. 2341 of 20 November 1927 and, with the same decree, ONB was given the task of dealing with "the physical education of students in public elementary schools" that Gentile's Law had neglected.

However, the area of primary school could never be suitably developed owing to lack of funds; on 9 August 1929 by Royal Decree Law No. 1594, ONB was awarded sole guidance and surveillance of physical education in primary schools, which remained entrusted to the goodwill and availability of teachers.

The issue of controlling existing sport clubs was quickly solved. Starting on 2 March 1927, those that had not spontaneously broken up were required to merge into 32 national federations, ${ }^{51}$ that in turn depended on CONI. This greatly 'fascistized' body, largely strengthened in its institutional tasks, was completely in the hands of the National Fascist Party- PNF.

Thanks to attempts to successfully carry out the Concordat between Church and State (Chapter 1.2), Catholic sport associations could still survive for a few more years; in September 1931, all the gymnastics and sports activities organized outside ONB were strictly prohibited. ${ }^{52}$ From then on ONB became the only, absolute source of youngsters' sports activities. 
Through ONB, Fascism not only tried to remedy ENEF failure in physical and sports education and in the military formation of school-age youths, but it also aimed for an important goal that Gentile's Law had missed: moulding Italian students, from primary school onward, to the principles of aesthetics and to the fascist style. (Chapters 2.3 and 5.7.)

Besides this, ONB also devoted itself to spreading those principles among school-age youngsters that were not enrolled in school, and to continuing the social assistance that the National Maternity and Infancy Body-ONMI was conducting, favouring the health of younger mothers and children. (Chapter 5.5.)

Established with Law No. 2247 of 3 April 1926, ONB was set the task of "assistance and physical and moral education of the young" (Art. 1), to which "minors under 18 years of both sexes" had a right (Art. 2). The following Article 3 specified that "especially training and preparation of youngsters for military life" would be pursued. ${ }^{53}$

Among the most urgent focuses of ONB was that of creating new schools for the training of physical education teachers, since the 1923 Law had suppressed the former Institutes of Magistery; the project was 'fast-tracked' for male teachers who, starting in 1928, could enjoy their Accademia Nazionale di Educazione Fisica [National Academy for Physical Education] of Farnesina in Rome, while female teachers had to wait until 1932. (Chapter 5.3)

The idea of a totalitarian institution such as ONB, that involved youngsters of all social classes - from students to workers - was from Mussolini himself, who had then entrusted its implementation to Renato Ricci.

Ricci was inspired by pre-existing fascist youth structures, such as the Inspectorate of Balilla organized by the PNF management, and the Juvenile Fascist Vanguard directed by the General Headquarters of the Milizia Volontaria per la Sicurezza Nazionale [Voluntary Militia for National Security]- MVSN.

Moreover, Ricci was inspired by other youth associations operating in Europe and America, by the Scouting associations operating in Italy in the first decade of the century, and by the Federazione delle Associazioni Sportive Cattoliche Italiane [Federation of Italian Catholic Sport Associations]- FASCI, founded in far-off 1906.54 
We will discover shortly how ONB female activities were organized.

\subsubsection{Female children's education from the Feminine Fasci to the ONB}

During the first years of the Twenties, the most emancipated women of the middle classes, and some of those working and living in the more industrialized regions applied themselves to the practice of some sports, particularly track and field, tennis and gymnastics which men considered more suitable for the 'weaker' sex.

They lived this sparkling postwar period on the same level as men, at a time when intellectual activism and physical dynamism were an expression of change and modernization. But while in the male range these values were widely accepted, in the female, the fact that the same values advertised in the whole country could have dangerously 'virilized' Italian women scared many.

The ENEF programmes of female physical education were the result of these fears. In fact, during its short life, ENEF pursued, for females, a completely different physical education programme from that of males, basing it on grace, elasticity and aesthetics, while it hindered the practice of sports to avoid the danger that women would want to imitate men. 55

With ENEF out of the picture and backed by Article 2 of the aforementioned institutional law, ONB should have taken over the scholastic and extra-scholastic motor activities of both sexes from its creation. In other words, ONB, for a number of years, was busy reorganizing only the male area, leaving the female entirely in the hands of the Fasci Femminili [Feminine Fasci].

The Feminine Fasci, that had enthusiastically applied themselves since 1921 to the organization of physical education and to the assistance of female youth, passed to the direct supervision of ONB in 1925. Girls from 8 to 14 years of age were called Piccole Italiane [Small Italians], while the older ones, from 14 to 18 years, were the Giovani Italiane [Young Italians].

It would be appropriate to stress that in those years the Feminine Fasci were not the only ones concerning themselves with the extra-scholastic organization of motor and recreational activities for young women.

In fact, since 1923, Forza e Grazia [Strength and Grace], a movement in favour of female gymnastics and sports activities run by the Gioventù 
Femminile di Azione Cattolica [Feminine Youth of Catholic Action], was also operational. Strength and Grace had subdivisions in Milan, Cuneo and Acireale, but was active for only five years. In April 1928, as had happened to the Scout movement, ${ }^{56}$ it was forced to break up to conform to the directives of the regime. ${ }^{57}$

In 1925, a paper, the Rassegna Femminile Italiana, was founded to advertise activities of the Feminine Fasci. Since its first issue, it clarified the subordinate role of fascist women. In fact, it stated that: "Men make the laws, women the customs. We do not write poems ... we only talk of mothers and not of Spartan mothers, too conventional and academic. We are talking about the Saintly Italian Mothers who blessed their children departing for war and waited to cry later. ... Reestablishing women in their reign (the home!) will give women back their mission ..."58

The young recruits of the Feminine Fasci, directed at the time by Elisa Mayer Rizzioli, (Chapter 4.1) actually followed a programme that better satisfied the tastes of upper-middle class ladies rather than the expectations of common young women. In fact, it was centred on recital competitions, domestic science, gymnastics, "fun get-togethers and instructive field-trips, sports and singing". 59

The principles to which those enlisted in the Feminine Fascis had to comply were 8:

1. Fulfill the duties of daughter, sister, scholar, and friend with kindness and happiness, even if the task is sometimes tiring.

2. Serve the country as the greatest Mother of all Italians.

3. Love the Duce who has made the Country stronger and greater.

4. Happily obey superiors.

5. Have the courage to oppose anyone who suggests evil and ridicules honesty.

6. Educate the body to overcome physical strain and the soul to fear no pain.

7. Avoid futile vanity and love beautiful things.

8. Love work: it is life and harmony. ${ }^{60}$ 
Statistical data reveal that in 1926 the number enlisted in the Feminine Fasci was 37,000 Small Italians (35,000) and Young Italians (2,000). ${ }^{61}$ (In addition, there were also the Giovani Fasciste [Young Fascists], young women between the ages of 18 and 21, for which, though, we have no figures.)

In the following year, 1927, 128,000 and 19,321 units existed;62 nevertheless, such growth was deemed insufficient, and an institutional turnover was advised at Ricci's suggestion.

So it was, in 1929, that the Feminine Fasci officially left the arena of youth supervised by ONB and by its leader, devoting themselves to the Young Fascists and to working women enrolled in the Spare-Time National BodyOND.

In 1929, 464,453 enlisted 364,300 Small Italians and 100,153 Young Italians; after an effective advertising campaign carried out by ONB, the number of enrolled women reached the substantial figure of 741,302 units in 19311932.63

On a comparative note, the l'Unione Femminile Cattolica Italiana [Italian Feminine Catholic Association], founded in 1908, numbered about 160,000 in 1925 and 250,000 in 1931.64

\subsubsection{Small Italians and Young Italians of ONB}

Since its creation in 1926 up to its transfer to GIL in 1937, ONB was always chaired by Renato Ricci who, in 1929, also took control of the Undersecretaryship for Physical and Juvenile Education under the Ministry of National Education.

Through this office, Ricci reopened the connection - interrupted by Gentile's Law in 1923 - between Italian schools and physical education; at the same time, he safeguarded the autonomy of his actions from excessive intrusiveness of both CONI and the Party. ${ }^{65}$

The approach to the school system and the distance from PNF probably helped the spread of scholastic and extra-scholastic physical education, now a monopoly of ONB, opposing a precocious 'sportivization' of youth. In 1930, an official publication reminded people that: 
a) According to the 1928 Sports Charter, athletic training of youngsters up to 17 years of age shall come exclusively under ONB.

b) For specialized sports CONI may supervise the training of minors up to 18 years of age only if enlisted in ONB.

c) CONI may not, in any way, be in charge of youngsters under the age of 14 even if enlisted in ONB.

d) Only the ONB shall organize or authorize gymnastics and sport festivals in Italian schools. ${ }^{66}$

Under Ricci's leadership, ONB paid special attention to the harmonious psycho-physical development of children and youths of both sexes, as well as to 'soldierly marches' and to the preparation of collective military displays.

Motor activities, mindful of auxologic laws and aimed at strengthening health, were carried out in new gymnasia, swimming pools and on sports grounds built within a few years in the main cities and wherever else possible.

In 1928, 502 sporting facilities existed in the whole country, while by 1933 the number had increased to 4,199.67 It is not possible to know with certainty how many of these facilities were actually new and of good quality, and how many were just hastened renovations of unused equipment.

Under ONB pressure, the number of pupils who took physical education classes increased as well. In 1928, there were about 220,000 students, while in 1933, there were 324,000 . To this last number, referring to public schools, we must add another 110,000 students attending private schools in the same year. 68

In 1933, ONB had, among its enlisted, 1,952,597 Balilla; 1,637,689 Piccole Italiane; 535,974 Avanguardisti; 200,971 Giovani Italiane. In 1928, only 166 teachers were qualified to teach physical education, but they had risen to 638 in 1933.69

The remaining teachers were recruited among elementary school teachers and other qualified professionals with expertise in physical education, and at the same time were supporters of the fascist 'credo'.

Such teachers could easily operate political control inside the school, as could the recently-appointed teachers. The latter, and the new principals, 
were preferably chosen from those who had been enlisted in PNF for at least five years, as had been determined by the Grand Council of Fascism at the beginning of 1930 .

In these conditions, teachers with higher seniority who did not abide by 'orthodox' behavior were easily noticed, so they usually acted as champions of Fascism, at least formally, in order to keep their jobs.

As for the young students of both sexes who enrolled in ONB, they received not only special benefits and assistance, but also an instruction booklet that, with the use of simple language and captivating images, told the story, the merits and the achievements of Fascism, at the same time precisely listing the numerous duties of ONB members towards the Fatherland, religion and family.

Commitment to ONB did not imply a lessening of scholastic duties. Certainly a high grade in physical education was positively taken into account, though it did not strongly affect annual advancement in a school which, as has already been stated, Gentile's Reform had rendered more strict and selective.

In regard to the technical content of physical education practiced by ONB, it must be said that under Ricci's management, as opposed to sport competitiveness and in favour of educative gymnastics, the ONB promoted the athletic, recreational, pre-sport and sport angles recommended by Eugenio Ferrauto.

This expert, a follower of Baumann and Guerra and at the same time an admirer of Mosso, supported Ricci's work in his capacity as head of the Gymnastics and Sports Central Service of ONB. His group was watchful of the distinct necessities of different ages and sexes and reserved ample room for traditional gymnastics, marching evolutions and group choreographies. Nor did Ferrauto neglect sports, though he regarded them as primarily male.

Ferrauto's programmes were excellent but many never took effect. Both the number of teachers and the financial means were inadequate to spread these programmes in detail around the country.

In addition to this, a large portion of the money assigned to the ONB was spent by Ricci to create one monumental sport complex, the Mussolini Forum in Rome, with stadia, swimming pools, sports grounds, gardens, 
and fountains as a symbol of the political commitment of the regime to promote sport among the young. ${ }^{70}$

Midway through the Thirties, ONB widened its range of action, enlisting children from birth to 8 years of age as Children of the She-Wolf. In this regard, in 1935 a doctor published a book promoting gymnastics for infants! $! 1$

In those years, ONB gathered much praise from abroad. Nazi Germany was not the only one to be inspired by the structure of ONB for the youth organization named Hitler Youth;72 also the Englishman Robert BadenPowell, founder of Scouting, favourably judged the work of ONB in the spring of 1933; actually his statement, which was made for political opportunism, was widely recanted later on. ${ }^{73}$

As for the female division in this specific instance, during the Thirties given the due consent of whoever had parental authority - girls and young women were received by ONB as Small Italians from 8 to 14 years of age and as Young Italians from 14 to 18 years.

The daughters of emigrants or of those residing in colonies could join the Gruppi Giovanili Fascisti [Fascist Juvenile Groups] as Small Italians, but in this case, their age went from 8 to 16 years.

Upon receiving their identification card and instruction booklet, the enlisted had to take a solemn oath, also taken by males: "In the name of God and Italy, I swear to carry out the orders of the Duce and to serve the Cause of the Fascist Revolution with all my strength and, if necessary, with my blood."74

The first programmatic regulations were outlined in the 39 articles of a pamphlet, edited by the NBB, but they were later extended and published with the title Norme programmatiche e regolamentari per le organizzazioni delle "Piccole e Giovani Italiane".75

These new rules, distributed to the district managers of ONB, were divided into 128 articles. They accurately specified the tasks of ONB regarding the training of young females in civic and domestic education, fascist culture and physical education.

More specifically they stated that: "Duty of ONB, through the organizations of Small and Young Italians, is that of preparing the new female generations, by the principles of the fascist doctrine" (Art. 1); "The goal set in the 
previous Article must be reached by instilling moral education and culture, as well as social assistance in all girls and young women, not necessarily belonging to the school population, through a methodical and pre-arranged action in physical education" (Art. 2); "Female physical education must aim at elevating the organism's resistance power and at improving aesthetic conformation of girls and young women, refraining from any form of competitiveness or athleticism as well as any tendency not fitting to female nature and body ..." (Art.4).

Obviously, this last clarification on the non-competitive nature of female motor activities accorded to what sports medicine stated, it being very cautious on the subject of sports for women and trying to preserve traditional Latin femininity. (Chapter 5.1)

In a contradictory fashion, for the most part female physical education hardly differed from its male counterpart, because it proposed the same army-style exercises - discipline, formation and marching - aimed at stimulating the virile and warrior spirit of citizens.

The Norme programmatiche e regolamentari per le organizzazioni delle "Piccole e Giovani Italiane" also specified that: "In moral, political, civil and religious education, special attention must be paid to infusing a deep sense of duty and responsibility, in order to nurture the perfect fascist woman, conscious of the tasks reserved to her and in spiritual unison with the Regime. Girls and young women must therefore be educated to love Religion, their Country and Family, to respect sound traditions, to be faithful to Fascism." (Art. 5); "Girls and young women must be prepared to worthily perform their duties as wives and mothers: essential to young women is to prepare for organizing and governing the household, raising children, assisting family members should the need ever arise." (Art. 7).

Other articles established how the offices for feminine formation within ONB district committees should be organized (Art. 14-17), and how activity at the House of the Young Italian was to be created.

This House, appointed to develop "cultural, physical, professional and domestic programmes", was supposed to be equipped with an infirmary, a conference room, a laboratory, a library, study halls, a kitchen for lessons in domestic science, a gymnasium, a swimming pool and sports grounds (Art. 18-19). 
The following Article 20, perhaps after realizing that the idea of creating Houses of the Young Italian across the country was unattainable due to a shortage of financial resources, recommended finding any suitable establishments, separate from those intended for ONB males, and required them to have a conference room and a kitchen.

The Small and Young Italians were divided into Groups. A Group was composed of 3, 4 or 5 Centurie [Centuries], every Century of 3 Manipoli [Maniples], every Maniple of 3 Squadre [Squads] and every Squad of 9 members (Art. 24). Each of these formations was managed by a leader, chosen among the enlisted (Art. 25). Each Group was provided with a Labaro [Labarum], and each Century with a Fiamma [Flame].

It was a military formation similar in structure to the Balilla and Avanguardisti [Vanguardist] boys. In appellation, both recalled the ancient Roman army in accord with a precise propagandistic choice of Fascism that, appealing to Roman greatness, proclaimed the Italian people legitimate heirs to that glorious line.

The Piccole Italiane and Giovani Italiane [Small Italians and Young Italians], as well as their leaders, were required to perform the Roman salute and to wear regulation uniforms - upon which badges and rankings were shown - during meetings, ceremonies and parades and during gymnastics and sports activities (Art. 27-34).

Uniforms, a simple model designed by the famous painter Mario Pompei, were not free but were bought by the families, who also had to pay an annual fee for the ONB membership card.

Disciplinary shortcomings of the enlisted were punished with oral and written reprimands, suspensions and, in more serious cases, expulsion from ONB; nevertheless, it was recommended that punishments take into account the "distinctive sensitivity of girls and young women" and be aimed at "correcting and educating" (Art. 38).

ONB leaders (Art. 42-44) were voluntary members of the PNF, usually primary and secondary school teachers or physical education teachers. People carrying a secondary school diploma and armed with goodwill who had little to do with the school system were also candidates. 
These leaders benefited from a certain power inside the scholastic institution and from prestige in society. Their ages ranged from 18 to 45, in accord with one of the most advertised fascist myths: youth.

Leaders were also organized according to a pyramidal hierarchical structure, always controlled by men. The male Central President of ONB checked on the work of male District Presidents who, in turn, watched over the coordinated activity of the female District Fiduciary and her substitute, the Vice-Fiduciary. Municipal, Rural, Fraction and Neighbourhood female Fiduciaries operated at an inferior level and, lowest of all were the female Head Group, Head Century and Head Maniple. All had precisely detailed duties (Art. 42-75).

In addition, annual training courses were organized for young women who aspired to the role of Head Group and Head Century; they were required to pass a final examination to obtain their licence (Art 76-88).

Women involved in the ONB at the directive level were numerous. In 1936, for example, among Fiduciaries, Head Groups, Head Centuries, Head Maniples and Commanders of the Children of the She-Wolf, they were about 50,000; in the same year, male leaders were 65,000.76

In regard to motor activity, Article 92 stated that: "Every initiative regarding female physical education will be clearly and absolutely separated from that of the males. Tennis, basketball, volleyball palla rilanciata, volantino, palla ribattuta and tamburello (Italian traditional ball games), ice and rollerskating, rhythmic gymnastics, swimming, walking, hiking, pre-athleticism as a means of physical culture fitting to Young Italians, etc., will be the preferred exercises, according to the distinctive programmes, integrated according to necessary precautions, contained in the publication of the Central Presidency of the Balilla Body."

Many of these sports activities were practiced only in the richest cities where the right equipment was available. In small country towns, much was left to the goodwill of teachers and trainers and to young women's initiative and ability to adapt.

The official ONB physical education programmes, approved by the Ministry of National Education, 77 were different for the two sexes, except from the ages of 8 to 11 years, when all children performed "general corrective and recreational exercises of moderate intensity."78 
From 11 to 14 years, male adolescents were required to perform "moderate general formative, corrective, developmental and disciplinary exercises", while females had "moderate recreational, corrective, developmental and grace exercises."78

From 14 to 16 years of age, young males were busy with "elementary preathletic and practical training exercises"80, young women with "grace, developmental and disciplinary exercises of moderate intensity." 81

Lastly, from 16 to 18 years, males performed a completely different programme from females, centred on sports and pre-military training. It included "pre-athletic, athletic and practical training exercises." 82 Specifically, the male programme included track and field in the various disciplines of running, launching and jumping, gymnastics, fencing, canoeing, cycling, swimming, boxing, horse racing, hiking, target shooting, Greco-Roman wrestling, skiing, tennis, skating. In addition, for the younger ones, $15-20 \mathrm{~km}$ walks and topographic expeditions in the countryside were required.

Young women from 16 to 18 years, on the other hand, followed a programme of "easy rhythmic exercises, elementary developmental exercises in pre-athletic style, precise disciplinary and sports exercises."83 Athletic sports activities (where it was possible to hold them) were limited to javelin throwing, shot put, archery and running distances of up to $70 \mathrm{~m}$, while prescribed sports were volleyball, basketball and skating.

Reconsidering the Norme programmatiche e regolamentari per le organizzazioni delle "Piccole e Giovani Italiane", we learn that special courses had been set up for those enlisted needing physical education for medical and correctional reasons; small non-competitive athletic displays were held to strengthen willpower and to instil a healthy spirit of emulation; health resorts were organized for little girls (Art. 93-95).

Moreover, it was recommended that leaders were to boost "women's sense of dignity, illustrating their mission in society and the duties they faced in the name of the Fascist Country" (Art. 98), and " to illustrate the ethical goals of the Balilla Body, arousing in young women the desire of belonging to it" (Art. 99).

The last articles (101-127) concerned the formation of numerous courses in the different branches of ONB; they concerned religious education, fascist 
doctrine, general culture, art culture, such as music, drama, figurative, plastic and applied arts, and working activities, such as cutting and sewing, foreign languages, shorthand typing, bookbinding.

Courses in domestic science, child welfare, hygiene, assistance to the sick were warmly recommended and, for young women who lived in the countryside, specific courses in gardening, apiculture, horticulture and livestock husbandry were held.

Lastly, once again, there was a need for female activities within ONB, from ceremonies to meetings, to trips, to health resorts, to be completely distinct from the males', in order to avoid any kind of mixed gender groups; this was strongly stressed. (Art. 128)

Norme programmatiche e regolamentari per le organizzazioni delle "Piccole $e$ Giovani Italiane" are a faithful portrait of the feminine model proposed by Fascism in the Thirties. These young women, according to the intentions of Fascism, "should have gained a strong and harmonious body structure in preparation for maternity and a strong sense of morality to undergo any type of sacrifice."

As soldiers, they were trained in camaraderie, discipline and hierarchical subordination, living an emancipating experience, which, at the same time, was conservative of the traditional values of Latin femininity.

Small Italians and Young Italians were encouraged to break traditions, leave home and attend ONB courses. During school vacations, they were invited to go on camping trips and to the colonies.

In general, the programmes recommended physical activities, political formation and social commitment; however, the optimistic theoretical statements never found complete implementation in everyday reality.

Teachers, gymnasia, equipment, funds (what was raised was used to modernize the more important male section) and family support were greatly lacking. Permitting young daughters - especially adolescents - to leave home to attend the ONB extra-scholastic activities was unthinkable for the more traditional families.

These families, attentive guardians of feminine morality, were not prepared to hand over control of their daughters to others, even though the ONB activities basically prepared girls for the traditional role of the busy mother and the good cook. To back this up, the aforementioned Article 20 must 
be recalled: it required the ONB House of the Young Italian to be provided with a conference room and a kitchen!

Also the ONB courses in work preparation, apparently in favour of female emancipation, if well examined, closely followed tradition. These courses offered work opportunities to women belonging to lower social classes, needy of an occupation, but were centered on the usual subordinate and/or low paying activities "fit for women", as secretary, seamstress, artisan.

Regardless of ONB relative success, and despite the female programmes posing many general limitations to full insertion of women in society, it must be recognized that the State, through ONB, was considering social integration of the female population for the first time in Italian history.

Prior to the fascist period, young women left home only to attend school or work in fields and factories, while the remaining time was dedicated to helping mothers with household chores and child raising.

Prestigious professions, diversions, cultural interests, politics, sports, were all activities reserved to men. In these fields, only a small female elite surfaced, favoured by family status, census and/or special abilities.

Instead, during the fascist years, all girls were encouraged to leave home in order to live, through ONB, a collective experience, even if following the rules of the fascist doctrine.

It is hard to fully understand the extent of such an experience because of the lack of confrontation with similar extra-scholastic institutions alien to Fascism. As said earlier, in the second half of the Twenties, other youth associations had been suppressed by law, while ONB obtained total control over physical education, diversions and interests of the entire (male and female) new generation.

Around the middle of the Thirties, to further boost enrolments, ONB started directly contacting new parents. They received formal congratulations by mail, but also a form to enlist newborns in ONB with an invitation to pay the fee!

Being enrolled in $\mathrm{ONB}$, or any other fascist organization, was not mandatory, but it was advisable. School age youngsters usually subscribed to $\mathrm{ONB}$, prompted by principals and teachers, by the desire of wearing a uniform or by the pure spirit of emulation. 
Since, as previously mentioned, socialist, Catholic and Scout youth associations had been suppressed, youngsters could follow their national calling for competing and socializing with their peers, outside the family, only through ONB.

Fascist ideology, with its rites and symbols, spoke to the imagination of ONB members, conquering even the youngest. With the passing of time and the tempering of a critical spirit, enthusiasm could fail; nevertheless, many young adults, either out of habit, opportunism or ideological affinity, usually enrolled in other PNF organizations, from which they received advantages and concessions.

The most active and able among the enlisted could aim at a real job in these organizations, especially if backed up by an influential figure of the time. Having been a member of ONB as a youth and owning a membership card to the PNF as an adult, helped any kind of career, especially a political one. Yet, excluding some state-employed categories such as teachers, there was no obligation of enrolment whatsoever. Obviously, being careful, not expressing critical attitudes towards Fascism and not openly displaying one's own political ideas if in contrast to the official ones, were all necessary actions.

Nevertheless, those who did not own membership cards were not labeled as real anti-fascists by the regime; they were seen more as lazy bourgeois, neutralists or, at worse, defeatists.

Concerning gymnastics and sports activities, enlistment in ONB - and from 1937 on in GIL - was compulsory. Enlisted members of both sexes could participate in performances and parades: with perfectly synchronized gymnastics movements, they had to show all Italians the positive effects that sports policies had on the new fascist youth.

\subsubsection{Physical education and sport under GIL (1937-1943)}

Halfway through the Thirties, the idea grew strong that sports victories, with records and idols, were the most effective means to show the world the greatness of fascist Italy.

It was therefore necessary to start raising future sport champions from a tender age, as CONI stated. ${ }^{84}$ But these ideas were in contrast to Ricci's ONB programmes. The latter - as mentioned before - was based on youth 
sport and physical education, but considered competitiveness dangerous, if instilled before the age of 18 .

Conflicts with the PNF followed, up to the loss of Mussolini's support of Renato Ricci, who had always operated with a certain independence. ${ }^{85}$ Consequently, with the Royal Legislative Decree of 27 October 1937, ONB was suppressed and all competencies regarding physical, sports, political and military education of the young were taken over by GIL.

This institution was created by the same Decree that passed into Law, No. 2566, on 23 December 1937. Since then, enrolment in GIL was mandatory, at least formally.

Article 1 of this Law stated that: "GIL, a unitary and totalitarian organization of young forces of the fascist regime, is established within the PNF, under direct supervision of the Secretary of the Fascist National Party (...). Youngsters of both sexes, between the ages of 6 and 21, belong to it and are assigned to the subdivisions of male Young Fascists, Vanguardists, Balilla, Children of the She-Wolf, and female Small Italians, Young Italians, Young Fascists, Children of the She-Wolf."

Article 5 stated some of the fundamental duties of GIL such as: "spiritual, sport and pre-military training; teaching of physical education in elementary and middle schools according to the programmes issued by GIL in agreement with the Minister of National Education; the creation and functioning of courses, schools, colleges, academies pertaining to the goals of GIL; assistance enacted through fields, health resorts and scholastic patronage or through other means provided by the PNF Secretary, Minister Secretary of State, Commanding General; the organization of trips and cruises."

The PNF Secretary at the time was a member of the fascist hierarchy, Achille Starace, who was also President of CONI and, by law, director of the new GIL organization.

In 1935, Starace had already instituted the 'Fascist Saturday', as opposed to the English weekend, to massively spread the 'fascist style' through activities of a political, militaristic, cultural and sports nature.86 Through GIL, Starace could now finally carry out the project of centralizing all youth activities in his and the Party's hands, turning Italians into a nation of determined sportsmen, this time with the priceless support of CONI. 
For this purpose, in 1938, Starace issued dispositions guaranteeing that all sport programmes of GIL be established in agreement and coordinated by both GIL and CONI. 87

To fully sustain the task of student 'fascistization' and 'sportivization', in 1939, the Minister of National Education reasserted the important role that GIL covered in the school system. Through the IV Declaration of Bottai's School Charter, the value of education bestowed by GIL was emphasized. The exercise technique had to aim "at obtaining harmony of development, validity of training, moral elevation, self-confidence, high sense of discipline and duty."88

Yet, despite the continuous services of proselytism conducted by GIL, the number of enlisted subjects was higher in the North than in the South and decreased with age. 89

The tendency was even more evident as years went by because, even though born and raised during Fascism, the young believed less and less in the social revolution and in the ideals of the Duce, finding GIL choreographic rituals and celebratory parades, pompous and meaningless. ${ }^{90}$ As an example, in 1937, GIL inherited 2,478,768 Balilla, 960,118 Vanguardists, 2,130,350 Small Italians and 483,145 Young Italians from ONB, but towards the end of 1941, GIL had only 1,865,290 Balilla, 988,733 Vanguardists, 1,759,625 Small Italians and 454,204 Young Italians. In conclusion, after four years of efforts and propaganda, the number of Vanguardists and Young Italians enlisted in GIL had remained about the same, while that of Balilla and Small Italians had visibly decreased. Also in the new section Giovani Fascisti [Young Fascists] from 18 to 21 years, enrolment numbers were not satisfactory, since in 1941 they showed only 1,313,900 male Young Fascists and 527,112 female Young Fascists. ${ }^{91}$

Other than numbers, the efforts made by the regime to 'fascistize' schoolage youngsters did not show expected results. As proof of this, it is noteworthy that among partisans in combat against fascists and their dangerous Nazi allies, about $85 \%$ were under the age of 22 and therefore educated in scholastic and extra-scholastic institutions of fascist faith, doctrine and aesthetics. 92

After 1937, a search for popular consensus occurred for the war-oriented political choices of the regime. The alliance with Germany and the desire to 
imitate its perfect organization, as well as the dream of arousing the admiration of the whole world thanks to sports achievements, further emphasized the phenomenon of champion-seeking and of turning sports into show business.

In those years, the competitive spirit of youngsters was underlined by GIL through the Ludi Juveniles [Juvenile Games] of arts and culture, reserved to students of secondary schools, and which included tests of sports of a paramilitary nature.

Following lively national propaganda that exalted the physical strength and moral courage of Mussolini's new Italians, all GIL members, from students to workers, were involved in spectacular displays organized jointly by GIL and CONI in the hope of discovering new sports talent.

The goal was to ensure the "control of sports disciplines for the training of future champions", to operate for "youth sport-perfecting, essential from an Olympic viewpoint, and for military preparation", to direct "the selected forces of fascist sports, not only in national competitions, but also in international ones, in order to once again claim the growing spiritual boldness, physical value and aggressive geniality of Mussolini's Italians."93 Towards the end of the Thirties, despite the usual prejudices and some antifeminist resurgence that still hindered female emancipation, the sports system received a great boost through an increase in gymnastics and sports competitions on a local, regional and national scale and of championships and international meets that saw Italian women compete with the best, and sometimes coming out on top. (Chapter .5.6)

\subsubsection{Physical education and sport in university}

During the first years of the fascist period nothing was done to promote sport in universities - not even for males - because it was considered an Anglo-Saxon custom, alien to Italian traditions. ${ }^{94}$

Nevertheless in 1920-1921, before Mussolini's government, a university elite of fascist faith created the Gruppi Universitari Fascisti [University Fascist Groups]- GUF on its own, while Catholic youth gathered in the Federazione Universitaria Cattolica Italiana [Italian Catholic University Federation]- FUCI. To complete university organizations, socialist-oriented and YMCA-associated groups were present as well. 
GUF of the time created the Comitato Olimpico Studentesco Italiano [Italian Students' Olympic Committee]- COSI, programming the Olimpiadi Nazionali Universitarie [University National Olympics] for April 1922 with competitions in sports, arts and literature. ${ }^{95}$

From 1923 to 1926, with Mussolini in power, GUF survived with much difficulty, because it lacked moral and financial support from the Party. But in December 1927, GUF was invited to draw up the first agreements with CONI on the massive sports campaign that was being carried out.

Lando Ferretti, at the time President of the CONI Board, carried out a thorough campaign in favour of university sports among members of the Party, urging them to "break down the bronze doors of universities in the name of Fascism and Sport" and to "create a Casa dello Studente [Student House] in every institute of higher instruction (...)."96

Playing on the nationalistic and imperialistic spirit advertised by the regime, Ferretti was able to convince the PNF managing members, claiming, for example, that: "whereas the English Colleges have prepared the basis for Britannic imperialism for centuries, our Student Houses will prepare the basis for Italian imperialism."97

The first positive outcomes were achieved towards the end of the Twenties at the National Sports Championships and later at the World University Championships where, according to Ferretti, Italian university students of GUF had become "athletes with a statue-like build, ... that lacked nothing compared to their Oxford, Cambridge, Harrow and Yale peers."98

The agreements between GUF and CONI were officially reconfirmed in December 1928, through the Sports Charter. Article 5 stated that: "University Groups will have to support all their activities through Federations or sports clubs, in full enforcement of the proceedings stipulated in the CONI-GUF pacts." 99

Therefore, GUF became officially dependant on CONI directed by Augusto Turati (1928-1930), by Iti Bacci (1930-1931), by Leandro Arpinati (19321933) and finally by Starace up to 1939.

In 1930, when the Fasci Giovanili di Combattimento [Juvenile Fasci of Combat] directed by PNF were created for young men between the ages of 18 and 21, the inclusion of GUF members in Ricci's ONB was requested, but that proposal was firmly refused. ${ }^{100}$ 
Every university sports and culture activity was in the hands of CONI, PNF and GUF operating jointly, and in the first months of 1931 an attempt to enrol high school students in GUF was made. ${ }^{101}$

This manoeuvre, organized without Ricci's knowledge, was not supported by Mussolini, who publicly denounced it in the Grand Council of 6 June 1931.102 On 29 May of the same year, Mussolini, in a telegram to the prefects, ordered the suppression of FUCI.

Lastly, in 1937, GUF was also absorbed by GIL, like every other Italian youth organization.

In 1934, GUF organized local intra-faculty competitions for the first time: the university Agonali Games; while on a national scale the Littoriali della Cultura e dello Sport [Littoriali of Culture and Sport] had been a reality since 1932.

This was the most important and most publicized university competition of the time. The complex ceremonial of the Littoriali was endowed with an oath of allegiance to Italy and Mussolini, brimming with sportive ardour and warlike spirit.

It stated: "I will fight to overcome every trial, to conquer every record. With strength in the contest, with knowledge in scientific assemblies, I will fight to win in the name of Italy. So I will fight, as the Duce orders: I swear!" 103

On an international level, GUF members were trained for the Campionati Mondiali Universitari [World University Championships], where they achieved good results.

The best GUF athletes were also selected for the Olympic Games where, in 1932 and 1936, important victories were obtained in Los Angeles and Berlin. 104

The first Littoriali were held in Bologna in 1932. To compete in the Littoriali, students had to be either enrolled in university or have graduated, but under the age of 28. A preliminary competition of target shooting was mandatory for every participant, in agreement with the militarization process of the time, after which every other competition ensued.

For the Littoriali of Sport held in Turin in 1933, female university students, who had started getting involved with GUF in 1931, were also summoned. These mixed Littoriali were an exceptional event never to be repeated 
during the Thirties, representing the completion of intense female mobilization campaign for physical activity carried out at the time.

The year before, ONB had officially inaugurated the courses of the prestigious Accademia Femminile Nazionale di Educazione Fisica [National Female Academy of Physical Education] in Orvieto, an efficient and modern structure that was the pride of ONB. (Chapter 5.3)

About 100 female GUF athletes competed in the aforementioned Turin Littoriali of 1933, in a limited number of athletic disciplines (swimming, basketball, track and field, tennis and fencing) gathered under the generic denomination of 'female games', ${ }^{105}$ but their presence, alongside the men's, caused both astonishment and bewilderment.

It is noteworthy that at the time, not only the most convinced Italian traditionalists, but also the Church of Rome and most sport physicians were against female competitive sports. ( Chapter 5.1) They all advised moderate physical activity in order to preserve the grace, composure and reserve of Italy's young women.

Towards the end of the Twenties, the Vatican had officially supported ONB female programmes, stating that: "(...) barring all excesses, eliminating every gymnastic form pertaining to male physical exercises, prohibiting coeducation, we gladly see Christian foundations being carried out in this very delicate section of public education: in other words, we see perfect harmony between the just concern for women's health and physical development, and the strict guarantees necessary to ensure their modesty and gentleness. The National Balilla Body, thus solving an issue largely debated by tradition, custom and good sense of our people, deserves the most sincere gratitude of Christian families."106

In fact, the Vatican had always been hostile to the presence of females on sports grounds, especially if in mixed groups. This firm opposition had already prevented the then director of CONI, Leandro Arpinati, from sending Italian female athletes to the 1932 Olympics held in Los Angeles, but the 1933 Littoriali of Turin once again raised the same troublesome issue. To prevent further disagreement, it was cautiously decided in future to confine the Littoriali only to males.

Under GIL, mass involvement in sport resulted in the creation of the female Littoriali, organized separately from males. Finally, in 1941, conformism 
and traditionalism having been demolished in the name of the superior fascist cause, university students of both sexes once again enacted the Littoriali of Culture and Sport.

It is important to point out that anybody could enrol in university even without being a member of fascist organizations, but they could not participate in any GUF cultural and sports activity without being affiliated to it.

As for the specific presence of female university students, this was quite scarce during Fascism. The enrolled formed a small elite coming from the higher, better-off social classes.

In the 1920-1921 academic year, about $18 \%$ of graduates were female, but the enrolled (about $17.4 \%$ of the total) attended courses directed at school teaching rather than the professions commonly considered unfit for female nature and ability. ${ }^{107}$

Often female students were mocked by their male colleagues and subjected to tasteless pranks, 108 as in tune with the chauvinist and 'goliardic' mentality of the time, and they were not usually encouraged by their parents to apply themselves to studies, as were males (Chapter 4.2). Consequently, in the 1936-1937 academic year a decrease in female enrolments, compared to 1920-1921, was reported: from $17.4 \%$, female students had become $16 \%$ of the total. 109

Nevertheless, at the beginning of the Forties, the general mobilization brought on by the war, produced positive effects for women. Not only could Italian women have access to jobs once monopolized by men (Chapter 4.3), but they also enrolled in great numbers in schools and universities.

In the 1941-1942 academic year, 22\% of the university population was female. ${ }^{110}$ These last data could be interpreted as the effect of abandonment by men then occupied by the war, but if the actual number of female graduates of those years is considered, the increase is still substantial. In fact, while in the 1936-1937 academic year, 1,929 women had graduated, in 1941-1942, the number had climbed to 3,012, with an effective increase of about $34 \% .111$

In conclusion, as was previously true of schools, women attained a certain space in universities as well during the fascist period. Next to the usual 
courses, available for an elite, the aforementioned National Female Academy of Physical Education in Orvieto was opened, as well as other universitylevel institutes directly organized by PNF. These institutes prepared women for secure and traditionally 'female jobs', like rural and pre-school teachers, social assistants and experts in domestic science. ${ }^{112}$

Towards the end of the Thirties and in the first years of the Forties, the rising presence of women in work and politics of the country, also favoured by men's war commitments, led to a general acceptance of a female presence in Italian society with favourable effects in culture, and in sport. 


\subsection{Training of physical education teachers}

By the end of the Twenties, the idea that a healthy physical and sporting education should be diffused not only at school but in society was widely shared by the fascist authorities, who assumed the task to convince people and bring their children to this activity.

As an example, in 1929, at Udine, the provincial head of ONB inaugurated the new scholastic year by saying: "Sport should be universalised, so as all children of any and every social class can usefully exercise. A healthy and diverting sports training should be given both to the child of a worker, who should be sometimes removed from its workshop or unhealthy house, and to the student of a wealthy family, who should be removed from his studies. This problem deals with societal morals as well."113

As has already been mentioned (Chapter 5.2), in those years there was a great lack of teachers qualified in physical education, to whom the task to train the body and forge people morally could be given, according to the cultural and ideological values of the fascist revolution.

The extra-scholastic ENEF institution had failed miserably not only in sporting organisation within the country, but also in the formation of staff. In truth, under General Grazioli's leadership, ENEF had organised a special university course to train physical education teachers in 1926, at Bologna, and similar initiatives were undertaken by other universities, but these experiments did not last long. ${ }^{114}$

In fact, in the following year the ONB, by assuming full control of juvenile physical education, urgently worked for the foundation of university courses to train secondary school students, according to Law Decree No. 2341 of 20 November 1927. Art. 8 of this Law said:" The Opera Nazionale Balilla (...) has been authorised to institute one or more fascist 
magisterial Schools for physical education, with superior functions and degree. 115

By means of financial support from the Government, and the strongest determination of the ONB leader Renato Ricci, the male Royal Fascist Academy for Physical and Juvenile Education was founded in Rome, in 1928. In only ten years qualified male staff increased notably: in 1926 there were 1,000, and in 1936 about 14,000 physical education teachers. They did not only find employment in the school, but also in extra-scholastic institutions of the state, such as ONB, OND and MVSN.

In addition, local summer courses were held from 1929 onwards to train primary school teachers and directors, ${ }^{116}$ but there was still a big lack of qualified staff for supporting the ambitious and wide programming of national 'sportivisation' and indoctrination planned by ONB. Ricci tried to more deeply involve primary school teachers by organising provincial, regional, and even a national course in the male Royal Fascist Academy of Rome. Teachers attending the Roman course were fully reimbursed and the final diploma opened the way to teaching physical education also in secondary schools. ${ }^{117}$

Once having worked hard and tried to resolve the problem of forming a male physical education staff, Ricci concentrated his attention on a political and financial campaign in favour of an Academy for women. In fact, as already mentioned (Chapter 5.2), from 1929 onwards the physical education of young women was officially in Ricci's hands, and the very same problem of a lack of teachers for schools, and staff for ONB, had to be resolved soon.

After about three years of experimental courses, 118 in 1932 all difficulties were overcome by Ricci, and the female Royal Academy for Physical and Juvenile Education finally opened in Orvieto, under the control of ONB and the Ministry for National Education. ${ }^{119}$

In 1937, ONB was abolished and total control of juvenile physical education was assumed by GIL and the Party. Under GIL, a third year course was added in male and female Academies, and they lasted until 2 August 1943, when the Party was abolished as a consequence of Mussolini's dismissal. Then, all competencies were assumed by the Ministry for National Education, while the Italian Social Republic, which had been founded by 
Mussolini in Northern Italy (Chapter 4.3), started new Academies for male and female physical education teachers, in Gallarate and Castiglione Olona respectively. ${ }^{120}$ These latter were newly organised by ONB, but their existence was difficult, due to the fact that a civil war was occurring in Northern Italy. Both Academies were finally closed in June 1945.

\subsubsection{ONB Academy of Orvieto, forge of the revolutionary new woman}

The female Academy was an imposing complex of old and new buildings, whose restorations and works were completed by the middle of the Thirties. In these buildings, surrounded by a big garden, there were dormitory, dining-room, kitchen, swimming pool, library, theatre, infirmary, a number of gymnasia, laboratories and classrooms, and church and stadium outside. The Academy was located on a green hill near the small and quiet town of Orvieto, really an ideal place for keeping young female brightness and morality fully controlled by service and teaching staffs, and headmastership. These people, according to strict norms, were qualified women of elevated morality and fascist faith, to whom parents had to entrust their daughters for a number of months.

Girls were selected among unmarried 17-23 year old applicants from all over Italy. They had to have a secondary school diploma, a healthy and robust physical constitution, and obviously ONB membership. Applicants admitted into the Academy realised a dream, as they really enjoyed physical activities to be practised in a beautiful and modern sporting university, and were proud to be an elite admired by the rest of Italian girls. In opposition to the current narrow-minded outlook, they left their families for an exciting experience far away, similarly to female students attending colleges in the USA, whose sentimental adventures and independent spirits were shown by popular movies of that time.

All former students who had been interviewed some years ago, declared that they had spent unforgettable years in the Academy of Orvieto. ${ }^{121}$ During that period they had met very important people, enriched their knowledge in very different fields and, what is more, developed a strongest esprit de corps. 
The Academy was rather expensive. Only food and accommodation were free, whereas the rest - fees (5,000 It. Lire per annum), insurance (150 It. Lire), books, travelling expenses and elegant uniforms - where paid for by the families, although with harsh financial sacrifices. Especially their mothers - the former students affirmed - had willingly agreed on that choice, in view of the fact that, once they obtained the diploma after a biannual course, their daughters could become independent and teach at school. What is more, after a special training course and a regular competition, these girls could be employed in the ONB managing staff.

Ricci helped the best students of lower social standing not only by annually instituting special grants of 3,000 It. Lire in each provincial committee of $\mathrm{ONB}$, but also by reducing the fees to half in a selected number of cases, i.e. to two sisters attending the Academy contemporarily, or daughters of ONB staff. 122 As a consequence, students from different social classes and regions lived together, and were educated to dignified manners just like the wealthiest girls of Italian society.

They were served by a number of maids, supported by tutors, and had to stress their privileged rank also outside the Academy. For instance, students had to wear white leather gloves, travel only in first class carriages, and were not allowed to carry suitcases personally.

In the Academy of Orvieto, a student's life was perfectly organised, and girls were strictly controlled during the classes and their spare-time. Teachers and inspectors enforced a rigorous discipline and all roles and norms had to be respected precisely. Students could not move freely in Orvieto, nor leave Orvieto and visit, for instance, the family, without previous approval and detailed information about the railway timetable, which was communicated to the family in advance.

In brief, one could say that the female Academy was organised like an aristocratic college, hard barracks and solitary convent all together. Within a smart and worldly framework, these women were educated to strength and camaraderie by following a non-conformist and alternative model, freed from any romantic and weak spirit, but inspired to futurist values such as revolution, dynamism and modernity. In addition, a moral and religious education was given to these students so as to please His Holiness the Pope. ${ }^{123}$ 
According to a female educator of the time, girls from the Academy of Orvieto "enjoyed motor and physical exercise, and hated idleness and crystallisation. ... They constituted a revolutionary power against any hidden seclusion at home, physical and mental laziness."124 Both male and female Academies had the highest reputation, being considered the most relevant result of the revolutionary politics of 'modernization' in the country. Disciplines taught there were about the same, apart from the 'military training' for men, and 'feminine works' for women.

If one looks at the programme of 1932, concerning the very first course held at the Academy of Orvieto, one can see that all subjects were divided into scientific, literary and technical groups.

In the scientific group there were classes on: a) human anatomy; b) general and applied physiology; c) anthropometry and traumatology. In the literary group were taught: a) general and applied pedagogy; b) history of physical and juvenile education; c) fascist laws and dispositions; d) one foreign language. In the technical group there were the following subjects: a) general theory, technology, training and command; b) formative and corrective exercises; b) pre-sporting and sporting exercises and games; c) dance, music and singing; d) feminine works; e) organisation techniques.

According to official medical advice (Chapter 5.1), not all sporting activities were practised by students of the female Academy, but there were swimming and diving, gymnastics, fencing, roller-skating, skiing, athletics, archery, tennis, and basketball. ${ }^{125}$

Teachers for scientific and literary groups were recruited from the university world, while experts in physical education and sports came from secondary schools. They were 9 all together, 8 women and 1 man. This latter taught pedagogy.

In their spare-time, students collected material for the annual review - such as drawings, poems, romances, interviews - wrote sketches and comedies to be played on special occasions, and created new choreographies and costumes for their performances.

Living on a sort of 'happy island', these girls had only a few personal contacts with their families during the academic year. Sometimes their parents could reach Orvieto for a weekend visit, but in general their links were made via mail or telephone. 
Students lived secluded from the local population as well. It was said that every Sunday these beautiful students - walking and singing, elegantly dressed in well ordered lines to the Dome for Holy Mass - were looked at by people with a lot of respect and admiration. ${ }^{126}$

Further contacts with local citizens were made for the annual exhibition organised by the Academy on different themes, or when these students assisted poor children and learned to teach by training primary school local pupils. Then people observed beautiful female legs emerging from comfortable shorts or light skirts, frankly with astonishment.

On the other hand, these students had social and cultural opportunities at a national and even international level. They were invited abroad or were visited by foreign delegations, for whom they exhibited in choreographic essays, and often went to Rome for political ceremonies and sporting displays.

On those occasions, students proudly marched in parade and/or performed in perfect synchrony, also together with male students of the Roman Academy, surrounded by general admiration. Sometimes female students went to the capital to visit exhibitions of culture and art, or to the most famous Italian resorts for skiing, just like the luckiest members of worldly society.

The Academy of Orvieto was firmly led by unmarried women, whose undoubted capacity left a positive memory in the students of that time. The first female Rector was Ismene Robecchi from Turin, a smart physical education teacher who directed the Academy from its foundation in 1932. She had to give up because of marriage. The second Rector, Maria Costa, led the Academy from 1933 to February 1937; she was depicted by her students as a very talented, human and beautiful person. ${ }^{127}$ Third and last leader of the Academy, up to its end in 1943 will be mentioned later.

We cite here part of a hagiographic and rhetorical article written in 1936 by Angelo Cammarata, whose title "Fucine della Rivoluzione: Le accademie dell'ONB" [Forges of Revolution: the academies of ONB] gives an idea of people's great expectations of the female Academy, as a consequence of the current political propaganda. 128

Cammarata affirmed: "In the propagandistic booklet (...) for the Fascist female Academy of Orvieto the Head [Mussolini] wrote: 'Feminine Fascism 
is destined to write a splendid history, leave memorable signs, give a deeper and deeper passion and working contribution to Italian Fascism'. (...) Soon the Revolution had to found these Academies, which are an inspiration of its spirit, so as so to rouse enthusiasm, discipline, strength, harmony and values that the new education should diffuse among Italians continuously. (...) Also the Academy of Orvieto, in its vast rooms, facilities, programmes, in the framework of its peaceful landscape, has faced a very important problem: that of the totalitarian preparation of fascist female Educators, i. e. grace and strength, kindness and vigour, smile and severity, splendour of spirituality in a firm physical harmony, maternity and future. In the whole of Italy, whoever has seen how much has been done for the physical and moral improvement of Children of the She-Wolf, Small and Young Italians, in only a few years, he can measure the value of the Academy in Orvieto, where the youth has been launched to new achievements, which directly or indirectly (by affecting female educators and mothers resolutely) concern the delicate flower of our race. (...) Also in the feminine Fascist Academy life is various and preparation is fruitful. Female academic students achieve habits and virtues which will benefit the feminine female youth, i. e. the sex by which the new education has eliminated the attributive adjective 'weak'."

A final comment on this article should be made. It mentioned subjects which were not included in the cited first course of 1932, such as eugenics, hygiene, demography, child-welfare and first-aid for the scientific group; fascist pedagogy, fascist culture and two foreign languages - English and French - for the literary group. About these two languages it was written that they "had the propagandistic task to spread the universal fascist ideology all over the world." 129

Indeed, in the year 1936 the atmosphere had changed considerably in Italy. The new Empire needed new soldiers for further expansionist plans, and women were asked for numerous children, stronger social support, and wider fascist indoctrination. These needs were nationally diffused among ONB female members by any and every diploma'd student of the Academy, who was really the most convincing ambassadress of the regime. ${ }^{130}$ But the progressive political engagement of Italian women at school and in society has already been described in detail. (Chapters 4.3 and 5.2) 


\subsubsection{GIL Academy of Orvieto, forge of the militarised fascist woman}

In 1937 a new body, GIL, took full control of juvenile physical education in Italy, under the National Fascist Party leadership. By Law No. 866 of 22 May 1939, the Academies of physical education became officially part of GIL, but also before this date the academic curricular programmes had changed, according to GIL's new plans.

Hitler's political and racist influence on Italian society brought German art and language into the Academies, as the one and only foreign culture to be taught there. This happened in 1937, and in the following year severe racial dispositions excluded students belonging to non-Aryan races; the sad consequence was that in 1940 one female student was expelled from the Academy of Orvieto. ${ }^{131}$

By the end of the Thirties, fascist indoctrination imbued the curricular programme of the Academy, and a new group, the 'political section', replaced the previous literary one. In this section there were subjects like history of the fascist revolution; history of fascist policy and doctrine; fascist policy; institution of fascist public right; PNF and other organisations; and pedagogy. In the scientific section there were added biology of the human races, bio-type studies and social hygiene, while the technical section included umpireship.

These disciplines were indicated in the new statute of the Academy, approved by Mussolini on 1 February 1940. It also stated that a third year course had to be attended, so as to totally and technically prepare both managers and instructors for juvenile fascist organisations, and teachers for every kind of school. In addition, all students of the Academy were engaged by GIL in the organisation of summer sporting contests in the territory.

In 1939, near the Academy was founded a special secondary school, the Lower Magisterial School, where about 150 selected students from different regions were admitted and trained in physical activities. Later, these students would have been automatically enrolled in the female Academy, without any further selection.

What is more, during summer holidays some 1,500 Young Italians attended special GIL courses of physical education and sport in the Academy of Orvieto. These girls, divided into three different groups, had an interesting 
experience, which was an efficacious way to both recruit future pupils for the Academy, and extend common women's interest in motor activity. In those years, the Academy of Orvieto was led by a former student, the charismatic Elisa Lombardi from Piedmontese region. In 1937 she was not simply nominated Rector, but Commander of the Academy, so as to stress the new military spirit of that university. Then, Commander Lombardi was really young - about 25 years old - but had been educated to the firmest discipline in a large middle class family, and possessed an independent and lively spirit.

Since her early years, Lombardi enjoyed motor activities and became a member of the Catholic Forza e Grazia sporting society of Cuneo (Chapter 5.2); then she attended the Academy of Orvieto from 1932 to 1934 . Once a teacher, she successfully organised the whole ONB feminine section in Bolzano, which was a difficult city on the border with Austria. There, two different needs, cultures and languages had to be combined with effective diplomacy. ${ }^{132}$

From Bolzano, Lombardi was called up to head the Academy by the ONB leader Renato Ricci, whose friendship and ideals influenced Lombardi's work also after the Academy was absorbed by GIL. ${ }^{133}$

There is evidence that Elisa Lombardi's style, energy, sense of measure and duty were undoubtedly the reasons for her success among students, who really considered their charming Commander as an example to imitate. ${ }^{134}$ Although discipline and diet were strictly controlled, and students could not use make up, nor smoke, or read letters without previous control, she was unanimously loved by her pupils. Elisa heartily reciprocated with a 'sweet severity'.

According to GIL military dispositions, under Lombardi's leadership all teachers and assistants had to wear soldierly Saharan uniforms, but students could keep both their elegant, feminine gala uniforms made by the Botti Sisters's fashion-house since 1932, and working aprons in light childish colours.

Students had to frequently change their aprons for different kinds of sporting wear, such as shorts for athletics, gymnastics and skating, different models of skirts for tennis and fencing, bathing-suits, and a light and short dress with ample sleeves, for rhythmic gymnastics and dance. 
In those years a student's life was quite busy (Lombardi had added classes of piano and other musical instruments), but also fun. It was said that in the Academy, students could see movies twice a week, selected themselves from those shown in local cinemas. ${ }^{135}$

Lombardi was in charge of managing staff and student life (also teaching Catholic religion in the Academy) and organising conferences, performances and meetings. Among meetings of political relevance one should cite at least those with Hitler, Chamberlain and Mussolini.

In 1937, students of the Academy were sent to Berlin by a special 'Train of Youth', and Hitler in person militarily reviewed the female squad; in 1938, in Rome, these girls marched in parade in front of him and the highest Italian authorities. In 1939, they displayed gymnastics in the Roman Stadium of Marbles, in honour of Chamberlain.

As far as Mussolini was concerned, he went to the Academy of Orvieto twice: in 1939, when the Duce expressed his admiration for the strength and grace of students, and in 1940, when they enthusiastically organised a special dance performance for him. ${ }^{136}$

The girls of the Academy used to annually display on the occasion of most important fascist celebrations, such as 24 May, the day dedicated to victory in the First World War, and 28 October, the date of the 'March to Rome'. In addition, they participated in GIL competitions at national level, such as the Littoriali dello Sport (Chapters 5.6 and 6.3) and other more soldierly sporting occasions, such as that with bows and javelins performed in Rome, in 1940.

The fame of the feminine Academy of Orvieto passed Italian borders, and in the years 1937-1941 foreign delegations came from Spain, Hungary, Romania, China, Japan, America and Germany. ${ }^{137}$

\subsubsection{A final view of the Academy of Orvieto}

According to propagandistic booklets issued annually for the enrolment of students in the female Academy, about 800 graduated in Orvieto from 1934 to 1943.138 One of the booklets wrote that "female youth struck from the coin of Orvieto was a perfect alloy of femininity and 'virility', which did not result in 'masculinization', but made their femininity more splendid and stronger". 139 
But these 800 girls, indeed a sort of Vestal Virgins forged in The Temple of Italian woman's physical culture - i. e. the Academy of Orvieto - were a rather dissonant elite, whom common women could not but look to with envy. Far from the family, but strictly under staff control, these dynamic girls were expecting a career, not a husband, and were prepared for an independent life in society, at men's side.

They spent about three years on a 'happy island' untouched much by external problems that were saddening other Italians. Even in the war years the habits of the Academy did not change much, apart from the fact that garments were suited for soldiers, and food was not as good as before.

What is more, in 1940, just after Italy had officially entered the Second World conflict, the Academy was involved in an exciting and amusing experience. That summer, a number of selected students participated in a propagandist documentary film, L'Accademia dei venti anni [The Academy of the Twenty Years], produced by the GIL section of Orvieto, and directed by Giorgio Ferroni. 140

This documentary displayed daily life in the Academy by means of various sporting, scholastic and spare-time activities, where female students were the collective and enthusiastic protagonists. This movie was finished by the end of summer, and was shown with success in the Venice Film Festival of 1941.

According to former students, life in the Academy was not influenced much by policy, although students were given regular classes of fascist indoctrination. In general, students of the Academy stressed much more their brilliant future than current dramatic events, which were followed rather distractedly. They enjoyed the privileged time they spent in training, chatting and cultivating friendships which - they said - had developed a strong sense of identity and independence, and deeply influenced the rest of their lives.

The fall of Fascism in 1943, and consequently the end of their golden isolation, were really a shock for all students, a nightmare which destroyed dreams and opened their eyes to a tremendous and unexpected reality. ${ }^{141}$

Students of the Academy, once considered like movie stars to be invited, admired and photographed, suddenly felt they not only counted for nothing, but were looked upon with suspicion, by being the living symbol of the 
detested fascist ideology. Some of them rejected Fascism, others aspired to the fascist Social Italian Republic (see Chapter 4.3), most hid to avoid persecution.

Did education given in the female Academy contribute to gender emancipation? If one assumes that there are two different types of education towards emancipation, the 'inner' stressing womanly emancipation in the domestic framework, and the 'outer' struggling for equal conditions outside the home, one should say that female students achieved both types in Orvieto. ${ }^{142}$

In those years a lot of words were officially spoken in favour of modernisation and socialisation of society, but this process involved much more men than women. However, the Academy of Orvieto was a privileged place where female students could experiment in a well-organised education towards both 'inner' and 'outer' emancipation. The first was based on subjects stressing traditional womanly values, such as grace, elegance, modesty, religiosity, childhood and feminine works; the second was based on modern sport sciences and fascist policy, similar to that given in the male Academy of Rome. Female 'outer' emancipation was also stressed by means of a brilliant social life and frequent participation in public events, although firmly under staff control. On the whole, one should say that this kind of modern and collective education had no precedent in the Italian common women's history.

Former students of Orvieto confessed that the main objective in their life was to become fully independent and get a good job, no matter if far from their native place and family protection. Deeply influenced by the strongly emancipated model embodied by the Commander Lombardi and the female staff of Orvieto, former students said they were not afraid to work at men's sides in comradeship and self-confidence.

By supporting the Academy of Orvieto as the best way to accomplish the holy mission to forge healthy people through capable and well-prepared teachers, perhaps the regime undervalued the impact of this new kind of modern woman on the traditional female population. Young teachers from Orvieto were really a small number in comparison with the 20 million more or less old-fashioned women living in the country, but soon they started to modernise the habits of Italian girls through sporting activities, as will be 
shown in the following Chapters 5.6 and 6. By stressing healthy bodily habits, organising gymnastics displays and addressing students to competitive disciplines even in mixed groups, these teachers removed a number of girls from the home and freed them from the exaggeratedly protective eyes of their parents.

However, it is difficult to assess to what extent these teachers influenced the general trend in terms of women's emancipation. The sudden fall of Fascism as a consequence of numerous military defeats did not allow these new physical education teachers to increase in number, so as to really popularise the new model of woman moulded in the Academy. Probably, by teaching for less than 9 years, these few teachers - in 1943 they attained the apex of 800 - could not reach a really extensive number of pupils. 


\section{$5.4 \quad$ Spare-time motor activity}

As been already said (Chapter 5.2), with the coming of Fascism the ONB, GUF, and then GIL, had the task of ideologically manipulating and organising the physical education and sports activity of young people. In a short time a new body, the Opera Nazionale Dopolavoro [Spare Time National Body]- OND was founded, engaging a worker's spare time.

OND took autonomy from Italians, but offered them a rationalised and assisted leisure practically for free. On the other hand, the masses were attracted by OND clubs, where they not only trained their body, but could buy goods, visit beautiful places and practice manifold activities - even those once reserved for high society - at low cost. In brief, OND was really popular among Italians who enjoyed the pleasant sensation of being at the centre of the Duce's attention. This chapter will give a general overview of OND and the involvement of female workers in it.

\subsection{1 'Dopolavoro' leisure time activities}

The OND was founded by Royal Decree on 1 May 1925.143 Through OND, the fascist state aimed at the nationalisation of worker's spare time, which previously was mainly a private affair, or had a sort of collective dimension, but was organised in different ideological and confessional unions, or most importantly the manufacturing concerns of northern and central Italy.

Officially, any policy was bannned in OND, but in so far as OND was in the hands of the Fascist National Party, men of the Party did not fail to express anti Communist opinions from the beginning, such as: "[In the OND] the worker rises again from Bolshevik abjection and quietly evaluates his rights and duties regarding the Fascist State."144 
In the first number of its Official Bulletin, the OND presented objectives and programmes. There, according to OND, every Dopolavoro local club had to avail itself of suitable sporting facilities. The declared target of the OND was not to present a worker with just an opportunity for amusement, nor emphasise different ideologies and classes as in the past, but improve individuals for their own good and that of the Fatherland.

The Official Bulletin also declared: "While young people of the highest social classes practice gymnastics at school, and later sports in pre-military and military courses for officers, the working-class and farmers practice gymnastics and sporting activities only during military service. For the rest of their life, they do manual work which does not better but, on the contrary, damages their body. Therefore, every kind of sport is encouraged by OND, which considers sporting activities as a powerful, unique instrument for physical and moral improvement, cohesion, loyal antagonism and reciprocal respect among workers." 145

In fewer than ten years Mussolini's aggressive policy involved OND considerably more, and the Duce's portraits, lapidary phrases and fascist symbols invaded OND local clubs, for the sake of propaganda. ${ }^{146}$

By the mid-Thirties, the Dopolavoro clubs and their initiatives were really popular among Italians. Both the working and lower middle classes met and spent a relaxing time there, away from concrete problems of money and jobs. Whoever enjoyed cultural events, or recreational activities such as cards, chess, music, drama and comedies, choral singing, dancing, sport, or was keen on tourism, could find companions and interesting recreation. In addition, workers could attend OND popular courses to improve their culture, or technical courses to better themselves professionally in the fields of agriculture, industry, commerce and insurance.

OND was a colossal organisation. Through the territory, there were OND clubs for different categories of employees in the state, army and merchant navy, or for artists, teachers and other professionals. Manual workers were enrolled in OND sections of manufacturing concerns, small industries, commercial shops and farms, namely the places where these people went to work.

In 1935, OND boasted many cinemas, theatres, libraries and choral-music schools. According to statistical data, OND hosted 2,066 companies of 
amateur actors, 2,130 orchestras, 3,787 bands, and 10,302 professional and cultural associations. In 1932, OND enrolled about 1,744,000, in 1935 about 2,376,000, and in 1939 reached the considerable number of 3,832,248 members. ${ }^{147}$

In 1940, an official book for Dopolavoro leading staff claimed that OND was a true political institution, writing: "OND is disciplined, co-ordinated and strengthened by PNF, on which it depends. As a consequence, OND has a double function: educational and political."148

Enrolment in OND was cheap (5 It. Lire per annum in 1940), 149 and easy. According to OND staff's opinion, young female workers of 12, and male workers of 18 years could become members of OND if they had good moral and political behaviour, but also younger boys were admitted if they were already GIL members. University students could enrol in OND as well, but Jewish people were excluded from 1938, according to Mussolini's racial laws. ${ }^{150}$ All members drew a lot of benefits from Dopolavoro clubs. For instance, they could buy books, travel by train, go to cinemas, theatres, museums and sporting events at a reduced price, ${ }^{151}$ and buy expensive goods by instalments. ${ }^{152}$

\subsection{2 'Dopolavoro' sports activities}

As far as sports and other physical activities were concerned, the OND programme was varied and ranged over tradition and modernity. A number of traditional games not recognised by CONI federations were organised by OND directly, according to both available sports facilities and regional habits. These activities were: rowing with a fixed seat, bocce (a popular kind of bowling), tamburello, elastico and sfratto (traditional ball games), and tug-of-war; but there were also modern activities such as marching, target-firing and volleyball. ${ }^{153}$

Initially, OND members could practice popular football as well. However, in 1929 this game was not considered suitable for Italian workers by the influential Augusto Turati, a member of the fascist hierarchy. As a consequence, this game of English tradition was replaced by the volata game, which recalled ancient Italian traditions. But volata, which was not a true traditional game but merely one of Turati's bizarre inventions, did not 
succeed at all. After three years it disappeared from the Dopolavoro sports programme. 154

From 1927, CONI and OND, both organising sporting activities for adult Italians, had to come to a compromise. In that year, the PNF press agency published the results of two meetings involving the PNF central sporting office, the leadership of CONI and its federations, and the head of OND. 155 In brief, it stated that CONI was to look after the most talented sports people, and OND the masses. Those enrolled in CONI federations could not take part in OND contests which, on the other hand, were organised independently of CONI. Those OND members who obtained important technical results had to leave OND immediately, and enrol in CONI sports federations. The next Sports Charter of 1928 stressed this agreement officially.

However, the fact that the most talented OND members would have to train within CONI did not mean they had to leave their OND membership completely, simply that they had to train for their favourite sport under CONI control, while the rest of their entertainment could be enjoyed in OND as well. As a consequence, many Italians owned more than one membership card, but statistics of the time hid this phenomenon, so as to stress that almost all young and adult Italians were sports people.

From 1932 onwards, OND and GUF competed in the research for potential champions for the Littoriali dello Sport annual contests (Chapter 5.2).156 In those years, OND became the most important means for developing the sector of sport amateurs, and selecting professionals. In 1933, the number of OND competitions reached its apex with 191,773 sporting events; ${ }^{157}$ in 1935, 11,159 non-competitive, and 4,704 competitive sport sections were counted in the territory; ${ }^{158}$ in 1937, some 130,000 contests were held by OND, including chess competitions, which should not be considered as 'physical' activities. 159

On 'paper', there was an ample range of sports led by OND, but in practice only a few of them were really popular. For example, in 1937, it was reckoned that in about 8,000 OND sections for competitive sports, 6,434 concerned the bocce game. 160 This traditional and quiet bocce, which did not need expensive facilities, just wooden balls and solid ground, was loved 
by Italians of different classes, including important people such as General Badoglio, the musician Mascagni and Pope Pio XI. ${ }^{161}$

Although in its first years the National Fascist Party had not encouraged the bocce game, which was not considered sufficiently dynamic and virile for forging the New Italian Man, later it had to give up opposition. ${ }^{162}$ In 1936, OND organised the first national championship of bocce in Rome, so as to celebrate the foundation of the Italian Empire through a 'truly national sport'. 163

In the Thirties, skiing became a popular activity in many sections of OND. The middle classes of both sexes enthusiastically participated in cheap OND excursions at the weekend, and went to exclusive winter sports resorts, imitating the habits of the wealthiest classes. ${ }^{164}$

In the winter sports ambit, and on the wave of the single Italian victory in the 1936 Winter Olympics, ${ }^{165}$ OND was also engaged in the organisation of local and national championships for 'Alpine skiing-and-target-firing', which involved both male and female teams.

At the beginning of the 1940s, OND had become a powerful body in the sports field, under effective GIL leadership. As an example, a list of dispositions stressed that: a) one member of OND had to be included in each national and local board of all sports federations affiliated to CONI; b) OND could organise championships in the following federated disciplines: gymnastics, fencing, target-shooting, roller skating, and partially athletics; c) other sports disciplines were still controlled by CONI directly, but at a basic level they could be practiced in OND sports groups. ${ }^{166}$

\subsection{3 'Dopolavoro' motor activities for women}

As far as female workers were concerned, one should assume that they had not much time for recreational activities, especially if they were mothers of a family. What is more, the idea that a working woman would spend spare time on her own outside, and not inside the home with her family, was too innovative to be easily accepted in Italian society. 167 This notwithstanding, before the advent of Fascism a small number of pioneer female workers practiced some physical education, gymnastics and athletics in their spare time, especially in the industrialised and modern regions of the country. 
Before 1925, these women used to train within worker societies founded by important industries, such as, for example, the Unione Sportiva Operaia [Sporting Union for Workers] by FIAT of Turin, Scuola di Educazione Fisica [School for Physical Education] by Cantoni's Cotton fabrics of Castellanza; Gruppo Sportivo [Sporting Group] by Cucirini's Coats of Milan; Società Sportiva [Sporting Society] by Magneti Marelli of Sesto San Giovanni; Gruppo Sportivo Dopolavoro Ferroviario [Railway Spare Time Sporting Group] of Milan, 168 Società Sportiva [Sporting Society] by Venchi Unica of Turin, and others.

After 1925, working sports amateurs, together with their societies and programmes, lost their last corner of freedom and were put under state control by OND. In fact, the women engaged in OND were a tiny minority. National statistics show that in 1929 there were 10,901 male and 183 female Dopolavoro clubs in total. 169 However, it is difficult to pinpoint the number of female sections, or that of women workers in OND clubs, because from 1930 the national statistics did not separate clubs and members by sex. But there are local reports which can give an idea of the trend, such as that of 1935 from Potenza in the deep south. That report proudly wrote that there were 549 female, and 6,736 male members enrolled in OND: namely, women were less than $10 \%$ of men. 170

In the beginning, OND organisers did not discriminate against women but, on the contrary, gave evident signs of appreciation. For instance, they had engaged a capable female lawyer, Adele Pertici Pontecorvo, to help draw up OND fundamental norms, 171 and in 1928, at Turin, the OND-FIAT sports section hosted mixed groups in a 'masculine' discipline like rowing (400 men and 50 women) and 'feminine' tennis (40 men and 60 women). ${ }^{172}$ However, when in 1929 the Feminine Fasci had to give up the Piccole Italiane and Giovani Italiane's leadership (Chapter 5.2.), their engagement in OND female groups brought an effective gender apartheid. Actually, Feminine Fasci women - having submitted to the male leadership of the Party - supported traditional woman's roles of mother and wife, according to the official position of both the fascist and Catholic gender ideologies.

As a consequence, female workers and housewives enrolled in OND were pushed towards boring 'womanly activities', such as domestic economy, hygiene and social assistance, much more than towards amusing pastimes. 
This was not a shared choice, according to the results of an enquiry held in 1930. On that occasion, the majority of 100,000 female workers enrolled in OND claimed to enjoy cinema, theatre, travelling and sports - the preferred pastimes of their male companions as well - much more than 'womanly activities'. 173

These emancipated choices of OND female members, being considered morally dangerous, were criticised severely by the Church which did not fail to affirm that OND was the promoter not only of the feminist cause and 'masculinization' of women, but of their eroticism and sterility. ${ }^{174}$

In fact, both in the ONB and OND, a woman's sporting activity was considered a marginal subject which was restricted to gymnastics and other graceful and quiet 'feminine' physical activities, according to most Italians of that time (Chapter 5.1). Even a quiet game like bocce - the Dopolavoro's most popular sport - by being reputed a man's game down the ages could not be played, but simply watched by female spectators. What is more, even 'feminine' physical activities were not practiced much, in so far as the available gyms, athletics and other sports fields were normally reserved for the training of OND male sports amateurs. ${ }^{175}$

In those years, a different kind of motor activity became popular within Dopolavoro clubs, the dance. ${ }^{176}$ By involving mixed couples of dancers, and therefore the moral and sexual behaviour of Italians, this activity did not fail to open ardent discussion among supporters and opponents. Supporters were almost all Italians - from the lowest to the highest classes who enjoyed dancing in private and public parties. Opponents were both the Church and Fascism.

The Church kept its firm opposition through the years for the sake of religious ethics. In 1936, a Catholic magazine dramatically wrote that when boys and girls left dancing parties (places of depravation!) they were not the same people anymore, detesting any expression of pure affection and love for the family. These people, undermined by sin and indifference, would provoke a fatal weakness and decadence in future families and the Fatherland. 177

Fascism sent contradictory messages on the topic 'dance'. Dancing was a physical exercise that could improve people's health, and Mussolini himself enjoyed dancing, and was especially good at the waltz. A biographical 
article on the Duce wrote: "Once he ended his studies, Benito [Mussolini] dived again into Sunday dancing parties and feasts. He danced on threshing-floors, vine pubs and in front of churches with the energy of a colt, capable at all physical exercises, naturally breathing rhythm, melody and music."178 On the other hand, dancing was widely practiced by the hated, lazy bourgeoisie whose degenerate habits the fascist ideology was severely opposed to.

For the sake of sobriety and civil ethics, first the fascists tried to convince people to change that "lavish, feast and pleasure-loving custom", 179 and "to stop dancing and cocaine parties [!] in the night." 180 But although in official fascist publications the moralists often wrote against dancing, ${ }^{181}$ Italians never gave up their preferred entertainment, and the regime had to compromise.

Finally, the beloved dancing could provide a further chance for increasing popular consensus and encouraging people to spend controlled time under the fascist flag. From 1931 onwards, dancing parties were organised by OND in its local Dopolavoro sections, and even the Party in its Case del Fascio [Fascio Houses]. Mussolini, his children and relatives, eminent members of the fascist hierarchy and local authorities participated in these parties, for the sake of both amusement and propaganda.

People enjoyed not only Italian but foreign dances and music - in particular the Afro-American ones - which were looked at suspiciously by the regime, as they could contaminate the purity of the Italian musical tradition and Latin race. A harsh battle against black music and in favour of the Italian engaged the regime for years. 182

At last, the problem to combine public morality, health and traditional values was solved by means of organised folklore shows in regional costumes. During the dancing parties these shows were performed by mixed groups of amateur dancers, musicians and singers, all members of OND who exhibited by turns. The Dopolavoro members and their families had to stop dancing and watch but, clapping their hands and singing together with the performers, they participated in an exciting and enjoyable experience as well. 183

In conclusion, dancing was the most practiced physical activity among OND members of both sexes. This mixed sexes entertainment, with its 
beautiful music and songs, helped the youth to meet together and encouraged a girl's most romantic dream, i. e. to find a sweetheart, and probably a good husband. On the other hand, sporting activities were not too popular among OND female members until the second part of the Thirties, when aggressive fascist policy mobilised the mass of women for colossal displays, as will be seen. (Chapter 5.6.)

\section{5 $\quad$ Health resorts}

Health resorts were not an invention of Fascism, but in those years they grew in number and prestige owing to the initiatives taken by the Regime for people's health.

Already present in different European countries by the beginning of Nineteenth Century, in Italy health resorts originated from sea hospices, a kind of summer hospital 'dependance' for the treatment of scrofula, rickets and lymphatism. In 1822, on the initiative and at the expense of the hospital of Lucca, an experiment was carried out, i. e. to take poor young patients to the sunny beaches of Viareggio.

During the following years, these laudable initiatives increased, mostly thanks to the work of Giuseppe Barellai, who, from 1853, had actively taken great pains so that a number of sick children, especially TB patients, could enjoy the helio- and thalassic-therapy. So numerous seaside hospices were built, above all in Liguria, Tuscany, Emilia-Romagna, Marche, and some others in different mountain localities.

The efficacy of the treatment given there can be deduced by reading annual reports which show, for instance, that in the fifteen years between 1871 and 1885 , of about five thousand patients admitted to the hospices, a quarter were restored to health, half improved considerably, and a sixth showed some progress. Naturally, since these children were really poor, the advantage also derived from more appropriate nourishment and hygiene. The hospices received patients of both sexes in different periods, but in July 
1892, there was an exception when a mixed squad of 11 male and 10 female children stayed at Camandona, near Biella, for two months. ${ }^{184}$

The results of the therapies given in the hospices seem to have been more encouraging for the boys because, according to the doctors, they had "greater organic resistance to cosmic influences, greater constancy of seabathing and a longer resistance on the beach."185 Moreover - and it is still the opinion of those doctors - the best results also came from the fact that, unlike females, males remained naked for one hour and more after a bath of burning, hot sand: that seems to have contributed "very much to strengthening the constitution of these [the boys] more than that of those [the girls]". 186

Setting gender aside for the moment, at the end of the Nineteenth Century mention must be made of the founding of sea and mountain health resorts for poor children, who were of delicate constitution, due to lack of food and hygiene, but not affected by specific illnesses. These new structures co-operated with the already existing therapeutical hospices.

The huge expenses of management and organisation of the hospices and health resorts were usually covered by single benefactors, by charitable institutions such as Opere Pie, by firms, by co-operatives, ${ }^{187}$ according to the charitable private model of a liberal kind.

During the First World War, a new period began, characterised by a certain form of state intervention: the Health and Education Ministries endeavoured, in fact, to financially support summer health resorts, which gave hospitality to soldiers' children. Furthermore, the State promoted inspections in regions where hospices and children's health resorts were more numerous, with the aim of controlling, cataloguing and organising the different kinds of intervention, which ranged from the therapeutic to the prophylactic, and to merely recreational.

Official statistics show that, in the six years between 1916 and 1921, the health resorts for children of frail constitution ran by Opere Pie tripled, from 13 to 35.188 Whereas in 1902 the assisted children were 25,000, in 1922 there were 100,000 young users of health resorts and summer hospices, testifying to a way of life which by then was deeply rooted in social customs. ${ }^{189}$ 


\subsubsection{Development during Fascism}

With the coming of Fascism, the organisation of children's health resorts was undertaken by the State, with a very considerable increase of users. A remarkable fact is that the 350,000 assisted children of 1932 doubled in 1936. ${ }^{190}$

The reasons for the interest in health resorts were manifold. In fact, over and above the already generalised sensibility towards damage caused by industrialisation and urbanisation, and the increasing interest in the conquests of medicine, it was considered a social aim to strengthen the 'Italic Descent' by improving health, and of ideologically manipulating youth even there.

The declared aim of such a capillary social assistance was "the formation of generations, physically and morally strong and healthy, through the protection and assistance of maternity and infancy, physical education and moral preservation of young people".191

As a matter of fact, in the family, in school, at work and in sport, everything was in a short time controlled by the regime with the creation of special bodies. ${ }^{192}$ To complete the picture, only the control of charitable private activities remained. Fascism subjected them to strict political ties or even absorbed them, and controlled that precious reserve of young people who were their guests in health resorts.

Fascism acted in a regime of almost total monopoly, taking possession in this way even of the last corner of freedom that remained - the holiday time. In fact, in 1927 the Opera Nazionale per la Maternità e l'Infanzia [National Maternity and Infancy Body]-ONMI started to be interested in health resorts, sending about 180,000 children there at its own expense. Then, under the direction of PNF, and helped by Feminine Fasci, ${ }^{193}$ Italian Red Cross and National Balilla Body-ONB, the OMNI deeply operated in the sector from 1930 onwards, taking the number of subscribed users from 100,000 to 250,000 .

Later on, from 1931 to 1937, the organisation of health resorts was also coordinated by the Ente Opere Assistenziali [Welfare Bodies Institution]EOA. 194 Finally, from 1937 to the fall of Fascism in 1943, every kind of educational, recreational and charitable activity was firmly in the hands of the Italian Littorio Youth- GIL. 195 
Special attention was paid by the regime to children of the numerous Italian emigrants who, from 1927 onwards, were regularly invited by PNF to spend a holiday period in sea- and mountain-health resorts of Italy. The main objectives were to maintain close ties with the Fatherland, and to bring up children according to the Mussolinian ideology "to believe, to obey, to fight", of which they could become the best envoys in the world.

Emblematic in that way are the words written in 1934 by Piero Parini, the director of the Italian Fasci abroad: "By ordering that the beautiful seashores and the picturesque Alpine landscape be opened to young Italians abroad, the Duce has operated the most tenacious conquest: that of the soul. Our young people are worthy of that. They redeem the ancient miseries of emigration, and in future events, whatever they may be, they will show that their faith will come forth as strong as granite".196

The charitable activity of the health resorts in the fascist period was distributed in a wide and efficient way over the territory, as the publications of the day report. In 1927, in the 410 health resorts, there were 80,000 guests, and in 1938, in the 4,357 health resorts there were 772,000 guests; in total, from 1931 to 1938 , no fewer than 4,262,000 male and female children stayed in health resorts. If those health resorts organised by farms and religious institutions are added (although controlled by PNF, they did not enter in official statistics), ${ }^{197}$ Mussolini's ambitious aim to involve one million young people in 1938, was not, by then, far from reality. 198

The powerful effort operated by the regime to offer holidays in the sun to Italian children, undoubtedly satisfied citizens' expectations of the health of new generations. At the same time, it constituted both part of a more general plan aimed at increasing the population and their health, and a precious tool of propaganda, i. e. a further means of political penetration into the young minds. Even the colossal buildings of the Thirties in the best tourist resorts, monuments to Fascist rhetoric - able to host up to 1,500 guests at a time - encouraged depersonalisation and uniformity of the youngest people, by offering a life which was increasingly similar to that of barracks rather than that of a holiday resort.

The activities programmed for those health resorts offer clear evidence of these attitudes. Young people who needed healthy air, sunshine and adequate food were sent to health resorts where all male or all female 
movements were organised; sometimes the two groups stayed inside the same structure, but rigorously separated.

At the beginning, it could not have been easy to make families accept the idea that even female children could live an experience of the community kind, outside the protection of domestic walls. In fact in the summer of 1927, about 50,000 boys were selected, among Balilla and Avanguardisti, while only 4,000 Piccole Italiane went to health resorts. ${ }^{199}$

In the following years the female presence increased, in response to the eugenic propaganda of the Regime, which took upon itself to reassure families, promising the constant presence of assistants of tested morality in the health resorts. Reactions were certainly positive. For instance, in the summer of 1930, in the health resort of Marina of Igea near Rimini, 1,421 guests were present at the 3 residence periods, of whom 683, just less than half, were girls. ${ }^{200}$

In addition, in the previous year 1,433 young women - already part of the working world - had attended the 12 health resorts reserved for them, as was said in a PNF publication. 201 With reference to this, it must be clarified that when there were no suitable health resorts, or quiet rooms within children's health resorts, available, ${ }^{202}$ the female workers of poorer health were often sent to simple boarding houses at the seaside, at the expense of the PNF.

The Bulletin of the General Headquarters of PNF, which reported with regularity on the measures and actions of the National Executive Board, is a valid source of information where we may find, for instance, the rules for admission to health resorts: female children needing treatment had to show, besides a medical certificate, also a certificate of ONB Piccole Italiane membership and a certificate of birth to prove they were between 7 and 1214 years old.

By reading the Bulletin it is also evident that in 1934 there were numerous kinds of health resorts spread all over the country, so that children might be admitted to sea-, mountain-, sun-, fluvial-, iodine- and lake-health resorts, according to their needs. ${ }^{203}$ To testify to PNF interest in this form of assistance, every year the Party Secretary reported on the numerous inspections carried out to verify the regular running of health resorts. ${ }^{204}$ 
The provincial Feminine Fasci reported on children needing treatment to the Sanitary Committee, which stated for each one the most suitable health resort after having given them a check up. The Sanitary Committee had, moreover, the responsibility to watch over and to control every health resort existing in the provinces, even those belonging to private bodies. ${ }^{205}$

\subsubsection{The assistants' training}

The task to technically prepare the assistants and the directresses of children's health resorts was entrusted to the Feminine Fasci. From 1929 onwards, in the provincial seats of the cities, the Feminine Fasci started to periodically organise courses aimed "at the sanitary and moral assistance of their guests". From their stay in a health resort children "not only had to flourish in health, but to elevate their little souls towards the supreme ideals of Fascism, love their country, and have a deep religious feeling and a precise moral education". 206

Such a proposition seems problematic if we consider that children remained in health resorts from 20 to 40 days at the most, ${ }^{207}$ but it must be remembered that young people were subjected to the same kind of indoctrination all year long, at school, in their families and during their spare time. For example, as regards the Piccole Italiane, ${ }^{208}$ they had gradually to learn " the value of the race, its mission in the world from ancient times up to the present (...) pride in their descent and yearn to perpetuate and hand on that glory to future generations; (...) to have a profound veneration for the home, for the family, (...) seen as deep-rooted and wise training in what their mission as mothers and brides would be". ${ }^{209}$ (Chapter 5.2)

As to the enrolment of staff for health resorts, in order to be admitted to the course and to become a health resort assistant, the female applicants younger than 35 years - had to be of fascist faith, proved by the registration at one of the PNF organisations, such as Feminine Fasci or Giovani Fasciste [Young female Fascists]. They also had to be in possession of a certificate of secondary education, usually the certificate of teacher training for primary schools.

The working programme was intense. There were lessons of physiology, alimentary science, medicine, prophylaxis, general hygiene, dietetics, first aid and climatic-helio-thalassic-therapy, classes of physical education, 
history and fascist culture, and the study of health resort statutes and regulations.210 At the end of the course, which lasted 40 days, all female students who were considered fit received the diploma of health resort assistant and could start their part-time job, which lasted about four months, i. e. the time of the school summer holidays.

Then, to obtain the qualification to manage the health resorts, a special examination had to be taken. To be able to sit it one had to possess the diploma of health resort assistant, enrolment in one of the PNF organisations, the certificate of at least three years good service in health resorts. ${ }^{211}$

A health resort directress, the female Dr. Grasca Diaz, in 1921 explained the difficulties of her job: "a sum of energies is requested which can be appreciated only by someone who knows how much sense of responsibility, what a lot of tact, how much goodness of health and readiness of mind and what a lot of physical endurance are necessary for this very important task. Do not believe that being the directress of a children's health resort is a holiday. The place may be enchanting, very healthy, the health resort operating wonderfully, but whoever assists children never has peace or rest." 212

\subsubsection{Training of children}

Young people who year after year, and in increasing numbers, attended the health resorts, received a homogeneous and standardised treatment which, in the name of efficiency and massification, glossed over individual differences. Heliotherapy, climatic cures, well-balanced nourishment, even if simple, attention to personal and environmental hygiene - unknown to most guests coming from poor and large families - were offered, together with a full programme of compulsory activities, which followed one after another during the day.

The nature and order of development of such activities, which had been programmed from 'higher quarters', did not leave any room for personal initiative. In fact all the guests were considered as passive subjects, simple mechanisms of a system which had to function perfectly and uniformly in every health resort of Italy, following the already cited motto "to believe, to obey, to fight". 
The daily programme, without significant differences between the sexes, was clearly stated. In the morning it included: rising at half past six; personal hygiene; gymnastics in the open air; prayers; breakfast; hoisting the flag ceremony including patriotic songs; heliotherapic cures and, at the seaside heath resorts, sea-bathing; lunch. In the afternoon it included intellectual activities (in particular, readings praising Fascism and its achievements); gymnastics and games; a snack; lowering of the flag and songs; dinner and bed. ${ }^{213}$

In children's health resorts, from the smallest to the most Pharaonic ones, a strict hierarchy assigned everyone a well-specified role. At the head there were the administrative disciplinary Directress and the technical sanitary Director, followed by a number of Assistants; then there were a few Nurses, and a Staff employed in the kitchens, in linen-rooms and other services. ${ }^{214}$ Even among the children, whether Balilla boys or Piccole Italiane girls, different roles existed. Being divided into squads of about 30 elements, 215 commanded by the head of the squad, all children assumed the name of the squad to which they belonged. For instance, in the Bolognese health resort in Riccione, which gave hospitality to children of both sexes at the same time, there is evidence that in 1932 the male squads were called young eagles, young cocks, chicks, crickets, whereas the female squads were called swallows, dragonflies, butterflies, fireflies, somehow following the Boy Scout way. 216

Later on, when the political purpose of the regime became more aggressive, the little female guests of the health resorts had to submit to hard rules, already accepted in other juvenile organisations, which transformed the health resorts from healthy holiday places into some kind of barracks. Following the military model of Ancient Rome, the Piccole Italiane were gathered in Manipoli (squads of 24 elements), Centurie and Coorti,217 carefully controlled by the assistants. In addition, the heads of the squad (a kind of corporal in skirts), chosen from among the fittest, had to control the group in a disciplined way.

Aiming at a policy of depersonalisation and massification, even regarding clothes, the little girls, once in the health resorts assigned to them, had to undress in order to wear the prescribed bathing suits, day-dresses, eveningwear, and night-shirts, which were given to them. Sometimes they also 
received hats and woolly vests of uniform shape and colour, to deal with the sun and the cold. ${ }^{218}$ Naturally, these dispositions had also a social impact, as they cancelled out any difference between the poor and the not so poor children.

As to the usual daily rites of hoisting and lowering the flag and saluting, they were present from the start in all children's health resorts. With the passing of years, they were executed with great military precision. The children, moreover, were compelled to march like little soldiers every time they moved, either inside the health resorts or in the streets. In this case, obviously, the wearing of the prescribed uniform of Piccola Italiana was obligatory. ${ }^{219}$

The political action, which was carried out in any children's health resort through the ideological indoctrination and militarization of youth, was also carried out through exaltation of the care of the body, the strengthening of which would contribute to the health of the 'Italic Descent'.

Particular emphasis was put on the eugenic education of little girls as future mothers: health and strength were required of them as well as a spirit of sacrifice and devotion to the Duce's ideals to raise numerous progeny at the service of the Fatherland.

In the health resorts of the Regime quite some time was dedicated to physical education, and in particular to corrective gymnastics. It was included twice a day - one hour in the morning and one in the afternoon - in the daily programme of activities.

In health resorts with more than 150 children, gymnastics was co-ordinated by a female 'manager of gymnastics', specialised in teaching that subject in the Italian health resorts. 220 All the assistants, following the directives given by this 'manager of gymnastics' or, in her absence, the detailed instructions of a guide-book, Gymnastics in health resorts, ${ }^{221}$ engaged all little female guests in a series of regimented and elementary exercises, such as jumping, vaulting, exercises with a corrective aim, special exercises after sea-bathing and games.

In the paragraph dedicated to advice for the assistants, the already mentioned guide-book stated moreover: "keep in mind that gymnastics wisely taught and applied in the right amount can make a delicate child become a strong one. Physical education is the medicine of the race." In 
addition, it pointed out: "children in health resorts are generally frail; for them gymnastics constitutes a very good prophylactic measure. Make sure that respiratory gymnastics and the exercises in decubitus [lying on the ground] are done in the right way".222

Particular attention was given to any symmetrical or asymmetrical imperfections of the spine, discovered during the initial medical examination. With their backs bare, in order to better show their movements, the Piccole Italiane were subjected to a series of specific exercises, the efficacy of which was verified during the final medical visit. The final task was to send them back home prettier, invigorated and trophic, to the joy of their parents.

\subsubsection{Conclusion}

Fascist children's health resorts had a preventive, prophylactic and curative value to fight illness, and demonstrated special attention to the state of the guests' health, as well as to their nourishment and hygiene. Both at the beginning and at the end of their journey, a physician controlled the children's chest circumference, weight, and muscular strength, and generally these values increased considerably.

The light, sun and air baths offered free to a growing number of users contributed, together with the motor activities practiced during all schoolmonths, to considerably strengthen the new generations of Italians.

Naturally, the children of both sexes enrolled in the health resorts missed their parents a lot, and vice versa. In general, Italian families expected that sacrifice and result compensated each another, while the little boys were somehow proud to avail themselves of this kind of pre-military service, according to the martial and virile ideals instilled into them since the first years of life. Female children, whose military spirit was not encouraged as much as domestic duties at home, could find it harder to leave their mothers and little brothers, with whom they spent most of their time. The press does not report any data on this, but from as little as we know about the feeling of female children, there is oral evidence that some problems did exist.

The propaganda did not fail to inform, in detail, citizens of the progress obtained in that field, in seeking the widest consent which could reflect on 
the political choices of the regime. Besides mentioning the majestic Exhibition of health resorts and of the assistance to infants, which was held in Rome in 1937 in order to illustrate how much Fascism had done for young people, the work of the press has to be remembered.

In summer, every day there were lots of articles on children's health resorts. They described health resort inaugurations, visits of the authorities, government inspections, departures, arrivals, and public displays, and documented each event widely by means of photographs as well. These various items of news were used to compose colourful pieces from the sentimental to the patriotic, and the ideological. In general, these articles were welcomed by the authorities, but also by parents who were more and more persuaded that sending their children to the health resorts was really a good choice.

Especially from the latter part the Thirties, a more military spirit changed the atmosphere of the children's health resorts in the name of order, sacrifice and efficiency. It aimed both at changing their nature and transforming those healthy holiday places to places of military drill and political indoctrination. Naturally, there is no evidence of the success, or failure, of this policy, due to the usual fascist censure, but we know that some of the activities practised in the health resorts, such as educational, corrective gymnastics and games, were impoverished in content. However, parades and displays, which required hours and hours of training in search of uniform and perfect synchronisation, invaded more and more the time previously dedicated to healthy lessons of physical education. 


\subsection{Visibility through sport: contests and displays}

This chapter gives a generic view of female motor activities, as well as important sport displays and contests, throughout the years of Fascism. On athletics more will be said in detail, since it was the most popular sport considered sufficiently 'suitable' for women.

In the early years of Fascism there is little information on female sports, in comparison to that given by the media on male sporting enterprises. In fact, although society was living through a dynamic and revolutionary period, and a number of modern women enjoyed 'manly' sports, their achievements did not interest the people. Turning the pages of specialist newspapers and magazines, one can find a few articles on female motor activities, 223 and often the non-specialist press commented on this kind of news ironically.

Pioneer sportswomen were signalled in the territory from at least the beginning of the Twentieth Century (Chapter 3.2), but also in the following years they were considered an eccentric elite to be looked upon with astonishment and/or suspicion. In many other European countries and the USA, however, sportswomen were fast growing in number and quality.

Under the push of international athletics events, the phenomenon of female athleticism started at the very beginning of the 1920s, i. e. before Mussolini came to power. However, in subsequent years the fascists appropriated, organised and at the same time channelled this phenomenon from on high, 
mainly stressing the capillary diffusion of those sports which did not interfere with its manly hegemonic plans.

The history of women's sports under Fascism has been here divided into three periods: the first - from 1923 to 1929 - was the time of the discovery of women's sports; the second - from 1930 to 1936 - was that of 'definition' and a framework within which sportswomen could move; the third - from 1937 to 1943 - was that of its popularisation and mass achievement.

In so far as the image of Italy as the Sporting Nation par excellence needed internal consensus and hence extensive 'visibility' (Chapter 2.3), male and female physical activities were often shown in public. This visibility involved the capital and other important cities in gigantic performances, combining both sporting and fascist ritual. Those events were positively commented on by the media and reached the whole of the people. Such a Sporting Nation, however, needed a wider visibility for internationally showing the astonishing results of Mussolini's efforts in shaping the New Italians; not only sportsmen but also sportswomen, although in a subdued tone, were engaged in international meetings, as will be mentioned later.

\subsubsection{Modern women and sports in the Twenties}

When Mussolini started to hold sway over Italians, gymnastics and other 'cheap' sports were already being practiced by a number of dynamic female students and manual or intellectual women from the north, while 'expensive' sports were regarded as the preserve of women of the upper classes. The latter followed the modern habits of high society, and whoever among them had enough energy, time and passion to train regularly, could compete in exclusive sports championships. Their inspirational models were sportswomen of the aristocracy, and especially the Royal Family.

Apart from King Vittorio Emanuele III, who had an inferiority complex about his small size and practiced only hunting, the rest of the Savoy Dynasty was keen on many sports. As has already been said (Chapter 3.1), Queen Margherita - an open-minded person of the Nineteenth Century - was a pioneer in female mountaineering, hiking and cycling. Unfortunately, her competitive spirit was not inherited by her only son Vittorio Emanuele, but was transmitted to her grandchildren, especially the first, Princess Jolanda of Savoy. 
Young Jolanda and her three sisters were trained in gymnastics, horseback riding and fencing, according to the Piedmontese sporting tradition of the family. Once adult, Jolanda became a 'militant' sportswoman, especially enjoyed outdoor sports, such as hunting, downhill skiing and horseback riding. This latter discipline, practiced also after she married Count Calvi of Bergolo and became a mother, gave Jolanda fame and some prizes. ${ }^{224}$ A further example of aristocratic sportswomen was the charming Princess Maria José from Belgium, who married Crown Prince Umberto of Savoy. Her father, King Albert, practiced several sports, and lost his life climbing a mountain. Maria Josè, good at mountaineering, tennis, skiing, skating, swimming, horseback riding and fishing, was often photographed by the press in elegant sportswear. 225

Exclusive sports activities such as golf, fencing, car racing and tennis were generally chosen by children of high society and the wealthy middle class. Turning the pages of specialist sports magazines, one can read important family names of Paola Medici of Vascello, Maria Bernasconi of Cernobbio and Carla Visconti of Modrone, who are mentioned in golf, and Isaline Crivelli-Massazza, who used to compete in golf also abroad, in mixed championships. ${ }^{226}$

In those years, tennis was also played by aristocratic ladies, such as Baroness Levi and Countess Aline Macchi of Cellere, but also bourgeois women. Among these were Lucia Valerio, who in 1929 became national champion, Sandra Perelli, especially good in doubles tennis, and Rosetta Gagliardi Prouse, all-round sportswoman and wife of a competent tennis player.227 They were members of the Tennis Society of Milan, and sometimes were engaged in international contests.

In 1920, for the first time in Italian history, a woman participated in the modern Olympic Games. This was the above-mentioned Rosetta Gagliardi, who went to Antwerp, the only woman in the Italian team, but unfortunately she did not qualify. However, she had the honour to be one of the bearers of the Italian flag.

In the Twenties, some sports disciplines excluded or discriminated against women more than others. Not only specialist physicians (see Chapter 5.1), but eminent technicians were critics, for example, of female fencing. 
On the occasion of the first female fencing championship, held in 1928 at Treviso, 228 the famous fencer Nedo Nadi (5 medals at the Olympics of Antwerp!) affirmed that he did not like female fencing at all. He confessed that during a previous mixed contest organised in Cremona, he had left the gymasium in disgust when the female team started fencing.

But one year later, Nadi admitted to be doubtful that fencing did not really suit modern women, at least for the lighter discipline of foil. In truth, he had been positively impressed by the talented female foiler Germana Schwaiger from Treviso, winner of the Italian championship in 1929.229 (Nadi's perception turned out to be correct, for Germana came first at the European meeting of Florence, in 1931.)

Elitist motor car racing attracted wealthy male drivers, and some eccentric women, under the influence of the futurist myth of 'motors'. These contests excited the passion of Italian spectators a great deal.

The first female driver was Maria Antonietta Avanzo, who, from 1920 onwards, participated with success in important contests such as the Targa Florio and Mille Miglia Cup,230 driving Packard and Alfa Romeo cars. Once, in the $423.5 \mathrm{Km}$ car-circuit of Brescia, she came third and achieved the notable average speed of $107 \mathrm{~km}$ per hour. 231

Her astonishing enterprise, and the fact that she was a happy mother as well, gave her a special popularity. In 1928, she could express herself in favour of women driving, by writing: "When for the first time I drove my car in Italian streets, I saw people trying to save themselves by jumping on the pavement! Today, a woman can easily drive with the same safety and capacity of a man. In this tumultuous life a car is more and more necessary. Does a woman driver lose her femininity, according to aesthetics? I do not think so. On the contrary, I guess her elegant figure perfectly suits the line of a car, and they complement each other."232

But, when in 1927 the first women's motor car race was organised in Tuscany, a single competitor entered! (However, seven years later, of about 30,000 driving licences 1,700 were given to women in Turin.)

In the 1920s, less expensive disciplines such as athletics, basketball and gymnastics involved a number of middle and working class women, from the most industrialised and modern regions of north and central Italy. Their engagement was a clear signal that, through school and/or job, they had 
freed themselves from most traditional womanly patterns, but also signaled that they were ready to start a new and exciting experience to compete, like other European women.

The push came from Patricia Milliat, who in 1921 organised the Monte Carlo Games for the first time. These Games were preferably called Olimpiadi della Grazia [Grace Olympic Games] in Italy, so as to stress the typical feminine 'grace', and reassure the usual right thinking. In 1921, Patricia Milliat founded both the Federation Sportive Feminine International - to which Italy adhered - and the Women's World Games, the latter lasting until 1936.233

The Monte Carlo Games of 1921 - Monte Carlo being near the western Italian border - attracted one team from Busto Arsizio, in Lombardy. Those neophyte female athletes competed in high jump, $60 \mathrm{~m}$ and $4 \times 75 \mathrm{~m}$ relay races, but unsuccessfully. However, this experience, which was positively commented on by the specialist newspaper La Gazzetta dello Sport, ${ }^{234}$ was important for the subsequent development of female sports within the country. In fact, in the same year, the Pro Patria et Libertate Society of Busto Arsizio organised a women's gymnastics, athletics and basketball contest, which involved about 100 women.

For the following Monte Carlo Games of 1922, a select number of Italians participated in athletics and basketball, but better results came from the next 1923 Monte Carlo Games, where two Italian athletes, Maria Piantanida and Lina Banzi, competed honourably and were congratulated by Patricia Milliat in person. ${ }^{235}$ Incidentally, after 1923 the Monte Carlo Games were discontinued, and the next Games were held twice in London, in 1924 and 1925.

In 1923, the Italian Federation for Women's Athletics - FIAF - was founded, aiming at the diffusion of female athletics and other sports, and the first Women's National Championship was organised. However, common people were not prepared for such a gender revolution, which opposed the patriarchal values of a society based on men's strong virility and women's weak femininity. As a consequence, that first Championship was commented on by spectators and press negatively.

The daily Il Giornale d'Italia wrote: "The first female championship was not followed by many spectators, and was not approved by right thinking 
people, who believe it necessary for a woman to keep strong and healthy, but not through deforming athletics exercises"; the keen fan of sports, Luigi Roffarè, declared that a woman athlete who exercised in discus, javelin and shot, could easily become a terrific 'cannon-woman' of the circus. ${ }^{236}$

In 1924, the national FIAF team went to London for the Women's International and British Games, which involved 6 countries, but they placed last. In the following years, apart from an unsuccessful meeting against France, women's activities were restricted to domestic championships. However, a number of athletics disciplines, such as long distance and cross-country races, were added, and some women demonstrated an indubitable capacity.

Among them, two all-round athletes and basketball players from Turin, Andreina Sacco and Marina Zanetti, should be mentioned. After brilliant careers at national level, these emancipated sportswomen continued to work in favour of female sports in Italy and abroad. Sacco became a competent technician, and was the founder of modern rhythmic gymnastics, ${ }^{237}$ and Zanetti was nominated national technical commissioner for the female athletics team. ${ }^{238}$ This happened just after FIAF had been abolished by the 1928 Charter of Sport, and FIAF members were automatically transferred to the Federazione Italiana di Atletica Leggera [Track and Field Italian Federation]-FIDAL, under CONI control.

To give an idea of the real number of qualified athletes enrolled in FIDAL, it has been calculated that by the end of the 1920s there were no more than 100 sportswomen; however, women enrolled in local sporting societies were numerous, especially in the north of Italy: for instance, 3,950 in Lombardy, 3,116 in Piedmont, but 717 in Latium and 154 in Sicily.239 In 1928, Canada and Italy were engaged in a female basketball meeting in Milan, which ended with the score: Canada 68, and Italy 2! In the same year, the female gymnastics and athletics teams were sent to Amsterdam for the Olympic Games. There, the national athletics team (6 women) qualified only for the final $4 \times 100 \mathrm{~m}$ relay race, where it placed last, while the young gymnastics team from Pavia was second and gained the silver medal. ${ }^{240}$ It should be added that in Amsterdam, among 16 male and 2 female judges for gymnastics, Mrs. Bonaretti was from Italy; as far as we know, it was the first time that an Italian female judge was involved in the Olympics. ${ }^{241}$ 
In the Twenties, gymnastics was one of the most practiced female activities, according to the Italian tradition of the previous century (see Chapter 3.2). However, because of the First World War and difficult post-war period, the whole of the female sector was re-organised in 1920.

A new National Feminine Committee was founded within the Federazione Ginnastica Nazionale Italiana [Italian National Gymnastics Federation]FGNI, and new norms and programmes stressed not only traditional 'gymnastics' but modern 'female sports and games'.242

Finally, after 9 years, the third National Female Gymnastics Contest could take place at Trento, in 1921. The fourth, re-named the first, enrolled about 1,800 young girls and was held at Rome in 1922;243 there, for the first time the southern part of Italy contributed by sending some teams.

The FGNI Feminine Committee worked hard in favour of 'gymnastics' and placed with honour in international meetings, such as the already mentioned Antwerp Olympics, and the gymnastics contest held in Dinard in 1929.244 However, the programme of 'female sports and games' was progressively abandoned by FGNI in FIAF hands.

National gymnastics and athletics displays were organised also for fascist female Young Italians (Chapter 5.2) each 24 May, so as to celebrate victory in the Great War. In 1928, after careful selection, the most talented Young Italians of 14-18 years were sent to Rome for the first Concorso GinnicoAtletico Nazionale [National Gymnastics-Athletics Contest]. Then, 151 teams from 71 provinces competed.

The Concorso Ginnico-Atletico Nazionale aimed at stressing physical strength and the combative spirit of modern fascist women, ${ }^{245}$ but it provoked trouble even before the performance was held. Its programme, which included hard and 'virile' athletics disciplines, and even 'target firing by musket', roused not only enthusiasm among the fascist organisers, but indignation of the Church and the usual right thinkers. 246

People were bound to think that a musket did not suit a gentle feminine hand, and the Church thought that girls, by displaying their young bodies in public, would lose womanly modesty. What is more, that 'indecent' display had to take place in the Holy Roman City!

On the whole, the fascist hierarchy was uncertain about female athleticism. Some were totally in favour, for the sake of women's modernity and a 
healthy race; others were more doubtful - including Mussolini - or even opposed, by claiming that women's 'sportivization' could be responsible for a demographic decrease of population, and too emancipated feminine ways. In conclusion, at the end of the 1920s, female sporting activities became a problem to be looked at very carefully, and solved as soon as possible.

\subsubsection{Suitable sports and displays from 1930 to 1936}

In the 1930s, track and field was the most popular sport practiced by girls, while gymnastics gradually lost support. Previously, gymnastics attracted women for being the only accepted female activity, but it was a really technical and selective discipline needing qualified teachers, indoor gymnasia and apparatus. Fashionable athletic disciplines attracted modern women for being natural, healthy, cheap, and easy to be practiced in the open.

The general problem of female athleticism and suitable sports involved the medical sciences at the start of the Thirties. (Chapter 5.1) It was stated that a woman would indulge in a selected range of activities, such as basic physical education, gymnastics, roller-skating, basketball and athletics (and skiing, fencing and tennis for the wealthiest girls) so as to preserve health, maternity, morality and Latin femininity.

Competitive activities were discouraged, and the very popular football remained strictly men's affair, although there is evidence that in the years 1932-1933 one female football team from Milan was allowed to train by Leandro Arpinati, then leading CONI, but on condition that the team did not perform in public. ${ }^{247}$

By the way, it has not been possible to find earlier sources on Italian female football, but simply information that a futurist ballet by Prampolini and Hrska [?], entitled Foot-Ball, was performed in 1928 at Turin. There, ballet-girls dressed in coloured and fancy 'futurist' blouses and shorts, and danced imitating the football game. ${ }^{248}$

In 1931, the Catholic magazine Azione Muliebre launched an enquiry among religious families, asking for their opinion on female sports. Mothers agreed that a moderate sporting activity was good, but mixed groups were a real 
danger. ${ }^{249}$ This crusade followed that led by the Azione Muliebre in 1926, supporting respectable people's plan to separate sexes also on the beach, 250 and in 1934 a Florentine public swimming pool reserved to women was closed due to the malicious curiosity of hidden male spectators. ${ }^{251}$

As a matter of fact, to please the Church, amateur swimming and cycling were little accepted or tolerated, and with a number of cautions that lasted for very long. At the start of the 1940s, the Bishop of Trento forbade female swimming contests in front of male spectators, and mixed genders in bathing pools and the beach; and female cyclists could not wear shorts. ${ }^{252}$ More generally, Fascism, trying to keep a reasonably good relationship with the Vatican, stated that training and contests had to be separated by sex. In 1932, severe dispositions by FIDAL obliged sportswomen not only to wear long trousers over shorts, but to take off their trousers just for the competition. ${ }^{253}$ As an example of religious prudery, the Bishop of Aosta did not fail to denounce the well-known athlete Vittorina Vivenza to the authorities, simply because she used to arrive at the stadium wearing comfortable and modest shorts. 254

However, in the wider plan of massive physical regeneration of genders, the whole of the state bodies in charge of people's bodily health (Chapters $\mathbf{5 . 2}$ and 5.4) continued to push common women towards motor activities, while CONI sought new female champions to enrol in its federations.

This notwithstanding, statistics show that at the end of 1936 the number of sportswomen was rather low, i. e. less than 5,000.255 Among them, 3,000 competed in track and field; 800 in basketball; 500 in gymnastics; 80 in swimming; 70 in foil fencing. In addition, 225 university students practiced a non-defined sporting activity, and about 300 women competed in mountaineering and skiing. Most of these women $(3,273)$ were Young Fascists, and especially indulged in track and field (about 2,500); others were Dopolavoro workers, mainly playing basketball. 256

The most important national meetings were the annual athletics championships led by FIDAL, 257 and ONB national displays. The latter involved many girls in athletics and choreographic gymnastics exercises, also with the use of small-size apparatus. In preparation for these displays, a detailed programme was sent to provincial ONB seats, distributed to local ONB sections, and taught young female members, step by step. Then, the 
best girls performed for the Victory Festival of 24 May in Rome, and, from 1934 onwards, participated in a new display, the National Gymnastics Contest for Young female Italians.

Amazingly, the male national GUF Littoriali of Sport contest involved women in 1933 as well (Chapter 5.2.6), but this mixed experiment was harshly criticised and not repeated for long; however, university Agonali Games for female students were instituted in 1935.258 These consisted of cultural and sporting meetings organised among different universities but, contrary to Littoriali of Sport, they did not end with a final national contest. In the following year 1936, ONB founded the provincial Agonali of Opera Balilla, for male and female members of 818 years. They were mixed contests involving culture, art and sport; in addition, there were military contests for boys, and contests of typical 'feminine' works. At the beginning, only girls of 14-18 years were allowed to compete in the sporting Agonali.259

From 1930 onwards, international events engaged Italian athletes with more or less success. In 1930, the Italian female team was sent for the first time to the Third Women's World Games, held in Prague. There, the best result was third place in the discus by Vittorina Vivenza, but on the whole the team placed only sixth.

Marina Zanetti, the FIDAL technical commissioner, organised for the first time a women's international meeting in Italy. It was not so easy to overcome the usual prejudices, and Marina had to ask for support from the Duce in person. Finally, the meeting was held in 1931 at Florence, and about 150 athletes from 11 nations participated in this Olimpiade della Grazia [Olympics of Grace].

Such a 'poetic' name had already been used for the quoted Monte Carlo Games, but Marina explained that "the poetry of this name was a necessity, because it was difficult for Italian girls to do sport, and compete against strong adversaries, without kicking up a great fuss and get involved in the usual polemics".260 The Florentine Olimpiade della Grazia, unsuccessful for Italians, was not repeated.

In the next year, 1932, the athletic team did not participate in the Los Angeles Olympics, and in the Fourth Women's World Games of London they competed unsuccessfully. In 1933, the athlete Ondina Valla became a 
star in track and field, and due to her results the Italian team won against France.

Finally, in 1935, the Italian team won again against France, and in the 1936 Berlin Olympics took off, through the victory of Valla in $80 \mathrm{~m}$ hurdles, and fourth place by both Claudia Testoni and the $4 \times 100 \mathrm{~m}$ relay race team. (Chapter 6.1 and 6.2)

As has been already mentioned (Chapters 4.3 and 5.2), the bellicose plans of the Duce in the mid-1930s brought the mobilisation of the country, including women. The ONB, GUF, OND and other state bodies stressed sporting activity, as the main way to gain consensus among Italians, to show the world to be a modern nation, and try to emulate powerful Nazi Germany, where sport and population policy went together. CONI federations were involved as well; in 1936 it was said that 30,000 sporting events were held, and about 40 million spectators watched them. ${ }^{261}$

Statistics of 1936 also showed that much had been done by the fascist government for sport and traditional Italian games, and their popularisation, among citizens. Those statistics did not separate by gender; however they gave a general idea of the importance of this phenomenon, probably also by manipulating figures, as will be mentioned later. For example, comparing the years 1929 and 1935, Italians learned that: a) at national level, sports and games championships involved 2,506 people in 1929, and 31,181 in 1935; b) at provincial and local level, about 3,000 and 3,719,507 people respectively; c) provincial and local managers, physical education teachers and sports judges were only 1,034 in 1929, but 14,038 in 1935. Finally, the Concorso Ginnico-Atletico Nazionale for female Young Italians involved 452,501 girls in 1929, but $1,991,871$ in 1935.262

\subsubsection{Mass displays and championships in the years 1937-1942}

In 1937, all the above-mentioned state bodies joined in a unique state institution, the powerful GIL, which took care of the mass 'sportivisation' of the country in the war years. (See Chapter 5.2) Under GIL leadership, the engagement of young people in sports was really extensive, if one trusts statistics of that time.

The data showed that the number of women practicing motor activities had increased a great deal. As an example, female Young Fascists involved in 
national displays were 9,819 in 1936 , but 23,977 in 1937 . In the same years, the male Young Fascists were 962,774 and 1,290,677, respectively, according to the PNF Yearbook issued in 1938.263

Young women's and young men's different increases were probably due to the fact that in previous times the male sector was implemented without problems, while the female sector, having aroused polemics everywhere, had been neglected; however, at the start of 1937, the nationalisation of women through sports, gymnastics displays and other social initiatives could not be delayed any further, according to the aggressive politics of that time. (Chapter 4.3)

Under GIL leadership, mass displays for both genders were organised at central and local levels - sometimes even in mixed groups - for the sake of the warlike fascist choices that needed popular consensus, cohesion and visibility more and more. The organisation of local displays engaged GIL managers and teachers of each province, who had to work hard to try to understand in detail the collective evolution and physical exercises prescribed by booklets sent from on high. Boys and girls were trained according to this programme, and were selected in view of the following GIL national sports meetings, where the best provincial teams would participate.

There is evidence that a perfect correspondence between the 'on paper' grand central plans, and their 'real' execution at lower levels, was difficult sometimes. Locally, there was lack of financial support and suitable facilities, especially for the minor women's sector. However, the organisers - most of them being truly keen on sports - used the 'typical' Italian fantasy for managing and overcoming obstacles, or hiding cheats. (Chapter 6.3) GIL national sports events were Pharaonic performances imitating those of the German Hitler Jugend, which engaged much money and thousands of competitors. The technical content of physical exercises was not too relevant, but uniform execution of exercises counted for much. There, Italian youth had to show that it was strong and disciplined, ready for the 'sporting' call and, metaphorically, for war. Royal and fascist flags waved jointly with those of sporting societies and provinces, and patriotic and fascist hymns were sung in choirs by both actors and spectators at such theatrical shows. Obviously, the media gave these performances extreme 
prominence, and photos, radio and newsreels reached the people in their homes.

The GIL annual programme of national sports events, and other important activities dealing with motor activities and health, was ambitiously wide. Looking at the calendar of 1941, in the depths of war, one knew for example that in February there were national winter sports championships for both genders, and also for officers; in April, training courses for teachers in health resorts; in May, the national Gymnastics Festival, and the national Physical Education Contest for Avanguardisti and Giovani Italiane; in June, there was the start of the GIL summer camps and health resorts; in July and August, national courses for fascist culture and physical education were held, involving GIL managers and teachers; again in August, national courses for future officers and GIL assistants; in October, the start of premilitary courses, and the celebration of the GIL anniversary; on 8 December, the celebration of the Balilla Day. ${ }^{264}$

The next lines will describe important women's displays organised by GIL in those years. First of all, we should mention the Concorso Nazionale di Ginnastica [National Gymnastics Contest] - also called the National Gymnastics Festival of GIL - that engaged female Young Italians and, from 1938 onwards, female Young Fascists as well. This contest was held each May, starting from 1934, and the programme included not only gymnastics but other sports championships, which increased year by year. For instance, the first Concorso Nazionale di Ginnastica, disputed in Rome in 1934, hosted only tennis and roller-skating championships; for that of Milan, in 1937, were added swimming, fencing, and track and field. ${ }^{265}$ But on these championships, further details will be given later.

In 1936, the Duce decided to increase the OND female sport sector as well, in particular supporting the participation of women in the Dopolavoro national contest, so as to propagate enthusiasm for sports among workers of both genders. For OND female members, in 1937 the first Female National Gymnastic-Athletic Contest of Dopolavoro was organised, alongside the male one that had started in 1928.

Each of 94 provinces was invited to train selected teams, and to work hard so as to convince the mass of workingwomen to spend their spare time in 
physical activities. As a consequence, for the 1937 national female Dopolavoro contest of Rome, about 180 of 350 teams were chosen. Half of the teams were constituted by industrial workers, about 60 came from provincial OND sections, and the rest were members of sports societies affiliated to OND. About 2,000 women reached Rome in 1937, and for three days they spent their leisure time visiting the capital together with male comrades, performed different sports - even archery - and concluded the contest with a spectacular and perfect gymnastics display, in front of Mussolini. 266 Nobody dared critic ise the participation of mixed groups. In 1937, GUF and GIL organised in Rome the first Littoriali of Sport for female university students. In the following years this contest was hosted by other important cities and, from 1941, male and female Littoriali of Sport were held jointly.

In Milan, for the 1939 Littoriali of Sport, about 1,000 girls competed in athletics, basketball, gymnastics, swimming, tennis, fencing and skiing. According to a journalist, the Littoriali of Sport of Milan were really significant, being: "the complete victory against old ideologies and traditions, the affirmation of women's new tasks and responsibilities, within a fascist imperial atmosphere."267

In 1939, GIL instituted the Ludi Juveniles [Juvenile Games], a contest of culture, art, physical education and sport for both sexes. These new games replaced the previous ONB Agonali, which has already been mentioned. The Ludi Juveniles were addressed to secondary school students of 16-18 years (later also to younger and older competitors) and involved different institutes at local and provincial levels.

It had been planned also to organise Ludi Juveniles at national level, but there is no official evidence that they really did take place, or were 'on paper' contests. One article reports that in 1939, about 7,000 students of both sexes were in Rome for the final contest, ${ }^{268}$ but probably this was the final contest of the Roman province.

In the following year 1940, female Young Fascists of 18-21 years were allowed to take part in Ludi Juveniles as well; ${ }^{269} 80,143$ girls were engaged in these games, while there were 147,789 boys. 270

Lastly, there is evidence that in 1941 and 1942 GIL also organised Concorsi Nazionali Femminili di Educazione Fisica [National Female Contests of 
Physical Education] at Montecatini Terme, engaging both female Young Italians and Young Fascists. ${ }^{271}$

In 1940 and 1941, female teams of GIL participated with some success, especially in tennis and swimming, in meetings involving the Hitler Jugend from allied Germany, and other European countries which were occupied, or under the influence of the Berlin-Rome Axis. In 1942, the European Youth Association was founded among these countries, where theatre, art, and especially sport, were important means to spread the idea of a new young Pan-European community, which was animated by a militant and anti-Bolshevist spirit. However, this association, owing to the difficult relations between the German and Italian presidency, after the first European Youth Sports Championships of 1942 attended by female teams from Italy as well, soon had to give up. ${ }^{272}$

The whole of activities mentioned above might have engaged a remarkable number of women. For official statistical data, we have to refer to the Sports Yearbook, a propagandistic, elegant and expensive publication (about 100 It. Lire, one tenth of a very good monthly salary), reporting the most important sporting displays and results of the years 1938-1941, and given free to local PNF seats. ${ }^{273}$ Statistics, drawings and photographs illustrated, and redundant Mussolini sentences commented on the text.

Once, in the Sports Yearbook of 1940, these sentences were also translated into German, so as to please Italy's ally and probably show that Nazi Germany and fascist Italy pursued successfully the same sport policy and, metaphorically, the same bellicose ideology. But in the following year, German disappeared from the review, and this was one of the signals that relationships between the two allies were not as good as in previous times. Sports information given by the whole of the Sports Yearbooks was not uniform, and the first numbers lacked details especially for the women's sector. For example, the Sports Yearbook of 1937 only reported that 23,977 Young Italians had taken part in a non-defined number of sports events. The young men totalled 1,290,677.

The following Yearbook of 1938 gave more details. It was reported that 111,415 Young Italians, together with Young Fascists, participated in 4,616 sport meetings (the boys numbered 1,903,051), and that female 
championships were held for track and field, gymnastics, swimming, basketball, roller-skating, fencing, winter sports, tennis, and target-firing. In the next year, according to the 1939 Yearbook, the number of female participants was said to have increased to 168,978 (the boys had relatively decreased to $1,846,359$, probably being engaged in Albania), and that of women's meetings reached 11,746; the number of female sports championships was exactly the same.

In 1940, the Sports Yearbook reported that in total 228,288 girls competed in 12,331 displays (the boys had slightly increased to 2,153,566). Finally, in 1941, female Young Italians and Young Fascists engaged in sports were said to be 253,459 (the boys $1,819,753$, but many were engaged in the conflict) and 10,581 women's displays were held. As for women's sports disciplines, in that very year mountaineering had been added, and other disciplines, such as female rowing and horse-riding, were practiced locally and supported by GIL as well.

Apart from GIL sporting activities, in the war years CONI federations were in charge of top level women's activity. The number of sportswomen, according to fascist propaganda, had increased considerably, as a consequence of the mass juvenile activity promoted by GIL. Talented athletes, selected by the federations for professional sports, took part in annual CONI championships, and made some international achievements, such as first place at the European female basketball championship in 1939, and a number of world records in roller skating.

(Chapter 6.2)

As far as female track and field was concerned,274 in 1937 the national team gained the world record in the $3 \times 800 \mathrm{~m}$ relay race at Turin (Chapter 6.2), and placed first in the $200 \mathrm{~m}$ race at the international meeting of Paris. In the following year 1938, at the first European female Championships of Vienna, the national team placed third in the $4 \times 100 \mathrm{~m}$ relay race, and won the $80 \mathrm{~m}$ hurdles, equalling the world record. That enterprise was enthusiastically commented on by the specialist press, which did not fail to stress that a very admirable 'fascist' achievement had been obtained, due to extraordinary courage and love for the Fatherland.

Competitive cross-country was abolished for both sexes in 1939, but lasted as a popular amateur discipline mainly engaging Dopolavoro workers. In 
the same year, the national female athletics team gained two world records in the 80m hurdles, competing against Poland and Germany. In 1940, when Italy was involved in the Second World War, the most important international contests came to a long-lasting standstill, as well as internal professional contests, but juvenile events continued until 1943. Then, the civil war divided Italy in two parts, and a few sporting displays were performed locally.

\subsubsection{Comments on the data}

In the last fascist period, characterised by GIL leadership, propaganda stressed the mass involvement of the nation in sport performances $(30,000$ in 1940), which were said to be directly seen by a huge number of spectators (in 1940, 40,000,000 of 45,000,000 inhabitants). In conclusion, the regime aimed at giving these displays the widest visibility and social involvement.

According to statistics presented above, one would think that Italians had voluntarily become a sportspeople, but one should add that, especially at local level, whoever did not participate repeatedly was noticed and signalled to the fascist authorities. In addition, Mussolini and his hierarchy used to mystify and/or manipulate data - and not only in the field of sport - by considering the mass as eternal children needing education and reproof, but also for protection and 'little white lies'. On this will be given examples now.

- In spite of propaganda on sports achievements, in the year 1930 the members enrolled in CONI sports federations were about 600,000 (namely $0.75 \%$ of total population) and, what is more, about half were hunters!275

- Although the enrolment of the youth in ONB and GIL was practically obligatory, and in the late Thirties membership cards were even sent to newborn babies, this was exaggerated by propaganda as the result of free and enthusiastic assent of Italians.

- There is evidence that, especially in small universities, students were more or less forced by GUF to train in different kinds of sport, without any previous selection; in case their number was not enough to form a team, or there was a shortage in some disciplines, common citizens were 'warmly' invited to join the university team, and were suddenly 'promoted' as 
university students for local contests among universites, in preparation for the next national Littoriali of Sport. Obviously, this kind of cheating was officially forbidden, but there is evidence that some rectors of universities closed both eyes. ${ }^{276}$

- There is also evidence that girls who did not study further participated in national university Littoriali of Sport, and their coaches were conscious of and supported these cheats, so as so to increase the prestige of their province. (See the interviews to Valla and Serafini, Chapter 6.1 and 6.3).

- In 1937, it was proudly declared that there were 5,000 sportswomen, but the press did not report that in earlier 1928 the number of girls involved in organised physical activities was much higher, i. e. about 7,000 women in Lombardy and Piedmont, and progressively less numerous in central and southern regions, the last being Sicily. ${ }^{277}$

- The increasing number of competitors, starting from 1937, concealed the fact that a number of all-round athletes enjoyed a number of disciplines, and participated in different championships. Looking at the lists of participants in detail, one finds the same names for female athletics, basketball, swimming, and so on. All the interviews granted by former athletes confirm this phenomenon. (Chapter 6.1 and 6.3.)

- The number of female participants was said to increase year after year, but this happened also because both adult women of 18-21 years, and girls of 8-14 years, were then allowed by GIL to take part in Ludi Juveniles, previously reserved for 14-18 years-olds. Female adults could also participate in Concorso Nazionale di Ginnastica, originally a contest reserved for younger girls.

- The huge number of local contests hid, sometimes, cheating by GIL organisers and coaches, who counted a simple training as a true contest, just to show they were good and efficient. (Interview E, Chapter 6.3.)

In conclusion, although nobody could deny that the phenomenon of women's involvement in physical activities assumed a more national dimension, it still remained a minor sector. Fascist data show that in the year 1939 - when female members notably increased, and male members relatively decreased their presence in sports contests organised by GIL the number of men was more than ten times that of women, namely $1,846,359$ and 168,978 . 
In addition, competitive women's sports were really under-represented in southern Italy, where juvenile fascist organisations fought against ancient prejudices on what was healthy and suitable for a woman, with really poor results. Those Yearbooks, reporting names and original provinces of female champions, show that these women lived in central Rome and Florence, and especially in the northern cities of Milan, Turin, Venice, Trieste, Genoa and Bologna, while Naples was the uniquely active province of the south, probably due to its early tradition in women's physical education. (See Chapter 3.1)

In truth, this gap brought evident consequences for the internationally. While Italian sportsmen gained a number of achievements, such as, for example, second place in the 1932 Olympics of Los Angeles and third at the Berlin Olympic Games of 1936, and the prestigious World Cup in the world football championship of 1934 and 1938, the women's best results came just from the $80 \mathrm{~m}$ hurdles race, and victory at the first European female basketball championship in 1938. Obviously, fascist propaganda exaggerated Italian women's achievements, but actually they were poor in comparison to those of sportswomen living in other modern countries, whether democratic or dictatorial. ${ }^{278}$ 


\subsection{Fashion, aesthetics and feminine form}

As has already been mentioned (Chapter 2.3), masculine aesthetics were incarnated by the Duce, whose strong body, 'bronze' torso, and fascist tough ways fascinated Italians. On the other hand, through the years female aesthetics were influenced by discordant bodily shapes, deriving from both international and fascist fashion and style.

In the Twenties there were no evident differences between domestic and foreign aesthetics of the body. From the USA, Great Britain and France, a 'sporty', tomboyish, nimble and slender prototype of woman had spread across the world, and among modern Italians as well.

Fascism dressed female members of its institutions in appropriate and fashionable clothes. In the years 1926-1929, Small and Young Italians, then led by Feminine Fasci, wore short black skirts, ties, straight and long white blouses, which made their hips and breasts look small, and their hair, cut $\grave{a}$ la garçonne, was held by coloured bands, so as to keep the view free.

Then, both fascist organisations and women's magazines urged girls "to disregard moonlight and feminine pallor",279 give up their lazy and weak lives without glory, and vigorously launch themselves into dynamic activities, like the men. These stereotypes were stressed according to the mores of the most industrialised countries, and the futuristic themes of dynamism and speed, which were national myths.

In sports magazines, some articles supported the new woman's aesthetics achieved through motor activities. A physician, Goffredo Barbacci, wrote a long article in favour of female swimming, as the most effective way to shape a beautiful and fashionable body. In his article, Barbacci first harshly 
criticised the sexual-phobic position of the Roman Church against child and adult 'nudity' in sporting activities. Then, he asked himself and readers why embittered spinsters and seminary teachers, who knew nothing about life and the family, should state what is moral and right. Finally, Barbacci exhorted Italian women to give up moralist prejudices and follow the modern habits of North European female swimmers, whose harmonious and supple bodies were displayed naturally, and looked on by men in admiration on the beaches.

Barbacci agreed that Italian women enjoyed sports such as tennis, horse riding, driving cars and dancing; however they did not swim, simply because they did not want to ruin their make-up and hair-style. In Italy, he wrote, the average male body approached the ideal of manly aesthetics, while women's bodies were frankly ugly. i. e. flat breasts and too round and flaccid hips. American women, however, were beautifully shaped, thanks to swimming, which was the most fashionable and popular activity, involving also 'classy' women and beloved movie stars. Barbacci ended by writing: "You [Italian women], who eagerly wait for American trend in fashion, even accepting that of Negroes and those of savage origins, why do you not imitate American women in the good things? Swim, go to swimming pools, and you will gain beauty and health, and be shaped like statuary women."280 In 1930, a humorist wrote about aesthetic, and especially moral, reasons for men to support a modern sportswoman. In the first part of his article, this writer observed that female 'sportivisation' had to be considered a revolutionary discovery, comparable to that of America. Nobody could but accept this phenomenon, which inevitably brought 'masculinisation' to women. "Once, he said, Italian women were sedentary, their small hands and feet, and big bottoms still remain a dream for many men; but nobody can stop or control this new phenomenon, which is like a meteorological event. Who could ever 'tear' a wheel from feminine hands? Although small feminine hands and feet are growing nowadays, nobody could deny that, although their smaller size was the sign of true feminine grace and sweetness, our great-grandmothers could be shrewish, ascerbic and gruff even in their prime of life."

"The big feet of a footballer, who, at the same time is a smiling and serene woman, is much better than small feet which metaphorically kick at much 
worse than a leather ball! Men should buy a punch-ball for the home, and leave their wives, daughters, and mothers-in-law to give vent to their exuberance and competitive spirit. Looking at them, streaming with perspiration, men should really bless sport."

"Nowadays, a woman plays tennis, cricket, golf, practices fencing, horse riding, cycling, and drives cars. She has short hair, and her body is not soft, but hardened by physical exercise; however, let her enjoy physical exercise honestly, and train peacefully, or she might even throw away saucepans and ask for female suffrage!"281

The famous intellectual and aesthete Anton Giulio Bragaglia, in 1929, wrote about sport and beauty, sport being the main way to achieve physical and spiritual harmony. Bragaglia illustrated his article with a charming athlete, Marina Zanetti (Chapter 5.6); photos of her slender and harmonious body showed a composed, luminous sense of beauty. 282

Naturally, Catholic magazines for women, such as Matelda and Fiamma Viva, had different opinions on what was good and aesthetic for a woman. In their opinion, girls could practice some sports, but with 'Christianity' and 'femininity', contrary to Anglo-Saxon or German women, who did sport with 'masculinity',283 and they added that female cycling should be definitely banned, being a disgraceful, coarse and anti-aesthetic activity for girls of good manners. ${ }^{284}$

At the start of the Thirties, Hollywood launched a new aesthetic form, embodied by blonde cinema stars. These had marked make-up and beautifully slender bodies, were self-confident, but less tomboyish than previously. In fascist Italy, however, both the current demographic campaign, and closer relationships between State and Church favoured a totally different, 'autarchic' model shape, that of the 'true-woman'. This woman had a very round body and was aesthetically old-fashioned, but this reinforced feminine modesty and fecundity.

As a consequence, Small Italians and Young Italians who enrolled in state institutions, being the official projection of fascist style and aesthetics, had to change their uniform and wear long pleated skirts and large blouses. It was an ensemble in black and white that covered knees and, at the same time, underlined round hips and breasts. 
The Young Italians had to add a long tie, and all girls had to put on a black beret that they generally disliked, according to oral testimonies of that period (Chapter 6.3). Both symbols of the fascio and Italian flag were sewn on their blouses, and their rank on sleeves. These girls had to wear modest uniforms for physical activities.

In truth, this uniform was simple and cheap, practically a 'normal' dress for common girls but, apart from ranks and symbols, it was completely different from the soldierly uniform of the boys, so as to stress that mild femininity had nothing to do with hard masculinity.

Obviously, the new and at the same time old-fashioned fascist aesthetics did not fit with the slender international woman. This latter was discriminated against, considered sterile, masculine and neurotic, and was ridiculed by fascist propaganda. She, who even dared to wear trousers, was negatively defined as a crisis-woman, and was said to be disliked by men not only for her too slim form, but also for her easy ways which discouraged any serious wedding proposals.

The regime and the Church opened a front against crisis-women and their trousers, even engaging fascist journals which normally debated serious political questions. ${ }^{285}$ One of these journals, Critica fascista, in 1930 ran an article by Mario Pompei, declaring: "nowadays, chic means to be a flatchested, skinny, pale woman (the opposite of a rural woman's ruddy complexion), with an eternally adolescent body. Women cut down on their meals, swallow pernicious pills, and practice other malignant expedients so as to obey this tyrannical and arbitrary fashion."286

Mussolini himself led a battle in favour of 'feminine fat', and entrusted medicine to convince common women, especially those living in the cities and therefore more in touch with dangerous foreign fashions, that diets and slimness were unhealthy, while a good weight was good.

However, not all physicians of the time agreed that 'fat' was aesthetic and healthy. For example, in 1933 Dr. Poggi-Longostrevi (Chapter 5.1) published an important book dedicated to physical culture of the female body, which said that the statuary feminine beauty of ancient Greece could be attained again, through aesthetic physical activities which would help women fight against the ugliness of skinny, but also fat and obese unhealthy bodies. 287 
At the beginning of the 1930s the regime mobilised propaganda for supporting the autarchic heavy shape. Gaetano Peverelli, then leading the press office of the government presidency, ordered elimination of images of too masculine and crisis-women from journals and magazines, and prohibited them from mentioning the slimness of Hollywood film stars, for the sake of Italian health and maternity. 288

On the other hand, this campaign promoting 'feminine fat' was in contradiction to the aims of juvenile state institutions, which educated girls in keeping their bodies fit and tonic, and also with specialist magazines. The latter did not fail to exhort sportswomen to practice different activities, so they could adhere to a sporting aesthetics which opposed fat and heavy bodies. For instance, articles celebrated famous sportswomen, such as the American swimmer Eleanor Holm, whose large shoulders, thin hips, quickness and tomboyish ways were said to be really envied by elegant women, ${ }^{289}$ other articles lauded German sportswomen, whose photos displaying slender legs and smart bodies were most convincing. 290

Other problems regarded the form of bathing costumes for Italian women, which could easily provoke scandalised reaction among people. In 1934, female swimmers engaged in the Turin international contest were allowed to dress in an elegant bathing suit designed exactly like that of male competitors; but, in 1935, the Rinascente chain stores offered decent bathing-costumes for women which covered shoulders and knees, in order to re-affirm 'feminine good taste' and moderation. ${ }^{291}$

But leaving aside contradictions and ambiguities, evident traces of the campaign against women's slimness can be found in popular songs and poems, and low profile humorous magazines of the mid-1930s. In this field, undoubtedly the most prominent but unintentional humorist was Mussolini himself, when he seriously affirmed that maternity suited feminine beauty; at the same time, discouraging photos of flabby and prematurely faded maternal bodies appeared in newspapers, magazines and newsreels! 292

The austere aesthetics of the 'true woman', who also had to avoid make-up and innocent feminine coquetry, were obviously supported by the misogynous Church and jealous Italian men, and possibly applied by common people with financial problems, or fanatical fascist women. 
However, they did not reach all working women, nor wealthy people who continued to adhere to the more agreeable imported aesthetic form. If one looks at photos of fascist parties of the time, for instance, there is an austerity in male dressing, but a worldly, sophisticated tone in women's clothes.

In the first years of the 1930s, a war was declared on foreign fashion, especially that from Paris. The National Fashion Body, an institution founded for spreading Italian fashion, opened at Turin the first National Exhibition on 12 April 1933. This exhibition, visited by the most important people, hosted a sector for modern sportswear, so as to stress that sporting activities were a means to transform female citizens into autarchic 'true women', probably fat, but strong and healthy. The press commented positively on the exhibition, and specialist magazines wrote in favour of the new sports aesthetics.

As an example, Lo sport fascista affirmed: "Modernity means sport, and through all kinds of sports the Fatherland can gain healthy, robust and youthful soldiers, and strong mothers. ... Nowadays, Italian fashion creates soft and agile lines because the new female body should be soft and agile as well. No corners or prominent bones any more, but harmony of form which is both healthy and beautiful." 294

In 1934, the war against foreign fashion brought women's magazines to publish fashion-plates of garments, but without mentioning that they were foreign. In general, fascist censorship was not interested much in magazines for women, by repute they were a minor sector of the press. However, in 1937 all foreign fashion-plates disappeared from women's magazines.

In fact, on May 1937 the Ministry for Popular Culture had been founded. It controlled all mass cultural activities, from theatre to music, books, press, cinema, and so on. From then onwards, this Ministry propagated a totalitarian 'national culture', according to Mussolini' s policy, excluding foreign influences, with more or less success. 295

In the women's fashion field, for example, there is evidence that a number of Vita femminile was confiscated in 1938 because it had a photo showing a French fashionable dress, and the famous international reviews Vogue, 
Harper Bazaar and Marie Claire were no longer imported, so the most elegant Italian women had to look for them elsewhere. 296

In the field of fashion there were also ambiguities between public prescriptions and fascist propaganda, and real applications of the autarchic 'true woman' dressing. In an official booklet published in 1936 by ONB, Small Italians could read that Italian women were not dominated by foreign fashion, but on the contrary dominated it, by creating a national fashion where only autarchic goods were used. ${ }^{297}$

Apart from wealthy people who lived and dressed according to current international fashion, also the national production of 'white telephones' films (Chapter 2.6.3) and feminine magazines and romances displayed different model women, who only rarely wore autarchic dress; they were neither fat nor modest, but had fashionable clothes, slim bodies and easy ways. What is more, they did not submit to men at all, but were the audacious protagonists of romantic, adventurous or sporting events.

As an example, by the mid-1930s, most covers of the cheap magazine $L a$ donna, la casa, il bambino - whose content dealt with domestic female work, such as embroidery and sewing - displayed designs of slender women engaged in sports on their own, or together with men. Their features, smartness and blonde hair were similar to those of American movie stars, who were unsurpassable aesthetic icons for most Italian women, in spite of national advice.

In fact, in the Thirties, the American 'happy end' comedies, were quite fashionable in Italy. In 1936, Vittorio Mussolini (one of the Duce's children) spoke favourably about the American movies, exhorting Italian cinema to follow that model, ${ }^{298}$ and in fact the Italian 'white telephones' movies were the cheap Italian version of them. Also Mussolini enjoyed American films, especially musicals and comedies played by Stan Laurel and Oliver Hardy. ${ }^{299}$ Incidentally, the Duce even allowed the clearly political film by Charlie Chaplin, Tempi moderni [Modern Times], to be shown in Italy, where the only censored scene was Charlie's involuntary consumption of cocaine. 300

All films were dubbed in Italian in as much as very few people knew and understood English. This language was [and still is!] difficult to pronounce by Italians, in comparison with the more friendly French of ancient Latin 
origin. French and Latin were commonly taught at school, while English was studied by a small minority; the stentorian German language became fashionable at school after Hitler and Mussolini allied. (Chapter 5.3)

Italy and America had kept strict links since the Nineteenth Century, when many Italians had emigrated for a work in the USA; also in the fascist period poverty had caused 193,192 Italians to reach the United States in the years 1926-1930, and 114,636 in 1931-1940.301 This fact contributed to the popularisation of the American myth, culture and habits in Italy; but most of the work was done by optimistic American movies, which were really loved by Italians.

In 1941, while Germany strictly forbade American movies, in Italy some could circulate till the end of the Second World War, due to the contradictory and ambiguous policy held by Fascism from the mid-Thirties. In 1934, about 200 American films were shown in Italy, according to an official agreement between Ciano and Hays, but in 1936 they fell to about 40. Finally, political reasons caused the end of the previous agreement by Alfieri's Law-Decree of 1938, but private pacts were stipulated between the two countries. In the years 1939-1942 for every 100 films, 18 came from the USA. 302 The incessant anti-American propaganda of the time, especially American music, literature and movies, could not be expunged from people's minds, and the regime was unable to control this phenomenon, deeply separating theory from practice.

In a wider perspective, the independence demonstrated by women in terms of bodily shape and fashion was a further signal that consensus with fascist policy was formal, and did not much influence the life of Italians. Mussolini himself was more and more doubtful about popular consensus. On 3 January 1943, he affirmed in public: "Today Italians have the historical chance to show their moral fibre. The problem is really serious for us. We should ask ourselves whether twenty fascist years have changed things superficially, or in profundity have left them approximately the same."303 With the coming of the war years, and mass mobilisation of the people, official women's fashion changed considerably. The uniform of Small and Little Italian corps had a short military blouse hiding the waist and Young Fascist (18-21 years) corps, who since 1930 - the year of their foundation had dressed in a uniform similar to that of the younger corps, from 1938 
wore a soldierly Saharan uniform, including a service cap. Also Fascist Women, especially those leading GIL feminine sections, such as teachers and inspectors, had to exchange their austere civil dresses for a real military uniform. And all female children of the She-Wolf dressed in uniform as well.

In general, although in the war years women were much more involved in social and political life, the quiet 'true woman' model was not replaced officially, but survived alongside the new and strong 'sportswoman' shape, the latter being stressed by the propagandistic art and press.

Turning the pages of specialist newspapers and magazines, one finds that photos and written comments on professional and amateur sportswomen found much more room than in previous years. In truth, information on women's sport replaced that on sportsmen, then engaged on the war fronts. Metaphorically, the regime made up for the want of war success with sportswomen's achievements, and in practice, gave the media the task of pushing women towards sporting activities, so as to become sufficiently strong and face successfully a hard life of deprivation and uncertainty.

In those war years, official publications and popular magazines competed with each other in prescribing which were the most suitable sports for a modern woman, and wrote about the aesthetic beauty of well-trained female bodies, but at the same time still supported old-fashioned prejudices. For instance, an article commenting on the participation of female athletes at the 1936 Olympic Games stressed that while a woman deputy was a deformation and aberration of both parliament and feminism, an athlete in her scanty sport costume was the perfect synthesis of the most beautiful qualities of the feminine sex; 304 and a booklet published by ONB clearly specified that Fascism wanted girls to be shaped in a healthy, strong, 'curvilinear' manner ... and not be 'slim' any more, so as to become respected and be loved mothers who would educate and enlighten children in the purest virtues. 305

On the other hand, a true sports woman could not be too 'curvilinear'. Students of the female Academy of Orvieto (Chapter 5.3) said that fat and spectacled applicants were not enrolled, and in general fat students had their meals severely controlled, while, on the occasion of public gymnastic 
displays, only well-shaped and tall girls, generally brunettes with gracious features, were placed in the first lines, hiding the rest of the students. ${ }^{306}$ Aesthetics became a goal not only for young but for adult women, who were advised to practice physical activities regularly, even in the home, so as to keep fit, and avert flaccidity and fat. This new attention to the female body could help women to become conscious of their identity and needs, but in reality it revealed its dark side soon.

An article written by a man of culture and sport, Sisto Favre, should be quoted at least, for being involuntarily humorous and misogynist. Favre advised busy and poor housewives to wash and clean basements and carpets, and do the rest of their domestic duties accurately, this being the best and easiest way to shape their body beautifully. As for female workers, Favre advised them to get up earlier than usual and, after having cleaned their rooms, to prepare children for school, and cook breakfast for the whole family; then they had to reach the workplace, walking fast and with elastic steps, so as to better their carriage. 307

Incidentally, one should stress that, according to patriarchal Italian habits, a father of a family did not help his wife at all. As has already been mentioned, a true fascist man's duty was to work hard and actively collaborate ... in increasing the number of children, following the manly hegemonic trend of the time. Domestic work and child rearing were considered ridiculous and unsuitable to men's virility, they were a woman's affair. The men spent their spare time together in organised activities, long discussions about their favourite sports idols, or secret gossip and jokes on detested personages of the fascist hierarchy.

But coming back to Favre, his article ended by saying that especially dancing was a recommended sport for women, according to the famous physician Nicola Pende. (Chapter 5.1) Pende supported dancing as the best ally of a woman, much better than tonics and cosmetics, because it educated women in aesthetics, gave the right form to feminine bodies, and increased beauty and health in view of women's highest mission to produce healthy and numerous children for the Fatherland. ${ }^{308}$

This supremacy of female dancing over the rest of sports suited perfectly Pende's misogyny and his conviction that women were different from men, and not only in the sporting field. For Pende, female Italians could not but 
aspire to subordinate roles in society, and would 'redeem' themselves only through maternity (Chapters 4.2 and 5.1). But apart from Pende and other anti-feminist journalists, the aesthetics of a woman's sporting body was positively emphasised both in the press and in works of art.

In 1939, an influential member of the fascist hierarchy, Alessandro Pavolini, founded the national Cremona Prize, a contest reserved for 'militant art', i.e. popular art totally at the service of fascist ideology (Chapter 2.4). The Cremona Prize hosted a great number of paintings dedicated to sport, according to fashion of the time, and many artists displayed well shaped female athletes performing in different disciplines.

'Militant art', namely a pseudo-photographic and flat representation of people, landscape and architecture in a symbolic fascist framework, gave more idea about the ideal 'atmosphere' where sports girls were supposed to train and shape their bodies.

Looking at sport paintings which did well at the Cremona Prize of 1941 one can find interesting information on this argument.For instance, the background of most paintings displayed fantastic Italian resorts, statues, columns, arches and other architectural elements in a pseudo-ancient Roman style, so as to stress that those events happened in Italy, the Sporting Nation above all.

All painted athletes were brunettes with long hair, and while the youngest were slender and wore skirts, the oldest dressed in shorts. Some were rather plump, with evident muscled legs, robust arms, strong shoulders and rounded breasts.

In general, those bodies were shaped in the pure autarchic style, far from American women's aesthetics; however nobody would define them as 'too fat', but simply strong and probably healthy. What is more, these painted prototypes of the fascist race could train, rest and perform together with male comrades, and their glassy stares and aseptic gestures could not but suggest 'purity' among observers.

A note should be made on the successful image of autarchic female shape drawn by the famous designer Gino Boccasile, which became a national case. The attractive Boccasile's model, named Signorina Grandi Firme [Miss Great Signatures], had exaggerated feminine attributes and inviting light garments, which excited the dreams of macho readers. But this blonde 
or brunette pin-up girl was too sexy for a Catholic country, and her provocative breasts and hips, long and well-shaped legs, and waspish-waist, excited also harsh reactions by right-thinking people.

As a consequence, and although this paper-girl was eagerly waited for by men in the magazine le grandi firme, Mussolini decided that she was too provocative, and therefore could not have room in austere Italian life any more. ${ }^{309}$ The magazine, after less than a year from its foundation, had to close in 1938.

As for Boccasile, he was still allowed to design his beautiful girl for posters and magazines, but she had to be more modestly dressed and dark-haired. In so far the American movie stars were natural blonde or dyed their hair, in Italy the ideal 'true woman' had to be rigorously brunette. This was one of the thorns in Mussolini's side that could not be removed. In fact, hairdyeing was a widely diffused fashion in Italy, in spite of the 'true woman' brunette model. What is more, many women living in the north, and some in the south of Italy, were originally blonde.

In conclusion, at the start of the 1940s, the fascist early theme of 'feminine sport for health', and the new theme of 'sporting true woman', including her bodily aesthetics, were officially affirmed in the country, after years of harsh debate and contrasting positions among state, Church, medicine, public opinion, and women's private desires.

Judging from all the paintings put forward for the Cremona Prize, one could argue that women had achieved a real emancipation through sport, and were ready to face not only sports but even war contests like men, perfectly suiting the revolutionary and bellicose Mussolini ideology. In theory, the statuary women painted for the Cremona Prize could embody the supreme symbol of sportswomen of the time, but, as will be seen (Chapter 6), in practice only some were perfectly suited to that strongly shaped image. 

Chapter 6 


\section{Sportswomen's profiles, biographies and interviews}

In this last part, we will first show how some women - living their early youth in the fascist era - put in practice successfully what they had received from a policy stressing physical education and sport. We will draw a brief biographical profile of them, and in particular of the famous Ondina Valla. (Chapter 6.1 and 6.2)

The next section (6.3) examines a series of interviews granted by common women who were actively dedicated to sporting activities, obtaining results at local, regional and even national levels, in the prime of life.

These interviews are not necessarily representative, but simply selected examples of a womanly specific interest and participation in the sporting phenomenon that had exploded in the last years of the fascist era. They help, therefore, to show how the plans were put into reality.

The oral testimonies have been collected in the region of Marche, in central Italy, where it has been easier for the interviewer to make contact with women sufficiently bright, and at the same time available to talk about their time. It has not been possible to collect information according to prearranged schemes, because those interviewed - well on in years - preferred to talk about their experience in 'semi-monologue form'.

The questions were necessarily submitted in 'open form', and in a few cases the answers were a little vague. In general, by telling their own stories, those interviewed revealed a certain nostalgia for their early youth and promise, but also a sort of embarrassment in talking about a period that, in Italy, has been taboo for decades, after the fall of the regime.

This notwithstanding, it was decided to add this fragmentary material, so as to integrate official sources and written texts described in the previous chapters.

In our opinion, oral witnesses constitute a different and innovative approach to history. ${ }^{1}$ They are based on single realities which cannot be represented in any way by official history. These realities touch private spheres, 
identities, emotions and silent memories, which would be irretrievably lost if they cannot find room in the writing.

\subsection{The 'little Italian wonder': Ondina Valla}

During the years of Fascism, the model of the prolific mother was officially imposed from on high as the most suitable symbol for the new Italian woman (see Chapter 4.2). But in spite of fascist hegemonic will, the athlete Trebisonda Valla - a woman of the people - made herself a different symbol that inspired Italian females.

The following lines will give a biographical profile of this athlete, and will report an interview that Valla granted some years ago.

\subsubsection{Story of the 'little Italian wonder'}

Trebisonda Valla - nicknamed 'Ondina' - was born on 20 May 1916 in Bologna, the last child after four males. ${ }^{2}$ Her family lived in a little village near the city, but soon moved to the centre of Bologna, a modern and wellorganised city of the north.

Her father was a blacksmith, and her beautiful mother a traditional housewife. As most mothers of the time, this busy lady preferred to stay at home and leave her daughter or maid in charge of shopping.

Female 'seclusion' was quite common in society of the time, due both to the typical Italian husband's jealousy and a question of 'image'. Women did not like to go out and carry heavy packs, or show themselves in public when not perfectly dressed, especially in little villages where most women spent their spare time watching people in the street from the windows.

Shopping, but also washing and shoe shining, were considered disgraceful work even for lower middle-class women like Trebisonda's mother. Fortunately she could avail herself of an obedient daughter, and a part-time maid, who helped her take care of five men.

When Trebisonda was only three years old she was sent out for shopping for the first time, and in the following years she used to walk to primary school, on her own for about $500 \mathrm{~m}$. She was quite a dynamic and 
independent little girl who enjoyed jumping across ditches and playing different children games.

Also her tall and strong brothers enjoyed physical activities and were particularly talented in high-jumping, but after the school years they did not continue training or competing. Trebisonda, however, started a brilliant career in athletics, lasting up to 1943.

In 1927, she was trained in high-jumping for about one month by a primary school male teacher, Mr. Formigini, and gained first place in the next scholastic championship of Bologna with a jump of $1.10 \mathrm{~m}$. In the following year, 1928, she could easily jump $1.25 \mathrm{~m}$, and was enrolled in the Bologna Sportiva association. There she met her strongest rival, Claudia Testoni, who became one of her best friends, and a good coach, who usually trained female athletes about three times a week.

In 1929, in Bologna, Trebisonda competed in an important athletics meeting against French, British, Polish and Czechoslovak athletes. She was the youngest of the Italians, but although she did not wear spikes, simply old gymnastics shoes, gained fifth place in both high and long jumps.

Trebisonda was growing up tall and strong, and practiced different sporting disciplines, such as putting the shot, $100 \mathrm{~m}$ and $80 \mathrm{~m}$ hurdle races, basketball, fencing, swimming, and skating.

In 1930, when she was only fourteen years old, the 'phenomenon' Trebisonda Valla was noticed during a meeting at Naples against Belgium. She was the youngest of the Italian team - then trained by Marina Zanetti (Chapter 5.6) - and did not win the 80m hurdles race, but the specialist press was quite impressed by the young athlete. There, during a boat excursion of the team and press, a journalist observed that the name Trebisonda was too long and heavy for such an adolescent, and proposed a nickname, 'Ondina'. It literally means small 'wave' [onda] but - it was said also re-echoed the easy way she overcame hurdles, just like a regular wave motion. With the nickname Ondina, Trebisonda Valla became a popular athlete in the country and the rest of the world.

In 1930, after having gained Italian records in the 80m hurdles and high jump, Ondina was officially chosen for the next Women's World Games of Prague. She then had to undergo a horrible trip by train for about 36 hours, just sitting in a cheap and uncomfortable second class carriage, and once in 
Prague accommodation and meals were cheap as well. In fact, first class tickets and accommodation were normally reserved only for Italian male athletes. ${ }^{3}$

In those years the few female athletes who competed, challenging the narrow-minded opinion of Italians, were not financially, nor practically supported, ${ }^{4}$ owing to the fact that sport was considered the pre-eminent expression of male Italian strength and virility. Competitive female sport was both criticised and under evaluated, although a number of nonconformist women were obtaining good results in more than one sport. ${ }^{5}$ As an example, Ondina asserted that female athletes were given good quality sporting dress and shoes, but only for competitive athletics events, and these goods had to be very soon given back! ${ }^{6}$

At the beginning of Ondina's career, most travelling expenses were paid by her father, who surprisingly was her best supporter together with her brothers. However, her mother insisted that Ondina should give up as soon as possible, saying she was not a little girl anymore. According to current mentality of the time, Ondina's mother preferred her daughter to be safe at home, waiting for a good husband. But Ondina, who really enjoyed athletics, continued to train with personal sacrifice and strong determination. Unfortunately, Ondina and the rest of the female athletic team could not reach Los Angeles for the next Olympic Games of 1932, especially owing to firm opposition by Pope Pio XI, but in 1933 Ondina competed internationally at the University World Games of Paris. ${ }^{7}$ There, she won the $100 \mathrm{~m}, 80 \mathrm{~m}$ hurdles and $4 \times 100 \mathrm{~m}$ relay-races, but one should add that she was not a real university student and that was a cheat. A French journalist, deeply impressed by this seventeen year old girl, called Ondina the 'little Italian wonder'.

In 1935, Ondina and other female athletes were appropriately preparing for the next Olympic Games. They not only trained together with the male team and by the same trainer, but lived in the same hotel in comradeship, in spite of the current spirit of gender apartheid. ${ }^{8}$

Her most celebrated victory was at the Berlin Olympics of 1936, when she placed first and gained a world record in $80 \mathrm{~m}$ hurdles race (11"6). The Führer shook hands with her, but Ondina confessed that she was not impressed at all; Hitler was nobody for her, in comparison with the Duce. ${ }^{9}$ 
Surprisingly, in Berlin the unique gold medal in athletics was gained by this girl, although the male athletic team had a very good reputation, and was long strongly supported by the Party and the press.

Only a few words had been spoken on those seven female athletes sent to Berlin, but they won the $80 \mathrm{~m}$ hurdles race and gained fourth place in both the $80 \mathrm{~m}$ hurdles and $4 \times 100 \mathrm{~m}$ relay-race. Finally, they read their names printed in block letters on the pages of national Italian newspapers and specialist sport reviews. ${ }^{10}$

Once she arrived from Berlin at the railway station of Bologna, Ondina was received like a movie star by local authorities and excited fans. Ondina confessed that was quite a surprise, she was not used to such ceremonies, normally given only to Italian sportsmen.

Later, she was congratulated by Mussolini in Rome, together with the Italian team, and received the Medaglia d'Oro al Valore Atletico [Gold Medal for Athletic Value] ${ }^{11}$ from his own hands. After that amazing success of the female team, Mussolini was more and more convinced that a selected number of sportswomen could contribute to spreading the strong image of fascist sports people all over the world. From then on, propaganda worked strenuously in favour of women's enrolment in ONB, GUF and GIL organisations. (Chapter 5.2)

What is more, during a special hearing in the Vatican, His Holiness Pope Pio XI shook hands with Ondina Valla and congratulated her. The Olympic victory suddenly opened a breach in the 'maschilist' wall erected against women's emancipation by the highest Italian authorities, the Duce and the Pope.

Hundreds of letters, flowers, suitors, invitations, interviews, photographs, and even the offer of a job as a movie-star, changed the life of Ondina considerably. The first female Olympic gold medalist in Italian history gained prestige, money, a good job in Bologna and, last but not least, a wealthy physician as her husband.

Ondina's fantastic enterprise in Berlin, and national records in high jumping (5 times), long jumping (1), pentathlon (1), 100m race (2), and $80 \mathrm{~m}$ hurdles (6), 320 made her a heroine for Italian young women, and undermined the feminine inferiority complex, which had deepened its roots both in the paternalistic tradition of the past and the new fascist ideology. 
In those years, as has already been mentioned (Chapter 5.1), female sport still aroused some suspicion of possible dangers to health, maternity and 'virilisation' of women among physicians, the authorities, and Italian families. On the other hand, common women were becoming aware of a possible female emancipation through sport, so much so that, after the gold medal gained at Berlin, Ondina Valla declared to the Italian press agency that she dedicated her victory to both the fatherland and the achievements of female Italian sport.

Famous Italian sportswomen of that time were depicted by the press as examples of modesty, femininity and filial love, so as to reassure the traditionalists and parents, ${ }^{12}$ but it was also murmured that Ondina Valla was sexually interested in female friendships. ${ }^{13}$ When she became a mother, the news was emphasised as an evident demonstration that sporting competition, femininity and maternity were not opposites. Like other famous athletes and mothers, such as Bruna Pizzini-Brianza, Ninì BordoniRay, and especially Vittorina Vivenza, the happy mother of 9 children, Ondina was interviewed and photographed with her child, to stop false and stupid gossip over her sexual proclivities.

\subsubsection{Interview with the myth}

In 8 May 1994, I went to l'Aquila to meet and interview Ondina Valla at home. Then, she was 78 years old and had some problems with her legs, but was still vivacious and bright.

Unfortunately, Ondina no longer had a good memory, and sometimes forgot or confused names and data. She had not preserved much of her past (just some photographs and articles), neither the Gold Medal of Berlin, which - she said - had been stolen. What is more, she did not like to speak about her faith or involvement in Fascism, but simply declared she agreed with Mussolini, like most Italians, and was highly honoured by the regime for her sporting enterprises. More from omission than her words one could deduce that if propaganda made use of Ondina's image and enterprises, this happened with her consent.

Ondina could not attend the prestigious Academy for female physical education in Orvieto (Chapter 5.3); she did not enjoy study, and had given up before the end of secondary school. Although Ondina was a member of 
ONB and later enrolled in the Fascist Women's organisation, she was not allowed to become an ONB teacher, as all ONB staff had a secondary school diploma at least. The Party gave her a job as secretary in the local Fascist House of Bologna, where she was paid more than other employees (about 500 It. Lire per mensem instead of 350), but she confessed she was not happy to spend her time simply sitting in a chair and typewriting membership cards. After a lot of complaints, Ondina could just train her body and get the same salary without working in the Fascist House, where officially she kept her position.

It was a pleasure to spend a couple of hours with Ondina. Her words were recorded, and now will be partially reported, both to integrate what has already been said about her, and know what she thought and felt about her sporting career.

- Ondina, when did you start doing physical activities?

"I was eleven years old when in Bologna I was recruited by Captain Costa, who came to my primary school looking for children naturally talented in athletics. I was tested together with some other pupils, but unsuccessfully in high jumping. Even so, I was noticed by him because I was thin and agile. Costa asked for my name, and when I answered Valla he said: "Valla? Are you the sister of the two famous brothers Valla, runners and jumpers?" My positive answer gave me the opportunity to be trained together with a small number of little girls by the male teacher of the boys. This person, Mr. Grimolizi [?] taught us to run and jump in the courtyard of the school, during the daily break."

- Which were the next steps?

"Well, at school we were engaged in gymnastics displays and competed against other schools of Bologna, but I did not like gymnastics as much as athletics. Leandro Arpinati, then secretary of the Party, was from Bologna, and being keen on sport encouraged this activity among his fellow-citizens. Students of both sexes were sent by bus and trained in the Littoriale Stadium.

When I became a member of the Bologna Sportiva sports association which later joined the Virtus Bologna society - I had a good trainer from Hungary, Mr. Gaspar. He used to train girls in athletic disciplines about 2-3 
times a week, but only in the good season. Sometimes we were trained and competed on Sunday evening, just after the crowded football match, and spectators looked at us as well.

When I was only fourteen, I was sent to Florence for the national championship. There, I won both the high jump and $80 \mathrm{~m}$ hurdles against older and strong competitors. I remember that after these victories the athletes Polacco and Martino from Trieste, and another from Venice, gave up competing."

- Can you tell the story of the nickname Ondina?

"There are several stories about it, but in truth this name derives from a mistake of a journalist, who wrote Trebitonda instead of Trebisonda. From the wrong Trebitonda somebody started to call me by the nickname Trebit-ondina, and then simply Ondina. Since then, this became my name, but my parents started to call me that way much later, namely after the Berlin Olympics."

- How could you participate in the Olympic Games of 1936?

"When I was included in the national women's athletic team for the next Olympics, I had already gained national records and participated in international contests. That spring the team went for training to Rapallo, where the weather was warmer and agreeable. We left Italy and arrived in Berlin one month in advance, so as to get accustomed to the different track and climate. Our trainer was Boyd Combstok from America, the official trainer of the Italian athletes. In Berlin, all sportswomen lived in the Woman's House, and we spent our spare time visiting the city and its fantastic shops."

- Could you say something about your victorious race in Berlin?

"In the semi-final of the $80 \mathrm{~m}$ hurdles race, I was not only the winner but my time equalled the world record, and as a consequence I thought I could probably win the final. On that day, I had run twice in about one hour, and my right leg was painful and heavy, but on the following day the final of the $80 \mathrm{~m}$ hurdles had to be run anyway.

As a matter of fact, in the final my start was really slow, but after the first two hurdles I had reached the rest of the runners. Four of us were so blanketed at the wire that only a photo could split us and determine that I was the winner. We had to wait for the result for about half an hour, and 
two hours for the prize-giving ceremony where only two athletes, the German and me, went up to the platform. Unfortunately, the third, a Canadian, thinking she was only fourth, had already left the stadium. The prize-giving was fantastic: among spectators there were Princess Jolanda of Savoy (Chapter 5.6) and Mussolini's son. The organisers presented me with a little oak plant and wreath, while the music of the Italian Royal March and the fascist hymn Giovinezza [Youth] were spreading their notes all over the very crowded stadium. And I was standing stiff in the fascist salute!" - How did you feel then, and what happened later?

"At that very moment I lived an amazing sensation, as if this victory did not involve myself. Later, I was greeted by my friends in the Women's House, where maids of honour, and a bottle of champagne, awaited me.

When I came home my father and brothers, together with important and common people, welcomed me. The Prefect of Bologna in person congratulated and presented me with a bouquet of flowers, and people sent me a mail-bag of telegrams.

In the following days, I was told I had to go to the railway station, where a parcel, sent by the Royal House from Rome, was waiting for me. I was really excited in trying to foresee what a wonderful thing could be in it, but when I opened the parcel I found just a silver frame, and a photograph signed by Queen Helen. I was young - only twenty years old at that time and my imagination was so vivid!

I delivered the little oak plant to the authorities of Bologna, who ordered it to be planted in the nearby stadium, and to add a plate with my name. Some time later somebody, I presume an anti-fascist, tried to cut down the plant, without success, but broke that plate in two which later on were joined again.

All classified athletes in the Berlin Olympics were received by Mussolini, and I was the one and only woman of the group. Everyone was trying to approach Mussolini, but he Duce said: "I want Miss Valla near me!" In Rome there was also a ceremony in the Stadium of Marbles, where a diploma and a medal were given to each of the group."

- Did you receive any reward for your sporting activity?

"In all my life I did not get any money from the Italian sporting organisation, apart from 5,000 Italian Lire, an amount of money that I 
received for the Olympic victory. [It was about half the annual salary of a secondary school teacher!]

In addition, in Berlin the Italians had 20 lire a day. With this sum I bought a little mechanical doll for myself, and a coat for my father. When I was engaged in national or international competitions, the organisers paid simply the out-of-pocket expenses, but petty expenses were paid by my father. I remember that he gave me 50 Italian Lire for national, and 100 for international journeys. Sometimes we also received little gifts and gadgets, collected from shops of the host town."

- Did you practice any other sport?

I enjoyed skiing, and this activity had made my arms so strong that I could compete in the 'classical pentathlon' as well. I learned to throw the javelin and put the shot, and also won a national championship and the Italian record in this discipline. By the end of the Thirties I was ready for the Olympic Games of Tokyo, but the coming of war destroyed my dreams. After the birth of my son Luigi, I was still fit and was planning to participate in the London Olympics of 1948, but later I had to give up for a number of physical problems."

- Was there any disagreement over female sport?

"Generally I had no problems, but once in Bologna a spectator was rude about me. I did not hear, but my brother, who immediately struck him with his fist, knocked the man to the floor. Often my sporting society was invited to bilateral meetings which were held in other Italian cities or abroad, and I was the only woman of the team. Of course, women had to be more careful, and dress ... in long shorts!"

- What about the Church?

"After Berlin, I even went to Saint Peter's Church, and was received by Pope Pio XII [?] in person, who said:" Well done, our compliments!" But let me remember ... Yes, the Pope was against female athleticism, because he thought it was dangerous for womanly health. In fact, in 1934 a newspaper wrote: "The dying swan of female athletics'!" 


\subsection{Biographies of eminent sportswomen}

Italian women involved in high-level sporting competitions were an exception during the fascist era. Looking at their enterprise, one should say that they constituted quite an opposite model of femininity to the official one. But, although openly in contradiction with the official anti-feminist policies of the time, their presence on the national and international sporting scene was not simply tolerated but supported by the regime.

As already mentioned, this elite of sportswomen could contribute to the greatness of the new fascist Italy throughout the world and, by being a minority, their emancipated ways would not have influenced the rest of the female population too much. These women obtained world, European and national records, won important championships, and were honoured by the regime and the press of that time. Like Valla, they received the Medaglia al Valore Atletico [Medal for Athletic Value] from Mussolini's hands.

This prestigious prize was one of the most appreciated of the Duce's inventions in the sporting field, together with the Stella al Merito Sportivo [Star for Sporting Merit]. These prizes, instituted by the end of 1933,14 were a perfect tool for propaganda in favour of mass 'sportivisation' of society.

While the Star for Sporting Merit was given annually to the heads of those sporting federations successfully involved in international competition, the Medal for Athletic Value - in gold, silver and bronze - was given to sports people who had gained the first, second and third place respectively in international contests. The Gold Medal was also assigned to those who had won a world or national record.

The following lines present a brief biographical profile of famous sports women of that period. 15

\subsubsection{Valla's alter-ego: Claudia Testoni}

In the athletic field, Claudia Testoni was both the best friend and the most dangerous rival of Ondina Valla. They spent most of their early years in Bologna, were Testoni was born on 19 December 1915, and trained in 
different sports because they were both all-round athletes. They were involved in the same sporting 'adventures' in Italy and abroad, used to travel together, live in the same hotels and shared the same emotions.

Like Ondina, Claudia was included in the women's athletic team which participated in the Women's World Games of Prague of 1930 and the Berlin Olympics of 1936, but in Germany fate was against her.

In fact, after the semi-final of the $80 \mathrm{~m}$ hurdles race, she was fourth and therefore did not qualify, but then it was discovered by photo that she was third.

The next day she ran a really exciting final, and the speaker announced the good news that Claudia was second. She was so happy, but, about half an hour later, it was officially declared that she was only fourth! From then onwards, in the hearts of Italians Ondina was eternally first, and Claudia Testoni second, although both were extraordinary athletes. (See Chapter 5.6)

Claudia took her revenge in 1938, when she became European champion in the $80 \mathrm{~m}$ hurdles race and equalled Valla's world record (11"6). In addition, she lowered the world record twice in international meetings of Milan (11"5), and Garmisch (11"3).

Claudia's brilliant career started at the beginning of the Thirties and ended at the beginning of the Forties, in parallel with that of Ondina Valla. In those years, Claudia was national recordswoman three times in the $100 \mathrm{~m}$ race (her best time was 12"); four times in the $200 \mathrm{~m}$ race (25"4); five times in the $80 \mathrm{~m}$ hurdles race (11"3) six times in the long jump (5.65m); once in the high jump $(1.54 \mathrm{~m})$; nine times in the $4 \times 100 \mathrm{~m}$ relay race.

Naturally, the Duce gave her a number of prizes. Claudia Testoni, who received one Gold, two Silver, and five Bronze Medals for Athletic Value, really was an eminent athlete, but her fame was somehow obscured by that of the fabulous Ondina.

\subsubsection{The three long distance Graces: Cleo, Leandrina and Candida}

In the years 1930-1938, long-distance female runners were enrolled in the Sporting Society Venchi Unica of Turin. The northern regions of Italy had a strong tradition in this discipline, and in the last years of the Nineteenth 
Century a number of long-distance female runners were already present in that territory. (Chapter 3.1.4)

In the years of Fascism, three graceful members of the already quoted Venchi Unica, Cleo Balbo from Turin, Leandrina Bulzacchi from Cremona, and Candida Giorda-Cecchetti from Turin, gained the world record in the 3 x 800 relay race (7'32.1) at Turin, in 1937. Due to this brilliant result, all of them obtained the Gold Medal for Athletic Value.

While this was the only notable enterprise for Candida, Cleo and Leandrina were more active in the sporting scene, and competed successfully in different kinds of race.

Leandrina Bulzacchi turned out to be the most talented athlete of the group. She was the Italian champion in the 800m nine times (from 1930 to 1938); in the cross-country race five times; in 4 x 100 relay-race twice. Apart from the cited Gold Medal as a world record woman, she was also given four Bronze Medals for Athletic Value.

In 1935, Cleo Balbo, together with Leandrina, was Italian record woman in the $3 \times 800 \mathrm{~m}$ race, and in 1938 Cleo gained a record in the $800 \mathrm{~m}$ foot-race. For these and other sporting enterprises she received four Bronze Medals for Athletic Value.

\subsubsection{Carina Negrone, a daring 'blonde angel in the sky'}

Aristocrat Carina Massone - married to Ambrogio Negrone - was born near Genoa on 20 June 1911. She was an extraordinary pilot whose legendary enterprises are part of the history of sporting aviation.

Before her, only a tiny number of female pilots were known in Italy. Among them, the first was Rosina Ferrario who gained her licence in 1913 (see Chapter 3.2.2) and, in the fascist years, the pilots Tatiana Fumagalli16 and Gaby Angelini. The latter was given the Gold Eagle for being the first Italian woman to make the tour of Europe by plane, but the still very young Gaby died during a flight, in 1932.17

Mussolini did not think this sport should be chosen by women. In June 1934, he had read in a daily newspaper of Bologna that women had been invited by the local air club to take part in a course for pilots. Soon after, the Duce sent a resentful telegram to the prefect of the city, which said: "Please, tell the head of Air-Club of Bologna that in fascist Italy the most 
fascist thing women should do is 'to pilot' numerous children. Obviously, they can fly for a hobby or necessity, but piloting is a very serious affair which should be left to men, who actually are still sufficiently numerous!" 18 Like most aristocratic women of her time, Carina Massone enjoyed engaging in different sports, such as tennis, skiing, swimming, hunting and fishing. In addition, she loved flying, which was an expression of dynamism and modernity celebrated by both Futurism and Fascism. 19 Carina got a second degree licence in 1933, and after only one year, on 5 May 1934, she reached a female world record height $(5.544 \mathrm{~m})$, in the category 'seaplane class $\mathrm{C}$ '. This was an amazing enterprise for a woman who lived in a country dominated by male hegemony. But Carina was really talented and determined to win new challenges in the future.

Fortunately, she gained sympathy and support from the famous pilot Italo Balbo, the most celebrated fascist hero of Italian aviation, and an important member of the fascist hierarchy. By Balbo's order, Carina was harshly tested and trained just like military men pilots by the Italian Aair Force.

Carina's son Vittorio said that when he was a child he was quite impressed by his daring mother, who used to train in the military airport of Montecelio in Rome, and wore the same clothes as the Air Force pilots, who naturally were all men.20

On 20 June 1935 Carina was ready to challenge the French woman Marise Hilsz, who had gained the female world record height $(11,289 \mathrm{~m})$ in 'seaplane class $\mathrm{C}^{\prime}$. She took off from Rome military airport equipped only with a rudimentary electrical warming overcoat, and an oxygen bottle.

Actually, the lack of oxygen and the icy temperature constituted the main problems at such a high altitude. Specialist physicians had calculated that Carina should not exceed the height of $11,000 \mathrm{~m}$, but she reached the height of $12,043 \mathrm{~m}$, an absolute record for women. In the history of aviation nobody could do better than Carina in the 'seaplane class $\mathrm{C}^{\prime}$.

Carina said that the temperature reached minus $35^{\circ} \mathrm{C}$, and she could only breathe through the oxygen bottle with difficulty; but even if her body was frozen and her mind obscured, her will-power was still so strong that she reached the goal and could perfectly control the speed in nose-diving. 
When she landed, the most important exponents and air-aces of the Italian Royal Air Force congratulated this new air-ace who, amazingly, was a woman. Carina was given the Gold Medal for Athletic Value twice.

In the following year, 1936, she got the third degree licence, and that for sail-flying in 1937. After the Second World War, in 1954 Carina tried a new record in non-stop flying in an amphibian.

She flew for about 30 hours, and covered the distance of $3,000 \mathrm{~km}$ - from Brescia in Italy to Luxor in Egypt - at an average speed of about $299 \mathrm{~km}$ an hour. In fact, Carina won the world record previously held by the US General Andrews since far-off 1936. This last story, which happened in the post-fascist period, is a sign that a number of girls became stronger and more self-confident by being involved in the general climate of enthusiasm for competition, generated by the sport policies of the regime.

\subsubsection{Ada, Adriana and Liliana, stars of roller-skating}

During Fascism, skating was considered a typical Italian sport whose roots went back to 1877 , when the first skating-rink was opened in Milan. In 1908, Princess Colonna founded the Skating Club of Rome, and on 18 March 1912, the first Roman championship for women skaters took place. The national Federation of Hockey and Roller-Skating was founded in 1922, and from then on people of both sexes were encouraged to practice this cheap and easy discipline in gymnasia, courts, squares and streets, and even on proper skating-rinks.

In the fascist scholastic programmes, roller-skating was one of the few recommended sports for women, and therefore it was easier to find talented girls for competition. Among them, the skaters Ada Spoto, Adriana Rianda and Liliana Sozzi-Spada should be mentioned for their national and international successes.

Ada Spoto from Catania (a Sicilian city) was a speed-skater and started a brilliant career in 1936, when she won the female team-race at the Italian Championship in Catania. For this she got her first Bronze Medal for Athletic Value, and the second Bronze came in 1937, for the first place in the $8,000 \mathrm{~m}$ in Monza at the Italian roller-skating championship.

The best results were obtained at the international meeting of Catania in 1938, when Ada was first in $500 \mathrm{~m}, 1,000 \mathrm{~m}, 5,000 \mathrm{~m}$ and $10,000 \mathrm{~m}$, and in 
1939, when she gained the world record in $10,000 \mathrm{~m}$. in Ferrara. For these victories Ada received two Gold Medals for Athletic Value.

Also Adriana Rianda from Rome was a specialist in speed-skating. In the last three years of the Thirties she was first in $1,000 \mathrm{~m}, 5,000 \mathrm{~m}$ and $10,000 \mathrm{~m}$ at international and world meetings. For Adriana's sporting enterprise she got one Gold Medal from Mussolini's hands.

Certainly the most eclectic of the group was Liliana Sozzi-Spada from Rome, who enjoyed also artistic roller-skating, in which she became national champion in 1935 and 1937. In the speed-skating race, Liliana was first in $1,000 \mathrm{~m}, 5,000 \mathrm{~m}$ and $10,000 \mathrm{~m}$ on the occasion of Italian (1934 and 1936), European (1937 and 1938), and World (1938) championships. For her success, Liliana received one Gold and three Bronze Medals for Athletic Value.

\subsubsection{Celina Seghi, the unforgettable 'Queen of the Snow'}

By the end of the Nineteenth Century, skiing was a new sport for aristocratic and wealthy people, but in the following years it became more popular in Italy. In 1913, the first Italian federation was founded, joining together 9 sporting societies, but in 1920 it was founded again with the name Italian Federation for Winter Sports-FISI. After two years, there were about 28 societies for skiing, and after ten years of efficient fascist propaganda they increased to 287 . In 1934, FISI was really important and covered about 423 societies. ${ }^{21}$

Following Mussolini's example (Chapter 2.5), common men were more and more involved in skiing in the Alps and Apennine Mountains, and women were invited to practice this healthy activity as well.

Among female skiers the most celebrated were Paula Weisinger and Celina Seghi. The latter was born in Abetone, a famous winter resort of Tuscany, on 8 March 1920. In 1937 she started a long and successful career which lasted up to 1954. This woman, especially talented in slalom and downhill skiing, became the Italian champion 24 times, indeed a 'queen of the snow'! In the Winter Olympics of 1936 at Garmisch-Partenkirchen, she was too young and did not place honourably, but in 1937, 1939, 1941 and 1942 she reached the best place in a number of national competitions. For her 
victories she gained one Gold Medal and four Bronze Medals for Athletic Value.

\subsection{Oral interviews: living testimony to the past}

The material collected here derives from interviews granted by a number of women who engaged in sporting activities during the years of Fascism. It has been decided to concentrate the research in the region of Marche, and more specifically in its capital, Ancona, and its most important province, Pesaro, where - one presumes - there should be a certain organisation.

The names of the interviewed have been mainly selected through reading the press of that period. Looking at articles on sport in local newspapers, one can frequently find the names of women involved in sporting competitions with more or less success. Judging by a number of articles, it seems that journalists and citizens of their towns followed these performances with a certain interest.

On the whole, the interviews selected and presented here show that in the Thirties and the beginning of the Forties a number of female students voluntarily practiced sporting activities at school and especially in their spare-time, with real enthusiasm. These activities were left to the goodwill of girls who spontaneously met sometimes and somewhere at local sporting facilities, or were somehow organised in a rough way.

Often the trainers were not specialists but keen on sport, and girls were addressed to sport at school by female physical education teachers. (Chapter 5.3)

Generally, these sportswomen, who were more or less aware of the different treatment they received in comparison with sportsmen, lived in families where sporting activities were already appreciated and practiced by their brothers. Mostly, the parents were uninterested to their daughter's sporting attitudes, but did not obstruct too much their aspirations if they were good students as well.

All interviews show that the most active girls of that time did not specialise in a single sport, but tried several activities, from tennis to basketball, athletics, swimming, skating, swimming, showing the typical curiosity of the neophyte. The interviews demonstrate as well that the traditional care for 
womanly modesty gave girls lots of problems. For example, the athletes had to jump or run wearing uncomfortable and heavy clothing.

Those women's memories show a very simple and provincial way of living, and more generally the portrait of a poor nation, which had a lot of financial problems in terms of sporting facilities, organisation, and general assistance to young sportspeople.

This portrait seams to be opposite to the official and powerful one displayed by the media. Probably, the money was only given for colossal national competitions, where youth and sport constituted a living and winning demonstration of fascist power, for the admiring eyes of the world.

\subsubsection{Memories from Ancona}

The capital of the Marche, Ancona, was a very provincial and lazy town. It had a lack of facilities, especially swimming pools and basketball halls, while it had tennis courts, a sailing club and an airport for tourism. Naturally, the latter were attended by wealthy people. The rest of the youth were trained in courts, gymnasia and stadia, and used to swim directly in the Adriatic Sea.

Among the interviews collected in Ancona, the most interesting are those granted by Lara Borghetti (A), good in gymnastics and a swimmer of a high level, and Consilia Del Sordo (B), keen on basketball. The interviewer met both these ladies in the winter of 1998-1999.

(A) "I was born in 1924, and started practicing sports when I attended the third year of primary school. I was in the gymnastics team, which had to show the teachers the collective exercises for the annual provincial display of the '24 May'. Students of both sexes attending the primary, and the first years of secondary schools, participated in this display. Gymnastics displays were compulsory then. The display of the '24 May' was beautiful, and each category of students had different exercises: boy's exercises were rather virile (the Avanguardisti used the musket), while female exercises were done without equipment, and accompanied by music. I remember that this display started everywhere in Italy at the same time, and was transmitted by radio from Rome. 
Mussolini considered youth to be the promise of the country, and whoever was talented in sport could participate in the national Ludi Juveniles (Chapter 5.6). The recruitment was done at school by the various federations, which selected the best students. This happened to me for the gymnastics discipline.

There were national meetings of gymnastics, and we used equipment such as parallel bars, vaulting horse, and so on, and the exercises were accompanied by music. I was good at the high jump as well, but could not train much. Often I had to fight against my mother, because I was not good at school.

In Ancona, I attended the Stamura Sporting Club as well, and I learned the breast-stroke in the sea. We were trained by expert male swimmers, and also when the weather was bad. I was noticed by officers of the Federation who agreed I could continue and compete at national level. When I participated in competitions, my travelling, accommodation and meals were paid, but not other expenses such as, for instance, the uniform. This was a heavy charge for my family. I could wear a suitable bathing-costume and sporting overalls for the contests, but then I had to give them back.

I participated in the national university GIL championships [the Littoriali] of Naples, Florence and Turin. There, I won third place in breast-stroke, and was asked for a more serious engagement, but my family opposed.

Sport was highly considered by the regime, and at school the marks in physical education counted for much in the final evaluation. The fascist ideology was diffused at school, and students were in accord with it, also because they did not hear discordant voices. At that time, on Sunday, we had to wear our 'fez'[?], which was disliked by many of us, and the 'black shirt'.

We were supported by our physical education teachers who spent their spare-time training squads of students for several disciplines. But while male students were also trained for professional sport, for female students the only possible way to practice sport was within the scholastic institutions.

Women were considered the 'angels of home life'. If they wanted to be more than this they could succeed, but this was much more difficult than for men. 
In Ancona, women's sport was only for amateurs, and trainers were amateurs as well. There was a lack of facilities and girls could practice only a few disciplines, such as swimming, athletics, fencing, horse riding and tennis. But the last two disciplines were expensive and therefore reserved for the elite. We common girls enjoyed taking part in the mass displays for the crowd, including the authorities from Rome and our families, where we felt really united and happy."

(B) "I played basketball from 1935 to 1950, when I married. The physical activity was organised at school by our physical education teacher, who selected the best students. I was one of them.

We met every Saturday afternoon wearing our uniforms, and walked in perfectly ordered squads up to the Monument of the Fallen, where we had to sing patriotic and fascist hymns. Once the squad had been formed, we could participate in a basketball tournament, together with squads from Pesaro, Zara, Forlì and Faenza, where the best students were selected for the following national championship. The strongest team was that of Pesaro, which won very often. Apart from basketball, the squad practiced gymnastics and learned collective exercises with equipment and music. The aim was to stress individual and collective harmony.

I started practicing sport at school because I liked it. The first basketball hall was the court of the Town Hall, then the entrance of the stadium. Any and every activity was done at our expense, apart from travelling and accommodation. Common people were critical of us when we showed our bare legs during training and matches. All the same, many followed our performances. The regime changed the name basketball to pallacanestro but, apart from this, did not interfere in our work.

Although sport was propagated by the regime, in my opinion it did not invest much capital in it. That was a society much poorer than the current, and sometimes the prize was simply a pair of rubber sports shoes. But even this prize was an exception.

We used to swim in the sea, and practiced this sport from May to September. Then, in Ancona there was no swimming pool, which was made later, and whoever wished to swim for the rest of the year, had to go 
to Pesaro [Pesaro is about $60 \mathrm{~km}$ north]. Ancona was always second to Pesaro.

The basketball team had a notable 'body-spirit', and used to participate in the Bellagamba tournament of Falconara [10km north]; this was followed by journalists, who commented on the results by the radio. The floor was horrible: it was made of asphalt, and the only floor in wood I saw was that in Forlì, but Mussolini was born near this town. At the beginning, basketball players were trained by Mr. Mineo, keen on this sport, for free; later we were enrolled by GIL, and then GUF.

Tennis was played in Ancona as well, and I tried it as well, but enjoyed basketball much more. I do not know about female long distance training, but remember women's rowing competitions.

Ancona did not have a university, and the recruitment was done among students in the last year of secondary school. By the end of each year of school we participated in the Ludi Juveniles, and had to wear the athletic uniform paid by our families. It was necessary to be present because of the presence of the Authorities. As far as I know, before Fascism sport was not important at all, but under the regime it was considered. The youth were enthusiastic because of the opportunity to live together and leave the town for competitions."

\subsubsection{Memories from Pesaro}

In the town of Pesaro there was a good tradition in woman's swimming, much earlier than female sporting activities became popular in the country under the regime's impetus. In fact, from 1929 to 1931, Anna Savi was Italian champion and gained a number of records in $50 \mathrm{~m}$ and $100 \mathrm{~m}$, in both crawl and back-stroke.

In the town there were some sporting facilities mainly used by men, but in 1934 some girls started practicing athletics, and then basketball, systematically. These athletes were trained by Alceo Moretti, a good technician who was in touch with the already-mentioned American Mr. Combstock (Chapters 5.1 and 6.1), the official trainer of the Italian athletic team for the Berlin Olympics. Later, Moretti's work was also supported by a national athlete from Pesaro, Amos Matteucci. 
The female basketball players were trained by male players and supervised by Agide Fava, who was also a local famous trainer whose career lasted a long time. As in most towns, roller-skating was also popular among women, and wealthy girls especially enjoyed tennis and fencing.

In the following interviews, granted in the summer of 1999, three sportswomen of different levels tell us how they lived their sporting youth. Their names and letters of identification are respectively: Teresa Badioli (C); Rina Serafini (D); Luciana Sisa (E).

(C) "I was born and still live in Pesaro. At school, our physical education teacher suggested which discipline was more suitable for each of us. In spring about $8-10$ of us and the teacher walked up to the stadium singing songs, and once there we tried running, jumping, and throwing according to our interests.

I started to practice organised sport when I was eleven years old, but I had learned to skate much earlier. I should have to add that my father and brother were true sportsmen. My father had competed in target-firing successfully, and my brother was keen on different sports. As far as I remember, I was as good as him in skating. I used to skate twice a week for about three hours in a gymnasium, wearing a long heavy skirt which obstructed my movements.

In summer I played tennis for free, like all members of ONB, but my racket was not too good in comparison to that of my brother. I also tried rowing. In winter I enjoyed skiing when possible. At school I was the best in physical education.

In athletics, I was good in javelin throwing and the high jump. My trainer was Matteucci, and we practiced athletics twice a week. For high jumping I did not have special shoes, and had to wear the same long skirt which obstructed the jump. Our underwear was compulsory, a black kind of 'Bermuda' shorts.

The most important sporting contests in my life were the Female Athletics Championship of GIL held in Florence in 1940 (there I played tennis, which was included in the athletics program: quite an exciting experience!), and I took first place in javelin throwing in 1941, during the provincial selection for the Ludi Juveniles. The female athletics team went to Florence by train. 
On the way back we had to sleep or sit on the floor, because nobody had booked seats for us. We were looked after by both male and female trainers.

My family did not obstruct my early sporting interests at all, but when I was at the University of Bologna my brother, after having tested the moral 'climate' of the stadium, said:" No, you will never go there again."

(D) "I was born in Chicago, but my parents were from Pesaro and soon we came back home. I started competitive gymnastics when I was fourteen years old. My school brought selected female students to Rome for a competition in basic gymnastics, rhythmic gymnastics and archery. I remember that we had to wear a ridiculous beret, and our plaited and ample shorts made us very similar to 'clowns'.

When I was sixteen, I started to play basketball just for fun, then athletics, where I tried different disciplines on a dirt track covered by cinders. Our trainer was Moretti; we met every 'Fascist Saturday', and possibly early in the morning, before school. Alceo Moretti knew the famous Combstock, who was Ondina Valla's trainer, and once he came to Pesaro just to look at us.

My coming out in national competitions was in 1938 for the Littoriali of Rome. I was second in the $80 \mathrm{~m}$ race but, by being only sixteen years old I must confess - I used a false name because that competition was only reserved for university students. And, what is more, I tried the same at the next Littoriali of Naples, but there I was soon unmasked. I cried a lot for being still so young!

Finally, in 1940, I became a university student and I had the right to participate in the next Littoriali of Milan. I was there for my preferred discipline, $80 \mathrm{~m}$ race, and ran in the final. When my trainer Moretti said that I could also try a second discipline, I chose long jump and, unexpectedly, won. I was the youngest of the winners, and they gave me the honour to deliver the solemn oath. 22

When I came back to Pesaro by train, I was received by a brass band, the most important authorities, and naturally all my friends. Imagine how I felt! I was only eighteen years old. 
After this experience, I started playing basketball and joined the female team of Pesaro which participated with success in many competitions, including the Littoriali of Genoa in 1941. In addition, I was fond of tennis and played on a tennis court in bad conditions, but it was fun. Once, I asked my younger brother to try a doubles tennis competition. We had never played together, and he thought I was completely crazy but, as a matter of fact, we won.

I enjoyed swimming as well. At the beginning we used to train near the harbour, and the water was oily and dirty. Anyway, this new discipline suited me as well, and after a number of victories I was asked to take part in the national team by a member of the swimming federation. But, due to the war, my parents did not allow me to go and train in the far region of Liguria. This was the end of my competitive career.

People say I was a good sportswoman. I can only say I was tall and thin, and every kind of sport was easy for me. But if one wants to know which was my preferred sport, I would answer skiing, although I won only a modest local competition.

In my opinion, female sport did not interest many common people. Traditionalists and middle classes looked unfavourably on us, saying that we were too often outside the home and with boys. At that time people thought girls should stay home and cook, and we were often out for tennis, swimming, athletics, and so on. There was a gender discrimination. Boys could do everything, we had to learn house-keeping.

My parents did not care about this, and allowed me to indulge in my passion, also because I was a good student at school and university. They were proud of my medals, but maybe because they had lived in the USA and had a different mentality. Many of my friends had to give up athletics and basketball because of the opposition of their parents.

Fortunately, when in Pesaro female basketball became more popular and the team played successfully against other towns, provinces and regions, the citizens looked at us in a different way. Although we trained and played in the same tournaments together with men, they felt so proud of us. In truth, there were no problems at all, and the boys were helpful and well educated. Our early years were a wonderful period. The day was too brief for us, as we had to run from one sport facility to another. 
In the fascist time we, the youngsters, became members of the Fascist Party from birth. A lot of adult people had the membership card as well, but my parents, who were not enrolled in any fascist organisation, had no troubles because of this.

In my sporting life, once I met Mussolini, as winner of the Littoriali. It happened in Rome, during a ceremony where the Duce gave the best athletes of both sexes a prize, the 'Gold $\mathrm{M}^{\prime}$ pin. It was an exciting experience also because I met many famous sportsmen of that time."

(E) "I was born in Pesaro but lived and studied in Urbino. When I married, I left this region and went to the North of Italy, but in 1968 I came back to Pesaro. I do not remember when I started physical activities, but my eldest brother was keen on sports and I wanted to imitate him by following his various experiences. I was really energetic and even enjoyed fighting against street-boys.

At the start of secondary school, I tried athletics in my spare time. Alceo Moretti was the trainer who brought this discipline to me, by means of good advice on the most suitable activities, such as running and high jumping. I was trained by Agide Fava as well. One should say that officially the trainer was Moretti, but any other capable person could help out. I also did other sports just for fun, roller-skating, basketball, and especially swimming together with my brother.

Only a few girls attended the stadium, and rather spasmodically. I don't remember if we had fixed dates for training, but I guess we voluntarily decided to go there during the week, and obviously the 'Fascist Saturday'. At that time there was no sports society, nor organised activities. Nobody gave us special sportswear, and we used our own clothes and common gymnastics shoes.

When we went to the stadium I used to bring some bread and a lemon, because it had no comforts, not even running water. I remember that everything was dusty and dirty, and if you had a muscular injury you had to ask the door-keeper for a bad-smelling oily lotion. The track was black and dusty, and for the running start we had to dig little holes in the ground with our own hands. When our coaches had enough time, we were trained for competition and tried to do our best, just for fun. Often there were no 
judges or spectators watching us, yet these poor attempts were considered true athletic contests!

My best results in athletics came from high jumping, but actually I was not a good athlete. Even so, I was sent to the national championship in Florence. There, in spite of the support of all my friends, I could jump only 1.25 metres! Anyway, I did not care about this because the most enjoyable thing was to be away from home with good friends. In Florence, the female team from Pesaro did its best with a lot of enthusiasm, and even invented a little song and knitted hats with the same colours, to be sung and displayed in the stadium of that city. We used to eat a lot of sugar lumps to increase our energy, and did not go to the toilet before running because it was murmured that we would have run faster!

We went to Florence by train, and were looked after by trainers, assistants and the oldest athletes, but our parents were left out of this. We performed on the same day and time together with male athletes. I do not remember about sexual discrimination, but in truth my brother received some money (about 5 Italian Lire) when he went swimming, while I was not paid at all.

At home, I had no problems to leave the house for training, probably because my father had died when I was only ten years old, and my mother was a physical education teacher. I should have to add that she never pushed nor obstructed my passion for all kinds of physical activities. At school, I enjoyed all kind of disciplines, from basic to rhythmic and artistic gymnastics, from physical exercises in the classroom or gymnasium to volleyball. Unfortunately, we had a class only once a week, and did not have any connection with organised extra-scholastic sports.

In conclusion, we, the few female athletes from Pesaro, were very proud to take part in sporting activities and competitions, no matter if the results were not too good. Nothing was more important than to live these experiences together. I remember that was a really happy period whose loss I regretted for a long time."

\subsubsection{A final comment}

All interviews granted by former athletes from Ancona and Pesaro show that in the second half of the 1930s female students living in the province 
were not really interested or pushed towards sports activities, although these students were the most privileged and wealthiest part of the population.

In truth, in Ancona and Pesaro, which are provincial cities of central Italy, life went on quietly, far from both the tumultuous political events of Rome and those occurring in most northern cities, where modernisation and industrialisation had promoted a form of 'outer' emancipation among women. 332 From the end of the Nineteenth Century, a number of working women living in the north not only gained a salary and learned to socialise by working outside the home, but could spend some of their spare time practicing a number of sports, like the female members of the aristocracy and bourgeoisie. (See Chapter 3.1 and 3.2)

If one looks at the biographies previously presented, one will note that mostly these famous sportswomen were born in the north (Turin, Genoa, Cremona and Bologna), or in important cities of central Italy (Florence and Rome), while only one of them came from the deep south (Catania).

As a matter of fact, in southern Italy a long-lasting paternalistic tradition, strong rural economy and gender apartheid - the latter due to both the Catholic Church and ancient eastern culture - were combined to keep women secluded in the home. In the rest of the country, i. e. the provinces, women's life was not as miserable as in the south, but also much less exciting that in the industrialised cities.

According to all interviewed, only a small number of energetic female students living in places like Ancona and Pesaro could enjoy sports systematically, but these sports were organised in a rather crude way.

However, on the occasion of most important sporting events, such as those openly linked to the fascist image and propaganda, things were organised better. Then, not only female physical education teachers and amateur trainers, but influential members of the national sporting federations reached provincial cities like Ancona and Pesaro for recruiting talented girls. (See interviews $\mathrm{A}$ and D)

Female students were selected at school by their female physical education teachers, who were generally good at traditional and rhythmic gymnastics, but did not know much about sport. As already mentioned (Chapter 5.3), only from 1932 to 1943 was an elite of young women properly trained for teaching sporting activities in the modern and prestigious Academy of 
Orvieto. In fact, other female teachers had been trained in physical education in the old-fashioned Istituti di Magistero led by ENEF from 1924 to 1927, and in subsequent years some had attended summer courses organised in the provinces and the female Academy of Orvieto by ONB. (See Chapter 5.2)

As a consequence, male professional or amateur coaches were mainly in charge of training girls for sporting activities and subsequent contests. According to those interviewed, male coaches worked enthusiastically for women's 'sportivisation', and girls felt deeply grateful for such help and attention. (See B, D and E) Being keen on sport in general, these coaches did not discriminate against people by gender but, on the contrary, surmounted the narrow-minded attitudes of male Italians who suppressed women's emancipation and considered sport a man's affair, although living under a regime which aimed to forge a new sporting race by means of healthy physical activities for all, at least 'on paper'.

On the other hand, the athletes interviewed constituted an exception in the quiet and provincial women's lives. From their words some argue that generally parents of their school friends discouraged the involvement of their female children in sport, according to a mentality which supported male 'sportivization' but preferred to keep young women in the home, under the physical and moral control of the family. (D) Even the more openminded families of the interviewed were not too permissive, in so far as they prohibited their daughters from playing sport at a higher level (A and D), or when moral problems could actually arise. (C)

On the other hand, commonly girls were not fond of sport, which was considered tiring and much too manlike. Some of the interviewed confessed they started sport just to imitate the virile sporting enterprise of their beloved brothers and/or fathers (C and D), but considered themselves 'different' from their school friends for having lived abroad (D), or for having been 'tomboyish'. (E)

Those interviewed complained about technical problems linked to the heavy and old-fashioned sportswear they were obliged to put on for the sake of morality, as well as the common people's harsh criticism of female athletes and their bare legs. (B, C and D) 
Even the most famous athlete, Ondina Valla, who enjoyed an innovative experience at the highest level and was frequently abroad on her own, had to maintain a blameless behaviour in Italy by following strict unwritten norms for daughters of a family. For instance, according to her father's will, she had to be back home before dinner time. ${ }^{24}$

One should add that not only in the years of Fascism, but also until the second half of the Twentieth Century, Italian women were secluded in the home at night, for the sake of morality. They were not allowed to go out after sunset, unless escorted by a man of the family, especially in the provinces and the south. A woman who was outside the home at night on her own, or together with friends, was commonly reputed to be dangerously light, possibly a prostitute! 
263

Chapter 7 


\section{Conclusions}

Summing up what has been said in the previous chapters, the Twenties should be seen as the years of battles for female emancipation and sporting activities. The new social status achieved by working women during the Great War, (Chapter 3.2) together with the wind of modernity blowing from futurist and fascist movements, helped women to resist bourgeois traditionalism and Catholic misogyny, and gain some room on the sporting stage. (Chapters 4.1 and 5.6)

However, in the Thirties, once the fascist regime was established, and the most traditional womanly values stressed again, the question was raised as to whether a woman should indulge in competitive sport. (Chapter 5.1) The model of sportswomen from democratic countries, such as the USA and other European nations, was considered too virile and unsuitable for Latin femininity and fascist women's style. (Chapters 4.2 and 5.7) A new austere model, the 'true woman', and special attention given to her health in view of maternity, were themes of vital importance for Mussolini, and they were spread through the country by fascist propaganda and concrete efforts involving school, extra-scholastic and after work institutions. (Chapters 5.2, 5.4 and 5.5)

At the same time, a number of young girls, being trained in physical activities within those institutions, started to compete at a higher level, supported by former female athletes of the magic 1920s, now managers and trainers of CONI federations, specialist teachers of the Academy of Orvieto, and professional male coaches. (Chapters 5.3 and 5.6) Being a 
minority that would not have 'disturbed' the quiet trend of common female fascists, those sportswomen interested the regime as a further chance to display to the world that Italy was a modern nation. In this contest, while Mussolini incarnated the symbol of the Italian sportsman (Chapter 2.5), the main inspirational female icon was the athlete Ondina Valla, the first gold medalist in Italian women's Olympic history, but other exemplary recordswomen were admired as well. (Chapter 6.1 and 6.2)

Women did not fail to progress considerably, also because from 1937 a unique state body mobilised the whole of young people in a really extensive programme of massive physical education, sporting activities and popular displays, so as to better the race, prepare the population for an 'indubitably' glorious future, and give these tasks the widest possible visibility. (Chapters 5.6 and 6.3)

At the start of the Forties, when the Second World War was harshly engaging men and means, women's sporting activities and public displays increased further, together with their involvement in work and politics. (Chapters 4.3 and 5.6) Sport became a way to especially strengthen womanly combative spirit, for both morally supporting their men at the front, and facing hard sacrifices at home. These female displays and sports achievements would possibly distract the country from vital war problems and sorrows for a future, which had been promised to be glorious, but in reality was revealed to be frightfully uncertain.

One may pose two important questions: "Did physical and sporting activity among Italian women really increase?" " Did the consciousness of possessing an athletic body, well-trained within fascist organisations by following the eugenic ideology, really promote the emancipation of Italian women in spite of the manly hegemony of the time?"

The answers cannot but be positive to both questions. There was some mystification in the enrapturing data on women's sports given by official statistics, and the 'outer' feminine emancipation achieved through sport was certainly an undesired result of the fascist politics of the body. However, sportswomen and, in a wider perspective, women involved in fascist organisations, experienced societal activities that drew them away from too strict family protection, and threw themselves into a modern dynamic life alongside men, although in more or less subordinate positions. 
But if one asks whether or not female achievements in fascist society, which even brought women to combat in the civil war of 1943-45, made shorter the way towards female emancipation in the post-war period, the answer would be doubtful.

In truth, the successful engagement of women in the Resistance, all deprivations and sacrifices suffered in their homes, and especially a diffused need to modernise the country, gained them the right to become all-round citizens. After the dramatic defeat of Fascism, for the first time in the history of the country $12,998,131$ women participated in the institutional referendum which gained the defeat of monarchy and the victory of the republican institution, in 1946. At the same time, the whole of Italy voted for a constitutional assembly in charge of preparing the new Constitution. In 1948, this Constitutional Law was issued, and it did not discriminate against people by gender. Art. 3 stated: "All citizens have the same social dignity and are equal before the law without any sexual distinction"; Art. 37: "Working women have the same rights and equal salaries of workmen engaged in the same jobs"; Art. 48: "All citizens, men and women, become electors when they come of age"; Art. 51: "All citizens of both sexes can equally be elected, and work in public offices, according to roles stated by law".

However, the gender equality stated by the Constitution found it difficult to be applied in practice, both in the major political and working fields, and the minor sports sector. Evidence of this trend can be found everywhere.

In politics, 529 men, but only 44 women $(6.3 \%)$, were elected as members of Parliament in 1948. Then, while emancipated women who had compromised their good name with fascist ideology were taboo, prominent female partisans, and anti-fascists persecuted under the regime, were candidates in the Communist and Socialist parties, and well-known female members of Catholic Action were in the lists of the Christian Democratic party. This notwithstanding, Italian people did not support female candidates adequately. Although the previous period had seen a number of capable, strong and self-confident female combatants, whether in fascist or anti-fascist fronts, even female electors did not trust women's political capacity, being afraid that the 'weaker sex' could not understand much about politics, a man's affair for ages. 
The whole of the political class of that time did not help female participation in society, although a very innovative Constitution had been published. Substantial discrimination in the work field existed in the long-lasting antifeminist norms and rules prohibiting women's access to working activities in the magistracy, diplomacy, provincial administrative councils, and the army (the latter having been finally opened to women only now).

Through the years, most of these misogynous dispositions had to be removed - after harsh political battles - by the Constitutional Court, for being judged openly in violation of the Constitution itself. For instance, the magistracy allowed women to participate in its contests only from 1963, after a long debate that opposed open-minded politicians to a number of old-fashioned jurists.

One of these was Ranelletti, who should be cited for his really out-of-date machismo. In 1957 he criticised the Minister of Justice Aldo Moro, then supporting women in magistracy, by saying that the Minister did not know women sufficiently, or he had forgotten the tremendous responsibility and difficulty of judging people.

What is more, Ranelletti wrote: "In general a woman is vain, light, superficial, emotional, passionate, impulsive, rather 'stubborn', approximate, without any logic, dominated by 'pietism', which is not 'piety', and therefore unable to evaluate delinquents and crimes in their right proportion, with objectivity, serenity and wisdom."1

Possible reasons for this retrograde attitude can be found in the authoritative Catholic Church, which proclaimed itself the defender of womanly modesty and family values, and for the sake of these values it continued to discriminate against women, but now having much more power. Supporters of Catholic values were mostly deputies of the Christian Democratic Party that in 1948 had obtained the electoral majority.

In addition, both the Christian Democratic and Communist Party (then the second party in Italy) had favoured the total transferring of the fascist Patti Lateranensi Concordat of 1929 (Chapter 1.1) in Art. 7 of the new Constitution. They knew that through the Concordat the fascist state had left in the hands of the Catholic Church all juridical principles which regulated marriage and separation between husbands and wives, thus 
favouring men and discriminating against women for the sake of family unity.

At that time, the minor political class of liberal, radical and socialist traditions could not oppose the transfer of that Concordat into the Constitution, neither help much in changing norms and rules which opposed the entry of women into work and society. As a matter of fact, most of the charismatic leaders of the minor parties were old gentlemen representing the political class of the early Twentieth Century, such as Croce, Orlando, Nitti, and De Nicola, who had no particular interest in, nor sensitivity to women's problems.

Apart from the weight of the patriarchal and rural culture in a country which was little industrialised, the biggest obstacles to women's emancipation were women themselves. Female gender identity and self awareness were still weak, being strongly limited by a misogynous past that considered women to be inferior creatures broken into two parts, namely the attractive 'devils' blackmailing men sexually, and the modest 'angels of home life' to be protected to the utmost. The post-war engagement of women in different parties led by men did not help them achieve a gender unity for helping the 'feminine question', but on the contrary set them in antithetical positions.

Italian history demonstrates that in general women have found sufficient will-power and courage to oppose men's hegemony only when they had to replace men in the emergency periods of the First and Second World Wars. But in subsequent years they gave it up, permitting the patriarchal tradition to hamper again any female progress and achievement. Italian women's emancipation started successfully very late, due to the revolutionary 1968 that actively involved Italians in world-wide gender progress, which rocked traditions and habits.

The end of this research on women's physical education and sport should include a few words on this matter, in the early post-war period. Then, physical education and sports disciplines, having been strictly joined with the hated fascist era, were again looked upon with suspicion, while physical education and sport teachers, 'children of Fascism', lost any privileged position and found it hard to be accepted again in society.

In those years, the Ministry of Education of the newly-constituted republican state resumed control of physical education in primary and high 
schools, but women's participation in competitive sports improved very slowly, together with their delayed entry at work and in society. Because of Fascism, women had learned that they owned a body, were strong enough, could enjoy movement and compete as men did, but they had lost again the capacity to fight against the traditionalist vision of what a woman should be. In fact, from the second part of the 1940s onwards, female physical education at school, still a compulsory discipline, was taught strictly separated by sex. Only female teachers could give classes to girls, and different programmes were stated for them. With regard to the content of women's programmes, they were still influenced by the previous times, incorporating a lot of basic, applied and rhythmic gymnastics for the sake of health, but sport had less room than in the late fascist period. (Incidentally, only in 1990 were the programmes for high schools unified, and mixed classes were taught by physical education teachers of both sexes, indifferently.)

In theory, in the post-war period competitive sports were open to women; but their recruitment was obstructed by a number of prejudices, as usual. ${ }^{2}$ Through CONI and local society efforts, in the second half of the 1940s and the 1950s, a few women practiced sporting activities regularly, and competed also at international level. Among them should be mentioned at least the athletes Amalia Piccinini and Edera Cordiale, who gained silver medals at the London Olympics of 1948; the skier Giuliana Minuzzo, bronze medal winner at the Winter Olympic Games of Oslo in 1952; the fencer Irene Camber, gold medal winner at those of Helsinki in the same year.

However, these sportswomen were an elite which was born and had been trained for competition under Fascism. In 1959, only $0.5 \%$ of female amateurs practiced some motor activity, and of every 100 sports people involved in competition, only 9.3 were women. ${ }^{3}$

The recruitment and engagement of amateur sportswomen were poor also in the following years. I can offer a personal example of this. When I was a young student in Rome, at the last minute my physical education teacher entered my name for a provincial championship. I had not trained previously, but being also a student in the Academy of Dance, the teacher thought I was the only person in my school to be sufficiently fit to face the 
contest. Obviously the poor result of this performance was in proportion to my delayed engagement in athletics.

Finally, in the 1970s, the international post-1968 feminist movement changed the mentality of adult and young Italian women, and the country could not but support the achievement of new goals, once firmly denied. Being aware of their own rights, and reassured of their identity, finally Italian women started a difficult, and still ongoing, process of gender emancipation involving also the sports ambit. A whole new story could be written on this matter. 
Footnotes 
Abbreviations used:

ANFAL National Fascist Association for Female Artists and Graduates

CONI Italian National Olympic Committee

COSI Italian Students' Olympic Committee

CRI Italian Red Cross

EOA Welfare Bodies Institution

FASCI Federation of Italian Catholic Sports Associations

FGC Juvenile Fasci of Combat

FGNI Italian National Gymnastics Federation

FIAF Italian Federation for Women's Athletics

FIDAL Track and Field Italian Federation

FILDIS National Federation for University and Secondary School Teachers

FIMS National Federation of Sport Physicians

FUCI Italian Catholic University Federation

GIL Italian Littorio Youth

GUF University Fascist Groups

GFC Juvenile Fasci of Combat

IOC International Olympic Committee

LUCE The Cinema Educational Union

MVSN Voluntary Militia for National Safety

ENEF National Physical Education Body

ONB National Balilla Body

OND Spare-Time National Body

ONMI National Maternity and Infancy Body

PNF National Fascist Party

RSI Italian Social Republic

SAF Feminine Auxiliary Service

n. p. no place of publication

n. d. no date of publication 


\section{Chapter one:}

1 Mattazzi, G.(ed.), Benito Mussolini. Breviario, Milan, 1977, p. 138.

2 On Antonio Gramsci and his political philosophy see for example: Caprioglio, S., and Funi, E., Antonio Gramsci. Lettere dal carcere, Turin, 1968; Salinari, C., and Spinella, M., Il pensiero di Gramsci, Rome, 1975; Consiglio, F., and Frosini, F. (eds.), Antonio Gramsci. Filosofia e politica. Antologia dei 'Quaderni del carcere', Florence, 1997.

3 De Grazia, V., Le donne nel regime fascista, Venice, 1993, pp. 285-295.

$4 \quad$ Renzo De Felice published his monumental work on Mussolini in 4 volumes and 6 tomes, printed from 1965 to 1990 at Turin, and these were reprinted in 1996: Mussolini il rivoluzionario 1883-1920; Mussolini Il fascista 1921-1929 [tome I, La conquista del potere 1921-1925; tome II, L'organizzazione dello Stato fascista 1925-1929]; Mussolini il duce 1929-1939 [tome I, Gli anni del consenso 1929-1936; tome II, Lo Stato totalitario 1936-1940; Mussolini l'alleato 1940-1945 [tome I, 2 voll.: 1. L'Italia in guerra 1940-1943, 2. Dalla guerra "breve" alla guerra lunga; tome II, 2 voll.: 1. Crisi e agonia del regime, 2. La guerra civile 1943-1945].

In addition, De Felice published a number of books on Fascism. Among them: Storia degli ebrei italiani sotto il fascismo, Turin, 1972; Il problema dell'Alto Adige nei rapporti italo-tedeschi dall'Anschluss alla fine della seconda guerra mondiale, Bologna, 1973; Le interpretazioni del fascismo, Rome-Bari, 1995; Il fascismo. Le interpretazioni dei contemporanei e degli storici, Rome-Bari, 1998. De Felice granted interviews edited by Leeden, M. A., De Felice. Intervista sul fascismo, Bari, 1977, and Chessa, P., Renzo De Felice. Rosso e nero, Milan, 1995

\section{Chapter 2:}

1 Naturally, the Russian revolution of 1917 has to be quoted, but different ideas were professed by it, such as " the aesthetic materialism and anti-religious scientism, the myth of internationalism (...) and it proceeded with smaller care in the institution of a collective cult." See Gentile, E., Il culto del littorio. La sacralizzazione della politica nell'Italia fascista, Rome-Bari, 1993, p. 310. For early fascists see for instance: Alatri, P., Le origini del fascismo, Rome, 1962; De Felice, R., Mussolini il rivoluzionario, Turin, 1965; Salvemini, G., La nascita del fascismo, Milan, 1972; Gentile, E., Le origini dell'ideologia fascista, Rome-Bari, 1975; Vivarelli, R., Storia delle origini del fascismo, vol. I, Bologna, 1991; 
Sternhell, Z., Nascita dell'ideologia fascista, Milan, 1993; Payne, S. G., A history offascism. 1914-45, London, 1995.

2 Guerri, G. B., Fascisti. Gli italiani di Mussolini. Il regime degli italiani, Milan, 1995, pp. 216-225.

3 Of probable Etruscan derivation, the fascio was constituted by an axe and numerous wooden rods tied together. In ancient Rome it symbolised power and it was carried by selected soldiers, the Lictores, who used to escort the maxima authorities.

4 The Fasci di Azione Rivoluzionaria had been founded in order to bring Italy from neutrality to war.

5 In the Renaissance, at the time of the French Revolution, and also in the Italian Risorgimento movement of the Nineteen Century, the emblem of the fascis had returned in favour, with some variations in comparison to the Roman ancient model. In its Renaissance variation the fascis became the first symbol of the Fascist Party, whereas the Roman lictorius fascis was officially used from 1923. After accurate studies commissioned to the archaeologist and politician man Giacomo Boni, the lictorius fascis was adopted to reaffirm the Roman roots of the Stirpe Italica [Italic Descent], and therefore in order to cancel any possible reference to the ideas expressed in the preceding centuries. On this argument see: Falchi, L., Le origini del Fascio littorio. In: Il Giornale di Roma of 12 April 1923, and Gentile, Il culto del littorio ... op. cit., pp. 84-90.

6 The Arditi were special assault troops who distinguished themselves in war by their bellicose spirit; the Irredentists aimed at re-uniting the city of Fiume and Dalmazia to the fatherland; the Futurists were followers of the modern cultural movement leaded by Marinetti; the Dannunziani were followers of the famous poet D'Annunzio.

7 Giuseppe Mazzini's political mysticism was based on the binomial GodPeople, where the People were seen as a community of believers in the religious cult of the Fatherland. It is interesting to underline that, besides promoting the political and moral unity of the Italians, Mazzini saw, in prospect, Rome as the centre of a future Council of European Nations harmoniously fraternised under the common religious cult of their Countries. In Italy Mazzini's ideology was the basis for a series of movements that opposed the monarchic institution and pressed for the foundation of the so called 'Third Italy'. See Gentile, E., Il mito dello Stato nuovo dall'antigiolittismo al fascismo, Rome-Bari, 1982, pp. 3-28, and Gentile, Il culto del littorio ... op. cit., pp. 7-12. More specifically on Mazzini's politics see Grandi, T. and Comba, A. (eds.), Scritti politici, Turin, 1972.

8 In the scholastic ambit, one should mention the Minister of Education, Francesco De Sanctis who, in 1878, introduced educational gymnastics in school, 
with the purpose of educating the will of the citizens - future soldiers for the fatherland - through the training of their bodies. See Gori, G., Educazione fisica, sport e giornalismo in Italia. Dall'unità alla prima olimpiade dell'era moderna, Bologna, 1989, pp. 71-89. The army, which was delegated to represent and defend the 'religion of the country', had the task to teach soldiers about the sense of 'national unity', and to spread it in their families. See Conti, G., Il mito della 'nazione armata'. In: Storia contemporanea (December 1990), pp. 1149-1195.

9 The year 1861, in which the Kingdom of Italy was constituted, saw the beginning of a kind of ethical war between Church and State. In that year the Pope, Pio IX, threw himself against the disbelief of the Italian State which accepted 'infidels' at school and in public offices. See Guerri, Fascisti ...op. cit., p. 6.

10 Enrico Corradini exalted the war as the forging together of heroes, as a 'living soul of the fatherland', whose cult could have celebrated the divinity of the nation. Corradini, E., Una nazione. In: Il Regno of 19 June 1904. On Corradini, see also Filippi, F., Una vita pagana. Enrico Corradini dal superomismo dannunziano a una politica di massa, Florence, 1989.

11 Foundation and Manifesto of Futurism. In: Le Figaro of 20 February 1909. On Futurism in general see: De Maria, L. (ed.), F. T. Marinetti. Teoria e invenzione futurista, Milan, 1990; De Felice, R. (ed.), Futurismo, cultura e politica, Turin, 1988.

12 On the 'sporting' enterprises of D'Annunzio, see Impiglia, M., Lo scudetto e il vate. In: Lo sport italiano, 1 (1998), pp. 60-63.

13 In September 1919 D'Annunzio, heading a group of ex-servicemen - among whom there were also officials and soldiers of the Italian army - occupied the town of Fiume in Dalmatia region, by means of a coup de main.

14 The Regency of Carnaro, a kind of small nationalistic and revolutionary state, gave itself a constitution. In it, a new society centred on the trade-unions was delivered, joining employers and workers. In the following years, Giolitti's Italian government regulated the matter with Yugoslavia by renouncing Dalmatia - with the exception of the city of Zara - and by declaring Fiume an independent town. D'Annunzio and his followers had to surrender themselves and leave Fiume. On 27 April 1920, an announcement was launched by D'Annunzio's aviators in the sky above the main cities of Italy. The announcement declared: "Through the spontaneous consent of all spirits aiming at freedom, of all peoples torn by injustice and oppression, which are defeated and disappointed, the League of Fiume has been formed. It lifts his flag and revolt against the League of Nations, a plot of robbers and privileged cheats."

15 On the complex relationship between Mussolini and D'Annunzio from 1921 to 1925, see Valeri, N., D'Annunzio davanti al Fascismo, Florence, 1963; De 
Felice, R. and Mariano, E., Carteggio D'Annunzio-Mussolini (1919-1938), Milan, 1971. On D'Annunzio's politics in general, see De Felice, R., D'Annunzio politico 1918-1938, Rome-Bari, 1978.

16 Guerri, op. cit., p. 90. The famous aviator Italo Balbo, who had supported Mussolini since the beginning, had prestigious engagements during the regime. On Balbo, see Ibidem, pp. 78-83.

17 On the myth of the superman see: Carrouges, M., La mystique $d u$ surhomme, Paris, 1948; Welte, B., Il superuomo di Nietzsche: ambigua doppiezza. In: Renzo, G. (ed.), Friedrich Nietzsche e il destino dell'uomo, Cittanuova, 1982, pp. 23-41.

18 Papini, G., Maschilità, Florence, 1915, p. 41.

19 Guerri, op. cit., p. 43.

20 Mosse, G. L., Futurismo e culture politiche in Europa: una prospettiva globale. In: De Felice, R., Futurismo ... op. cit., p. 17.

21 Marinetti said: "We exalt patriotism and militarism; we sing of war, as the only hygiene of the world, the haughty flame of enthusiasm and generosity, the noble bath of heroism (...)" See Hulten, P., Futurismo e Futurismi, Milan, 1986, p. 18.

22 These words are taken from a writing by Marinetti of December 1915, eloquently titled 'Orgoglio italiano' [Italian pride]. See De Maria, op. cit., p. 503.

23 Futurism was exported to Russia, where it had particular success, and to many other European countries, such as Germany, Scandinavia, Great Britain, Spain, Portugal, and even Japan and Mexico.

24 Mussolini was an admirer of Gustave Le Bon, the scholar of mass psychology. His essays Psycologie des foules, and Psycologie des temps noveaux, were frequently read by Mussolini. See Moscovici, S., L'âge des foules. Un traité historique de psycologie des masses, Paris, 1981, p. 93. The Duce said he had experimented to discover that "the tendency of the modern men to believe was absolutely unbelievable!". Guerri, op. cit., p. 172. On fascist mass psychology in general, see Reich, W., Psicologia di massa del fascismo, Milan, 1982.

25 Mussolini replaced the May Day holiday, which was tied to the left wing, by the 21 April holiday, both celebrating the ancient Rome foundation and Italian production and work.

26 The celebration of 20 September, remember the victory of the State over the Church of Rome in 1870, was abolished by Mussolini. He did not want to aggravate further the problems of coexistence between two different religions, the fascist - new and nationalist - and the Catholic - ancient and international - the latter having its Holy centre in the very heart of the Capital of the Italian state. 
27 On the 'sacralisation' of fascist ideology, see Gentile, Il culto littorio ... op. cit., pp. 63-103.

28 Cantalupo, R., La classe dirigente, Milan, 1928, pp. 74-75.

29 In his speackes in form of questions and answers, Mussolini imitated the previous D'Annunzio style, used on the occasion of the enterprise of Fiume. On the Duce's language see: Ardau, G., L'eloquenza mussoliniana, Milan, 1929; Daneo, G. C., Benito Mussolini oratore, Genoa, 1932; Bianchi, L., Mussolini scrittore ed oratore, Bologna, 1937; Ellwanger, H., Sulla lingua di Mussolini, Milan, 1939; Saracinelli, M., and Totti, N., L'Italia del Duce. L'informazione, la scuola, il costume, Rimini, 1983, pp. 157-173.

30 For further searches on fascist mystics, see Betri, M. L., Tra politica e cultura. La scuola di mistica fascista. In: Storia contemporanea, 1-2 (1989), pp. 377-398.

31 On Duce's biographies, see Passerini, L., Mussolini immaginario. Storia di una biografia 1915-1939, Rome-Bari, 1991, pp. 153-234.

32 Manacorda, G., Letteratura e cultura del periodo fascista, Milan, 1974, p. 241. On the veline for the press, Ibidem., pp. 232- 246. On censure in general, see for example Lepre, A., L'occhio del Duce. Gli italiani e la censura di guerra 1940-43, Milan, 1992.

33 Mosse, G. L., Estetica fascista e società. In: Del Boca, A., Legnani, A. M., and Rossi, M. G., (eds.), Il regime fascista. Storia e storiografia, Rome-Bari, 1995, p. 110. See also Casini, L., La riscoperta del corpo, Rome, 1990, passim.

34 Mosse, Il regime fascista ... op. cit., p. 111.

35 On the ONMI: Fabbri, S., L'Opera Nazionale per la protezione della Maternità e dell'Infanzia, Milan, 1933; Fabbri, S., L'assistenza della maternità e dell'infanzia in Italia, Naples, 1933; Lo Monaco-Aprile, A., La protezione della maternità e dell'infanzia, Rome, 1934.

36 Ferretti, L., Il libro dello sport, Rome-Milan, 1928, p. 189.

37 From 1923 to 1936 the school system, from primary to university, doubled the number of affiliates. See Guerri, op. cit., pp. 156-157.

38 Ibidem, pp. 198-199.

39 Ibidem, p. 178. In general, on the OND body, see: Tannenbaum, E., R., L'esperienza fascista. Cultura e società in Italia dal 1922 al 1945, Milan, 1974, and De Grazia, V., Consenso e cultura di massa nell'Italia fascista, Rome-Bari, 1981.

40 The popular games of OND were: bocce (a kind of bowling), tamburello (little drum game), elastic-ball game, pulling the rope, volleyball, rowing with fixed seat, sfratto-ball game, and chess. See Stefanelli, R., Dopolavoro. Norme pratiche per i dirigenti, Turin, 1940, pp. 75-90. 
41 Marinetti expressed his sympathies to Italian students for physical culture, by declaring that Futurism was: "the cult of progress and speed, of sport, physical strength, rash courage, heroism and danger, against the obsession of culture, classical studies, museums, literature and ruins." De Maria, op. cit., pp. 328-340.

42 Ibidem, p. 370.

43 Ibidem, p. 340, and p. 372.

44 Marinetti, F. T., Alcune parti del film "Vita futurista", punto IV. In: L'Italia futurista, 8 (1916).

45 Among these facilities there should be quoted at least the monumental Littoriale of Bologna (1926), Berta Stadium of Florence (1929), Stadium of the Marbles in Rome (1932), Mussolini Stadium of Turin (1933), Vigorelli Cycleracing track of Milan (1933), and the Stadium of the Victory in Bari (1934).

46 In 1928, on the standard project by D'Albora, the model of Littorio sport track was standardised. It had to be built in every commune of Italy, with the economic support of the state. In 1930, 3.280 sport tracks were counted, mainly settled in the North of Italy. See Fabrizio, F., Sport e fascismo. La politica sportiva del regime 1924-1936, Rimini-Florence, 1976, pp. 22-24.

47 In 1928, the Royal Fascist Male Academy of Physical and Juvenile Education was founded in Rome, and in 1932 the Female Academy was founded in Orvieto. On the latter see Chapter 5.3.

48 Comparative statistics in the years 1928-1935 (ONB). In: Lo sport fascista, 4 (1936), p. 10. See also Ferrara, P., L'Italia in palestra. Storia, documenti e immagini della ginnastica dal 1833 al 1973, Rome, 1992, p. 241.

49 In 1924, the Federazione delle Associazioni Sportive Cattoliche [Federation of Catholic Sporting Associations]-FASCI closed spontaneously [!], and in 1927 the YMCA and the association of the Giovani Esploratori [Boy Scouts] were suppressed by the authorities. Some gymnastics sections of Catholic Youth lasted until 1931, even though operating with many limitations. See. Fabrizio, F., Storia dello sport in Italia. Dalle società ginnastiche all'associazionismo di massa, Rimini-Florence, 1977, pp. 104-112; Ferrara, op. cit., pp. 234-237.

$50 \quad$ Fabrizio, Storia dello sport ... op. cit., pp. 113-120.

51 Fabrizio, Sport e fascismo... op. cit., pp. 39-42.

52 On the Olympic Games of 1936, see Gori, G., L'atleta e la nazione. Saggi di storia dello sport, Rimini, 1996, pp. 97-139.

53 Among the most famous sportsmen we quote Carnera, Bindi, Guerra, Bartali, De Pinedo, Balbo, Nuvolari.

54 In 1933 two prizes, the Medaglie al Valore Atletico [Medals for Athletic Value] and the Stelle al Merito Sportivo [Stars for Sporting Merit] were instituted. 
Made of gold, silver and bronze, they rewarded athletes and the leaders of the sporting federations respectively, celebrating their victories in international and national competitions. See PNF, Foglio d'Ordini n.117, of 20 December 1933.

55 That discourse, held on 28 October 1934, was quoted by Vaccaro, G., Giorgio Vaccaro illustra i modi e i fini dello sport fascista. In: Lo sport fascista, 5 (1935), p. 11.

56 Banti, A., L'importanza dello spettacolo sportivo. In: Lo sport fascista, I (1936), p. 31.

57 In the Twenties the myth of Mussolini 'the great seducer' was only emphasised as a potential state, being in contrast with the Duce's 'austerity' in life. In the Thirties it was somehow accepted, as it became more and more compatible with the Latin male stereotype of the good husband and good father. Then, the virile fascist man adopted the dictum: 'many women, much honour'. Passerini, Mussolini immaginario ... op. cit., pp. 35-36.

58 Gobetti, P., Rivoluzione liberale, 9 (1924), p. 34.

59 According to Mussolini, boxing was 'an exquisitely fascist way of selfexpression.' See Mack Smith, D., Mussolini, Milan, 1981, p. 149.

60 "[He is] dominator and multiplier of the titanic energies of his athletic body, by using methodology, enthusiasm and discipline in any and every hour of the day. [He is] the virile and generous personification of triumphant Italian sport." See Ferretti, L., Mussolini, primo sportivo d'Italia. In: Lo sport fascista, 1 (1933), 3. See also: Dall'Ongaro, C., Mussolini e lo sport, Mantova, 1928; Cotronei, A, Cesare gladiatore. In: Il Popolo d'Italia of 28 October 1934; Fabrizio, Sport e fascismo... op. cit., pp. 114-119.

61 Papa, A., and Panico, G., Storia sociale del calcio in Italia. Dai club dei pionieri alla nazione sportiva 1887-1945, Bologna, 1983, p. 135.

62 Mack-Smith, D., Vincere, vincere, vincere. In: FMR, 26 (1984), p. 112.

63 Hoberman, J. M., Politica e sport. Il corpo nelle ideologie politiche dell'800 e del 900, Bologna, 1988, p. 137.

64 Preti, L., Giovinezza, giovinezza, Milan, 1972, pp. 109-110.

65 On the arts during the fascist era, see: Sapori, F., L'arte e il Duce, Milan, 1932. Among recent studies on this matter: Manacorda, op cit., passim; A.A. V.V., Anni Trenta. Arte e cultura in Italia, Milan, 1982; Alfassio-Grimaldi, U., and Addis-Saba, M., Cultura a passo romano. Storia e strategie dei littoriali della cultura e dell'arte, Milan, 1983; Masi, A., Un'arte per lo Stato, Naples, 1992; Brunetti, F., Architetti e fascismo, Florence, 1993; Biondi, M., and Borsotti, A. (eds.), Cultura e Fascismo. Letteratura arti spettacolo di un Ventennio, Florence, 1996. 
66 Giovanni Gentile - with his idealism, his religious background and his conception of the Ethical State - was the philosopher of early Fascism, but in the Thirties his star progressively declined. On Gentile see Chapter 5.2.

67 The liberal Benedetto Croce, by editing the magazine La Critica, became the reference point for those who believed in freedom.

68 In fact, one of the eminent intellectuals of our time, Norberto Bobbio, substantially modifies the idea of blind enslavement of Italian culture to the regime, by affirming: "Whoever looks today at the cultural panorama of those years, ... above all at literary, historical and philosophical culture ... finds it hard to realise that in Italy there had been such an earthquake that Fascism had been, or was said to be until the obsession." See Guerri, op. cit., p. 154.

69 Mosse, G. L., Il fascismo. Verso una teoria generale, Rome-Bari, 1996, p. 65.

$70 \quad$ Passerini, op. cit., p. 166.

71 Malaparte, C., Cantata dell'ArciMussolini. In: L'Italiano, 7-8-9 (1927).

72 De Maria, op. cit., p. 575.

73 Manacorda, op. cit., pp. 160-161.

74 "The Duce's portraits are thousands. They will reach fabulous numbers, they will not be countable anymore." See Sapori, F., op. cit., p. 135.

75 A collection of the Duce's portraits, including those realised by petals of flowers and grains of wheat, illustrated the book by Malvano, L., Fascismo $e$ politica dell'immagine, Turin, 1988, passim.

76 Bianchi, C., Il nudo eroico del fascismo. In: Bertelli, S., and Grottarelli, C., Gli occhi di Alessandro. Potere sovrano e sacralità del corpo da Alessandro Magno a Ceausescu, Florence, 1990, p. 162.

77 De Maria, op. cit., p. 340.

78 Sironi, M., Manifesto della pittura murale. In: Colonna, I (1933), p. 10.

79 Armellini, G., Le immagini del fascismo nelle arti figurative, Milan, 1980, p. 165. As for the Cremona Prize, which started in 1939 thanks to the initiative of Farinacci, see Ibidem, pp. 175-176, and Chapter 5.7.

80 Among the artists we quote: Albino Manca, who carved the Duce's bust dressed as a Roman emperor; the painter Emilio Florio, who represented him completely naked, as a kind of Roman she-wolf, having the twins Romulus and Remus at its feet. The relief by Publio Morbiducci, La storia di Roma attraverso le opere edilizie, was a kind of modern Traiana Column where Mussolini was engraved as the commander, hieratically erect on the stirrups of his horse.

81 As an example, Giuseppe Graziosi portrayed the Duce in an equestrian statue, which recalled both the heroes Gattamelata by Donatello, and Colleoni by Verrocchio. 
82 The subject of the Duce riding a horse, with his cloak lifted by the wind, was proposed in a painting by Primo Conti, and a sculpture by Cleto Tomba. Both artists imitated the famous painting Napoleone al Gran San Bernardo, by David.

83 In Montreal Mussolini was even portrayed like a kind of Saint, in an ingenuously blasphemous fresco. This was made on the apse of the Catholic Church named Madonna della Difesa, by the painter Guido Nincheri, who titled the fresco Mussolini circondato dai Quadrumviri, dal Duca degli Abruzzi e da Marconi.

84 The futurist Ferruccio Vecchi, in his sculpture L'Impero balza dalla testa del Duce, represented Mussolini's head while it was giving birth to the Empire. This latter was sculptured as a strong, virile and athletically naked figure, having the same Duce's features. Not only in the figurative arts, but in literature Mussolini's image was compared to mythological heroes and the most famous heroes of the past. See for example: Ferrara, M., Machiavelli, Nietzsche, Mussolini, Paris, 1923; Gennaioli, G., Mussolini e Napoleone I Sansepolcro, 1926; DuncanDarlymple, H., Son of Vulcano: Benito Mussolini. An impersonation of the Superman, Florence, n. d. (but before 1931); Viganoni, G., Mussolini e i Cesari, Milan, 1933; Speciale, F., Augusto fondatore dell'Impero romano. Il Duce fondatore dell'Impero italiano, Treviso, 1937.

85 More broadly on that Exhibition, see Gentile, Il culto del littorio ... op. cit., pp. 213-235.

86 On the athletes of the Stadium of Marbles, as symbols of Mediterranean bisexuality, see Arbasino, A., Giovinezza giovinezza. In: FMR, 26 (1984), pp. 9698. On Mussolini Forum, today Foro Italico, see: Paniconi, M., Criteri informativi e dati sul Foro Mussolini. In: Architettura, XII (1933); Del Debbio, E., Le arti figurative. In: Panorami di realizzazioni del fascismo, 7 (1938-1942).

87 It was very soon decided to hide the sex of most statues, applying a rudimentary fig leaf in cement, in respect to the decency of Catholics.

88 Cresti, C., Forum Beniti. In: FMR, 26 (1984), p. 106.

89 Mack-Smith, Vincere ... op. cit., p. 118.

90 Catania, A., L. Freddi e il libro della solitudine. In: Biondi and Borsotti, op. cit., p. 296.

91 On cinema and Fascism, see: Gori, G. M., Patria diva. La storia d'Italia nei film del ventennio, Florence, 1988; Casadio, G. F., Telefoni bianchi. Realtà e finzione nella società e nel cinema italiano degli anni Quaranta, Manduria, 1991; Brunetta, G P., Storia del cinema italiano. Il cinema di regime, 19291945, Rome, 1993; Freddi, L., Il cinema. Il governo dell'immagine, Rome, 1994.

92 Saracinelli and Totti, op. cit., pp. 78-81.

93 Isnenghi, M., Il corpo del Duce. In: Bertelli and Grottarelli, op. cit., p. 171. 
94 Among the titles in daily newspapers: Sulle orme del fascismo, Hitler cancelliere del Reich guida al potere le giovani forze innovatrici delle Germania. In: Il Resto del Carlino of 31 January 1933; Hitler afferma che al glorioso esempio di Roma è dovuto il trionfo dell'idea nazionalisocialista. In: Il Popolo d'Italia of 1 February 1933.

95 Krüger, A., Fasci e croci uncinate. In: Lancillotto e Nausica. Critica e storia dello sport, I-II (1991), pp. 88-101.

96 In order to defend the Italian race some decrees were passed: the Law of 17 November 1938, that of 29 June 1939, and that of 13 May 1940. By then, the natives of Libya, Eritrea, Somalia and Ethiopia had a civil status lower than that of the colonisers.

97 "The Great Council of Fascism ... reminds us that fascism has been carried out for ten years, and it still carries out, a positive activity directed to the quantitative and qualitative improvement of the Italian race - improvement which could be heavily compromised ... by crossbreeds and degeneration. The Hebrew problem is only the metropolitan aspect of a problem of a more general character." And Mussolini affirmed: "The racial problem has not blown up suddenly, ... the empires are conquered by weapons and they are kept by prestige, .. we need a severe racial consciousness which states not only the differences, but also the very clear superiority." See Del Boca, A., Le leggi razziali nell'impero di Mussolini. In: Del Boca, Legnani and Rossi, op. cit., pp. 338-339.

98 In 1936, the Minister for the Colonies - Alessandro Lessona - had given detailed dispositions to avoid any kind of fraternity between the two races. In 1937 he summarised the fascist racial politics in: "a) clear and absolute separation between the two races; b) collaboration without promiscuity; c) humanity, according to past errors; d) implacable severity to future errors." See Ibidem., pp. 336-337.

99 Among his lovers, two Hebrew women of great culture - Angela Balabanov and Margherita Sarfatti - have to be quoted. They would have been unacceptable partners for Hitler! See Chessa, P., Renzo De Felice. Rosso e Nero, Milan, 1995, p. 153. On this argument see also Spinosa, A., Mussolini: razzista riluttante, Rome, 1994.

100 Chessa, op. cit., pp. 156-157.

101 Racist announcements are in Manacorda, op. cit., pp. 247-253. On Italian racism of the time, see: Muggiani, E., Razzismo: autarchia del pensiero. In: Il Popolo d'Italia of 21 August 1938; Orano, P., Inchiesta sulla razza, Rome, 1939; Tarchi, M., Julius Evola e il fascismo: note su un percorso non ordinario. In: Biondi and Borsotti, op. cit., pp. 123-142. 
102 This substitution was made inside the project of one of the sections Ortogenesi Fascista della Stirpe - co-ordinated by Dr. Pende (on the latter see Chapter 5), for the future E 42 Exhibition. See Malvano, op. cit., p. 156 and p. 172. 103 Chessa, op. cit., pp. 149-163. In general, on the Hebrew problem see De Felice, R., Storia degli ebrei italiani sotto il fascismo, Turin, 1961.

104 Mosse, G. L., Sessualità e Nazionalismo, Rome-Bari, 1966, p. 199; Mosse, G. L., The image of man. The creation of modern masculinity, New York, 1996, passim.

105 Ferretti, Il libro dello sport ... op. cit., p. 217.

106 Armellini, op. cit., pp. 159-176.

107 Silva, U., Ideologia e arte del fascismo, Milan, 1973, p. 68.

108 Pivato, S., Sport et rapports internationaux. Le cas du fascisme italien. In: Arnaud, P., and Wahl, A. (eds.), Sports et relations internationales, Metz, 1994, pp. 64-72.

109 Passerini, op. cit., p. 179.

110 Hoberman, op. cit., p. 146. On cross influences among fascist countries such as Italy, Germany and Spain, see Krüger, A., Strength through joy. The culture of consent under fascism, Nazism and Francoism. In: Riordan, J., and Krüger, A. (eds.), The International politics of Sport in the Twentieth Century, London, 1999, pp. 67-99.

\section{Chapter 3:}

1 Under Carl Albert's Kingdom of Sardinia, the Swiss Rudolf Obermann (1812-1869) was in charge of teaching gymnastics within the army in Turin, in 1833. Being successful, he spent his life developing gymnastics in the territory, and later in the Kingdom of Italy as a whole. Obermann's methodology was mainly based on Jahn's Turnen and Spiess's pedagogical gymnastics.

2 Illuminist ideals inspired also Italian intellectuals. Being influenced by Locke and Rousseau, some of them considered bodily culture as an essential part of education. Among them, Gaetano Filangieri wrote about physical culture in his Scienza della legislazione (Chapter IV: "Delle leggi che riguardano l'Educazione, i Costumi, e l'Istruzione Pubblica"), Milan, 1786, and Antonio Genovesi, in his essay Lezioni di commercio, o sia d'economia civile, Bassano, 1788, recommended pedagogists to give great consideration to Jacques Ballexerd's book Dissertazione sull' educazione fisica de' fanciulli, Naples, 1763.

3 On the history of the Italian Gymnastics Federation see: Ballerini, F., La Federazione ginnastica italiana e le sue origini, Rome, 1931; Riva, A. (ed.), Cento anni di vita della Federazione Ginnastica d'Italia, Rome, 1969, Ferrara, 
P., L'Italia in palestra. Storia, documenti e immagini della ginnastica dal 1833 al 1973, Rome, 1992; Gori, G., L'atleta e la nazione. Saggi di storia dello sport, Rimini, 1996.

4 Among the national sports federations, that of sailing (Unione delle Società Veliche Italiane) was fouded in 1879, of cycling (Unione Velocipedistica Italiana) in 1885, of rowing (Federazione Italiana Canottaggio) in 1888, of tennis (Federazione Italiana Tennis) in 1895, of football ( Federazione Italiana Gioco Calcio) in 1898, and of running (Unione Pedestre Italiana) in 1899. The Genoa Cricket and Football Society, the first football Italian association, was founded in 1893 by British people in Genoa.

5 On the game 'pallone con il bracciale' see Pivato, S., I terzini della borghesia. Il gioco del pallone nell'Italia dell'Ottocento, Milan, 1990.

6 See Gori, G., Sports Festivals in Italy between the 19th and 20th Centuries: A Kind of National Olympic Games? In Naul, R. (ed.), Contemporary Studies in the National Olympic Games Movement, Vol. 2, Frankfurt am Main, 1997, pp. 1952.

7 On the Italian 'pedagogical' body see the introduction of the ample and welldocumented volume by Bonetta, G., Corpo e nazione.L'educazione ginnastica, igienica e sessuale nell'Italia liberale, Milan, 1990, pp. 11-69.

8 During the Nineteenth Century, the first Law in favour of curricular gymnastics was signed by the Minister of Education Gabrio Casati in 1859. After the Kingdom of Italy was established, in 1878 the Minister of Education Giovanni De Sanctis signed a new Law. The 1878 programmes of physical exercises were reviewed in 1884 and 1893, but it still maintained a conservative trend, mostly following the German militarist gymnastics, and little room was given to sports and games.

9 In Italy imperialist expansionism led to the colonial war, and subsequent occupation of Libya, in 1912.

10 In 1880, Pope Leone XIII wrote the Arcanum Encyclical, in which maternity was highly exalted as well as the female role within the family.

11 Art. 134 of Pisanelli's Codex.

12 In that century, also access to instruction was poor and mainly reserved to male pupils. In 1871, only $24.2 \%$ of women, and $38.2 \%$ of men were literate. On the Italian feminist movement in general see Pieroni-Bortolotti, F., Alle origini del movimento femminile in Italia, 1848-1892, Turin, 1963.

13 Eugenio Young did not only propagate the practice of gymnastics within the military College of Milan that he led, but published books translating or inspired by Clias's, Guts Muths's and Amoros y Odeana's gymnastics. 
14 On this educational programme, see Sancipriano, M., and Macchietti, S. S. (eds.), F. Aporti, Scritti pedagogici e lettere, Brescia, 1976.

15 Obermann, R., Della ginnastica. VII. Dei Ginnasticanti. In Letture di famiglia, 26, (1845), pp. 207-208.

16 See Di Ferdinando, D., Contro le bugie del cosmetico.Alle origini della ginnastica femminile. In: Lancillotto e Nausica. Critica e storia dello sport, 7 (1990), p. 42.

17 Ceci, G., Reali educandati femminili in Napoli, Naples, 1900, pp. 96-97. See also art. 12 of Statuto dei Reali educandati femminili. In: Gazzetta Ufficiale of 4 December 1861.

18 Statistica delle scuole di ginnastica del Regno d'Italia. Anno 1863-64. In: Monografia della società ginnastica di Torino e Statistica generale delle scuole di ginnastica in Italia, Turin, 1873, pp. 60-61.

19 Gallo, P., VI Relazione annua per Pietro Gallo direttore della ginnastica, Venice, 1872, p. 6.

$20 \quad$ Ferrara, op. cit., p. 59.

21 Baumann, E., Progetto di una Scuola magistrale di Ginnastica compilato dal direttore della palestra Dott. cav. Emilio Baumann, Bologna, 1877. In: ACS, Ministero della Pubblica Istruzione, Segreteria Affari Generali, Ginnastica, b 50.

22 Anonym, Lettera del Segretario Generale ai provveditori agli studi, ai sindaci e agli Ispettori Scolastici del Regno in data 9-6-1884. In: ACS, Ministero della Pubblica Istruzione, Segreteria Affari Generali, Ginnastica, b 3.

23 During one of the parliamentary debates concerning that law, deputy Tizzoni, who supported De Sanctis's project of female gymnastics at school, earned the derision of his colleagues. On those parliamentary debates and De Sanctis's Law, see Gori, G., Educazione fisica, sport e giornalismo in Italia. Dall'unità alla prima olimpiade dell'era moderna, Bologna, 1989, pp. 73-99.

24 Cammarota, G., Lettera del R. Provveditore agli studi di Firenze al ministro della Pubblica Istruzione, 2 Aprile 1879. In: ACS, Ministerodella Pubblica Istruzione, Segreteria Affari Generali, Ginnastica, b 50.

25 See Gallo, P., Discorso pronunciato dal direttore della Ginnastica Pietro Gallo in occasione del saggio dato dagli alunni delle scuole comunali il 13.7.1871, Venice, 1871, p. 4.

26 Valletti, F., La ginnastica come mezzo di educazione civile e militare negli stati d'Europa. In: Bollettino ufficiale del Ministero dell'Istruzione of 6 July 1887, p. 47.

27 Il Ginnasiarca, 3 (1887), p. 20. The precarious position and poor salary given to gymnastics teachers were problems that will be faced, but not totally solved, by Daneo's Law of 1909. From 1878 onwards, a number of letters 
denouncing the discrimination gymnastics teachers had to face - not only in terms of low salary but also of lower consideration within schools - was sent to the Ministry of Education. On this argument, see Ferrara, op. cit., pp. 134-139.

28 De Amicis, E., Non si sgomentino le signore ... In: Ferraro-Bertolotto, M. C., Prospettiva storica dell'educazione fisica nel trentennio successivo all'unità, Genoa, 1984, pp. 91-135.

29 De Amicis, E., Amore e ginnastica, Turin, 1971, p. 88. See also SalinaBorello, R., Raccontare lo sport. In: Di Donna-Prencipe, C. (ed.), Letteratura e sport, Bologna, 1986, pp. 69-73.

30 ISTAT (ed.), Sommario di statistiche storiche dell'Italia. 1861-1985, Rome, 1987.

31 Mosso, A., La riforma della ginnastica. In: Nuova Antologia (1892), p. 263, and Mosso, A., L'educazione fisica della gioventù, Milan, 1894, pp. 76-77.

32 Mosso, A., L'educazione fisica della donna, Milan, 1892, passim. In 1892, during a meeting organised in Rome by the Female Society of Education, Angelo Mosso bitterly affirmed that female gymnastics with apparatus was not practiced sufficiently, because most young girls considered it as a practice for little girls. See De Giorgio, M., Le italiane dall'Unità a oggi. Modelli culturali e comportamenti sociali, Rome-Bari, 1993, pp. 242-243.

33 Gamba, A., La riforma della ginnastica. Note ed osservazioni. In: Gazzetta medica, 30 (1892), p. 400.

34 Those programmes were prepared by a commission led by the most important Italian scholars of that time, such as Mosso, Baumann, Gamba, and Abbondati from Naples.

35 In fact, in 1893 it was reported that: "the Commission traced back the Italian traditions still in use in various villages, collected and briefly described typical Italian games which it proposed for the new programmes of physical education. Primary school teachers were given the faculty of adding any other games which may have been in use in different regions." The report of the Commission has been published again in Gori, Educazione fisica ... op. cit., pp. 100-110. About gymnic games, see Jacomuzzi, S., Gli sport, vol. II, Turin, 1965, pp. 648-652.

36 Anonym, Lettera al Presidente della Commissione Sua Eccellenza Il Ministro. In: Bollettino ufficiale del Ministero dell'Istruzione, vol. 2, 1893, p. 4105.

37 Mosso, A., I giuochi olimpici a Roma? In: Nuova Antologia (1905), p. 422.

38 Anomyn, Arona. In: Bollettino della Società Ginnastica Milanese Forza e Coraggio, October 1889, pp. 2-3.

39 See Giuntini, S., La donna e lo sport in Lombardia durante il fascismo. Paper presented at the Congress "Donna Lombarda 1860-1945", Milan, 1989. 
40 On Giulia De Luca see Martini, M., Correre per essere. Origini dello sport femminile, Rome, 1996, pp. 43-46.

41 Ibidem., pp. 42-43.

42 Ibidem, p. 43.

43 Ibidem, pp. 40-41.

44 Candela, S., I Florio, Palermo, 1986, p. 329.

45 De Giorgio, op. cit., p. 246.

46 Jacomuzzi, S., Gli Sport, Vol. 3, Turin, 1965, p.208.

47 For further information on these events see De Giorgio, op. cit., p. 246, and La Bicicletta, September 1895, respectively.

48 On the Audax prize see Martini, op. cit., pp. 32-33.

49 On this and other 'sporting' performances held at La Scala in the Eighteenth and Nineteenth Century, see Macchi, G., Lo Sport alla Scala. In: Lo sport fascista, 2 (1929), pp. 73-78.

50 ISTAT (ed.), Sommario di statistiche storiche dell'Italia 1861-1975, Rome, 1976, pp.10-14.

51 Ballerini, F., La Federazione ginnastica italiana e le sue origini, Rome, 1931, p. 214.

52 Ibidem, p. 92.

53 Giacometti-Ferrari, D., Relazione del Comitato Centrale Femminile al XVI Consiglio Federale, Rome, 16 March 1903.

54 Ballerini, op. cit., p. 232.

55 Giuntini, S., Sport e storia. La nascita della ginnastica femminile. In: Ricerche storiche, 3 (1989), p. 705. Data about Turin are in Caimi, N. G., Mens sana in corpore sano. In: La Donna, 19 (1907), pp. 24-25.

56 Valle, G., Echi del Concorso di Milano. In: Il Ginnasta, 9 (1902).

57 A detailed report on the 1904 Contest of Florence is in: Il Ginnasta, 12 (1906).

58 On the event of Vercelli, Ballerini, op. cit., pp. 211-212. A detailed account of the Venetian event was published in: Il Ginnasta, 6 (1907).

59 This negative trend in the south of Italy had been already denounced in an alarming article by Guerra, R., L'indirizzo della ginnastica sociale in Italia. In: Il Ginnasta, 9 (1906).

60 Di Ferdinando, op. cit., pp. 48-49. On the female contest of Turin, see also La Gazzetta del Popolo of 14 May 1911, where a dramatic description of the foot-race can be found.

61 On the tennis player Gagliardi see Martini, Correre per essere ... op. cit., pp. 67-68. 
62 Giuntini, S., Società ginnastica milanese Forza e Coraggio. Alle origini dello sport a Milano, Milan, 1994, p. 98.

63 Giuntini, La donna e lo sport ... op. cit., pp. 2-3.

64 On Ferrario see La prima aviatrice italiana. In: Margherita, 3 (1913), p. 46; on Sambri, Martini, M., Sesso debole? Un secolo di smentite. In: Lo Sport Italiano, 8-9 (1994), pp. 40-41.

65 On Gagliardi and Mancio, see Martini, Sesso debole? ... op. cit., p. 41, and Martini, Correre per essere ... op. cit., pp. 67-69.

66 Martini, Correre per essere ... op. cit., pp. 72-74.

67 Ibidem, p. 72. Information on early mountaineering is in De Giorgio, op. cit., p. 248.

68 For more information on the hygienic conditions of Italian schools and gymnasia at the beginning of the Twentieth Century, see Ferrara, op. cit., pp. 188194.

69 The books Inferiorità mentale delle donna by Moebius P. J., and Sesso e carattere by Weininger O. were issued in Turin in 1904 and 1912, respectively.

70 Sighele, S., La donna e l'amore, Milan, 1913, p. 28.

71 See Papini, G., Maschilità, Florence, 1915, passim.

72 Most D'Annunzio writings represented negative figures of vamps.

73 See Programma politico futurista of 1913, signed by Marinetti, Boccioni, Carrà, and Russolo.

74 See Marinetti's manifesto In questo anno futurista of 29 november 1914.

75 In the 1930s, Marinetti's manifesto Simultaneità nello sport displayed a long list of bizarre 'simultaneous sports', sometimes involving spectators, such as: boxing and wrestling during foot-races; cycling at the lowest possible speed while spectators were throwing fruit, eggs or water at the cyclists; playing golf while spectators were shooting at the white golf ball in flight; and others.

76 All 'aerodanza' performed by the dancer Giannina Censi aimed at offering the same sensations and scenario that pilots felt in flight. As far as fisicofollia (meaning physical madness) was concerned, it was the theatrical way to freely express futurist values by means of the body. On futurist ballets see: Marinetti's manifesto La danza futurista of 1917; Bentivoglio, L., La danza moderna. Da Isadora Dancan a Maurice Béjart, Milan, 1977; Lista, G., Lo spettacolo futurista, Florence, 1989; Bonfanti, E., Il corpo intelligente-Giannina Censi, Turin, 1995.

77 See Marinetti's manifesto Contro l'amore e il parlamentarismo of 1910.

78 In 1919, a Futurist writer asked women not to be 'Females' - meaning sheep - anymore, but to become true 'Women', that is actively taking part in a policy of 
action, side by side with the most daring Italian men. See Vianello, A., Donne: a voi! In: Roma futurista, 1-2 (1919), p. 2.

79 Futurism favoured divorce and love-making outside marriage, up to exalting prostitution, as was clearly demonstrated by futurist writings, such as that of Tavolato, I., Elogio della prostituzione, published in the famous review Lacerba of 1 May 1924. During the Carnaro Regency, D'Annunzio's women obtained full recognition of their rights, after D'Annunzio's innovative Constitution of 27 August 1920 which abolished any gender discrimination among citizens (Art. 4). This and other political proclamations were collected by D'Annunzio, G., in his book Per la più grande Italia, Rome, 1939. On D'Annunzio, see both recent essays by Ledeen, M. A., Gabriele D'Annunzio: l'avventura fiumana e la politica del Novecento, and Nolte, E., L'impresa di Fiume e lo scenario europeo. In: Nuova Storia Contemporanea, 5 (1999), pp. 15-21, and pp. 23-30, respectively.

80 On feminine movements before the Great War see: De Grazia, V., Le donne nel regime fascista, Venice, 1993, pp. 42-54.

81 Laura Casartelli, one of the protagonists of the Italian female movement, in the first number of the review Almanacco della Donna Italiana, published in Florence in 1920, wrote a long article on these patterns, stigmatising the lack of women's participation in Italian political parties, with the exception of some Catholic and socialist women.

82 D'Annunzio, G., op. cit., p. 183 (Art. 8). See also De Felice, R., La carta del Carnaro nei testi di Alceste De Ambris e di Gabriele D'Annunzio, Bologna, 1973.

83 See Mondello, E., La nuova italiana. La donna nella stampa e nella cultura del Ventennio, Rome, 1987, p. 166.

\section{Chapter 4}

1 Matilde Serao, who was one of the most famous female writers, supported this ideology in her writing Parla una donna. Diario femminile di guerra, maggio 1915-marzo 1916, Milan, 1916. On the peculiarity of Italian feminism, see, for example Parla, G., L'avventurosa storia del femminismo, Milan, 1976, passim, and De Giorgio, M., Le italiane dall'Unità ad oggi, Rome-Bari, 1993, pp. 508-511.

2 The 'Arditi' were volunteer assault soldiers of the First World War, famous for being very courageous and pitiless. 
3 De Grazia, V., Le donne nel regime fascista, Venice, 1993, p. 9 and 57-58. In particular, on Regina Terruzzi's activity, see Detragiache, D., Du socialisme au fascisme naissant: formation et itinéraire de Regina Terruzzi. In: Thälmann, R. (ed.), Femmes et fascismes, Paris, 1986, pp. 41-66.

4 Lazzero, R., Il Partito Nazionale Fascista, Milan, 1985, passim. In general, on the fascist female movement of the first years, see Detragiache, D., Il fascismo femminile da San Sepolcro all'affare Matteotti, 1919-1924. In: Storia contemporanea, 2 (1983), pp. 211-251.

5 RADA (pseudonym), Una pagina d'italianità sportiva. In: Lo sport fascista, 1 (1931), pp. 39-40.

6 On the assault in Verona see Bertoldi, S., Camicia nera, Milan, 1994, pp. 111-112 and, on that near Udine, see Macciocchi, M. A., La donna 'nera'. 'Consenso' femminile e fascismo, Milan, 1976, pp. 16-17.

$7 \quad$ Margherita Sarfatti and Elisa Majer Rizzioli were fascinated by Mussolini's strong personality, so much so that they were faithful to him even when they fell into disfavour in the following years. See De Grazia, op. cit., pp. 57-61.

8 During a patriotic and fascist celebration at San Lorenzo Square of Rome, hidden opponents started shooting at the crowd, but these courageous women did not panic and helped the wounded. See Garibaldi, L., Le soldatesse di Mussolini, Milan, 1997, p. 34.

$9 \quad$ Ibidem, pp. 34-35.

10 Mattazzi, G. (ed.), Benito Mussolini. Breviario, Milan, 1997, p. 148.

11 See the journal La Provincia di Padova of 1-2 June 1923.

12 Mattazzi, op. cit., p. 150-151.

13 Montesi-Festa, I., La Donna italiana. In: La Donna italiana, 1 (1924), p. 6.

14 On anti-fascism see: Enciclopedia dell'antifascismo e della Resistenza, Milan, 1968-1989; Colombo. F., and Feltri, V., Fascismo, antifascismo, Milan, 1994; De Luna, G., Donne in oggetto. L'antifascismo nella società italiana (1922-1939), Turin, 1995.

15 A brief profile of the powerful intellectual Margherita Sarfatti is in De Grazia, op. cit., pp. 305-308. See also Sarfatti's biographical book Acqua passata, Bologna, 1955, passim.

16 Scaramuzza, E., Professioni intellettuali e fascismo. L'ambivalenza dell'Alleanza muliebre culturale italiana. In: Italia contemporanea, 151 (1983), p. 121.

17 Mussolini, B., My autobiography (written by Arnaldo Mussolini and edited by Richard Washburn Child), New York, 1928. On the relationship between Mussolini and his mother see also: Passerini, L., Mussolini immaginario. Storia di una biografia 1915-1939, Rome-Bari, 1991, pp. 90-93. 
18 In 1928 the most prolific Italian families (about one and a half million) became the object of an investigation on their morphological characteristics by a group of researchers. The result of this research, co-ordinated by Corrado Gini of the Central Institute of Statistics, showed that inelegant [!] and short women with broad hips were the most prolific. De Grazia, op. cit., p. 79.

19 On this speech see Fusco, G. C., Le rose del ventennio, Milan, 1974, p. 29.

20 See Mussolini, B., Opera Omnia (Susmell E. and D. eds.), vol. 22, Florence, 1951-1980, p. 360.

21 In general, on women's employment and specific laws, see De Grazia, op. cit., pp. 229-271.

22 Ibidem, p. 125.

23 Ibidem, pp. 107-111.

24 Critica fascista (1933), pp. 303-304.

25 Gianfranceschi, L., Un'italiana fra i semidei ariani. In: Panathlon International Club Valdarno Inferiore (ed.), Proceedings of the National Prize "L'atleta nella Storia" 1988 Ondina Valla, Montecatini Terme, 22 October 1989, Montecatini, 1989, p. 29.

26 SVIMEZ (ed.), Un secolo di statistiche italiane Nord e Sud, 1861-1961, Rome, 1961, p. 79, Table 77.

27 On number of children in different social classes during Fascism see LiviBacci, M., A History of Italian Fertility during the Last Two Centuries, Princeton, 1972, pp. 176-273.

28 See Il Popolo d'Italia of 30 May 1934.

29 This is part of the interview with Mussolini by the journalist Bodil Borge Ciccarella in Rome, November 1934. See Mattazzi, op. cit., p. 149.

30 Ibidem.

31 Momigliano, E. (ed.), Tutte le encicliche dei Sommi Pontefici, Milan, 1973, p. 932 .

32 Pende, N., Bonifica umana razionale e biologia politica, Bologna, 1933, p. 102.

33 Parla, G., L'avventurosa storia del femminismo, Milan, 1976, p. 96.

34 Scaramuzza, op. cit., pp.121-123.

35 Meldini, P. Sposa e madre esemplare. Ideologia e politica della donna e della famiglia durante il fascismo, Rimini-Florence, 1975, p. 266.

36 See Mondello, E., La nuova italiana. La donna nella stampa e nella cultura del Ventennio, Rome, 1987, pp. 58-59.

37 Ibidem, p. 189.

38 This number, which refers to the year 1937, is in Ceserani, G. P., Vetrina del Ventennio 1923-1943, Rome-Bari, 1981, p. 132. In general, on fascist 
propaganda through the media see: Cannistrato, P. V., La fabbrica del consenso. Fascismo e mass-media, Rome-Bari, 1975; Castronovo, V., and Tranfaglia, N., La stampa italiana nell'età fascista, Rome-Bari, 1980; Saracinelli, M., and Totti, N., L'Italia del Duce: l'informazione, la scuola, il costume, Rimini, 1983.

39 Mondello, op. cit., p. 83.

40 Mattazzi, op cit., pp. 152-153.

41 A comment on women's militarization in the colonies is in Salvatici, S., Modelli femminili e immagine della donna attraverso la fotografia della stampa fascista. In: AFT-Rivista di Storia e Fotografia, 18 (1993), p. 51; data on women's mobilisation in Italy are in ISTAT (ed.), Compendio statistico, Rome, 1938, p. 16.

42 De Grazia, op. cit., pp. 351-352.

43 Mussolini's speech addressed 'To fascist women' is in Opera Omnia, op. cit., vol. 28, pp. 204-205.

44 Loffredo, F., Politica della famiglia e della razza. In: La difesa della razza, 2 (1939), p. 31.

45 Loffredo, F., Politica della famiglia, Milan, 1938, p. 361 and p. 370. On Loffredo's anti-feminist theories see Macciocchi, op. cit., pp. 107-114.

46 Macciocchi, op. cit., pp. 91-93.

47 On these Mussolini projects see: De Felice, R., Mussolini il Duce, vol. 2, Turin, 1981, pp. 73-82; De Grazia, op. cit., p. 351; Mondello, op. cit., p. 61.

48 See Castellani, M., La nazione armata. Donne professioniste e laureate ausiliarie civili. In: Almanacco della donna italiana (1936), pp. 52-54.

49 A vivid description of this parade is in De Grazia, op. cit., pp. 300-301, and official documents are in ACS, Presidenza del Consiglio dei Ministri, 1937-1939, dossier 1.7.7493.

50 SVIMEZ, op. cit., p. 79.

51 Mattazzi, op. cit., p. 155.

52 De Grazia, op. cit., p. 147.

53 Gozzini, L., La donna nel quadro del Regime. In: Almanacco della donna italiana, 20 (1939), pp. 39-45.

54 Comments on this investigation are in Macciocchi, op. cit., p. 102, and Mondello, op. cit., p. 111.

55 This speech was given on 30 September 1939. See Mattazzi, op. cit., p. 152.

56 ACS, Presidenza delConsiglio dei Ministri, 1940-1941, dossier 582 and 586.

57 On the way towards the civil Code of 1942, see Ungari, P., Storia del diritto di famiglia in Italia, Bologna, 1974, pp. 217-243; on the content of that Code, which drew its inspiration from the previous Pisanelli Code of 1865, see for example Bessone, M., Alpa, G., D'Angelo, A., Ferrando, G., Spallarossa, M. R., La 
famiglia nel nuovo diritto. Principi costituzionali, riforme legislative, orientamenti della giurisprudenza, Bologna, 1995, pp. 8-15.

58 This man, Oberdan Freddosio, was the winner of the Littoriali of Culture in 1940. For the quoted sentence, see his book: Freddosio, O., Il regime per la razza, Rome, 1941, p. 87.

59 Macciocchi, op. cit., pp. 87-88.

60 De Grazia, op. cit., pp. 375.

61 Parla, op. cit., pp. 100-102.

62 De Grazia, op. cit., p. 368.

63 Garibaldi, op. cit., p. 105.

64 Ibidem, pp. 31-89.

65 On combatant women of RSI see: Giuliani, F., Donne d'Italia. Le ausiliarie della RSI, Rome, 1952; Lazzero, R., Le Brigate Nere, Milan, 1963; Scarpellini, A., La Repubblica Sociale Italiana nelle lettere dei suoi caduti, Rome, 1963; Pisanò, G., Storia delle Forze Armate della RSI, Milan, 1967; Fraddosio, M., La mobilitazione femminile: i gruppi fascisti repubblicani femminili e il SAF. In: Annali della Fondazione Luigi Micheletti, 2 (1986); Garibaldi, op. cit., passim. On partisan women see for example: Banfi-Malaguzzi, D., A Milano nella resistenza, Rome, 1964;. Battaglia, R., Storia della Resistenza italiana, Turin, 1964; Bilenchi, R., Cronache degli anni neri, Rome, 1984.

\section{Chapter 5:}

1 For a general view of the history of FIMS during Fascism, see Barbieri, F., Evoluzione storica della federazione medico sportiva italiana. Cinquant'anni di attività della FIMS, Siena, 1979, pp. 5-36.

2 Poggi-Longostrevi, G., Cultura fisica della donna ed estetica femminile, Milan, 1933, p. 241.

3 A long list of the international works which influenced the Italian constitutional school is in Chiurco, G. C., L'Educazione fisica nello stato fascista. Fisiologia e patologia chirurgica dello sport, Siena, 1935, pp. 59-61.

4 Ibidem, pp. 78-84.

5 Some of these scientists presented their research during FIMS Congresses, such as Davì, M., Bevande eccitanti e sport. In: FIMS (ed.), Atti del I Congresso Nazionale di Medicina dello Sport, Roma 19-20-21 Aprile 1932, Rome, 1932, and Cassinis, U., Caffè, caffeina, cloruro di sodio nel rendimento lavorativo. FIMS 
(ed.), Atti del Congresso Internazionale di Medicina dello Sport, Torino-Roma, Settembre 1933, Rome, 1934.

$6 \quad$ See FIMS (ed.), Atti del Congresso Internazionale di Medicina dello Sport, Torino-Roma, Settembre 1933, Rome, 1934, passim.

7 Cassinis, U., Può la donna fare lo sport? In: FIMS (ed.), Atti del I Congresso Nazionale di Medicina dello Sport, Roma 19-20-21 Aprile 1932, Rome, 1932, pp. 5-13.

8 Viziano, A., Prime indagini sull'influenza dello sport femminile sul periodo mestruale e considerazioni generali. In: Ibidem, pp. 15-33.

9 Giaccone, A., Può la donna fare dello sport durante il periodo mestruale? In: Ibidem, p. 43.

10 Viziano, op. cit., p. 33.

11 Zanetti, M., Deve la donna praticare lo sport? In: FIMS (ed.), Atti del I Congresso Nazionale di Medicina dello Sport, Roma 19-20-21 Aprile 1932, Rome, 1932, p. 37.

12 Ibidem, p. 38.

13 Lugnani, L'educazione fisica della donna col metodo Mensendick. In: Ibidem, pp. 47-52.

14 Baglioni, S., Donna e sport. In: Ibidem, pp. 53-58.

15 Rabino, A., Rapporti tra mestruazione e fatica sportiva. In: Atti del Congresso Internazionale di Medicina dello Sport, Torino-Roma Settembre 1933, Rome, 1934, pp. 453-454.

16 Lentini, S., L'educazione fisica e sportiva per l'avvenire della razza. In: FIMS (ed.), Atti del II Congresso Nazionale di Medicina dello Sport, Bologna 24-26 Ottobre 1935, Bologna, 1936, p. 65.

17 Ibidem, p. 67.

18 Tranquilli-Leali, E., Casistica sui traumatismi sportivi. In: FIMS (ed.), Atti del II Congresso Nazionale di Medicina dello Sport, Bologna 24-26 Ottobre 1935, Bologna, 1936, pp. 20-21.

19 Montanari-Reggiani, M., L'assistenza sanitaria e medico-sportiva nei G.U.F. In: FIMS (ed.), Atti del III Congresso Nazionale di Medicina dello Sport, Genova 12-14 Novembre 1938, Rome, n. d., pp. 405-409.

20 Sorrentino, G., La donna deve praticare gli sports atletici. In: La Gazzetta dello Sport of 22 November 1921.

21 Pende, N., La sorveglianza medica per gli esercizi ginnici sportivi nei campeggi e nelle colonie. In: ONB (ed.), Atti ufficiali del I Convegno Nazionale dei Medici dell'ONB, Roma 2-4 Febbraio 1930, Rome, 1932, passim. Among the most influential of Pende's bio-political writings: Bonifica umana razionale e 
biologia politica, Bologna, 1933, and Trattato di biotipologia umana individuale e sociale, Milan, 1939.

22 Poggi-Longostrevi, G., La donna e lo sport. La università dello sport femminile: l'atletica leggera. In: La Gazzetta dello Sport of 8 October 1930.

23 Poggi-Longostrevi, G., I lavori del Gran Consiglio Fascista. La delicata questione dello sport femminile affrontata: la donna non deve essere distolta dalla sua missione fondamentale. In: La Gazzetta dello Sport of 18-19 October 1930.

24 Poggi-Longostrevi, Cultura fisica della donna ... op. cit., pp. 232-241.

25 Chiurco, op. cit., pp. 69-70.

26 Fabrizio, F., Sport e fascismo. La politica sportiva del regime 1924-1936, Rimini-Florence, 1976, pp. 124-125.

27 Loffredo, F., Politica della famiglia, Milan, 1936, passim.

28 Poggi-Longostrevi, G., Medicina sportiva, Milan 1940, pp. 99-113.

29 Ibidem, p. 102.

30 Chiurco, op. cit. pp. 52-53.

31 Pio XI, Lettera al Cardinale Vicario. In: Civiltà Cattolica, 2 (1928), pp. 367-372.

32 That censure was pronounced on 21 March 1931.

33 B. P., La donna e l'atletismo. In: L'Osservatore Romano of 16 May 1934.

34 De Grazia, V., Le donne nel regime fascista, Venice, 1993, p. 293.

35 The athlete Ondina Valla tells how she was noticed and recruited in her primary school of Bologna, and who were her subsequent coaches, in the book of Artom, S., and Calabrò, A. R., Sorelle d'Italia. Quattordici Grandi Signore raccontano la loro (e la nostra) storia, Milan, 1989, pp. 273-279. (On this, see the next Chapter 6.1)

36 ONB (ed.), Norme programmatiche e regolamentari per le organizzazioni delle "piccole e giovani italiane", Rome, n. d., p. 6.

37 On this, see also Gori, G. Sport Medicine and Female Athleticism in the Years of the Fascist Regime. In: Terret, T. (ed.), Sport and Health in History.

Proceedings of the 4th ISHPES Congress, Lyon 16-22 July 1997, Sankt Augustin, 1999, pp. 192-201.

38 Mussolini, B., Discorso agli universitari fascisti. In: La Nuova Scuola Italiana, 1 (25 December 1923).

39 In this regard, see for example: Bonetta, G., Storia della scuola e delle istituzioni educative, Florence, 1997; Bonetta, G., Genesi e formazione della concezione scolastica gentiliana. In: Spadafora, G. (ed.), Giovanni Gentile. La pedagogia. La scuola, Rome, 1997; Genovesi, G., Storia della scuola in Italia dal Settecento a oggi, Rome-Bari, 1998.

40 Gentile, G., Il problema scolastico del dopoguerra, Naples, 1919, p. 8. 
41 Genovesi, op. cit., p. 227.

42 Ibidem. See also De Grazia, V., Le donne nel regime fascista, Venice, 1993, pp. 213-214.

43 Ibidem, p. 214

44 Ibidem, pp. 211-212.

45 De Felice, F., Mussolini il Duce. Gli anni del consenso 1929-1936, Turin, 1974, p. 189.

46 Consult Bottai, G., La Carta della Scuola, Milan, 1939; Gentili, R., Bottai e la riforma fascista della scuola, Florence, 1979; Charnitzky, J., Fascismo e scuola. La politica scolastica del regime (1922-1943), Florence, 1996. For a biography of Bottai, see Guerri, G. B., Giuseppe Bottai, fascista, Milan, 1996. On Jewish students in the Italian school, see Ostenc, M., L'éducation en Italie pendant le fascisme, Paris, 1980, pp. 356-361.

47 Bottai, op. cit., pp. 209-210, and Rossi, G., Educazione fascista, Milan, 1942 , p. 191.

48 This and other compositions supporting the fascist ideology are in Bertone, G., "I figli d'Italia si chiaman balilla." Come e cosa insegnava la scuola fascista. Rimini-Florence, 1975, pp. 161-176.

49 Motti, L., and Rossi-Caponeri, M., Accademiste a Orvieto. Donne ed educazione fisica nell'Italia fascista 1932-1943, Ponte San Giovanni, 1996, pp. 45-46.

$50 \quad$ Ferretti, L., Il libro dello sport, Rome-Milan, 1927, p. 84.

51 In 1926, 423,763 Italians were enrolled in national sport federations, according to Ferretti, op. cit., p. 171.

52 See ONB (ed.), Opera nazionale "Balilla" per l'Assistenza e l'Educazione Fisica e Morale della gioventù. Norme legislative e regolamentari, Rome, 1927, p. 38.

53 On this see Salvatorelli, L., and Mira, G., Storia d'Italia nel periodo fascista, vol. I, Milan, 1972, pp. 523-529.

54 Regarding FASCI, see Fabrizio, F., Storia dello sport in Italia. Dalle società ginnastiche all'associazionismo di massa, Rimini-Florence, 1977, pp. 4049. About 27,000 young people enlisted in Catholic sports societies in 1927.

55 See Motti and Rossi-Caponeri, op. cit., p. 24.

56 The 1926 Law regarding the institution of ONB was modified by the Royal Decree of 4 January 1927; specifically Article 4 specified that Italian Catholic Scouts had to add the symbol of the fascio and the initials ONB to their labaruses and pennants; later on, by Law Decree of 9 April 1928, the Catholic Scout organisation was abolished. Concerning the history of Italian Scouts, see Sica, M., Storia dello Scoutismo in Italia, Florence, 1987. 
57 In regard to Forza e Grazia movement, see Annali dell'Italia Cattolica 1925, Milan, !926, pp. 216-219. On the priest Gemelli, who was in favour of moderate physical activity for Catholic girls, see Gemelli, A., La educazione fisica della donna, Milan, 1923, passim.

58 Rassegna Femminile Italiana, 1 (1925), p. 3.

59 Betti, C., L'Opera Nazionale Balilla e l'educazione fascista, Florence, 1983, p. 160. On this programme also consult PNF (ed.), Il Partito fascista e le sue opere "I fasci femminili", Milan, 1929, pp. 13-26.

60 Refer to Pomba, G. L. (ed.), La civiltà fascista illustrata nella dottrina e nelle opere, vol. 8, Turin, 1928, p. 604.

61 Mayer-Rizzioli, E., I fasci femminili italiani. In: Almanacco della donna italiana 1926 (1927), p. 279. On the activity of the Feminine Fasci, see also Diby (pseudonym), La donna nel partito fascista. In: La Scuola Fascista, 17 (1929).

62 These data are taken from PNF (ed.), Il Gran Consiglio del Fascismo nei primi quindici anni di vita, Bologna, 1938, p. 354.

63 See ONB (ed.), Bollettino dell'Opera Nazionale Balilla of 1 January 1930, p. 3; ONB (ed.), Bollettino dell'Opera Nazionale Balilla of 1 November 1932, p. 12.

64 Mondello, E., La nuova italiana. La donna nella stampa e nella cultura del Ventennio, Rome, 1987, pp. 121-122. For more information on women's Catholic associations at the time, see the ample bibliography quoted by Di Cori, P., Storia, sentimenti, solidarietà nelle organizzazioni femminili cattoliche dall'età giolittiana al fascismo. In: Nuova DWF, 10-11 (1979), p. 84.

65 On the problematic relationship among Ricci, Mussolini, and the hierarchy of PNF, consult Ferrara, P., L'Italia in palestra. Storia, documenti e immagini della ginnastica dal 1833 al 1973, Rome, 1992, pp. 228-240. Also see Teja, A., Le fascisme entre éducation physique et sport. In: Krüger, A. and Trangbaek, E. (eds.), The History of Physical Education and Sport from European Perspectives, Copenhagen, 1999, pp. 249-266.

66 O. N. Balilla-Comitato Provinciale di Vicenza (ed.), Norme e programmi dell'O. N. Balilla, Vicenza, 1930, pp. 58-59.

67 Camera dei Deputati (ed.), La legislazione fascista 1929-1934, Rome, 1934 , p. 1,444 .

68 Ibidem.

69 ACS, Segreteria Particolare del Duce, Carteggio riservato, 1922-1943, b. 31, f. 242/R; Starace, 1.

70 Refer to Finocchiaro, S., Il Foro Mussolini. Unpublished paper presented at the 4th CESH Congress on the History of Sport in Europe, Florence, 2-5 December 1999. Comparative research shows that in Italy and France the 
programmes of physical education and sports at school were about the same, and they were inspired by Mosso and Demeny, respectively. See Terret, T., and Vescovi, R., L'éducation physique à l'école primaire dans l'entre-deux guerres. Une comparaison des systèmes Français et Italiens. In: Kruger, A., and Trangbaek, E. (eds.), The History of Physical Education and Sport from European Perspectives, Copenhagen, 1999, pp. 269-283.

71 Paulin, E., La ginnastica del lattante, Trieste, 1935.

72 Regarding the Italian origin of most German sporting organisations during Nazism, see Krüger, A., Fasci e croci uncinate. In: Lancillotto e Nausica. Critica e storia dello sport, 1-2 (1991), pp. 88-101.

73 On Baden Powell and ONB, see Sica, op. cit., p. 191, and Betti, op. cit., p. 169.

74 ONB (ed.), La capo-squadra piccola italiana, Milan, 1935, p. 8.

75 The first pamphlet, edited by ONB, entitled Norme regolamentari per le piccole e giovani italiane, was printed in Rome in 1931. The second edition, $\mathrm{ONB}$, Norme programmatiche e regolamentari per le organizzazioni delle "Piccole e Giovani Italiane", was printed in Rome as well, but without a date; however, considering the military content of most norms, one may assume that it was published during the mid-1930s. A general comment on ONB programmes for female members can be found in Ostenc, op. cit., pp. 254-261.

76 Campagnuolo, E., L'Opera Balilla e l'educazione fisica, Portici, 1937, p. 42.

77 See ONB (ed.), Programmi d'insegnamento e d'esame di educazione fisica per alunni ed alunne delle scuole elementari e medie pubbliche e private e per $i$ privatisti in genere, Rome, $\mathrm{n}$. d.

78 Ibidem, pp. 7-8 and 13.

79 Ibidem, pp. 8-9 and 13-14.

80 Ibidem, pp. 9-11.

81 Ibidem, pp. 14-15.

82 Ibidem, pp. 11-12.

83 Ibidem, pp. 15-16.

84 Regarding this, see Ferrara, op. cit., p. 254.

85 Betti, op. cit., pp. 162-179.

86 Regarding the Sabato Fascista, see Del Buono, O. (ed.), Eja, eja, eja, alalà, Milan, 1971, p. 64; Salvatorelli, L., and Mira, G., Storia d'Italia nel periodo fascista, vol. 2, Milan, 1972, p. 318.

87 Ferrara, op. cit. p. 246

88 PNF (ed.), Foglio di disposizioni n. 905 of 15 November 1938, and Rossi, op. cit., p. 184. 
89 PNF (ed.), Foglio di disposizioni n. 1,377 of 3 August 1939.

90 On this argument see Betti, op. cit., pp. 176-179, and Ostenc, op. cit., pp. 381-384.

91 Guerri, G. B., (ed.), Rapporto al Duce, Milan, 1978, p. 5.

92 Consult Del Boca, A., Legnani, M., Rossi, M. G., Il regime fascista. Storia e storiografia, Rome-Bari, 1995, pp. 11-12.

93 PNF (ed.), Foglio di disposizioni n. 38 of 26 December 1939.

94 Fabrizio, F., Sport e fascismo. La politica sportiva del regime 1924-1936, Rimini-Florence, 1976, pp. 35-36.

95 Refer to Il Ginnasta, 10 (1921), and Fabrizio, Storia dello sport in Italia ... op. cit., p. 114.

96 Lando Ferretti addressed these words to the assembly during the Fifth PNF Congress. See Ferretti, op. cit., p. 110.

97 Ibidem.

98 Ibidem, pp. 111-112. For more detail on the University World Championships during the Fascist period, see Impiglia, M., and Lange, P., Goliardi in gara. I Giochi mondiali universitari prima delle Universiadi. In: Lancillotto e Nausica. Critica e storia dello sport, 1 (1997), pp. 8-39.

99 For the complete Sports Charter, see Fabrizio, Sport e fascismo ..., op. cit., pp.39-43.

100 Regarding this proposal, see ACS, Segreteria particolare del Duce, Carteggio riservato, 1922-1943, b. 31, f. 242/R; Riunione del Direttorio del 3/6/1931, and Acquarone, A., L'organizzazione dello Stato totalitario, Turin, 1965, p. 180.

101 ACS, Segreteria particolare del Duce, Carteggio riservato, 1922-1943, b. 31, f. 242/R, 1, Relazione 11/7/1931.

102 Ibidem. Also see Betti, op. cit., pp. 164-165.

103 Fabrizio, Sport e fascismo..., op. cit., p.97.

104 On the Olympics during the fascist period, see Gori, G., L'atleta e la nazione. Saggi di storia dello sport, Rimini, 1996, pp. 97-139.

105 De Betta, G., L'evoluzione dei littoriali. In: Lo sport fascista, 4 (1936), pp. 43-45.

106 See Caporilli, P., L'educazione giovanile nello stato fascista, Rome, 1930, pp. 159-160.

107 Ferrara, op. cit., p. 44.

108 Regarding the difficult relationship between male and female university students, see De Grazia, op. cit., pp. 222-224.

109 These statistical data are in ISTAT (ed.), Compendio statistico italiano, 1947-48, vol. 2, Rome, 1948, p. 168. 
110 Ibidem.

111 Ibidem.

112 In regard to these schools, i.e. Scuola Superiore Fascista per Istruttrici d'Infanzia, Scuola Superiore Fascista delle Maestre Rurali, Scuola Superiore Fascista di Economia Domestica, and Scuola Superiore Fascista di Assistenza Sociale, see Benedettini-Alferazzi, P., La donna in regime fascista: l'assistenza e i fasci femminili. In: Almanacco della donna italiana 1933 (1934), pp. 137-154.

113 De Puppi, R., La funzione educativa dell'Opera Nazionale Balilla. Conferenza tenuta dal co. dott. $R$. de Puppi, presidente del Comitato Provinciale dell'Opera Nazionale Balilla, nell'aula Magna del R.. Istituto Tecnico di Udine li 5 febbraio 1929 - VII, Udine, 1929, p. 25.

114 See Ferretti, L., Il libro dello sport, Rome-Milan, 1928, pp. 94-95.

115 ONB (ed.), Leggi-Regolamenti-Decreti, Brescia, 1931, p. 50.

116 ONB (ed.), Bollettino dell'Opera Nazionale Balilla of 1 May 1930, p. 2.

117 Ibidem, and Betti, C., L'Opera Nazionale Balilla e l'educazione fascista, Florence, 1983, pp. 154-155.

118 Motti, L., and Rossi-Caponeri, M. (eds.), Accademiste a Orvieto. Donne ed educazione fisica nell'Italia fascista 1932-1943, Ponte San Giovanni, 1996, p. 24.

119 See Law Decree No. 1227 of 28 August 1931.

120 Di Donato, M., Indirizzi fondamentali dell'educazione fisica moderna, Rome, 1962, p.182.

121 Two very interesting chapters in the book edited by Motti and Rossi Caponeri (op. cit., pp. 75-148 and pp. 149-176), tell the story of the Academy of Orvieto through 29 written and 31 oral testimonies granted by former students. The present chapter will frequently refer to news reported there.

122 Bollettino Ufficiale dell'ONB of 15 May 1933.

123 A former student, Elisa Lombardi, confessed that when she reached the Academy and saw the high convent walls, she thought:" This is not a school of gymnastics but a convent!" See Motti and Rossi-Caponeri, op. cit., p. 109.

124 Benetti-Brunelli, V., Una visita all'istituto superiore femminile fascista di educazione fisica in Orvieto. In: Rivista pedagogica, 3 (1932), p. 447.

125 See Arcamone, G., L'Accademia Femminile Fascista di educazione fisica. In: Rivista dell'istruzione elementare, 3 (1932), pp. 68-74.

126 In general, on relationships between people from Orvieto and students of the Academy, see Motti and Rossi-Caponeri, op. cit., pp. 94-97.

127 Ibidem, p. 98.

128 Cammarata, A., Fucine della Rivoluzione: le accademie dell'ONB. In: Lo sport fascista, 5 (1936), pp. 13-15.

129 Ibidem, p. 15. 
130 In 1936 there were 496 female physical education teachers; if one compares this number to that of 1921 , i. e. 386 teachers, one should say that the increase was not relevant, but one should anyway consider that there did not exist institutes for training teachers from 1923 to 1932, and many teachers had retired.

131 The letter of expulsion, which was sent to Grazia Del Bianco's father by the Academy in October 1938, is reported in Motti and Rossi-Caponeri, op. cit., p. 148, note 195. On the racial dispositions for the Academy of Orvieto, see PNFGIL General Command (ed.), Accademie e Collegi della GIL, ammissioni anno $X X-X X I$, Rome, 1942, pp. 8-9.

132 Biographical details on Elisa Lombardi can be found in two small books she wrote in the recent past: Quand'ero piccola, Dronero-Rome, 1991-1992, and ... Da grande, edited by herself in 1993, without any further detail on the place of publication.

133 On Ricci-Lombardi's relationship, see Motti and Rossi-Caponeri, op. cit., pp. 111-116.

134 Ibidem, chapters pp. 75-148 and pp. 149-176, passim.

135 Ibidem, p. 192.

136 Sources on these visits can be found in Lombardi, ... Da grande, op. cit., p. 26, and the ACS, Segreteria particolare del Duce, Carteggio ordinario, dossier 540.186, 'Orvieto, Accademia femminile della GIL'.

137 On these visits from abroad see the ASO, Archivio Lombardi, b. 2 and 4.

138 In Ibidem, dossier B, there are booklets of propaganda on the Academy of Orvieto, issued from 1935 to 1942, from which and further information are taken.

139 See the article by Piero Bargellini, an authoritative member of the Ministry for National Education, which was published in the propagandistic booklet entitled: L'Accademia femminile di Orvieto, Rome, n. d., pp. 12-13.

140 For further information on this director and the film, see FILMLEXICON degli autori e delle opere, vol. I, Rome, 1959, passim.

141 Oral and written comments on the fall of Fascism by former students are in Motti and Rossi-Caponeri, op. cit., pp. 218-219.

142 On 'inner' and 'outer' emancipation, see Trangbaek, E., "Purity of Heart and Strength of Will"- The Role of Female Teachers in the Modern Sports Movement. In: Trangbaek, E. and Krüger, A. (eds.), Gender \& Sport from European Perspectives, Copenhagen, 1999, p. 45 and pp. 61-62. On women's emancipation and sport, see also: Trangbaek, E., Gender in Modern Society: Femininity, Gymnastics and Sport. In: The International Journal of the History of Sport, 3 (1997), pp. 136-156; Müller, A., Women in sport and society. In: Riordan, J., And Krüger, A. (eds.), The International Politics of Sport in the Twentieth Century, London, 1999, pp. 121-149. 
143 On 18 March 1926 this Decree was transformed into Law No. 562. In the following years this Law was reviewed several times by Royal Decrees No. 1936 of 11 November 1926, No. 516 of 7 April 1927, and No. 817 of 24 May 1937. In general, on OND organisation, see: Tannenbaum, E. R., L'esperienza fascista: Cultura e società in Italia dal 1922 al 1945, Milan, 1974; De Grazia, V., Consenso e cultura di massa nell'Italia fascista. L'organizzazione del Dopolavoro, Rome-Bari, 1981; Cannistraro, P. V., La fabbrica del consenso. Fascismo e mass-media, Rome-Bari, 1975.

144 Ferretti, L., Il libro dello sport, Rome-Milan, 1928, p. 141-142.

145 Ibidem, p. 133.

146 Guerri, G. B., Fascisti. Gli italiani di Mussolini. Il regime degli italiani, Milan, 1995, p. 178.

147 Ibidem, and De Grazia, Consenso ... op. cit., p. 64.

148 Stefanelli, R., Dopolavoro. Norme pratiche per i dirigenti, Turin, 1940, p.

12.

149 Ibidem, p. 40.

150 Ibidem, p. 39.

151 Ibidem, pp. 70-72.

152 For example, in local Dopolavoro clubs, furniture, radio sets and sewingmachines were sold to OND members. See De Grazia, Consenso ... op. cit., pp. 178-184.

153 On these sports in detail, see Stefanelli, op. cit., pp. 75-87.

154 On the volata see: Starace, A., L'opera nazionale Dopolavoro, Milan, 1933, p. 49; De Grazia, Consenso ... op. cit., pp. 201-202; Pivato, S., I terzini della borghesia. Il gioco del pallone nell'Italia dell'Ottocento, Milan, 1990, pp. 9-10; Impiglia, M., The volata game. When fascism forbade Italians to play football. In: Krüger, A. \& Teja, A, La comune eredità dello sport in Europa. Atti del I Seminario Europeo di Storia dello Sport, Roma 29 November-1 December 1996, Rome, 1997, pp. 420-426. 155 Those meetings were held on 14 July and 17 August 1927. What was stated there has been reported by Ferretti, op. cit., pp. 241-243, and commented on at pp. 132-142.

156 Fabrizio, F., Storia dello sport in Italia. Dalle società ginnastiche all'associazionismo di massa, 1997, Rimini-Florence, p. 119. On Littoriali dello Sport see Chapter 5.2.6.

157 De Grazia, Consenso ... op. cit., p. 206.

158 De Felice, R., Mussolini il duce. Gli anni del consenso 1929-1936, Turin, 1974, p. 219.

159 De Grazia, Consenso ... op. cit., p. 206.

160 See OND (ed.), Annuario, 1937, p. 43. 
161 Cuesta, U., Il libro del Dopolavoro, Rome, 1937, p. 123.

162 De Grazia, Consenso ... op. cit., p. 196.

163 OND, op. cit., p. 45.

164 De Grazia, Consenso ... op. cit., pp. 202-203.

165 On the 1936 Winter Olympics see Gori, G., L'atleta e la nazione. Saggi di storia dello sport, Rimini, 1996, pp. 105-112.

166 See PNF, Foglio di Disposizioni No. 93 of 29 February 1940.

167 De Grazia, V., Le donne nel regime fascista, Venice, 1993, pp. 281-282.

168 See the essay by Giuntini, S., La donna e lo sport in Lombardia durante il Fascismo. In: Torcellan, N., and Gigli-Marchetti, A. (eds.), Donna lombarda 1860-1945, Milan, 1992, p. 601.

169 See Bollettino del lavoro e della previdenza sociale of 31 July-31 December 1930, p. 161.

170 De Grazia, Consenso ... op. cit., p. 141.

171 De Grazia, Le donne nel regime ... op. cit., p. 242.

172 De Grazia, Consenso ... op. cit., p. 91.

173 Ibidem, p. 51.

174 See Civiltà Cattolica, 3 (1938), p. 230.

175 De Grazia, Consenso ... op. cit., p. 203.

176 On the dance in Italy see Tonelli, A., E ballando ballando. La storia d'Italia a passi di danza (1815-1996), Milan, 1998. Many of the following quotations have been taken from this well-documented book.

177 Anonym, Ancora sui balli e il Dopolavoro. In: Diario Cattolico of 18 July 1936.

178 De Rensis, R., Mussolini musicista, Mantova, 1927, pp. 14-15.

179 Anonym, 'Sobrietà'. In: Il Popolo di Romagna of 4 July 1926.

180 Anonym, Crisi di costume?. In: Critica fascista of 1 July 1931, p. 249.

181 Against the bourgeoisie and its worldly spirit, for example see the Critica fascista of: 15 February 1930, p. 69

, 1 January 1933, pp. 18-19, and 15 April 1938, p. 190.

182 On this argument see for example: Anonym, Italia e americanismo. In: Critica fascista of 15 April 1928; Anonym, Ordini del giorno. In: Il Popolo d'Italia of 23 July 1935; Anonym, La radio. Musica da ballo. In: Il Popolo d'Italia of 14 August 1938.

183 Information on OND folk dances and songs in traditional costumes is in De Grazia, Consenso ... op. cit., pp. 238-248.

184 The information reported here is taken from: Anonym, Colonie alpine per $i$ fanciulli poveri, Relazione morale, fisiologica ed economica del $2^{\circ}$ esperimento 1873, Turin, 1895, pp. 6-7 and 16; Anonym, Colonie alpine per i fanciulli poveri, 
Relazione e rendiconto della stagione estiva 1875, Turin 1896, p. 6. From now onwards: Relazione 1873 and Relazione 1875.

185 Jocteau, G, C., Ai monti e al mare. Cento anni di colonie per l'infanzia XIX, XX, Milan, 1990, p. 22.

186 Relazione 1873 ... op. cit., p. 9, and Relazione 1875 ... op. cit., p. 14.

187 The Turin co-operative alliance, founded in 1902, created numerous children's health resorts for its associates; in 1927, under the control of Fascism, it gave hospitality to about 600 children every summer. On the matter see: Jocteau, op. cit., pp. 38-39.

188 These data are taken from ISTAT (ed.), Yearbook 1916-1922.

189 Sanjust, F., Un problema ricorrente - le colonie estive. In: Assistenza d'oggi, 1 (1950), p. 6.

190 Ibidem.

191 Lo Monaco-Aprile, A., La protezione della maternità e dell'infanzia, Rome, 1934, p. 7.

192 On 1 May 1925 the Opera Nazionale Dopolavoro-OND was founded to organise the free-time of intellectual and manual workers (Chapter 5.4); on 10 December 1925 ONMI, Opera Nazionale Maternità e Infanzia, to educate and to direct children and mothers in hygienic and moral fields; on 3 April 1926 ONB, Opera Nazionale Balilla, for assistance and for physical and moral education of youth (Chapter 5.2). CONI, Comitato Olimpico Nazionale Italiano, at the head of every sports association, was absorbed by PNF, Partito Nazionale Fascista, in 1925; the GUF, Gruppi Universitari Fascisti, in 1927.

193 On female fascist organisations see De Grazia, V., Le donne nel regime fascista, Venice, 1993, pp. 55-67.

194 The Ente Opere Assistenziali-EOA, with sections in every Italian province, since 1931 financed and organised different charitable activities, including health resorts and camps.

195 The Gioventù Italiana del Littorio-GIL, founded on 27 October 1937, absorbed all the pre-existing bodies, under the PNF Secretary's direction.

196 Parini, P., I figli degli Italiani all'Estero in patria nell'anno XII, 1934, p. 8. 197 Jocteau, op. cit., p. 45.

198 Ibidem. From 1938 onwards, national statistics on the total number of children engaged in the health resorts are not available. Official documents and publications of the time demonstrate that up to 1944, at least, these resorts were functioning. See for instance: Deganutti, V., L'alimentazione nelle colonie estive, Padova, 1939; Roatta, G. B., La leggenda del sole, del mare e della montagna, ossia del clima qualunque, Bologna, 1940; Pignatari, M., Colonie estive della GIL. Identità di criteri direttivi. In: Gioventù del Littorio, 8 (1941); PNF (ed.), 
Ginnastica nelle colonie climatiche, Rome, 1942; Monterisi, F., Le colonie marine e montane. In: Quaderni Italiani, 5 (1943); ONB (ed.), Guida per le direttrici e vigilatrici delle colonie climatiche. In: Posta da campo, 711 (1944). 199 Betti, C., L'Opera Nazionale Balilla e l'educazione fascista, Florence, 1984, p. 127.

200 PNF (ed.), Colonie Fasciste della provincia di Pavia. Come sorsero come funzionano, Pavia, 1930, p. 12.

201 The data are taken from: PNF (ed.), Il Partito Fascista e le sue opere "I fasci femminili", Milan, 1929, pp. 28-29.

202 In 1930 in Romagna, at the children's seaside health resort 'Duce', some beds were reserved for fascist female workers, so that in three 15-day shifts, 45 young female workers could enjoy the benefits of the sea. See: Anonym, Primo anno di vita della colonia Duce. In: Il Popolo di Romagna of 22 December 1930.

203 PNF (ed.), Bollettino del Comando Generale of 2 July 1934, p. 52.

204 PNF (ed.), Bollettino del Comando Generale of 26 July 1933, pp. 40-46.

205 PNF (ed.), Il Partito Fascista ... op. cit., pp. 29-30.

206 Ibidem, pp. 30-31.

207 In general the ordinary period of stay was 30 days, but according to Ilvento (Ilvento, A., Colonie estive. In: Maternità ed Infanzia, 5 (1927), p.4), sometimes the days were reduced to 20 to accept more children, whereas an article published in the same periodical reports that 40-day shifts were foreseen. On the latter, see Anonym, La vita in colonia. In: Maternità ed Infanzia, 4 (1927), p. 79.

208 In 1929 Piccole Italiane were under the direct control of Feminine Fasci, then ONB took over and in 1937 they passed under GIL.

209 PNF (ed.), Il Partito Fascista ... op. cit., pp. 33-34 and 38.

210 The programme of the courses, obviously, was brought up to date many times during the years; the reference is to that issued in the Circolare n.100-3/13 of 24 February 1938.

211 GIL (ed.), Bollettino quindicinale della GIL, 10 (1938), p. 6.

212 Diaz, G., Che cosa si chiede ad una direttrice di colonia per bambini. In: Bollettino della Croce Rossa Italiana, 1 (1921). See also: La vita in colonia ... op. cit., pp. 78-84.

213 Collina, P., Donde è nata e come funziona una colonia marina. In: Argento vivo: campeggio dei fasci giovanili bolognesi di combattimento, Rimini 10-20 Agosto, anno 10, Bologna, 1932, p. 27.

214 PNF (ed.), Norme per il funzionamento delle colonie climatiche temporanee e diurne, Rome 1932, pp. 11-18. This first official regulation for children's health resorts was improved in 1935, and modified in 1937, on transfer to GIL. 
215 "Attention to child assistance during summer cures! It will be right to gather them in squads (of about 30) and to entrust each of them to an assistant (...)". In: PNF (ed.), Bollettino del Comando Generale, 13 April 1933, p. 228.

216 Collina, op. cit., p. 26.

217 PNF (ed.), Regolamento per la ginnastica nelle colonie climatiche, anno XIX, Rome 1941, pp. 4-5.

218 On clothes worn in children's health resorts refer to photographs included in: Jocteau, op. cit., pp. 24-25; 70-71; 93 and 147.

219 PNF (ed.), Regolamento per la ginnastica ... op. cit., pp. 6-9.

220 Ibidem, p. 6.

221 Ibidem, pp. 9-11.

222 Ibidem, pp. 16-17.

223 See for example La Gazzetta dello Sport and Lo sport fascista.

224 A sporting profile of Jolanda was drawn by an Anonym, 'La principessa sportiva'. In: Lo sport fascista, 4 (1929), pp. 19-22.

225 On Maria José sportswoman see: Boin, V., La bella coppia sportiva. In: Lo sport fascista, 12 (1929), pp. 6-9; Petacco, A., Regina. La vita e i segreti di Maria José, Milan, 1997, pp. 96-99.

226 See Gerbi, G., Successi italiani nel 'golf'. In: Lo sport fascista, 9 (1930), pp. 75-76. Isaline was also a good hunter, swimmer, skier and tennis payer, according to the article she wrote in 1929. See Crivelli-Massazza I., Sport e Maternità. In: Lo sport fascista, 7 (1929), p. 73.

227 Set (pseudonym), Le emule italiane della 'diva Suzanne'. In: Lo sport fascista, 3 (1929), pp. 80-83.

228 Nadi, N., La scherma femminile. In: Lo sport fascista, 11 (1929), pp. 4143. For Nadi's biography see Ferralasco-Nadi, R., Nedo Nadi l'alfiere dello sport delle tre armi nel mondo, Genoa, 1969.

229 Anonym, Scherma femminile a Firenze. In: Lo sport fascista, 6 (1931), p. 70.

230 On Mille Miglia see Gori, G., The Classic "Mille Miglia MotorRace"(1927-1938): Tourism and Propaganda in the Years of the Fascist Regime. Unpublished paper presented at the 2nd CESH Seminar, The History of Sport and Tourism in Europe, 17-21 September 1997, Katowice, Poland.

231 On Avanzo and her car races see: Martini, M., Correre per essere. Origini dello sport femminile in Italia, Rome, 1996, p. 90.

232 Avanzo, M. A., La donna al volante. Lo sport fascista, 1, (1928), p. 65.

233 On Patricia Milliat and her activity in favour of women's sports, see Simri, U., A concise world history of women's sports, Netanya, 1983, pp. 47-48. 
234 La Gazzetta dello Sport of 27 March 1921. On those Monte Carlo Games see also Anonym, L'Olimpiade della Grazia tra le palme e i fiori della Costa Azzurra. In: Lo sport Illustrato of 3 April 1921.

235 Simri, op. cit., p. 52. Most information on female athleticism has been taken from Martini, M., Storia dell'atletica italiana femminile. This unfinished work, divided into seven booklets, was enclosed in the specialist magazine Atletica (edited by FIDAL at Rome), in the years 1995, 1996 and 1997. See also Giuntini, S., Società ginnastica milanese Forza e Coraggio. Alle origini dello sport a Milano, Milan, 1994, pp. 97-109.

236 See: Il Giornale d'Italia of 8 May 1923, and Roffarè, L., Atletesse. In: La cultura fisica, 7 (1952), p. 1.

237 On Andreina Sacco's athletics and technical activities see: Teja, A., Educazione fisica al femminile. dai primi corsi di Torino di ginnastica educativa per le maestre (1867) alla ginnastica moderna di Andreina Gotta-Sacco (19041988), Rome, 1995, pp. 67-120.

238 Marina Zanetti was a strong supporter of female athleticism, and defended the 'cause' also in the medical field (Chapter 5.1).

239 Martini, Storia dell'atletica ..., cit., p. 54, and De Giorgio, M., Le italiane dall'Unità a oggi, Rome-Bari, 1993, p. 252.

240 For a report on the female teams in Amsterdam see: Bononcini, T., Atletica leggera. In: Lo sport fascista, 3 (1928), pp. 32-33; Tifi, C., Le 'Piccole Italiane' in maglia azzurra. In ibidem, pp. 58-60.

241 Simri, op. cit., p. 51.

242 On this Committee see Martini, Correre per essere..., cit., pp. 58-60.

243 In those first years, gymnastics, but also different athletic disciplines, were part of the programmes. At the Roman contest, for example, manlike disciplines such as target-firing, javelin throwing and putting the shot were performed. On this, see the specialist magazine Il Ginnasta, 6-7 (1922), pp. 11-18.

244 On the Dinard meeting see Sacco, A., Come abbiamo vinto a Dinard. In: Lo sport fascista, 8 (1929), pp. 98-99.

245 Lazotti, U., Le giovani italiane. In: Lo sport fascista, 6 (1928), pp. 49-52.

246 On this polemic, see: Pio XI, Lettera al Cardinale Vicario. In: Civiltà Cattolica, 2 (1928), pp. 367-372; Anonymous, Contro l'atletismo femminile. Lettera di Pio XI al Cardinale Vicario di Roma. In: Lancillotto e Nausica. Critica e storia dello sport, 3 (1988), pp. 79-81.

247 On this, see De Grazia, V., Le donne nel regime fascista, Venice, 1993, p. 293. 
248 Information on Futurism and motor activities can be found in the article by Gori, G., Supermanism and the Culture of the Body in Italy: The Case of Futurism. In: The International Journal of the History of Sport, 1 (1999), pp. 159-165.

249 Anonym, Collaborazione delle Abbonate. Che pensate degli sports femminili. In: Azione Muliebre, 6 (1931), pp. 368-376.

250 See Azione Muliebre, 6 (1926), p. 358.

251 See Almanacco della donna italiana 1934 (1934), p. 255.

252 Giuntini, S., La donna e lo sport in Lombardia durante il fascismo. In: Torcellan, N., and Gigli-Marchetti, A. (eds.), Donna lombarda 1860-1945, Milan, 1992 , p. 597 and p. 600.

253 Ibidem, p. 598; Isidori Frasca, R., ... e il duce le volle sportive, Bologna, 1983, pp. 98-102. On the uncomfortably 'chaste' sportswear for women, see the interviews with sportswomen in Chapter 6.3.

254 Martini, Storia dell'atletica ... op.cit., p. 56.

255 See the article by Cassinis, U, Denatalità e sport femminile. In: Il Ginnasta, 5 (1937), pp. 11-14.

256 Ibidem, p. 12.

257 On the 1930-1936 female athletic championships, see Martini, Storia dell'atletica ... op. cit., pp. 60-95.

258 De Betta, G., L'evoluzione dei Littoriali. In: Lo sport fascista, 4 (1936), p. 45.

259 On norms for Agonali see: ONB (ed.), Gli Agonali dell'Opera Balilla, 1936, pp. 3-29.

260 Zanetti, M., Ragazze del Littorio. In: Lo sport fascista, 8 (1937), pp. 12-14.

261 Banti, A, L'importanza dello spettacolo sportivo. In: Lo sport fascista, 1 (1936), p. 31.

262 These statistics were reported in an article by Ferrauto, E., L'educazione fisica giovanile. In: Lo sport fascista, 4 (1936), p. 10.

263 See PNF (ed.), Annuario sportivo dei Giovani Fascisti e delle Giovani Fasciste - $A X V$, Varese, 1938. The next Yearbooks were: PNF-GIL (eds.), Annuario generale sportivo della GIL dell'anno XVII, Varese, 1940; PNF-GIL (eds.), Annuario sportivo generale della GIL-A. XVIII, n. p., 1941; PNF-GIL (eds.), Annuario sportivo generale-A. XIX, Bergamo, n. d. (probably at the start of 1942).

264 These data are in Anonym, Piccolo prontuario magistrale 1940-41, Rome, 1940 , p. 31.

265 On this contest in detail, see the booklet published by Opera Balilla, $I V$ concorso per giovani italiane. Programma-regolamento, Milan, n. d., pp. 1-22. 
266 On OND female contests see Pizzi, E., La donna al Concorso Ginnico del Dopolavoro. In: Lo sport fascista, 8 (1937), pp. 11-13; Pizzi, E., La G.I.L. e l'O.N.D. In: Lo sport fascista, 1 (1938), pp. 15-17.

267 Colonnelli, I. C., I littoriali femminili. In: Lo sport fascista, 6 (1939), pp. 40-41.

268 Favre, S., Ludi Luveniles e Littoriali, vaglio delle promesse della stirpe. In: Lo sport fascista, 6 (1939), pp. 13-15.

269 Piccolo prontuario ... op. cit., p. 5.

270 PNF (ed.), Annuario sportivo generale della GIL-a. XVIII, Rome, 1941, p.

10.

271 PNF-Comando Generale GIL-Servizio Educazione Fisica (ed.), Concorsi Nazionali di Educazione Fisica A. XX. Programma-Regolamento, Rome, 1942.

272 On this argument in detail, see Ölrich, H., 'Whoever has Youth has a Future'. Youth Sports Activities of the Berlin-Rome Axis from 1940 to the Foundation of the European Youth Association in 1942. In: Krüger, A. and Teja, A. (eds.), La comune eredità dello sport in Europa, Proceedings of the 1st European Seminar for the History of Sport, Rome 29 November-1 December 1996, Scuola dello Sport-CONI, Rome 1997, pp. 427-439.

273 Unfortunately, it has not been possible to find the Yearbook of 1942, which probably was not published at all, due to the subsequent political events. Some information on 1942, however, can be found in an article by Tedeschi, L. L., Il VII raduno dello sport femminile a Torino. In: Lo sport della GIL, 4 (1942), p. 5.

274 On track and field, information is taken from Martini, Storia dell'atletica ... op. cit., pp. 96-112, GIL Sport Year-book issued in the years 1937-1941, and A.M.O.V.A. (ed.), Medaglie d'oro al valore atletico 1934-1985, Rome, 1987, passim.

275 A writer said that when he was a university student in Padusa, two policemen had been enrolled in the GUF rugby team, and a manual worker 'transformed' into a medical student for javelin and discus throwing contests. The rectors of universities were personally responsible for the real situation of participants, but under the insistent push of local GUF and PNF managers, sometimes they supported such cheats. See Fabbri, A. M., Giovinezza, giovinezza ..., Milan, 1964, pp. 18-25.

276 Cataldo, G., Gli sportivi col ma. In: Il Littoriale of 29 April 1930.

277 Bassetti, R., Storia e storie dello sport in Italia. Dall'Unità a oggi, Venice, 1999, p. 110.

278 Simri, op. cit., pp. 67-88.

279 Pierazzi, R. M., Piccola posta. In: Cordelia, 14 (1923), p. 669. 
280 Barbacci, G., Per voi, donne italiane, che non nuotate ... In: Lo sport fascista, 4 (1929), pp. 32-37.

281 Pensuti, M., La donna e lo sport. In: Lo sport fascista, 4 (1930), pp. 99-101.

282 Bragaglia, A. G., Sport e bellezza. In: Lo sport fascista, 11 (1929), pp. 55-

57.

283 Anonym, La gioventù femminile e lo sport. In: Matelda, 13 (1921), pp. 227-228.

284 Patrizi, M., Un pò di galateo. Giuochi e sport. In: Fiamma Viva, 12 (1929), p. 722.

285 On this engagement, see Mondello, E., La nuova italiana. La donna nella stampa e nella cultura del Ventennio, Rome, 1987, pp. 111-112.

286 Guerri, G. B., Fascisti. Gli italiani di Mussolini. Il regime degli italiani, Milan, 1995, pp. 187-188.

287 Poggi-Longostrevi, G., Cultura fisica della donna ed estetica femminile, Milan, 1933, p. 214.

288 De Grazia, V., Le donne nel regime fascista, Venice, 1993, p. 287; Tonelli, A., E ballando ballando. La storia d'Italia a passi di danza (1815-1996), Milan, 1998, p. 211.

289 She (pseudonym), Ondine americane. In: Lo sport fascista, 3 (1933), pp. 66-68.

290 See for example Anonym, Donne sportive in Germania. In: Lo sport fascista, 4 (1933), pp. 58-60.

291 De Giorgi, Le italiane dall'Unità a oggi. Modelli culturali e comportamenti sociali, Rome-Bari, 1992, p. 264.

292 A positive comment on these old-fashioned bathing-costumes is in an anonymous article in the magazine Fiamma Viva, 6 (1935), pp. 210-211.

293 The Duce's expression "Maternity does not dim feminine beauty" was the sub-title of the fascist women's magazine Il Giornale della donna.

294 See Livia (pseudonym), La moda di noi sportivi. In: Lo sport fascista, 6 (1933), pp. 52-56.

295 On the manifold activities of this Ministry, see De Felice, R., Mussolini il duce. Lo stato totalitario 1936-1940, Turin, 1981, pp.109-112, and Cannistrato, P. V., La fabbrica del consenso, Rome-Bari, 1975, pp.101-173.

296 Saracinelli, M., and Totti, N., L'Italia del Duce. L'informazione, la scuola, il costume, Rimini, 1983, p. 137, and Mondello, op. cit., p. 115. On Italian fashion and its relationship with international fashion, see Gnecchi-Ruscone, A., La moda italiana dalla crisi alla guerra. AA. VV.(eds), Anni trenta. Arte e cultura in Italia, Milan, 1983; Giordani-Aragno, B., La moda italiana fra le due guerre. In: Comune di Roma-Ipsoa (eds.), L'economia italiana tra le due guerre, Rome 1984. 
297 ONB (ed.), La capo-squadra piccola italiana, Rome, 1936, pp. 57-58.

298 See Mussolini, V., Emancipazione del cinema italiano. In: Cinema, 9 (1936), and De Felice, R., Mussolini il duce. Lo Stato totalitario 1936-1940, pp. 107-108.

299 See Biondi, M., and Borsotti, A., Cultura e fascismo. Letteratura, arti e spettacolo di un ventennio, Florence, 1996, p. 388.

300 Ibidem, pp. 393-394. On Fascism and cinematography in general, see also Argentieri, M., L'occhio del regime. Informazione e propaganda nel cinema del fascismo, Florence, 1979; Redi, R. (ed.), Cinema italiano sotto il fascismo, Venice, 1979; Brunetta, G. P., Storia del cinema italiano. Il cinema del regime 1929-1945, Rome, 1993.

301 ISTAT (ed.), Sommario di statistiche storiche 1926-1985, Tivoli, 1986, p. 59.

302 See Annuario del cinema italiano 1939-1942, Rome, 1943. Discrimination against foreign culture existed in Italy since 1935, when the country was preparing for war in Ethiopia. One of the counter-measures was that all words of foreign origin commonly used by Italians, such as the French broche, garage, pardon, or English bar, film, bridge, were officially forbidden and replaced by fancy Italian versions of them (even the name of the jazz player Louis Armstrong was literally translated in the ridiculous 'Luigi Fortebraccio').

303 Mattazzi, G., Benito Mussolini. Breviario, Milan, 1997, p. 243, reports this Duce's prophetic doubt.

304 Favre, S., Venti ragazze hanno provato a Rapallo il costume azzurro. A chi l'onore di indossarlo a Berlino? In: Lo sport fascista, 3 (1936), p. 35.

305 Motti, L., and Rossi Caponeri, M. (ed.), Accademiste a Orvieto. Donne ed educazione fisica nell'Italia fascista 1932-1943, Ponte San Giovanni, 1996, pp. 203-204.

306 Campagnuolo, E., L'opera balilla e l'educazione fisica, Portici, 1937, p. 44.

307 Favre, S., Sport e ginnastica per la salute e la bellezza della donna. In: Lo sport fascista, 6 (1939), pp. 55-58.

308 Ibidem, p. 59.

309 See Boccasile, G., La signorina grandi firme, Milan, 1981, passim.

\section{Chapter 6:}

1 On women's oral history see Marcuzzo, C., and Rossi-Doria, A. (eds.), La ricerca delle donne. Studi femministi in Italia, Turin, 1987; Società Italiana delle 
Storiche (ed.), Discutendo di storia. Soggettività, ricerca, biografia, Turin, 1990; Passerini, L., Storie di donne e femministe, Turin, 1991.

2 The biographical information on Trebisonda Valla is taken from: Giovannini, A., La gara di Ondina Valla campione olimpionica vista e raccontata da lei. In: Lo sport fascista, 9 (1936), pp. 17-19; Anonym, Primato olimpionico delle atlete azzurre. In: Tutti gli Sports, 33 (1936), p. 5; Dotti, R., La quercia di Ondina Valla. In: Stadio of 24 October 1958; Artom, S., and Calabrò, A. R., Sorelle d'Italia. Quattordici Signore raccontano la loro (e nostra) Storia, Milan, 1989, pp. 271285; Dominici, F., Gli intramontabili - Ondina Valla. Oro a Berlino negli 80 ostacoli primatista nel lungo e nell'alto. La regina con le ali. In: Corriere dello Sport - Stadio of 1 April 1989; Panathlon International Club Valdarno Inferiore (ed.), Proceedings of the National Prize "L'atleta nella Storia" 1988 Ondina Valla, Montecatini Terme, 22 October 1989 (hereafter L'atleta nella storia), Montecatini, 1989, pp.1-32; Valla, O., Ondina Valla. In: Ternisport, Terni, n.d., p. 5. Besides, there are some articles in daily newspapers that will be quoted from time to time.

3 De Grazia, V., Le donne nel regime fascista, Venice, 1993, p. 293.

4 Artom and Calabrò, op. cit., p. 275.

5 At least a famous pilot, a skier, three roller-skaters and three long distance runners might be quoted for their world records. A brief profile of these women will be given in the following pages.

$6 \quad$ Many female athletes denounced this problem, as will be seen later.

7 She was registered again as a university student, but in truth this was false, as she had left off studying and was not allowed to go to university.

8 Artom and Calabrò, op. cit., p. 279.

9 Ibidem, p. 280.

10 Daily newspapers entitled, for example: Un'altra luminosa giornata azzurra allo Stadio Olimpico. Ondina Valla vince la semifinale $80 \mathrm{~m}$. ostacoli migliorando il primato mondiale; Oberweger conquista all'Italia per la prima volta un terzo posto nel disco; Luigi Beccali domina nella batteria dei 500 metri. (La Gazzetta dello Sport of 6 August); Il tricolore sventola nel cielo di Berlino. La giornata trionfale dei nostri azzurri. La Valla negli 80 metri con ostacoli e Gaudini nel fioretto campioni olimpionici (Il Popolo d'Italia of 7 August); Il tricolore d'Italia sul più alto pennone dello Stadio per la vittoria di Ondina Valla negli $80 \mathrm{~m}$. ostacoli ( $L a$ Gazzetta dello Sport of 7 August).

11 See A.M.O.V.A. (ed.), Medaglie d'oro al valore atletico 1934-1985, Rome, 1987, p.1061. A.M.O.V.A. is an acronym, meaning Gold Medals for Athletic Value Association, whose oldest members were given this prize from 1934 to 1943. 
12 See for example: a) the article by Colonnelli, I. C., La donna italiana e lo sport. In: Lo sport fascista, 9 (1940), p. 29, where Angela Cressi was celebrated for being twice Littoriali female champion in javeling throwing, and twice a mother; b) the end of the article on Ondina Valla by Giovannini, op. cit., p.19, where it was written: "And Ondina Valla, Olympic Champion, now runs away, as it is 7.45 p. m. In spite of any victory, Father Valla does not allow her to be home after 8 o'clock!".

13 Artom and Calabrò, op. cit. p. 279.

14 See PNF (ed.), Foglio d'ordini n. 117 of 20 December 1933.

15 Biographical information is taken from Martini, M., Correre per correre. Origini dello sport femminile, Rome, 1996, passim, and A.M.O.V.A., op. cit., passim.

16 On Tatiana Fumagalli see Castellini, R., Tatiana Fumagalli prima aviatrice italiana. In: Lo sport fascista, 1 (1931), pp. 6-7.

17 To this girl was dedicated a moving portrait by Mura (pseudonym), Ritorno di Gaby. In: Lo sport fascista, 1 (1933), pp. 21-22.

18 See De Giorgio, M., La italiane dall'Unità a oggi. Modelli culturali e comportamenti sociali, Rome-Bari, 1992, p. 259.

19 On the flight and other futurist symbols see Gori, G., Supermanism and the Culture of the Body in Italy: the Case of Futurism. In: The International Journal of the History of Sport, 1 (1999), pp. 159-165.

20 This and the following biographical notes are taken from a simple sheet printed for the photographic and historical exhibition dedicated to Carina Massone Negrone. This was part of the most important exhibition Futurismo. I Grandi Temi 1909-1944, held in Genoa a few years ago.

21 These data are in Enrile, E. (ed.), Enciclopedia dello sport, Rome, 1977, p. 1082 .

22 On Serafini's achievement at the Littoriali of Milan, see Colonnelli, G. C., I Littoriali femminili. In: Lo sport fascista, 6 (1939), p. 39.

23 On 'inner' and 'outer' women's emancipation, see Chapter 5.3.

24 See the previous note 12 , second example, namely b).

\section{Chapter 7:}

1 Ranelletti, E., 'La donna-giudice', ovverosia le 'grazia' contro la 'giustizia'. In: Sepe, O. (ed.), "e così piantò in asso Adamo", Milan, 1995.

2 On female sports in the second post-war period, see for instance: Andreoli, P., La donna e lo sport nella società industriale, Rome, 1974, passim; Salvini, A., Identità femminile e sport, Florence, 1982, pp. 33-48. 
3 CONI (ed.), I numeri dello sport. Atlante della pratica sportiva in Italia, Florence, p. 31.

Bibliography 
Archives:

Archivio Centrale di Stato of Rome [ACS]:

ACS, Ministero della Pubblica Istruzione, Segreteria Affari Generali, Ginnastica, b 3.

ACS, Ministero della Pubblica Istruzione, Segreteria Affari Generali, Ginnastica, b 50 .

ACS, Presidenza del Consiglio dei Ministri, 1937-1939, dossier 1.7.7493.

ACS, Presidenza del Consiglio dei Ministri, 1940-1941, dossier 582.

ACS, Presidenza del Consiglio dei Ministri, 1940-1941, dossier 586.

ACS, Segreteria Particolare del Duce, Carteggio riservato, 1922-1943, b. 31, f. 242/R; Starace, 1.

ACS, Segreteria particolare del Duce, Carteggio riservato, 1922-1943, b. 31, f. 242/R; Riunione del Direttorio del 3/6/1931.

ACS, Segreteria particolare del Duce, Carteggio riservato, 1922-1943, b. 31, f. 242/R, 1, Relazione 11/7/1931.

ACS, Segreteria particolare del Duce, Carteggio ordinario, dossier 540.186, 'Orvieto, Accademia femminile della GIL'.

Archivio di Stato of Orvieto [ASO]:

ASO, Archivio Lombardi, dossier B.

ASO, Archivio Lombardi, b. 2 and 4.

Statistics: 
-Statistica delle scuole di ginnastica del Regno d'Italia. Anno 1863-64. In: Monografia della società ginnastica di Torino e Statistica generale delle scuole di ginnastica in Italia, Turin, 1873.

-ISTAT (ed.), Annuario of 1916-1922.

-ISTAT (ed.), Compendio statistico, Rome, 1938.

-ISTAT (ed.), Compendio statistico italiano, 1947-48, vol. 2, Rome, 1948.

-SVIMEZ (ed.), Un secolo di statistiche italiane Nord e Sud, 1861-1961, Rome, 1961.

-ISTAT (ed.), Sommario di statistiche storiche dell'Italia 1861-1975, Rome, 1976.

-ISTAT (ed.), Sommario di statistiche storiche 1926-1985, Tivoli, 1986.

-ISTAT (ed.), Sommario di statistiche storiche dell'Italia. 1926-1985, Rome, 1987.

\section{Primary references (1786-1945)}

A) Books and Articles:

Anonym, Arona. In: Bollettino della Società Ginnastica Milanese Forza e Coraggio, October 1889.

Anonym, Lettera al Presidente della Commissione Sua Eccellenza Il Ministro. In:

Bollettino Ufficiale del Ministero dell'Istruzione, vol. II, 1893.

Anonym, Lettera del Segretario Generale ai provveditori agli studi, ai sindaci e agli Ispettori Scolastici del Regno in data 9-6-1884. In: Archivio Centrale di Stato, M.P.I., Segreteria Affari Generali, Ginnastica, b 3.

Anonym, Colonie alpine per i fanciulli poveri, Relazione morale, fisiologica ed economica del $2^{\circ}$ esperimento 1873, Turin, 1895.

Anonym, Colonie alpine per i fanciulli poveri, Relazione e rendiconto della stagione estiva 1875, Turin 1896.

Anonym, La prima aviatrice italiana. In: Margherita, 3 (1913).

Anonym, L'Olimpiade della Grazia tra le palme e i fiori della Costa Azzurra. In: Lo sport Illustrato of 3 April 1921.

Anonym, La gioventù femminile e lo sport. In: Matelda, 13 (1921).

Anonym, 'Sobrietà'. In: Il Popolo di Romagna of 4 July 1926.

Anonym, La vita in colonia. In: Maternità ed Infanzia, 4 (1927).

-Anonym, Italia e americanismo. In: Critica fascista of 15 April 1928.

Anonym, La principessa sportiva. In: Lo sport fascista, 4 (1929). 
Anonym, Primo anno di vita della colonia Duce. In: Il Popolo di Romagna of 22 December 1930.

Anonym, Scherma femminile a Firenze. In: Lo sport fascista, 6 (1931).

Anonym, Collaborazione delle Abbonate. Che pensate degli sports femminili. In: Azione Muliebre, 6 (1931).

Anonym, Crisi di costume?. In: Critica fascista of 1 July 1931.

Anonym, Donne sportive in Germania. In: Lo sport fascista, 4 (1933).

Anonym, Ordini del giorno. In: Il Popolo d'Italia of 23 July 1935.

Anonym, Ancora sui balli e il Dopolavoro. In: Diario Cattolico of 18 July 1936.

Anonym, Un'altra luminosa giornata azzurra allo Stadio Olimpico ... In: La Gazzetta dello Sport of 6 August 1936.

Anonym, Il tricolore d'Italia sul più alto pennone dello Stadio per la vittoria di Ondina Valla negli 80 m. ostacoli. In: La Gazzetta dello Sport of 7 August 1936.

Anonym, Il tricolore sventola nel cielo di Berlino ... In: Il Popolo d'Italia of 7 August 1936.

Anonym, Primato olimpico delle atlete azzurre. In: Tutti gli Sports, 33 (1936).

Anonym, La radio. Musica da ballo. In: Il Popolo d'Italia of 14 August 1938.

Anonym, Piccolo prontuario magistrale 1940-41, Rome, 1940.

Arcamone, G., L'Accademia Femminile Fascista di educazione fisica. In: Rivista dell'istruzione elementare, 3 (1932).

Ardau, G., L'eloquenza mussoliniana, Milan, 1929.

Avanzo, M. A., La donna al volante. Lo sport fascista, 1, (1928).

B. P., La donna e l'atletismo. In: L'Osservatore Romano of 16 May 1934.

Baglioni, S., Donna e sport. In: FIMS (ed.), Atti del I Congresso Nazionale di Medicina dello Sport, Roma 19-20-21 Aprile 1932, Rome, 1932.

Ballerini, F., La Federazione ginnastica italiana e le sue origini, Rome, 1931. Ballexerd, J., Dissertazione sull' educazione fisica de' fanciulli, Naples, 1763. Banti, A., L'importanza dello spettacolo sportivo. In: Lo sport fascista, I (1936).

Barbacci, G., Per voi, donne italiane, che non nuotate ... In: Lo sport fascista, 4 (1929).

Bargellini, P., Introduction. In: L'Accademia femminile di Orvieto, Rome, n. d.

Baumann, E., Progetto di una Scuola magistrale di Ginnastica compilato dal direttore della palestra Dott. cav. Emilio Baumann, Bologna, 1877. In: Archivio Centrale di Stato, Ministero della Pubblica Istruzione [M.P.I.], Segreteria Affari Generali, Ginnastica, b 50.

Benedettini-Alferazzi, P., La donna in regime fascista: l'assistenza e i fasci femminili. In: Almanacco della donna italiana 1933 (1934). 
Benetti-Brunelli, V., Una visita all'istituto superiore femminile fascista di educazione fisica in Orvieto. In: Rivista pedagogica, 3 (1932).

Bianchi, L., Mussolini scrittore ed oratore, Bologna, 1937.

Boin, V., La bella coppia sportiva. In: Lo sport fascista, 12 (1929).

Bononcini, T., Atletica leggera. In: Lo sport fascista, 3 (1928).

Bottai, G., La Carta della Scuola, Milan, 1939.

Bragaglia, A. G., Sport e bellezza. In: Lo sport fascista, 11 (1929).

Caimi, N. G., Mens sana in corpore sano. In: La Donna, 19 (1907).

Camera dei Deputati (ed.), La legislazione fascista 1929-1934, Rome, 1934.

Cammarata, A., Fucine della Rivoluzione: le accademie dell'ONB. In: Lo sport fascista, 5 (1936).

Cammarota, G., Lettera del R. Provveditore agli studi di Firenze al ministro della Pubblica Istruzione, 2 Aprile 1879. In: Archivio Centrale di Stato, M.P.I., Segreteria Affari Generali, Ginnastica, b 50.

Campagnuolo, E., L'opera balilla e l'educazione fisica, Portici, 1937.

Cantalupo, R., La classe dirigente, Milan, 1928.

Caporilli, P., L'educazione giovanile nello stato fascista, Rome, 1930.

Cassinis, U., Può la donna fare lo sport? In: FIMS (ed.), Atti del I Congresso Nazionale di Medicina dello Sport, Roma 19-20-21 Aprile 1932, Rome, 1932.

Cassinis, U., Caffè, caffeina, cloruro di sodio nel rendimento lavorativo. In: FIMS (ed.), Atti del Congresso Internazionale di Medicina dello Sport, Torino-Roma, Settembre 1933, Rome, 1934.

Cassinis, U, Denatalità e sport femminile. In: Il Ginnasta, 5 (1937).

Castellani, M., La nazione armata. Donne professioniste e laureate ausiliarie civili. In: Almanacco della donna italiana (1936).

Castellini, R., Tatiana Fumagalli prima aviatrice italiana. In: Lo sport fascista, 1 (1931).

Cataldo, G., Gli sportivi col ma. In: Il Littoriale of 29 April 1930.

Ceci, G., Reali educandati femminili in Napoli, Naples, 1900.

Chiurco, G. C., L'Educazione fisica nello stato fascista. Fisiologia e patologia chirurgica dello sport, Siena, 1935.

Collina, P., Donde è nata e come funziona una colonia marina. In: Argento vivo: campeggio dei fasci giovanili bolognesi di combattimento, Rimini 10-20 Agosto, anno 10, Bologna, 1932.

Colonnelli, I. C., I Littoriali femminili. In: Lo sport fascista, 6 (1939).

Colonnelli, I. C., La donna italiana e lo sport. In: Lo sport fascista, 9 (1940).

Corradini, E., Una nazione. In: Il Regno of 19 June 1904.

Cotronei, A., Cesare gladiatore. In: Il Popolo d'Italia of 28 October 1934. 
Crivelli-Massazza, I., Sport e Maternità. In: Lo sport fascista, 7 (1929).

Cuesta, U., Il libro del Dopolavoro, Rome, 1937.

D'Annunzio, G., Per la più grande Italia, Rome, 1939.

Dall'Ongaro, C., Mussolini e lo sport, Mantova, 1928.

Daneo, G. C., Benito Mussolini oratore, Genoa, 1932.

Davì, M., Bevande eccitanti e sport. In: FIMS (ed.), Atti del I Congresso Nazionale di Medicina dello Sport, Roma 19-20-21 Aprile 1932, Rome, 1932.

De Betta, G., L'evoluzione dei Littoriali. In: Lo sport fascista, 4 (1936).

De Puppi, R., La funzione educativa dell'Opera Nazionale Balilla. Conferenza tenuta dal co. dott. R. de Puppi, presidente del Comitato Provinciale dell'Opera Nazionale Balilla, nell'aula Magna del R.. Istituto Tecnico di Udine li 5 febbraio 1929 - VII, Udine, 1929.

De Rensis, R., Mussolini musicista, Mantova, 1927.

Deganutti, V., L'alimentazione nelle colonie estive, Padova, 1939.

Del Debbio, E., Le arti figurative. In: Panorami di realizzazioni del fascismo, 7 (1938-1942).

Diaz, G., Che cosa si chiede ad una direttrice di colonia per bambini. In: Bollettino della Croce Rossa Italiana, 1 (1921).

Diby (pseudonym), La donna nel partito fascista. In: La Scuola Fascista, 17 (1929).

Duncan-Darlymple, H., Son of Vulcano: Benito Mussolini. An impersonation of the Superman, Florence, n. d.

Ellwanger, H., Sulla lingua di Mussolini, Milan, 1939.

Fabbri, S., L'assistenza della maternità e dell'infanzia in Italia, Naples, 1933.

Fabbri, S., L'Opera Nazionale per la protezione della Maternità e dell'Infanzia, Milan, 1933.

Falchi, L., Le origini del Fascio littorio. In: Il Giornale di Roma of 12 April 1923.

Favre, S., Venti ragazze hanno provato a Rapallo il costume azzurro. A chi l'onore di indossarlo a Berlino? In: Lo sport fascista, 3 (1936).

Favre, S., Ludi Luveniles e Littoriali, vaglio delle promesse della stirpe. In: Lo sport fascista, 6 (1939).

Favre, S., Sport e ginnastica per la salute e la bellezza della donna. In: Lo sport fascista, 6 (1939).

Ferrara, M., Machiavelli, Nietzsche, Mussolini, Paris, 1923.

Ferrauto, E., L'educazione fisica giovanile. In: Lo sport fascista, 4 (1936).

Ferretti, L., Il libro dello sport, Rome-Milan, 1928. 
Ferretti, L., Mussolini, primo sportivo d'Italia. In: Lo sport fascista, 1 (1933).

Filangieri, G., Scienza della legislazione, Milan, 1786.

FIMS (ed.), Atti del Congresso Internazionale di Medicina dello Sport, TorinoRoma, Settembre 1933, Rome, 1934.

FIMS (ed.), Atti del I Congresso Nazionale di Medicina dello Sport, Roma 1920-21 Aprile 1932, Rome, 1932.

FIMS (ed.), Atti del II Congresso Nazionale di Medicina dello Sport, Bologna 24-26 Ottobre 1935, Bologna, 1936.

FIMS (ed.), Atti del III Congresso Nazionale di Medicina dello Sport, Genova 12-14 Novembre 1938, Rome, n. d.

Freddosio, O., Il regime per la razza, Rome, 1941.

Gallo, P., Discorso pronunciato dal direttore della Ginnastica Pietro Gallo in occasione del saggio dato dagli alunni delle scuole comunali il 13.7.1871, Venice, 1871.

Gallo, P., VI Relazione annua per Pietro Gallo direttore della ginnastica, Venice, 1872.

Gamba, A., La riforma della ginnastica. Note ed osservazioni. In: Gazzetta medica, 30 (1892).

Gemelli, A., La educazione fisica della donna, Milan, 1923.

Gennaioli, G., Mussolini e Napoleone I, Sansepolcro, 1926.

Genovesi, A., Lezioni di commercio, o sia d'economia civile, Bassano, 1788.

Gentile, G., Il problema scolastico del dopoguerra, Naples, 1919.

Gerbi, G., Successi italiani nel 'golf'. In: Lo sport fascista, 9 (1930).

Giaccone, A., Può la donna fare dello sport durante il periodo mestruale? In: FIMS (ed.), Atti del I Congresso Nazionale di Medicina dello Sport, Roma 19-20-21 Aprile 1932, Rome, 1932.

Giacometti-Ferrari, D., Relazione del Comitato Centrale Femminile al XVI Consiglio Federale, Rome, 16 March 1903.

Giovannini, A., La gara di Ondina Valla campione olimpionica vista e raccontata da lei. In: Lo sport fascista, 9 (1936).

Gobetti, P., Rivoluzione liberale, 9 (1924).

Gozzini, L., La donna nel quadro del Regime. In: Almanacco della donna italiana, 20 (1939).

Ilvento, A., Colonie estive. In: Maternità ed Infanzia, 5 (1927).

Lazotti, U., Le giovani italiane. In: Lo sport fascista, 6 (1928). 
Lentini, S., L'educazione fisica e sportiva per l'avvenire della razza. In: FIMS (ed.), Atti del II Congresso Nazionale di Medicina dello Sport, Bologna 24-26 Ottobre 1935, Bologna, 1936.

Livia (pseudonym), La moda di noi sportivi. In: Lo sport fascista, 6 (1933).

Lo Monaco-Aprile, A., La protezione della maternità e dell'infanzia, Rome, 1934.

Loffredo, F., Politica della famiglia e della razza. In: La difesa della razza, 2 (1939).

Loffredo, F., Politica della famiglia, Milan, 1938.

Lugnani, L'educazione fisica della donna col metodo Mensendick. In: FIMS (ed.), Atti del I Congresso Nazionale di Medicina dello Sport, Roma 19-20-21 Aprile 1932, Rome, 1932.

Macchi, G., Lo Sport alla Scala. In: Lo sport fascista, 2 (1929).

Malaparte, C., Cantata dell'ArciMussolini. In: L'Italiano, 7-8-9 (1927).

Marinetti, F. T., Fondazione e Manifesto del Futurismo. In: Le Figaro of 20 February 1909.

Marinetti, F. T., Manifesto Contro l'amore e il parlamentarismo of 1910.

Marinetti, F. T., Boccioni, U., Carrà, C. D., and Russolo, L., Programma politico futurista of 1913.

Marinetti, F. T., Manifesto In questo anno futurista of 29 November 1914.

Marinetti, f. T., Manifesto Orgoglio italiano of December 1915.

Marinetti, F. T., Alcune parti del film "Vita futurista", punto IV. In: L'Italia futurista, 8 (1916).

Marinetti, F. T., Manifesto La danza futurista of 1917.

Marinetti, F. T., Manifesto Simultaneità nello sport, n.d.

Mayer-Rizzioli, E., I fasci femminili italiani. In: Almanacco della donna italiana 1926 (1927).

Moebius P. J., Inferiorità mentale delle donna, Turin, 1904.

Montanari-Reggiani, M., L'assistenza sanitaria e medico-sportiva nei G.U.F. In: FIMS (ed.), Atti del III Congresso Nazionale di Medicina dello Sport, Genova 12-14 Novembre 1938, Rome, n. d.

Monterisi, F., Le colonie marine e montane. In: Quaderni Italiani, 5 (1943).

Montesi-Festa, I., La Donna italiana. In: La Donna italiana, 1 (1924).

Mosso, A., L'educazione fisica della donna, Milan, 1892.

Mosso, A., La riforma della ginnastica. In: Nuova Antologia (1892).

Mosso, A., L'educazione fisica della gioventù, Milan, 1894.

Mosso, A., I giuochi olimpici a Roma? In: Nuova Antologia (1905). 
Muggiani, E., Razzismo: autarchia del pensiero. In: Il Popolo d'Italia of 21 August 1938.

Mura (pseudonym), Ritorno di Gaby. In: Lo sport fascista, 1 (1933).

Mussolini, B., Discorso agli universitari fascisti. In: La Nuova Scuola Italiana, 1 (25 December 1923).

Mussolini, B., My autobiography (written by Arnaldo Mussolini and edited by Richard Washburn Child), New York, 1928.

Mussolini, V., Emancipazione del cinema italiano. In: Cinema, 9 (1936).

Nadi, N., La scherma femminile. In: Lo sport fascista, 11 (1929).

O. N. Balilla-Comitato Provinciale di Vicenza (ed.), Norme e programmi dell'O. N. Balilla, Vicenza, 1930.

Obermann, R., Della ginnastica. VII. Dei Ginnasticanti. In Letture di famiglia, 26, (1845).

ONB (ed.), Opera nazionale "Balilla" per l'Assistenza e l'Educazione Fisica e Morale della gioventù. Norme legislative e regolamentari, Rome, 1927.

ONB (ed.), Leggi-Regolamenti-Decreti, Brescia, 1931.

ONB (ed.), Norme regolamentari per le piccole e giovani italiane, Rome, 1931. ONB (ed.), Atti ufficiali del I Convegno Nazionale dei Medici dell'ONB, Roma 2 4 Febbraio 1930, Rome, 1932.

ONB (ed.), La capo-squadra piccola italiana, Milan, 1935.

ONB (ed.), La capo-squadra piccola italiana, Rome, 1936.

ONB (ed.), Gli Agonali dell'Opera Balilla, 1936.

ONB (ed.), Guida per le direttrici e vigilatrici delle colonie climatiche. In: Posta da campo, 711 (1944).

ONB (ed.), IV concorso per giovani italiane. Programma-regolamento, Milan, n. d.

ONB (ed.), Norme programmatiche e regolamentari per le organizzazioni delle "piccole e giovani italiane", Rome, n. d.

ONB (ed.), Programmi d'insegnamento e d'esame di educazione fisica per alunni ed alunne delle scuole elementari e medie pubbliche e private e per $i$ privatisti in genere, Rome, $\mathrm{n} . \mathrm{d}$.

Orano, P., Inchiesta sulla razza, Rome, 1939.

Paniconi, M., Criteri informativi e dati sul Foro Mussolini. In: Architettura, XII (1933).

Papini, G., Maschilità, Florence, 1915.

Parini, P., I figli degli Italiani all'Estero in patria nell'anno XII, 1934. 
Patrizi, M., Un pò di galateo. Giuochi e sport. In: Fiamma Viva, 12 (1929).

Paulin, E., La ginnastica del lattante, Trieste, 1935.

Pende, N., La sorveglianza medica per gli esercizi ginnici sportivi nei campeggi e nelle colonie. In: ONB (ed.), Atti ufficiali del I Convegno Nazionale dei Medici dell'ONB, Roma 2-4 Febbraio 1930, Rome, 1932.

Pende, N., Bonifica umana razionale e biologia politica, Bologna, 1933.

Pende, N., and Trattato di biotipologia umana individuale e sociale, Milan, 1939.

Pensuti, M., La donna e lo sport. In: Lo sport fascista, 4 (1930).

Pierazzi, R. M., Piccola posta. In: Cordelia, 14 (1923).

Pignatari, M., Colonie estive della GIL. Identità di criteri direttivi. In: Gioventù del Littorio, 8 (1941).

Pio XI, Lettera al Cardinale Vicario. In: Civiltà Cattolica, 2 (1928).

Pizzi, E., La donna al Concorso Ginnico del Dopolavoro. In: Lo sport fascista, 8 (1937).

Pizzi, E., La G.I.L. e l'O.N.D. In: Lo sport fascista, 1 (1938).

PNF (ed.), Il Partito Fascista e le sue opere "I fasci femminili", Milan, 1929.

PNF (ed.), Colonie Fasciste della provincia di Pavia. Come sorsero - come funzionano, Pavia, 1930.

PNF (ed.), Norme per il funzionamento delle colonie climatiche temporanee e diurne, Rome 1932.

PNF (ed.), Il Gran Consiglio del Fascismo nei primi quindici anni di vita, Bologna, 1938.

PNF (ed.), Regolamento per la ginnastica nelle colonie climatiche, anno XIX, Rome 1941.

PNF-Comando Generale GIL-Servizio Educazione Fisica (ed.), Concorsi Nazionali di Educazione Fisica A. XX. Programma-Regolamento, Rome, 1942.

PNF-GIL General Command (ed.), Accademie e Collegi della GIL, ammissioni anno XX-XXI, Rome, 1942.

PNF (ed.), Ginnastica nelle colonie climatiche, Rome, 1942.

Poggi-Longostrevi, G., La donna e lo sport. La università dello sport femminile: l'atletica leggera. In: La Gazzetta dello Sport of 8 October 1930.

Poggi-Longostrevi, G., I lavori del Gran Consiglio Fascista. La delicata questione dello sport femminile affrontata: la donna non deve essere distolta dalla sua missione fondamentale. In: La Gazzetta dello Sport of 18-19 October 1930.

Poggi-Longostrevi, G., Cultura fisica della donna ed estetica femminile, Milan, 1933.

Poggi-Longostrevi, G., Medicina sportiva, Milan 1940. 
Pomba, G. L. (ed.), La civiltà fascista illustrata nella dottrina e nelle opere, vol. 8, Turin, 1928.

Rabino, A., Rapporti tra mestruazione e fatica sportiva. In: Atti del Congresso Internazionale di Medicina dello Sport, Torino-Roma Settembre 1933, Rome, 1934.

RADA (pseudonym), Una pagina d'italianità sportiva. In: Lo sport fascista, 1 (1931).

Ranelletti, E., 'La donna-giudice', ovverosia le 'grazia' contro la 'giustizia'. In: Mussolini, V., Emancipazione del cinema italiano. In: Cinema, 9 (1936).

Roatta, G. B., La leggenda del sole, del mare e della montagna, ossia del clima qualunque, Bologna, 1940.

Rossi, G., Educazione fascista, Milan, 1942.

Sacco, A., Come abbiamo vinto a Dinard. In: Lo sport fascista, 8 (1929).

Sanjust, F., Un problema ricorrente - le colonie estive. In: Assistenza d'oggi, 1 (1950).

Sapori, F., L'arte e il Duce, Milan, 1932.

Serao, M., Parla una donna. Diario femminile di guerra, maggio 1915-marzo 1916, Milan, 1916.

Set (pseudonym), Le emule italiane della 'diva Suzanne'. In: Lo sport fascista, 3 (1929).

She (pseudonym), Ondine americane. In: Lo sport fascista, 3 (1933).

Sighele, S., La donna e l'amore, Milan, 1913.

Sironi, M., Manifesto della pittura murale. In: Colonna, I (1933).

Sorrentino, G., La donna deve praticare gli sports atletici. In: La Gazzetta dello Sport of 22 November 1921.

Speciale, F., Augusto fondatore dell'Impero romano. Il Duce fondatore dell'Impero italiano, Treviso, 1937.

Starace, A., L'opera nazionale Dopolavoro, Milan, 1933.

Stefanelli, R., Dopolavoro. Norme pratiche per i dirigenti, Turin, 1940.

Tavolato, I., Elogio della prostituzione. In: Lacerba of 1 May 1924.

Tedeschi, L. L., Il VII raduno dello sport femminile a Torino. In: Lo sport della GIL, 4 (1942).

Tifi, C., Le 'Piccole Italiane' in maglia azzurra. In: Lo sport fascista, 3 (1928).

Tranquilli-Leali, E., Casistica sui traumatismi sportivi. In: FIMS (ed.), Atti del II Congresso Nazionale di Medicina dello Sport, Bologna 24-26 Ottobre 1935, Bologna, 1936. 
Vaccaro, G., Giorgio Vaccaro illustra i modi e i fini dello sport fascista. In: Lo sport fascista, 5 (1935).

Valle, G., Echi del Concorso di Milano. In: Il Ginnasta, 9 (1902).

Valletti, F., La ginnastica come mezzo di educazione civile e militare negli stati d'Europa. In: Bollettino ufficiale del Ministero dell'Istruzione of 6 July 1887.

Vianello, A., Donne: a voi! In: Roma futurista, 1-2 (1919).

Viganoni, G., Mussolini e i Cesari, Milan, 1933.

Viziano, A., Prime indagini sull'influenza dello sport femminile sul periodo mestruale e considerazioni generali. In: FIMS (ed.), Atti del I Congresso Nazionale di Medicina dello Sport, Roma 19-20-21 Aprile 1932, Rome, 1932.

Weininger O., Sesso e carattere, Turin, 1912.

Zanetti, M., Deve la donna praticare lo sport? In: FIMS (ed.), Atti del I Congresso Nazionale di Medicina dello Sport, Roma 19-20-21 Aprile 1932, Rome, 1932. Zanetti, M., Ragazze del Littorio. In: Lo sport fascista, 8 (1937).

B) Newspapers, magazines, yearsbooks, bulletins:

Almanacco della Donna Italiana (1920).

Almanacco della donna italiana (1934).

Almanacco della donna italiana (1936).

Almanacco della donna italiana, (1939).

Annali dell'Italia Cattolica (1925).

Annuario del cinema italiano 1939-1942, (1943).

Architettura, 12 (1933).

Argento vivo: campeggio dei fasci giovanili bolognesi di combattimento, Rimini 10-20 Agosto, anno 10, Bologna, 1932.

Azione Muliebre, 6 (1926).

Azione Muliebre, 6 (1931).

Bollettino del lavoro e della previdenza sociale of 31 July-31 December 1930.

Bollettino della Croce Rossa Italiana, 1 (1921).

Bollettino ufficiale del Ministero dell'Istruzione of 6 July 1887.

Bollettino ufficiale del Ministero dell'Istruzione, vol. 2, 1893.

Cinema, 9 (1936). 
Civiltà Cattolica, 2 (1928).

Civiltà Cattolica, 3 (1938).

Colonna, 1 (1933).

Cordelia, 14 (1923).

Critica fascista of 15 April 1928.

Critica fascista of 15 February 1930.

Critica fascista of 1 January 1933.

Critica fascista of 15 April 1938.

Diario Cattolico of 18 July 1936.

Fiamma Viva, 12 (1929).

Fiamma Viva, 6 (1935).

Gazzetta medica, 30 (1892).

Gazzetta Ufficiale of 4 December 1861.

GIL (ed.), Bollettino quindicinale della GIL, 10 (1938).

GIL (ed.), Gioventù del Littorio, 8 (1941).

Il Ginnasiarca, 3 (1887).

Il Ginnasta, 9 (1902).

Il Ginnasta, 12 (1906).

Il Ginnasta, 6 (1907).

Il Ginnasta, 10 (1921).

Il Ginnasta, 6-7 (1922).

Il Ginnasta, 5 (1937).

Il Giornale d'Italia of 8 May 1923.

Il Giornale di Roma of 12 April 1923.

Il Littoriale of 29 April 1930.

Il Popolo d'Italia of 1 February 1933.

Il Popolo d'Italia of 28 October 1934.

Il Popolo d'Italia of 23 July 1935.

Il Popolo d'Italia of 7 August 1936.

Il Popolo d'Italia of 14 August 1938.

Il Popolo d'Italia of 21 August 1938.

Il Popolo di Romagna of 4 July 1926.

Il Popolo di Romagna of 22 December 1930.

Il Resto del Carlino of 31 January 1933. 
L'Italia futurista, 8 (1916).

L'Italiano, 7-8-9 (1927).

L'Osservatore Romano of 16 May 1934.

La Bicicletta, September 1895.

La difesa della razza, 2 (1939).

La Donna italiana, 1 (1924).

La Donna, 19 (1907).

La donna, la casa, il bambino, 3 (1935).

La donna, la casa, il bambino, 8 (1935).

La donna, la casa, il bambino, 9 (1935).

La donna, la casa, il bambino, 9 (1936).

La Gazzetta del Popolo of 14 May 1911.

La Gazzetta dello Sport of 27 March 1921.

La Gazzetta dello Sport of 8 October 1930.

La Gazzetta dello Sport of 18-19 October 1930.

La Gazzetta dello Sport of 6 August 1936.

La Gazzetta dello Sport of 7 August 1936.

La Nuova Scuola Italiana, 1 (25 December 1923).

La Provincia di Padova of 1-2 June 1923.

La Scuola Fascista, 17 (1929).

Le Figaro of 20 April 1909.

Letture di famiglia, 26, (1845).

Lo sport della GIL, 4 (1942).

Lo sport fascista, 3 (1928).

Lo sport fascista, 6 (1928).

Lo sport fascista, 2 (1929).

Lo sport fascista, 3 (1929).

Lo sport fascista, 4 (1929).

Lo sport fascista, 7 (1929).

Lo sport fascista, 8 (1929).

Lo sport fascista, 11 (1929).

Lo sport fascista, 12 (1929).

Lo sport fascista, 4 (1930).

Lo sport fascista, 9 (1930).

Lo sport fascista, 1 (1931).

Lo sport fascista, 6 (1931).

Lo sport fascista, 1 (1933).

Lo sport fascista, 3 (1933).

Lo sport fascista, 4 (1933). 
Lo sport fascista, 6 (1933).

Lo sport fascista, 5 (1935).

Lo sport fascista, 1 (1936).

Lo sport fascista, 3 (1936).

Lo sport fascista, 4 (1936).

Lo sport fascista, 5 (1936).

Lo sport fascista, 9 (1936).

Lo sport fascista, 8 (1937).

Lo sport fascista, 6 (1939).

Lo sport fascista, 7 (1939).

Lo sport fascista, 9 (1940).

Lo sport Illustrato of 3 April 1921.

Margherita, 3 (1913).

Matelda, 13 (1921).

Maternità ed Infanzia, 4 (1927).

Maternità ed Infanzia, 5 (1927).

Nuova Antologia (1892).

ONB (ed.), Bollettino dell'Opera Nazionale Balilla of 1 January 1930.

ONB (ed.), Bollettino dell'Opera Nazionale Balilla of 1 May 1930.

ONB (ed.), Bollettino dell'Opera Nazionale Balilla of 1 November 1932.

ONB (ed.), Bollettino Ufficiale dell'ONB of 15 May 1933.

OND (ed.), Annuario, 1937.

Panorami di realizzazioni del fascismo, 7 (1938-1942).

PNF (ed.), Bollettino del Comando Generale, 13 April 1933.

PNF (ed.), Bollettino del Comando Generale of 26 July 1933.

PNF (ed.), Bollettino del Comando Generale of 2 July 1934.

PNF (ed.), Foglio d'Ordini n.117, of 20 December 1933.

PNF (ed.), Foglio di disposizioni n. 905 of 15 November 1938.

PNF (ed.), Foglio di disposizioni n. 1,377 of 3 August 1939.

PNF (ed.), Foglio di disposizioni n. 38 of 26 December 1939.

PNF (ed.), Foglio di disposizioni No. 93 of 29 February 1940.

PNF (ed.), Annuario sportivo dei Giovani Fascisti e delle Giovani Fasciste -A. $X V$, Varese, 1938.

PNF-GIL (eds.), Annuario generale sportivo della GIL dell'anno XVII, Varese, 1940. 
PNF-GIL (eds.), Annuario sportivo generale della GIL-A. XVIII, n. p., 1941.

PNF-GIL (eds.), Annuario sportivo generale-A. XIX, Bergamo, n. d.

Posta da campo, 711 (1944).

Quaderni Italiani, 5 (1943).

Rassegna Femminile Italiana, 1 (1925).

Rivista dell'istruzione elementare, 3 (1932).

Rivista pedagogica, 3 (1932).

Roma futurista, 1-2 (1919).

Tutti gli Sports, 33 (1936).

Secondary references (1946-1999)

\section{A) Books and articles:}

A.A. V.V., Anni Trenta. Arte e cultura in Italia, Milan, 1982.

A.M.O.V.A. (ed.), Medaglie d'oro al valore atletico 1934-1985, Rome, 1987.

Acquarone, A., L'organizzazione dello Stato totalitario, Turin, 1965.

Alatri, P., Le origini del fascismo, Rome, 1962.

Alfassio-Grimaldi, U., and Addis-Saba, M., Cultura a passo romano. Storia e strategie dei littoriali della cultura e dell'arte, Milan, 1983.

Andreoli, P., La donna e lo sport nella società industriale, Rome, 1974.

Anonym, Contro l'atletismo femminile. Lettera di Pio the XI al Cardinale Vicario di Roma. In: Lancillotto e Nausica. Critica e storia dello sport, 3 (1988).

Argentieri, M., L'occhio del regime. Informazione e propaganda nel cinema del fascismo, Florence, 1979.

Armellini, G., Le immagini del fascismo nelle arti figurative, Milan, 1980. Arbasino, A., Giovinezza giovinezza. In: FMR, 26 (1984).

Arnaud, P., and Wahl, A. (eds.), Sports et relations internationales, Metz, 1994.

Artom, S., and Calabrò, A. R., Sorelle d'Italia. Quattordici Signore raccontano la loro ( e nostra) Storia, Milan, 1989.

Banfi-Malaguzzi, D., A Milano nella resistenza, Rome, 1964.

Barbieri, F., Evoluzione storica della federazione medico sportiva italiana. Cinquant'anni di attività della FIMS, Siena, 1979.

Bassetti, R., Storia e storie dello sport in Italia. Dall'Unità a oggi, Venice, 1999. Battaglia, R., Storia della Resistenza italiana, Turin, 1964. 
Bentivoglio, L., La danza moderna. Da Isadora Dancan a Maurice Béjart, Milan, 1977.

Bertelli, S., and Grottarelli, C., Gli occhi di Alessandro. Potere sovrano e sacralità del corpo da Alessandro Magno a Ceausescu, Florence, 1990.

Bertoldi, S., Camicia nera, Milan, 1994.

Bertone, G., "I figli d'Italia si chiaman balilla." Come e cosa insegnava la scuola fascista. Rimini-Florence, 1975.

Bessone, M., Alpa, G., D'Angelo, A., Ferrando, G., Spallarossa, M. R., La famiglia nel nuovo diritto. Principi costituzionali, riforme legislative, orientamenti della giurisprudenza, Bologna, 1995.

Betri, M. L., Tra politica e cultura. La scuola di mistica fascista. In: Storia contemporanea, 1-2 (1989).

Betti, C., L'Opera Nazionale Balilla e l'educazione fascista, Florence, 1983.

Bianchi, C., Il nudo eroico del fascismo. In: Bertelli, S., and Grottarelli, C., Gli occhi di Alessandro. Potere sovrano e sacralità del corpo da Alessandro Magno a Ceausescu, Florence, 1990.

Bilenchi, R., Cronache degli anni neri, Rome, 1984.

Biondi, M., and Borsotti, A. (eds.), Cultura e Fascismo. Letteratura arti spettacolo di un Ventennio, Florence, 1996.

Boccasile, G., La signorina grandi firme, Milan, 1981.

Bonetta, G., Corpo e nazione.L'educazione ginnastica, igienica e sessuale nell'Italia liberale, Milan, 1990.

Bonetta, G., Genesi e formazione della concezione scolastica gentiliana. In: Spadafora, G. (ed.), Giovanni Gentile. La pedagogia. La scuola, Rome, 1997.

Bonetta, G., Storia della scuola e delle istituzioni educative, Florence, 1997.

Bonfanti, E., Il corpo intelligente-Giannina Censi, Turin, 1995.

Brunetta, G. P., Storia del cinema italiano. Il cinema del regime 1929-1945, Rome, 1993.

Brunetti, F., Architetti e fascismo, Florence, 1993.

Candela, S., I Florio, Palermo, 1986.

Cannistraro, P. V., La fabbrica del consenso. Fascismo e mass-media, RomeBari, 1975.

Caprioglio, S., and Funi, E., Antonio Gramsci. Lettere dal carcere, Turin, 1968.

Carrouges, M., La mystique du surhomme, Paris, 1948.

Casadio, G. F., Telefoni bianchi. Realtà e finzione nella società e nel cinema italiano degli anni Quaranta, Manduria, 1991.

Casini, L., La riscoperta del corpo, Rome, 1990. 
Castronovo, V., and Tranfaglia, N., La stampa italiana nell'età fascista, RomeBari, 1980.

Catania, A., L. Freddi e il libro della solitudine. In: Biondi, M., and Borsotti, A. (eds.), Cultura e Fascismo. Letteratura arti spettacolo di un Ventennio, Florence, 1996.

Ceserani, G. P., Vetrina del Ventennio 1923-1943, Rome-Bari, 1981.

Charnitzky, J., Fascismo e scuola. La politica scolastica del regime (1922-1943), Florence, 1996.

Chessa, P., Renzo De Felice. Rosso e Nero, Milan, 1995.

Colombo. F., and Feltri, V., Fascismo, antifascismo, Milan, 1994.

Comune di Roma-Ipsoa (eds.), L'economia italiana tra le due guerre, Rome 1984.

CONI (ed.), I numeri dello sport. Atlante della pratica sportiva in Italia, Florence, 1987.

Consiglio, F., and Frosini, F. (eds.), Antonio Gramsci. Filosofia e politica. Antologia dei 'Quaderni del carcere', Florence, 1997.

Conti, G., Il mito della hazione armata'. In: Storia contemporanea (December 1990).

Corriere dello Sport - Stadio of 1 April 1989.

Cresti, C., Forum Beniti. In: FMR, 26 (1984).

De Amicis, E., Amore e ginnastica, Turin, 1971.

De Amicis, E., Non si sgomentino le signore ... In: Ferraro-Bertolotto, M. C., Prospettiva storica dell'educazione fisica nel trentennio successivo all'unità, Genoa, 1984.

De Betta, G., L'evoluzione dei littoriali. In: Lancillotto e Nausica. Critica e storia dello sport, 1 (1997).

De Felice, R., Storia degli ebrei italiani sotto il fascismo, Turin, 1961.

De Felice, R., Mussolini il rivoluzionario, Turin, 1965.

De Felice, R. and Mariano, E., Carteggio D'Annunzio-Mussolini (1919-1938), Milan, 1971.

De Felice, R., Storia degli ebrei italiani sotto il fascismo, Turin, 1972.

De Felice, R., La carta del Carnaro nei testi di Alceste De Ambris e di Gabriele D'Annunzio, Bologna, 1973.

De Felice, R., Il problema dell'Alto Adige nei rapporti italo-tedeschi dall'Anschluss alla fine della seconda guerra mondiale, Bologna, 1973.

De Felice, R., Mussolini il duce. Gli anni del consenso 1929-1936, Turin, 1974.

De Felice, F., Mussolini il Duce. Gli anni del consenso 1929-1936, Turin, 1974.

De Felice, R., D'Annunzio politico 1918-1938, Rome-Bari, 1978. 
De Felice, R., Mussolini il Duce, vol. 2, Turin, 1981.

De Felice, R., Mussolini il duce. Lo stato totalitario 1936-1940, Turin, 1981.

De Felice, R. (ed.), Futurismo, cultura e politica, Turin, 1988.

De Felice, R., Mussolini, Turin, 1996:

-Mussolini il rivoluzionario 1883-1920;

-Mussolini Il fascista 1921-1929 [tome I, La conquista del potere 1921-1925; tome II, L'organizzazione dello Stato fascista 1925-1929];

-Mussolini il duce 1929-1939 [tome I, Gli anni del consenso 1929-1936, tome II, Lo Stato totalitario 1936-1940;

-Mussolini l'alleato 1940-1945 [tome I, 2 voll.: 1. L'Italia in guerra 1940-1943,

2. Dalla guerra "breve" alla guerra lunga; tome II, 2 voll.: 1. Crisi e agonia del regime, 2. La guerra civile 1943-1945].

De Giorgio, M., Le italiane dall'Unità a oggi. Modelli culturali e comportamenti sociali, Rome-Bari, 1993.

De Grazia, V., Consenso e cultura di massa nell'Italia fascista. L'organizzazione del Dopolavoro, Rome-Bari, 1981.

De Grazia, V., Le donne nel regime fascista, Venice, 1993.

De Luna, G., Donne in oggetto. L'antifascismo nella società italiana (19221939), Turin, 1995.

De Maria, L. (ed.), F. T. Marinetti. Teoria e invenzione futurista, Milan, 1990.

Del Boca, A., Le leggi razziali nell'impero di Mussolini. In: Del Boca, A., Legnani, A. M., and Rossi, M. G., (eds.), Il regime fascista. Storia e storiografia, RomeBari, 1995.

Del Buono, O. (ed.), Eja, eja, eja, alalà, Milan, 1971.

Del Giudice, E. and V., Italiani tutti in divisa, Castel Bolognese, 1980.

Detragiache, D., Du socialisme au fascisme naissant: formation et itinéraire de Regina Terruzzi. In: Thälmann, R. (ed.), Femmes et fascismes, Paris, 1986.

Detragiache, D., Il fascismo femminile da San Sepolcro all'affare Matteotti, 19191924. In: Storia contemporanea, 2 (1983).

Di Cori, P., Storia, sentimenti, solidarietà nelle organizzazioni femminili cattoliche dall'età giolittiana al fascismo. In: Nuova DWF, 10-11 (1979).

Di Donna-Prencipe, C. (ed.), Letteratura e sport, Bologna, 1986.

Di Ferdinando, D., Contro le bugie del cosmetico.Alle origini della ginnastica femminile. In: Lancillotto e Nausica. Critica e storia dello sport, 7 (1990).

Dominici, F., Gli intramontabili - Ondina Valla. Oro a Berlino negli 80 ostacoli primatista nel lungo e nell'alto. La regina con le ali. In: Corriere dello Sport Stadio of 1 April 1989.

Donato, M., Indirizzi fondamentali dell'educazione fisica moderna, Rome, 1962. Dotti, R., La quercia di Ondina Valla. In: Stadio of 24 October 1958. 
Enciclopedia dell'antifascismo e della Resistenza, Milan, 1968-1989.

Enrile, E. (ed.), Enciclopedia dello sport, Rome,1977.

Fabbri, A. M., Giovinezza, giovinezza ..., Milan, 1964.

Fabrizio, F., Sport e fascismo. La politica sportiva del regime 1924-1936, Rimini-Florence, 1976.

Fabrizio, F., Storia dello sport in Italia. Dalle società ginnastiche all'associazionismo di massa, Rimini-Florence, 1977.

Ferralasco-Nadi, R., Nedo Nadi l'alfiere dello sport delle tre armi nel mondo, Genoa, 1969.

Ferrara, P., L'Italia in palestra. Storia, documenti e immagini della ginnastica dal 1833 al 1973, Rome, 1992.

Ferraro-Bertolotto, M. C., Prospettiva storica dell'educazione fisica nel trentennio successivo all'unità, Genoa, 1984.

FIDAL (ed.), Atletica, 1995-1996-1997.

Filippi, F., Una vita pagana. Enrico Corradini dal superomismo dannunziano a una politica di massa, Florence, 1989.

FILMLEXICON degli autori e delle opere, vol. I, Rome, 1959.

Finocchiaro, S., Il Foro Mussolini. Unpublished paper presented in the 4th CESH Congress of the History of Sport in Europe, Florence, 2-5 December 1999.

Fraddosio, M., La mobilitazione femminile: i gruppi fascisti repubblicani femminili e il SAF. In: Annali della Fondazione Luigi Micheletti, 2 (1986).

Freddi, L., Il cinema. Il governo dell'immagine, Rome, 1994.

Fusco, G. C., Le rose del ventennio, Milan, 1974.

Garibaldi, L., Le soldatesse di Mussolini, Milan, 1997.

Genovesi, G., Storia della scuola in Italia dal Settecento a oggi, Rome-Bari, 1998.

Gentile, E., Le origini dell'ideologia fascista, Rome-Bari, 1975.

Gentile, E., Il mito dello Stato nuovo dall'antigiolittismo al fascismo, Rome-Bari, 1982.

Gentile, E., Il culto del littorio. La sacralizzazione della politica nell'Italia fascista, Rome-Bari, 1993.

Gentili, R., Bottai e la riforma fascista della scuola, Florence, 1979.

Gianfranceschi, L., Un'italiana fra i semidei ariani. In: Panathlon International Club Valdarno Inferiore (ed.), Proceedings of the National Prize "L'atleta nella Storia" 1988 Ondina Valla, Montecatini Terme, 22 October 1989, Montecatini, 1989. 
Giordani-Aragno, B., La moda italiana fra le due guerre. In: Comune di Roma-Ipsoa (eds.), L'economia italiana tra le due guerre, Rome 1984.

Giuliani, F., Donne d'Italia. Le ausiliarie della RSI, Rome, 1952.

Giuntini, S., La donna e lo sport in Lombardia durante il fascismo. Paper presented at the Congress "Donna Lombarda 1860-1945", Milan, 1989.

Giuntini, S., Sport e storia. La nascita della ginnastica femminile. In: Ricerche storiche, 3 (1989).

Giuntini, S., La donna e lo sport in Lombardia durante il fascismo. In: Torcellan, N., and Gigli-Marchetti, A. (eds.), Donna lombarda 1860-1945, Milan, 1992.

Giuntini, S., Società ginnastica milanese Forza e Coraggio. Alle origini dello sport a Milano, Milan, 1994.

Gnecchi-Ruscone, A., La moda italiana dalla crisi alla guerra. AA. VV.(eds), Anni trenta. Arte e cultura in Italia, Milan, 1983.

Gori, G. M., Patria diva. La storia d'Italia nei film del ventennio, Florence, 1988.

Gori, G., Educazione fisica, sport e giornalismo in Italia. Dall'unità alla prima olimpiade dell'era moderna, Bologna, 1989.

Gori, G., L'atleta e la nazione. Saggi di storia dello sport, Rimini, 1996.

Gori, G., Sports Festivals in Italy between the 19th and 20th Centuries: A Kind of National Olympic Games? In Naul, R. (ed.), Contemporary Studies in the National Olympic Games Movement, Vol. 2, Frankfurt am Main, 1997.

Gori, G. Sport Medicine and Female Athleticism in the Years of the Fascist Regime. In: Terret, T. (ed.), Sport and Health in History. Proceedings of the 4th ISHPES Congress, Lyon 16-22 July 1997, Sankt Augustin, 1999.

Gori, G., Supermanism and the Culture of the Body in Italy: The Case of Futurism. In: The International Journal of the History of Sport, 1 (1999).

Gori, G., The Classic "Mille Miglia Motor-Race"(1927-1938): Tourism and Propaganda in the Years of the Fascist Regime. Unpublished paper presented at the 2nd CESH Seminar, The History of Sport and Tourism in Europe, 17-21 September 1997, Katowice, Poland.

Grandi, T. and Comba, A. (eds.), Scritti politici, Turin, 1972.

Guerra, R., L'indirizzo della ginnastica sociale in Italia. In: Ricerche storiche, 3 (1989).

Guerri, G. B., (ed.), Rapporto al Duce, Milan, 1978.

Guerri, G. B., Fascisti. Gli italiani di Mussolini. Il regime degli italiani, Milan, 1995.

Guerri, G. B., Giuseppe Bottai, fascista, Milan, 1996. 
Hoberman, J. M., Politica e sport. Il corpo nelle ideologie politiche dell'800 e del 900, Bologna, 1988.

Hulten, P., Futurismo e Futurismi, Milan, 1986, p. 18.

Impiglia, M., and Lange, P., Goliardi in gara. I Giochi mondiali universitari prima delle Universiadi. In: Lancillotto e Nausica. Critica e storia dello sport, 1 (1997). Impiglia, M., The volata game. When fascism forbade Italians to play football. In: Krüger, A. \& Teja, A, La comune eredità dello sport in Europa. Atti del I Seminario Europeo di Storia dello Sport, Roma 29 November-1 December 1996, Rome, 1997.

Impiglia, M., Lo scudetto e il vate. In: Lo sport italiano, 1 (1998).

Isidori Frasca, R., ... e il duce le volle sportive, Bologna, 1983.

Isnenghi, M., Il corpo del Duce. In: Bertelli, S., and Grottarelli, C., Gli occhi di Alessandro. Potere sovrano e sacralità del corpo da Alessandro Magno a Ceausescu, Florence, 1990.

Jacomuzzi, S., Gli sport, voll. 3, Turin, 1965.

Jocteau, G, C., Ai monti e al mare. Cento anni di colonie per l'infanzia XIX, XX, Milan, 1990.

Krüger, A., Fasci e croci uncinate. In: Lancillotto e Nausica. Critica e storia dello sport, I-II (1991).

Krüger, A. and Teja, A. (eds.), La comune eredità dello sport in Europa, Proceedings of the 1st European Seminar for the History of Sport, Rome 29 November-1 December 1996, Scuola dello Sport-CONI, Rome 1997.

Krüger, A. and Trangbaek, E. (eds.), The History of Physical Education \& Sport from European Perspectives, Copenhagen, 1999.

Krüger, A., Strength through joy. The culture of consent under fascism, Nazism and Francoism. In: Riordan, J., and Krüger, A. (eds.), The International politics of Sport in the Twentieth Century, London, 1999.

Lazzero, R., Le Brigate Nere, Milan, 1963.

Lazzero, R., Il Partito Nazionale Fascista, Milan, 1985.

Leeden, M. A., De Felice. Intervista sul fascismo, Bari, 1977.

Ledeen, M. A., Gabriele D'Annunzio: l'avventura fiumana e la politica del Novecento. In: In: Nuova Storia Contemporanea, 5 (1999).

Lepre, A., L'occhio del Duce. Gli italiani e la censura di guerra 1940-43, Milan, 1992.

Lista, G., Lo spettacolo futurista, Florence, 1989. 
Livi-Bacci, M., A History of Italian Fertility during the Last Two Centuries, Princeton, 1972.

Lombardi, E., Quand'ero piccola, Dronero-Rome, 1991-1992.

Lombardi, E., ... Da grande, n.p. 1993.

Macciocchi, M. A., La donna 'nera'. 'Consenso' femminile e fascismo, Milan, 1976.

Mack Smith, D., Mussolini, Milan, 1981.

Mack-Smith, D., Vincere, vincere, vincere. In: FMR, 26 (1984).

Malvano, L., Fascismo e politica dell'immagine, Turin, 1988.

Manacorda, G., Letteratura e cultura del periodo fascista, Milan, 1974.

Marcuzzo, C., and Rossi-Doria, A. (eds.), La ricerca delle donne. Studi femministi in Italia, Turin, 1987.

Martini, M., Sesso debole? Un secolo di smentite. In: Lo Sport Italiano, 8-9 (1994).

Martini, M., Correre per essere. Origini dello sport femminile, Rome, 1996.

Martini, M., Storia dell'atletica italiana femminile. In: FIDAL (ed.), Atletica, 1995-1996-1997.

Masi, A., Un'arte per lo Stato, Naples, 1992.

Mattazzi, G., Benito Mussolini. Breviario, Milan, 1997.

Meldini, P. Sposa e madre esemplare. Ideologia e politica della donna e della famiglia durante il fascismo, Rimini-Florence, 1975.

Momigliano, E. (ed.), Tutte le encicliche dei Sommi Pontefici, Milan, 1973.

Mondello, E., La nuova italiana. La donna nella stampa e nella cultura del Ventennio, Rome, 1987.

Moscovici, S., L'âge des foules. Un traité historique de psycologie des masses, Paris, 1981.

Mosse, G. L., Sessualità e Nazionalismo, Rome-Bari, 1966.

Mosse, G. L., Futurismo e culture politiche in Europa: una prospettiva globale. In: De Felice, R., (ed.), Futurismo, cultura e politica, Turin, 1988.

Mosse, G. L., Estetica fascista e società. In: Del Boca, A., Legnani, A. M., and Rossi, M. G., (eds.), Il regime fascista. Storia e storiografia, Rome-Bari, 1995.

Mosse, G. L., Il fascismo. Verso una teoria generale, Rome-Bari, 1996.

Mosse, G. L., The image of man. The creation of modern masculinity, New York, 1996.

Motti, L., and Rossi Caponeri, M. (eds.), Accademiste a Orvieto. Donne ed educazione fisica nell'Italia fascista 1932-1943, Ponte San Giovanni, 1996.

Mussolini, B., Opera Omnia (Susmell E. and D. eds.), voll. 35, Florence, 19511963. 
Naul, R. (ed.), Contemporary Studies in the National Olympic Games Movement, Vol. 2, Frankfurt am Main, 1997.

Nolte, E., L'impresa di Fiume e lo scenario europeo. In: Nuova Storia Contemporanea, 5 (1999).

Ölrich, H., 'Whoever has Youth has a Future'. Youth Sports Activities of the BerlinRome Axis from 1940 to the Foundation of the European Youth Association in 1942. In: Krüger, A. and Teja, A. (eds.), La comune eredità dello sport in Europa, Proceedings of the 1st European Seminar for the History of Sport, Rome 29 November-1 December 1996, Scuola dello Sport-CONI, Rome 1997.

Ostenc, M., L'éducation en Italie pendant le fascisme, Paris, 1980.

Panathlon International Club Valdarno Inferiore (ed.), Proceedings of the National Prize "L'atleta nella Storia" 1988 Ondina Valla, Montecatini Terme, 22 October 1989, Montecatini, 1989.

Papa, A., and Panico, G., Storia sociale del calcio in Italia. Dai club dei pionieri alla nazione sportiva 1887-1945, Bologna, 1983.

Parla, G., L'avventurosa storia del femminismo, Milan, 1976.

Passerini, L., Mussolini immaginario. Storia di una biografia 1915-1939, RomeBari, 1991.

Passerini, L., Storie di donne e femministe, Turin, 1991.

Payne, S. G., A history of fascism. 1914-45, London, 1995.

Petacco, A., Regina. La vita e i segreti di Maria José, Milan, 1997.

Pieroni-Bortolotti, F., Alle origini del movimento femminile in Italia, 1848-1892, Turin, 1963.

Pisanò, G., Storia delle Forze Armate della RSI, Milan, 1967.

Pivato, S., I terzini della borghesia. Il gioco del pallone nell'Italia dell'Ottocento, Milan, 1990.

Pivato, S., Sport et rapports internationaux. Le cas du fascisme italien. In: Arnaud, P., and Wahl, A. (eds.), Sports et relations internationales, Metz, 1994.

Preti, L., Giovinezza, giovinezza, Milan, 1972.

Ranelletti, E., 'La donna-giudice', ovverosia le 'grazia' contro la 'giustizia'. In: Sepe, O. (ed.), "e così piantò in asso Adamo", Milan, 1995.

Redi, R. (ed.), Cinema italiano sotto il fascismo, Venice, 1979.

Reich, W., Psicologia di massa del fascismo, Milan, 1982.

Renzo, G. (ed.), Friedrich Nietzsche e il destino dell'uomo, Cittanuova, 1982. 
Riordan, J., and Krüger, A. (eds.), The International politics of Sport in the Twentieth Century, London, 1999.

Riva, A. (ed.), Cento anni di vita della Federazione Ginnastica d'Italia, Rome, 1969.

Roffarè, L., Atletesse. In: La cultura fisica, 7 (1952).

Salina-Borello, R., Raccontare lo sport. In: Di Donna-Prencipe, C. (ed.), Letteratura e sport, Bologna, 1986.

Salinari, C., and Spinella, M., Il pensiero di Gramsci, Rome, 1975.

Salvatici, S., Modelli femminili e immagine della donna attraverso la fotografia della stampa fascista. In: AFT-Rivista di Storia e Fotografia, 18 (1993).

Salvatorelli, L., and Mira, G., Storia d'Italia nel periodo fascista, voll.2, Milan, 1972.

Salvemini, G., La nascita del fascismo, Milan, 1972.

Salvini, A., Identità femminile e sport, Florence, 1982.

Sancipriano, M., and Macchietti, S. S. (eds.), F. Aporti, Scritti pedagogici e lettere, Brescia, 1976.

Sanjust, F., Un problema ricorrente - le colonie estive. In: Assistenza d'oggi, 1 (1950).

Saracinelli, M., and Totti, N., L'Italia del Duce: l'informazione, la scuola, il costume, Rimini, 1983.

Sarfatti, M., Acqua passata, Bologna, 1955.

Scaramuzza, E., Professioni intellettuali e fascismo. L'ambivalenza dell'Alleanza muliebre culturale italiana. In: Italia contemporanea, 151 (1983).

Scarpellini, A., La Repubblica Sociale Italiana nelle lettere dei suoi caduti, Rome, 1963.

Sica, M., Storia dello Scautismo in Italia, Florence, 1987.

Silva, U., Ideologia e arte del fascismo, Milan, 1973.

Simri, U., A concise world history of women's sports, Netanya, 1983.

Società Italiana delle Storiche (ed.), Discutendo di storia. Soggettività, ricerca, biografia, Turin, 1990.

Spadafora, G. (ed.), Giovanni Gentile. La pedagogia. La scuola, Rome, 1997.

Spinosa, A., Mussolini: razzista riluttante, Rome, 1994.

Sternhell, Z., Nascita dell'ideologia fascista, Milan, 1993.

Tannenbaum, E., R., L'esperienza fascista. Cultura e società in Italia dal 1922 al 1945, Milan, 1974. 
Tarchi, M., Julius Evola e il fascismo: note su un percorso non ordinario. In: Biondi, M., and Borsotti, A. (eds.), Cultura e Fascismo. Letteratura arti spettacolo di un Ventennio, Florence, 1996.

Teja, A., Educazione fisica al femminile dai primi corsi di Torino di ginnastica educativa per le maestre (1867) alla ginnastica moderna di Andreina GottaSacco (1904-1988), Rome, 1995.

Teja, A., Le fascisme entre éducation physique et sport. In: Krüger, A. and Trangbaek, E. (eds.), The History of Physical Education \& Sport from European Perspectives, Copenhagen, 1999.

Terret, T., and Vescovi, R., L'éducation physique à l'école primaire dans l'entredeux guerres. Une comparaison des systèmes Français et Italiens. In: Kruger, A., and Trangbaek, E. (eds.), The History of Physical Education and Sport from European Perspectives, Copenhagen, 1999.

Thälmann, R. (ed.), Femmes et fascismes, Paris, 1986.

Tonelli, A, E ballando ballando. La storia d'Italia a passi di danza (18151996), Milan, 1998.

Torcellan, N., and Gigli-Marchetti, A. (eds.), Donna lombarda 1860-1945, Milan, 1992.

Trangbaek, E., Gender in Modern Society: Femininity, Gymnastics and Sport. In: The International Journal of the History of Sport, 3 (1997).

Trangbaek, E., "Purity of Heart and Strength of Will"- The Role of Female Teachers in the Modern Sports Movement. In: Trangbaek, E. and Krüger, A. (eds.), Gender \& Sport from European Perspectives, Copenhagen, 1999.

Ungari, P., Storia del diritto di famiglia in Italia, Bologna, 1974.

Valeri, N., D'Annunzio davanti al Fascismo, Florence, 1963.

Valla, O., Ondina Valla. In: Ternisport, Terni, n. d.

Vivarelli, R., Storia delle origini del fascismo, vol. I, Bologna, 1991.

Welte, B., Il superuomo di Nietzsche: ambigua doppiezza. In: Renzo, G. (ed.), Friedrich Nietzsche e il destino dell'uomo, Cittanuova, 1982.

B) Newspapers, magazines and yearbooks:

AFT-Rivista di Storia e Fotografia, 18 (1993).

Annali della Fondazione Luigi Micheletti, 2 (1986).

Assistenza d'oggi, 1 (1950). 
Corriere dello Sport - Stadio of 1 April 1989.

FMR, 26 (1984).

Italia contemporanea, 151 (1983).

Lancillotto e Nausica. Critica e storia dello sport, 3 (1988).

Lancillotto e Nausica. Critica e storia dello sport, 7 (1990).

Lancillotto e Nausica. Critica e storia dello sport, 1-2 (1991).

Lancillotto e Nausica. Critica e storia dello sport, 1 (1997).

Lo sport italiano, 1 (1998).

Nuova DWF, 10-11 (1979)

Nuova Storia Contemporanea, 5 (1999).

Ricerche storiche, 3 (1989).

Stadio of 24 October 1958.

Storia contemporanea, 1-2 (1989).

Storia contemporanea (December 1990).

Ternisport, Terni, n. d.

The International Journal of the History of Sport, 3 (1997).

The International Journal of the History of Sport, 1 (1999). 